\title{
Field Testing and Load Rating of a Short-Span Thermoplastic Bridge System, Bridge T-8519
}

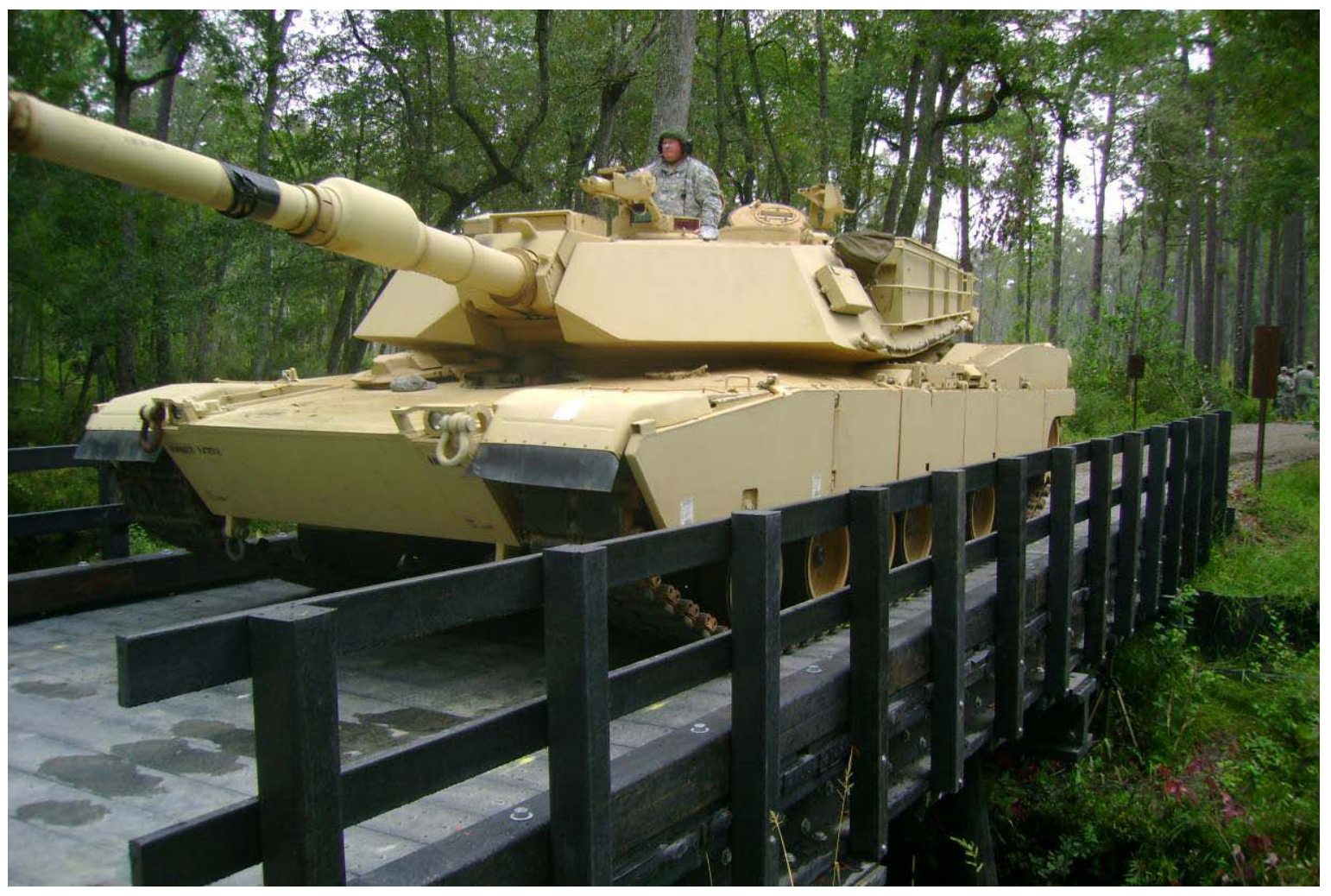




\title{
Field Testing and Load Rating of a Short-Span Thermoplastic Bridge System, Bridge T-8519
}

\author{
Brett Commander \\ Bridge Diagnostics, Inc. \\ 1965 57th Court North, Suite 106 \\ Boulder, C0 80301 \\ Henry Diaz-Alvarez \\ Geotechnical and Structures Laboratory \\ U.S. Army Engineer Research and Development Center \\ 3909 Halls Ferry Road \\ Vicksburg, MS 39180
}

Final report

Approved for public release; distribution is unlimited.

\footnotetext{
Prepared for U.S. Army Installation Management Command Arlington, VA 22202

Under Installation Technology Transition Program
} 


\begin{abstract}
Live-load tests were conducted on Bridge T-8519, located on Tuckers Road in Camp Mackall near Fort Bragg, North Carolina. This bridge was tested in conjunction with a similar nearby bridge (T-8518). Both bridges were constructed of a new structural material consisting primarily of recycled plastic lumber (RPL). The primary goal of the liveload testing was to determine load capacity ratings for civilian and military vehicles and, specifically, to determine whether the RPL structures could safely carry an M1 tank.
\end{abstract}

\begin{abstract}
A finite element model of the entire superstructure was developed and used to simulate the responses of the RPL bridge. The resulting model was very accurate; however, responses were very sensitive to small variations in load position due to the flexibility of the plank deck and the spacing of the support beams. Following the addition of deck fasteners, the bridge performance was much more consistent for the M1 tank responses, and more accurate modeling was obtained. Therefore, all ratings were based on the model developed from the second set of load test results.
\end{abstract}

Once a realistic yet conservative model of the structure was obtained, load ratings were computed based on an allowable stress approach. Allowable stress limits that were provided by the manufacturer corresponded to stresses that could be applied to the RPL material for a long period of time with deformations being $100 \%$ recoverable once the load was removed. These allowable stress limits were a small fraction of the ultimate stress limits for RPL. However, an ultimate stress approach would be difficult to calculate because it would result in highly nonlinear and time-dependent responses with extremely large deformations.

The load rating results apply only to the bridge superstructure. Pile deformations were measured during the load test, but no assessment could be made concerning the pile capacity. The pile capacity should be verified through the design engineer and the piling contractor to ensure the piles have sufficient bearing capacity to support the load limits of the superstructure. 


\section{Contents}

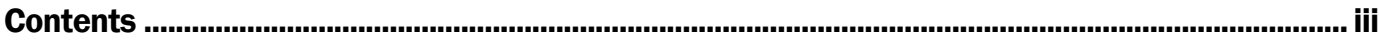

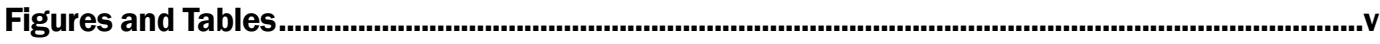

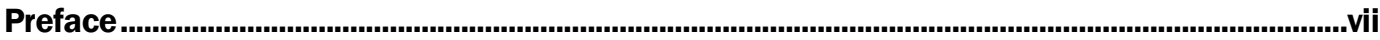

Unit Conversion Factors ..................................................................................................................... viii

1 Introduction and Result Summary................................................................................. 1

2 Structural Testing Information ....................................................................................................... 3

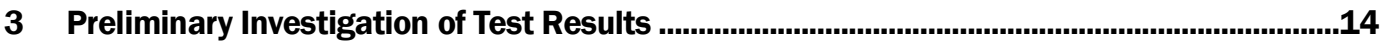

Reproducibility and linearity ....................................................................................... 14

Variations in deck connection during dump truck tests............................................. 14

Consistency in spans after repairs ........................................................................ 17

Pile and beam displacement ................................................................................... 19

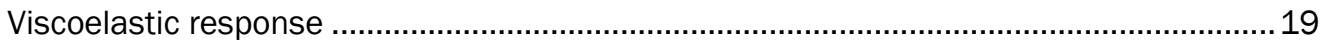

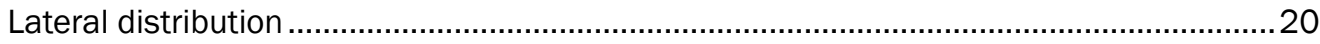

Peak stress measurements .................................................................................. 22

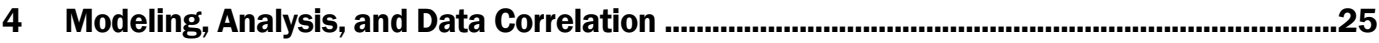

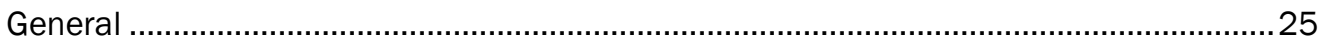

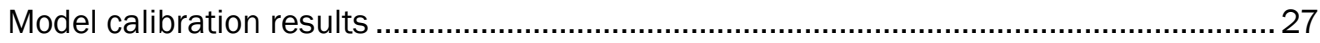

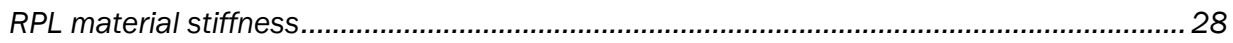

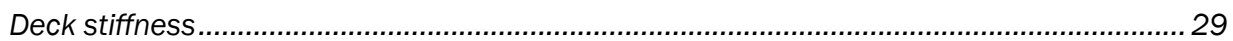

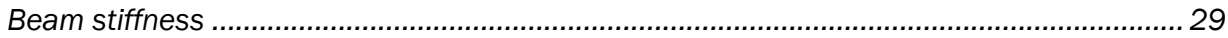

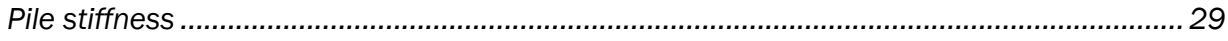

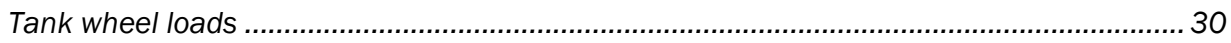

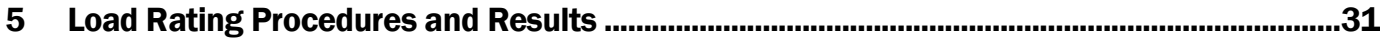

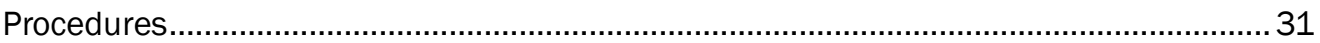

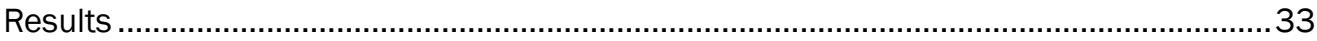

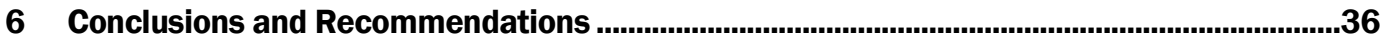

References .................................................................................................................................................38

Appendix A: Measured and Computed Stress and Displacement .............................................39

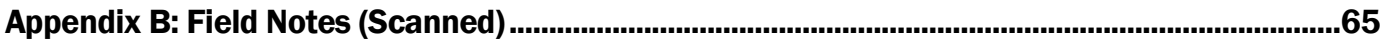

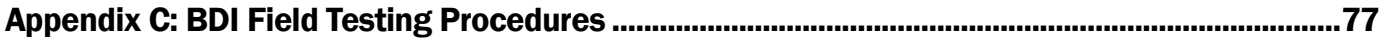

Appendix D: BDI Equipment Specifications ..............................................................................83 


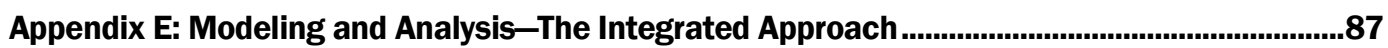

Appendix F: Load Rating Procedures

Report Documentation Page 


\section{Figures and Tables}

\section{Figures}

Figure 1. RPL cross section and material properties. …….............................................................

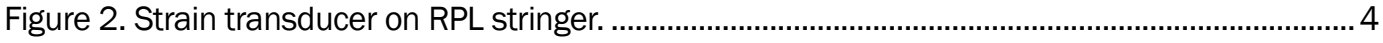

Figure 3. LVDTs at stringer mid-span. ……………………….................................................... 4

Figure 4. Structure plan with truck paths. ..............................................................................

Figure 5. Structure plan with BDI sensor locations and sensor numbers........................................ 6

Figure 6. Elevation view of BDI sensors on superstructure ...............................................................

Figure 7. Sensor locations and numbers for cross sections A-A through F-F. ..................................... 8

Figure 8. Sensor locations and numbers for cross section E-E at Pier 2. ........................................

Figure 9. Dump truck approaching bridge during initial test...............................................................10

Figure 10. M1 tank crossing bridge during final test. ......................................................................10

Figure 11.Tandem-axle dump truck footprint with wheel loads in kips. ............................................12

Figure 12. M1 tank footprint with weight distribution in kips. ........................................................13

Figure 13. Reproducibility of dump truck test results - stress histories. .........................................15

Figure 14. Reproducibility of dump truck test results - displacement histories...............................15

Figure 15. Reproducibility of M1 tank test results - strain histories. ...............................................16

Figure 16. Reproducibility of M1 tank test results - displacement histories. ....................................16

Figure 17. Comparison of Span 2 and Span 3 stress - directly loaded beam line............................17

Figure 18. Comparison of Span 2 and Span 3 stress - indirect loading. ..........................................18

Figure 19. Consistency of beam responses between spans during M1 crossing..............................18

Figure 20. Beam and pile displacements due to 144-kip M1 tank................................................19

Figure 21. Viscoelastic strain observed during static test - M1 tank ...............................................20

Figure 22. Viscoelastic displacement observed during static test - M1 tank. .................................21

Figure 23. Lateral stress distribution at mid-span - dump truck @ Y1.............................................21

Figure 24. Lateral stress distribution at mid-span - M1 tank. ........................................................22

Figure 25. Finite element model of superstructure..............................................................................26

\section{Tables}

Table 1. Structure description and testing notes.............................................................................11

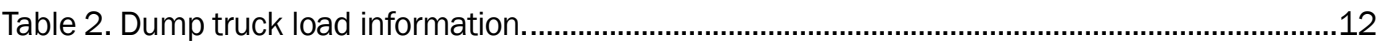

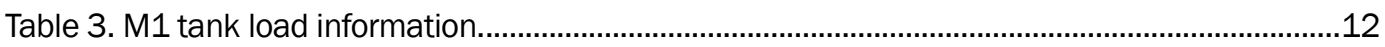

Table 4. Peak stress and displacement during M1 tank crossing. ......................................................23

Table 5. Analysis and model details. ............................................................................................26

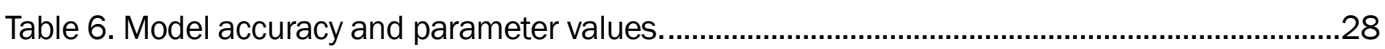

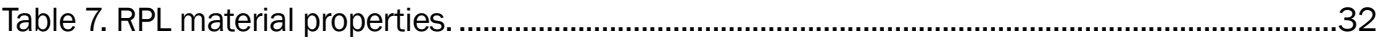

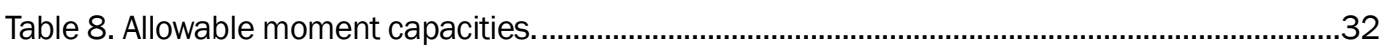




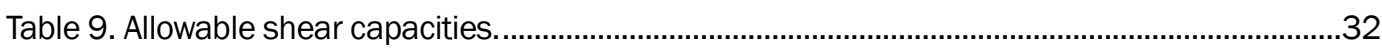

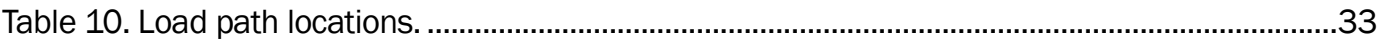

Table 11. Vehicle rating factors and responses - positive moment in RPL beams..........................34

Table 12. Vehicle rating factors and responses - shear in RPL beams............................................34

Table 13. Critical load rating factors and weights..........................................................................34

Table 14. Rating factor calculation for HS-20. …………...........................................................

Table 15. Rating factor calculation for M1 tank (tracked)...................................................................35 


\section{Preface}

The U.S. Army Engineer Research and Development Center's (ERDC) Construction Engineering Research Laboratory (CERL) requested the assistance of the ERDC Geotechnical and Structures Laboratory (GSL) in conducting a live-load testing and load rating determination for thermoplastic Bridge T-8519 in Camp Mackall, North Carolina. The testing summarized in this report was sponsored by the Assistant Chief of Staff for Installation Management under the U.S. Army's Installation Technology Transition Program. Points of contact were Richard Lampo, CERL, and Ali Achmar, Army Installation Management Command.

Load testing was performed under contract to ERDC by personnel of Bridge Diagnostics, Inc. (BDI), under supervision of Brett Commander, BDI. Instrumentation support for the load testing was provided by personnel of BDI and the ERDC Information Technology Laboratory. Henry Diaz-Alvarez, Structural Engineering Branch (StEB), GSL, and Brett Commander, BDI, performed the finite element modeling of the load tests and load rating calculations and prepared this report. The authors were assisted in the testing phase by Kevin Tillman, Rodney Gonzalez, and Orlando Carrasquillo, StEB.

During this investigation, Terry R. Stanton was Chief, StEB; Bartley P. Durst was Chief, Geosciences and Structures Division; Dr. William P. Grogan was Deputy Director, GSL; and Dr. David W. Pittman was Director, GSL.

COL Gary E. J ohnston was Commander and Executive Director of ERDC. Dr. J effery P. Holland was Director. 


\section{Unit Conversion Factors}

\begin{tabular}{|l|l|l|}
\hline Multiply & \multicolumn{1}{|c|}{ By } & To Obtain \\
\hline degrees Fahrenheit & $(\mathrm{F}-32) / 1.8$ & degrees Celsius \\
\hline feet & 0.3048 & meters \\
\hline foot-pounds force & 1.355818 & joules \\
\hline inches & 0.0254 & meters \\
\hline inch-pounds (force) & 0.1129848 & newton meters \\
\hline kips (force) & 4.448222 & kilonewtons \\
\hline miles per hour & 0.44704 & meters per second \\
\hline pounds (force) & 4.448222 & newtons \\
\hline pounds (force) per foot & 14.59390 & newtons per meter \\
\hline pounds (force) per inch & 175.1268 & newtons per meter \\
\hline pounds (mass) & 0.45359237 & kilograms \\
\hline square feet & 0.09290304 & square meters \\
\hline square inches & $6.4516 \mathrm{E}-04$ & square meters \\
\hline tons (force) & $8,896.443$ & newtons \\
\hline
\end{tabular}




\section{Introduction and Result Summary}

A joint investigation that involved field load testing of a new bridge constructed of recycled plastic lumber (RPL) and then calculating its load ratings was conducted by personnel from Bridge Diagnostics, Inc. (BDI), and the U.S. Army Engineer Research and Development Center (ERDC). The bridge, numbered T-8519, is located on Tuckers Road in Camp Mackall near Fort Bragg, NC. Bridge T-8519 is a new four-span structure constructed entirely of RPL, a wood-like product made from recovered plastic or from recovered plastic mixed with other materials that can be used as a substitute for concrete, wood, and metals. The product is clean, nontoxic, nonporous, and lasts longer than wood. In addition, all types of RPL, except for wood-filled RPL, are moisture and chemical resistant, impervious to insects, flexible (can be curved and shaped), maintenance free, and require no sealants or preservatives.

Load tests were performed in J une of 2009 and again in September 2009. During the preliminary test, the BDI structural testing system (STSII) was used to measure strains at 48 locations and vertical displacements at four locations while the bridge was being subjected to a series of controlled load tests. Initial tests were done with a 60-kip dump truck. During the test, deck screws popped out at several locations. While this occurrence did not pose a safety issue, it did have a significant effect on the load test responses. Therefore, the follow-up tests with the M1 tank were postponed until after deck repairs were made. The instrumentation and data acquisition for the second test consisted of 50 strain transducers and 10 linear variable differential transformer (LVDT) displacement sensors, all of which were recorded with the BDI-STS-wireless (WiFi) system. Even though the loss of deck screws caused inconsistent results, the model generated from the initial test was used to verify that the M1 tank could safely cross the bridge. Data from the tank crossing tests were used to reevaluate the bridge after repairs were made, and the revised model was used to generate military load classifications (MLC) for the bridge.

Detailed descriptions of the bridge and the load tests are given in Chapter 2 and results of a preliminary analysis of the load test data in Chapter 3. Chapter 4 describes the detailed finite-element model developed for the bridge structure and comparisons of the calculated bridge responses 
with the measured field data. Procedures for calculating the bridge load ratings and results of these calculations are outlined in Chapter 5. Chapter 6 presents conclusions and recommendations from this investigation. 


\section{Structural Testing Information}

Bridge T-8519 is a four-span structure whose members are constructed entirely of RPL, including the entire superstructure and the piles. It was constructed in a manner similar to a timber bridge with relatively short longitudinal stringers and a plank deck. The stringers were 18-in. by 18-in. I-beams with 3-in.-thick flanges and a 5-in.-thick web. I-beams were manufactured as two T-sections that were attached with glue and screws (Figure 1). The stringers were continuous over two or three of the spans, and end-joints were staggered to prevent a continuous joint over any pier. The end-spans were approximately $9 \mathrm{ft}, 9 \mathrm{in}$., and the two interior spans were approximately $12 \mathrm{ft}$ long; however, actual span lengths varied by as much as 6 in. The 3-in.-thick by 12-in.-wide deck planks were aligned transversely across the bridge and attached by deck screws to the top flange of the I-beams. The substructure consisted of abutments with three RPL piles and interior piers with four RPL piles driven about $60 \mathrm{ft}$ deep. The design pile capacity wais an allowable load of $40 \mathrm{kip}$ with an ultimate load of at least 120 kip.

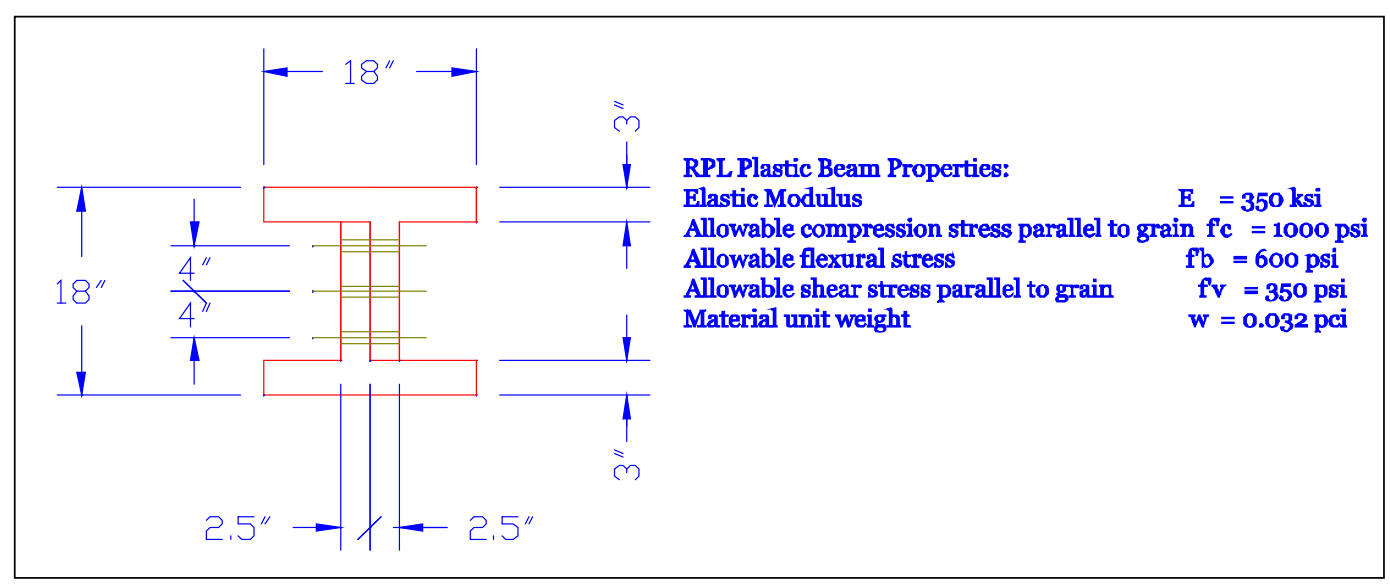

Figure 1. RPL cross section and material properties.

The initial instrumentation installed by BDI personnel consisted of 48 strain transducers and 4 vertical displacement sensors. The purpose of the instrumentation was to determine the load transfer characteristics of the superstructure. The second setup was nearly identical to the first but with the addition of 6 more displacement sensors. Strain transducers were attached with glue-mounted tabs (Figure 2) and were typically located at mid-span and near the supports of the stringers. An interior bent was also 
instrumented along with strains on one pile. Vertical displacements were measured at mid-span of 6 adjacent stringers (Figure 3) at Span 2 and also at the bent immediately adjacent to all four piles. The locations of the sensors on the structure are shown in Figure 4 through 8.

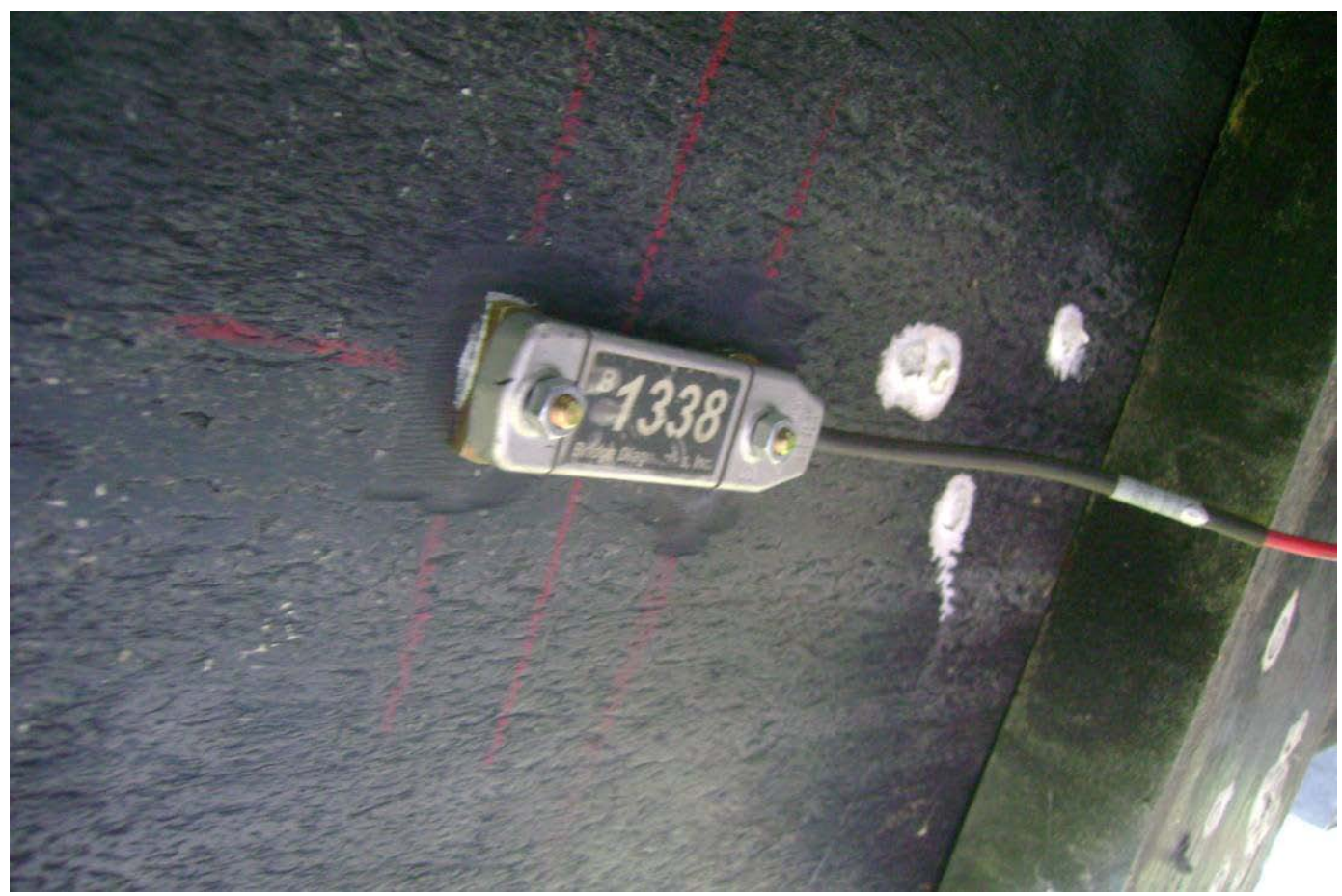

Figure 2. Strain transducer on RPL stringer.

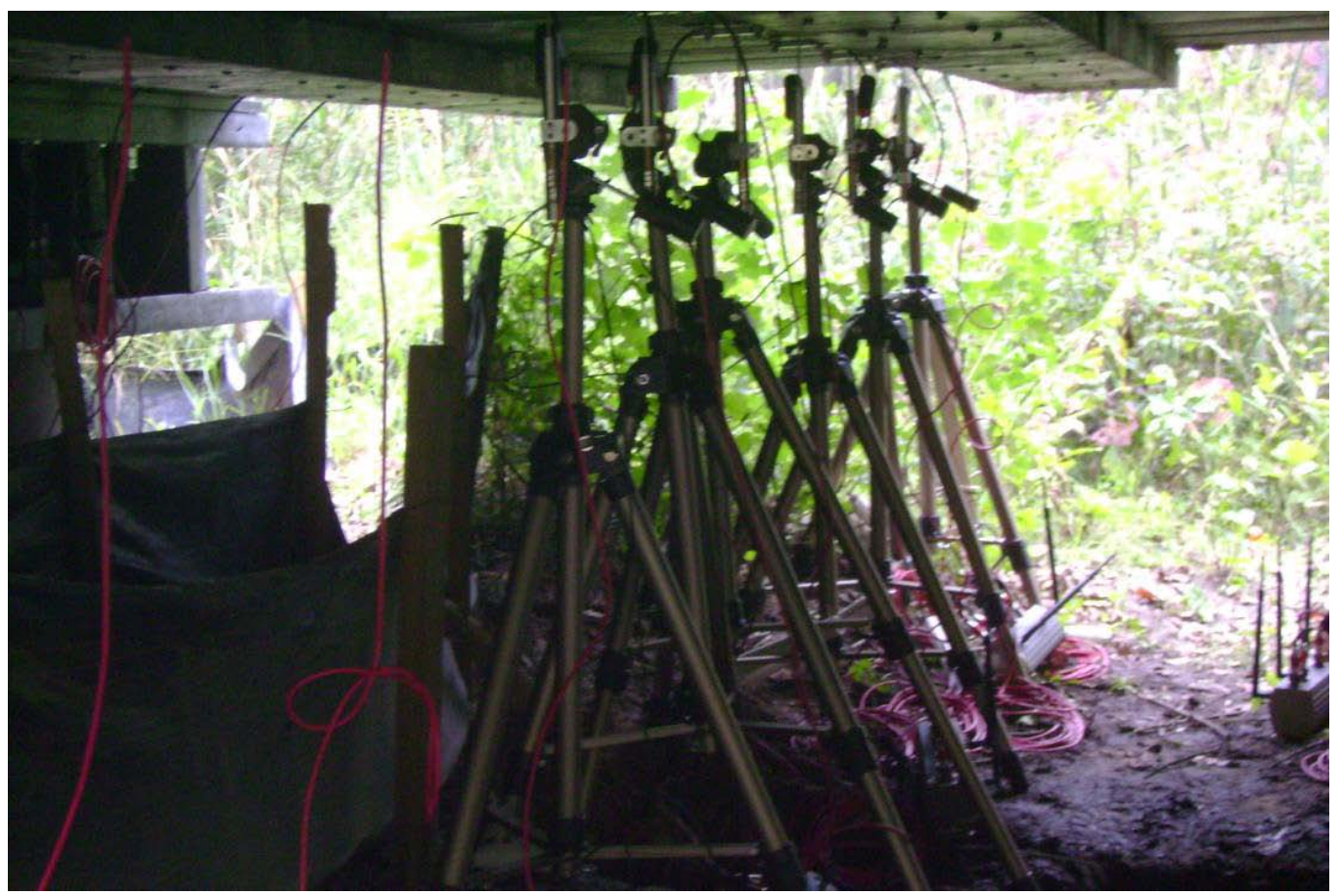

Figure 3. LVDTs at stringer mid-span. 


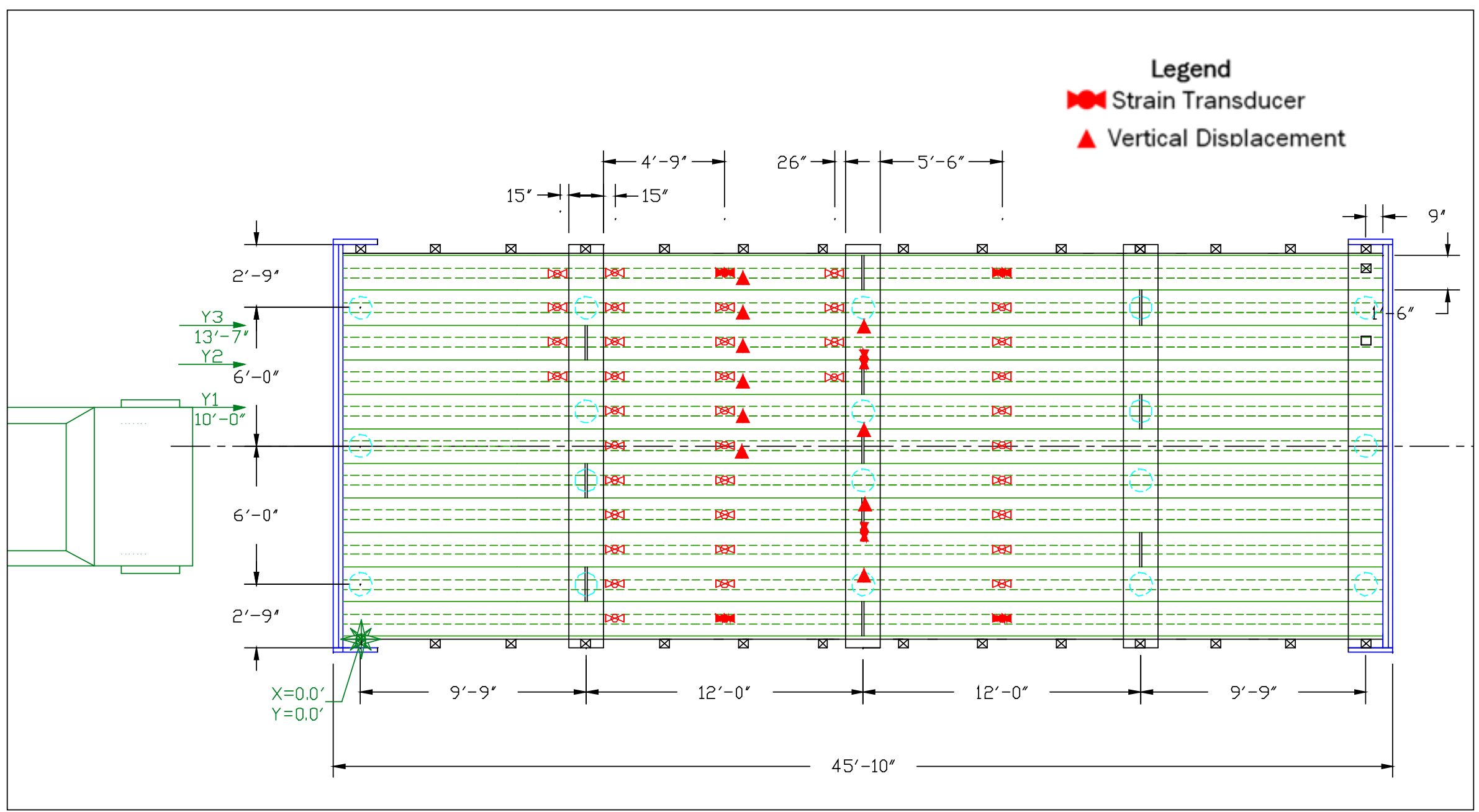

Figure 4. Structure plan with truck paths. 


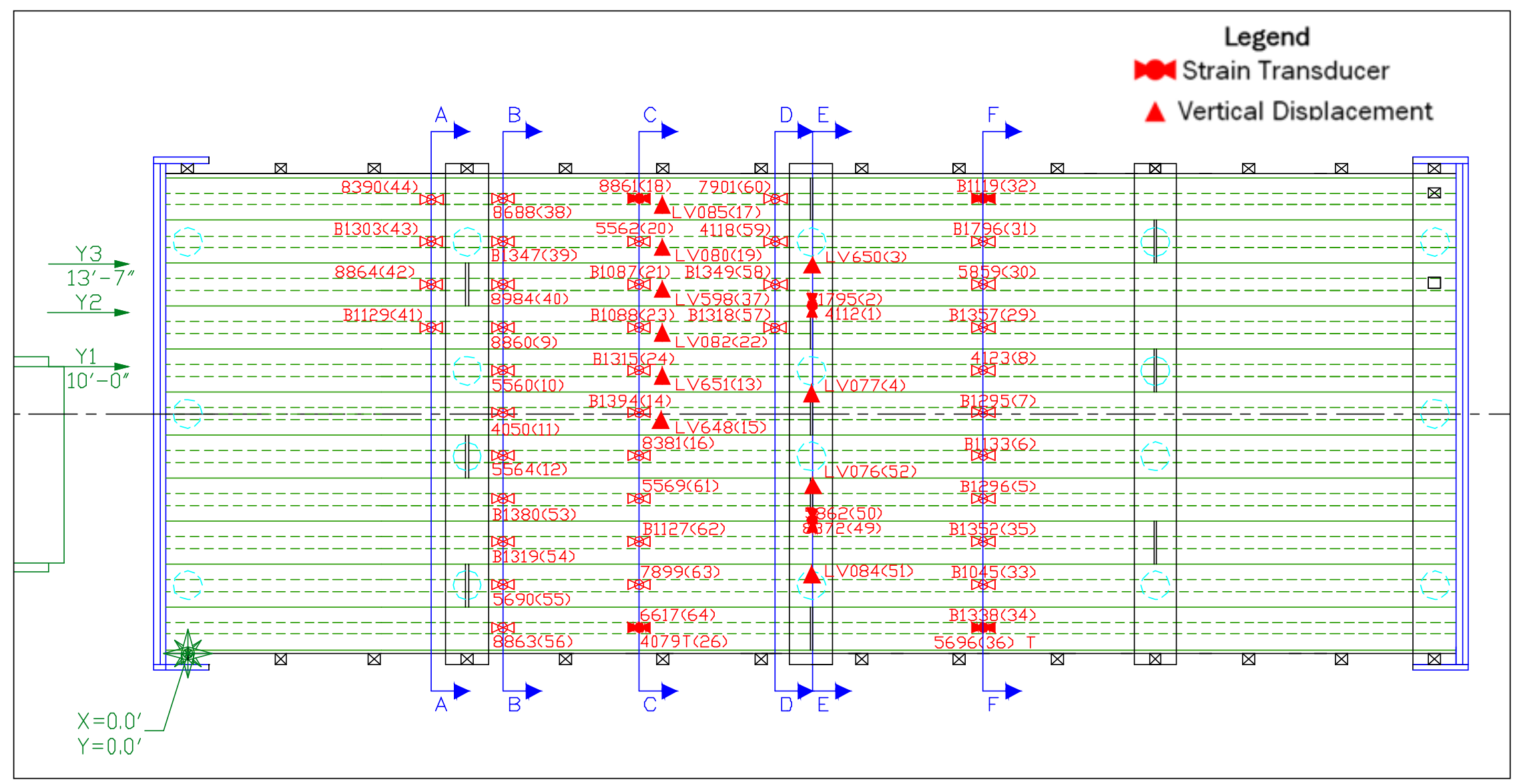

Figure 5. Structure plan with BDI sensor locations and sensor numbers. 


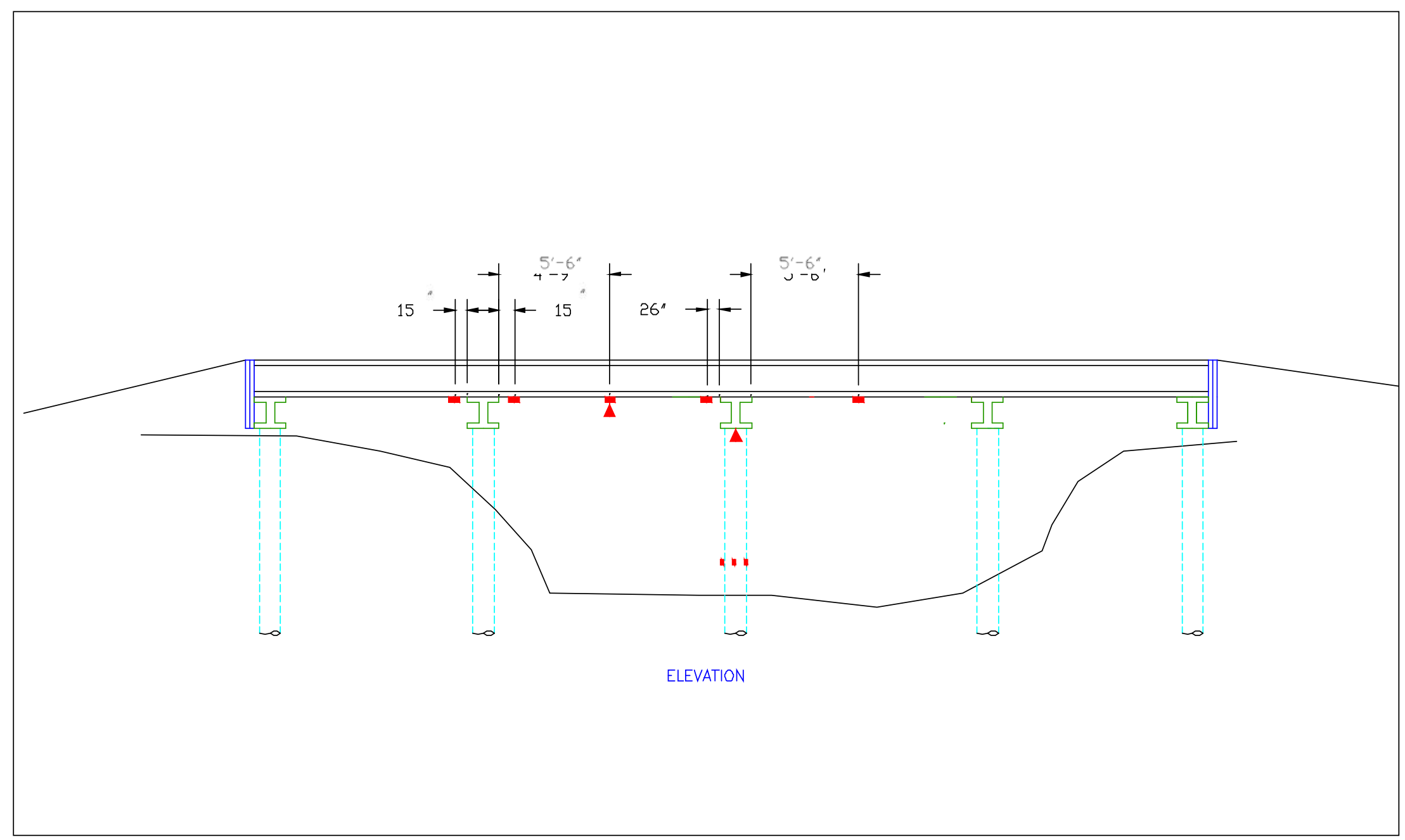

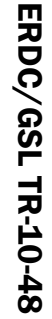

Figure 6. Elevation view of BDI sensors on superstructure. 


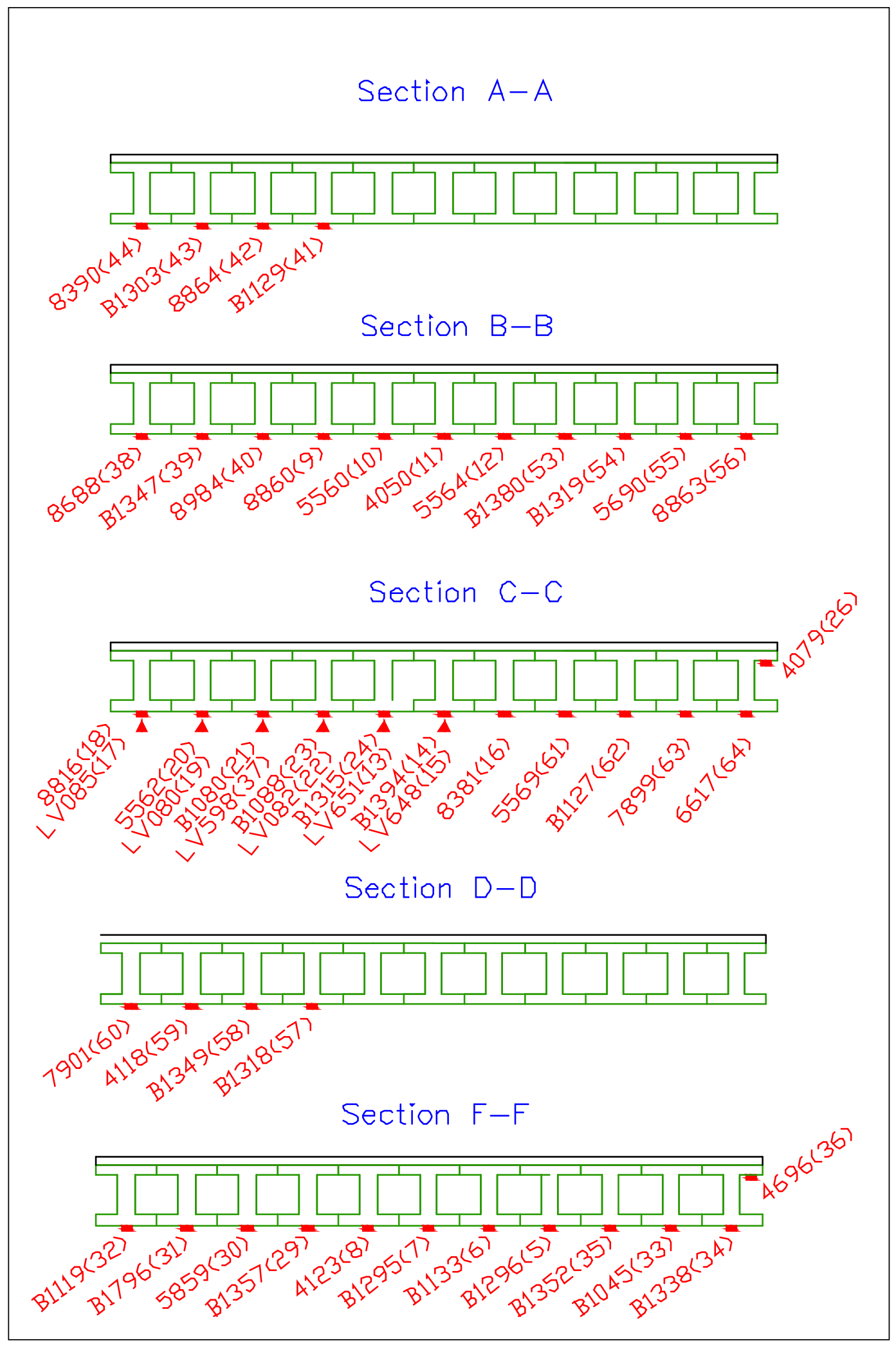

Figure 7. Sensor locations and numbers for cross sections A-A through F-F. 


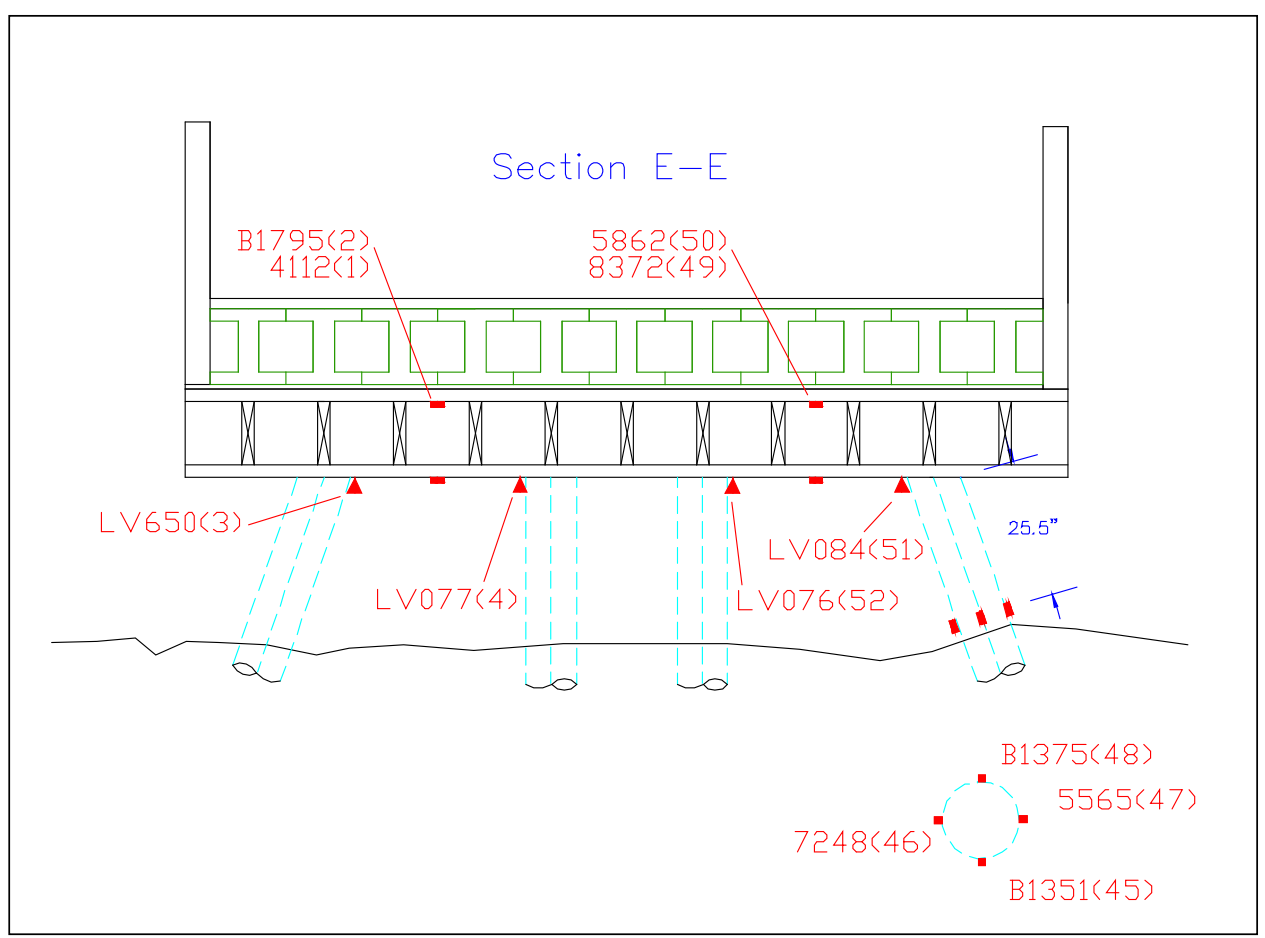

Figure 8. Sensor locations and numbers for cross section E-E at Pier 2.

The live-load tests were performed by researchers who measured and recorded strains and displacements as a specific vehicle was driven across the bridge along prescribed paths. All measurements were recorded at a frequency of $40 \mathrm{~Hz}$. Vehicle position was monitored along with the sensor measurements so that all measured responses could be correlated with applied load. Most of the tests were conducted quasi-statically with the vehicle traveling 3 to $5 \mathrm{mph}$. Because of the viscoelastic nature of the RPL, two static tests were also performed to capture the responses of the structure to sustained loads. Initial tests were conducted with a 60-kip dump truck as shown in Figure 9. The dump truck was driven across the bridge along three different paths, and each path was repeated at least once to verify reproducibility in responses and test procedures. After it was determined that the bridge would be safe, the controlled load tests were repeated with an M1 tank as shown in Figure 10. Due to the width of the tank relative to the bridge, only two paths were utilized for the load test.

Information specific to this load test can be found in Table 1, and the field notes are summarized in Appendix B. The test vehicles' gross-weights and wheel rollout distances (required for tracking positions across the structure) are provided in Table 2 and Table 3. Footprints of the vehicles, including wheel weights, are shown in Figure 11 and Figure 12. 


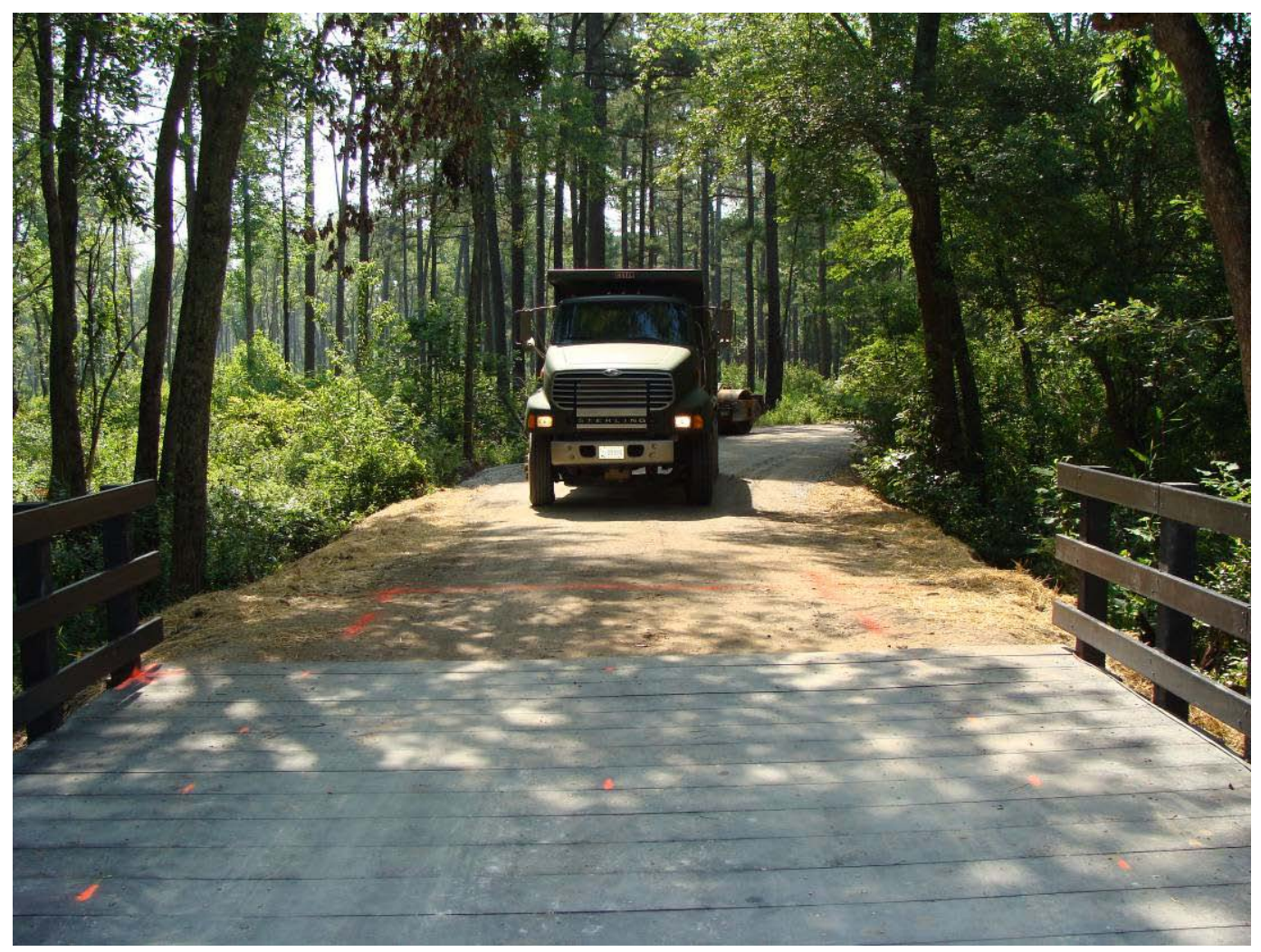

Figure 9. Dump truck approaching bridge during initial test.

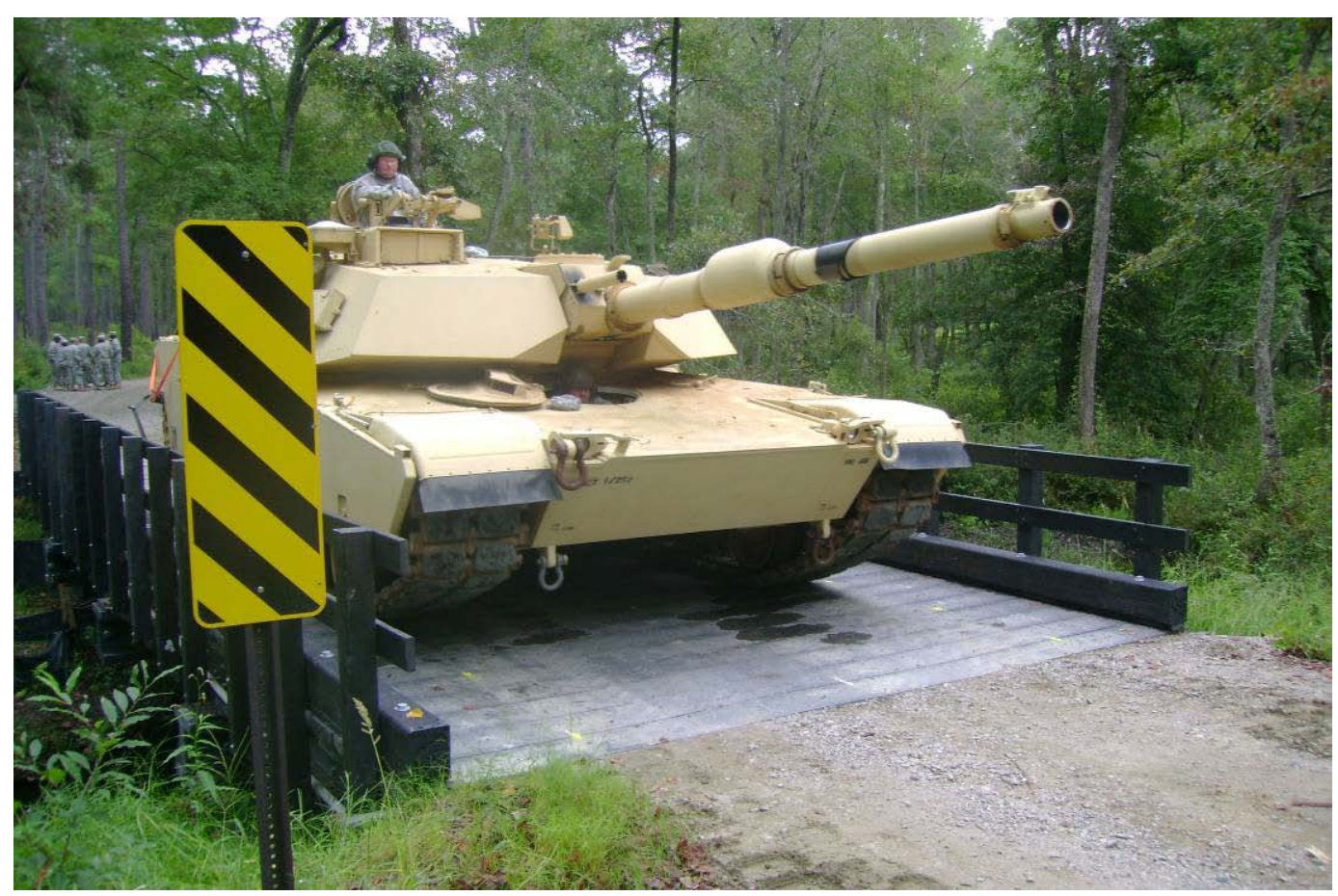

Figure 10. M1 tank crossing bridge during final test. 
Table 1. Structure description and testing notes.

\begin{tabular}{|c|c|c|}
\hline Item & \multicolumn{2}{|c|}{ Description } \\
\hline Structure Name & \multicolumn{2}{|c|}{ Plastic Bridge over Big Muddy Creek } \\
\hline BDI Project Number & \multicolumn{2}{|c|}{ 090428NC } \\
\hline Testing Date & \multicolumn{2}{|c|}{ June 10, 2009} \\
\hline Client's Structure ID \# & \multicolumn{2}{|l|}{ T-8519 } \\
\hline Location/Route & \multicolumn{2}{|c|}{ Gravel road, Camp Mackall, North Carolina } \\
\hline Structure Type & \multicolumn{2}{|c|}{ RPL bridge } \\
\hline Total Number of Spans & \multicolumn{2}{|l|}{4} \\
\hline Span Length(s) & \multicolumn{2}{|c|}{ South to North: 9'-9", 12'-0", 12'-0", 9'-9" } \\
\hline Skew & \multicolumn{2}{|l|}{$0^{\circ}$} \\
\hline Structure/Roadway Width & \multicolumn{2}{|c|}{$17^{\prime}-6 "$ / 16'-6" } \\
\hline Wearing Surface & \multicolumn{2}{|c|}{ RPL decking (3"x12") } \\
\hline Other Structure Info & \multicolumn{2}{|l|}{ N/A } \\
\hline Spans Instrumented & \multicolumn{2}{|c|}{ North end-span and 2 center spans } \\
\hline Test Reference Location $(X=0, Y=0)$ & \multicolumn{2}{|c|}{ Southeast corner of deck } \\
\hline Test Vehicle Travel Direction & \multicolumn{2}{|c|}{ South to north } \\
\hline Test Beginning Point & \multicolumn{2}{|c|}{-15 from reference location } \\
\hline Lateral Load Position(s) & \multicolumn{2}{|c|}{$\begin{array}{l}3 \text { (symmetrically located) - dump truck } \\
2 \text { Y1 \& Y3 for M1 tank }\end{array}$} \\
\hline Number/Type of Sensors & \multicolumn{2}{|c|}{50 strain transducers \& 10 LVDTs } \\
\hline STS Sample Rate & \multicolumn{2}{|c|}{ Slow speed: $40 \mathrm{~Hz}$} \\
\hline Number of Test Vehicles & \multicolumn{2}{|l|}{2} \\
\hline Structure Access Type & \multicolumn{2}{|c|}{ Ground, Waders } \\
\hline Structure Access Provided by & \multicolumn{2}{|c|}{ BDI / ERDC } \\
\hline Traffic Control Provided by & \multicolumn{2}{|l|}{ N/A } \\
\hline Total Field Testing Time & \multicolumn{2}{|c|}{16 hours (Test 1 ) and 16 hours (Test 2 ) } \\
\hline Field Notes & \multicolumn{2}{|c|}{ See Appendix B } \\
\hline Visual Condition & \multicolumn{2}{|c|}{ New structure } \\
\hline $\begin{array}{l}\text { Test File Information } \\
\text { File Name }\end{array}$ & $\begin{array}{l}\text { Lateral } \\
\text { Position }\end{array}$ & Comments \\
\hline $\begin{array}{l}\text { Dump truck 6 /9/09 } \\
\text { Plastic4S_1.dat } \\
\text { Plastic4S_2.dat } \\
\text { Plastic4S_3.dat } \\
\text { Plastic4S_4.dat } \\
\text { Plastic4S_5.dat } \\
\text { Plastic4S_6.dat } \\
\text { Plastic4S_7.dat }\end{array}$ & $\begin{array}{l}\text { Y1 } \\
\text { Y1 } \\
\text { Y2 } \\
\text { Y2 } \\
Y 3 \\
Y 3 \\
Y 3\end{array}$ & $\begin{array}{l}\text { Clicks spaces weird - erratic speed } \\
\text { Good } \\
\text { Good after Jesse's computer crashed } \\
\text { Good - deck screws popped up } \\
\text { Good - more deck screws popped up } \\
\text { Good - more deck screws popped up } \\
\text { Stopped with rear axle at mid-span } 2 \text { (5 min) }\end{array}$ \\
\hline M1 tests $9 / 17 / 09$ & & \\
\hline
\end{tabular}




\begin{tabular}{|l|l|l|}
\hline Item & \multicolumn{2}{|l|}{ Description } \\
\hline Plastic4SM1_1_1 & Y1 & Good \\
Plastic4SM1_1_2 & Y1 & Good - reverse \\
Plastic4SM1_1_3 & Y1 & Good \\
Plastic4SM1_1_4 & Y1 & Static test - reverse - stopped with 2nd front wheel \\
& & directly over middle pier - 5 min \\
Plastic4SM1_2_1 & Y2 & Good \\
Plastic4SM1_2_2 & Y2 & Good \\
\hline
\end{tabular}

Table 2. Dump truck load information.

\begin{tabular}{|l|l|}
\hline \multicolumn{2}{|l|}{ Vehicle Type - Tandem rear-axle dump truck (see Figure 11) } \\
\hline Gross Vehicle Weight (GVW) & $59,800 \mathrm{lb}$ \\
\hline Wheel Rollout 5 Revs & $54^{\prime 2}$ " $^{\prime}\left(10.83^{\prime} / \mathrm{rev}\right)$ \\
\hline \# Crawl Speed Passes & 15 \\
\hline \# High Speed Passes/Speed & $1 / 25 \mathrm{mph}$ \\
\hline No. of Static Tests & 1 \\
\hline
\end{tabular}

Table 3. M1 tank load information.

\begin{tabular}{|l|l|}
\hline \multicolumn{2}{|l|}{ Vehicle Type - M1 Tank (see Figure 12) } \\
\hline Gross Vehicle Weight (GVW) & $144,288 \mathrm{lb}$ \\
\hline Wheel Rollout 10 Revs & $71^{\prime} 2^{\prime \prime}\left(7.12^{\prime} / \mathrm{rev}\right)$ \\
\hline \# Crawl Speed Passes & 5 \\
\hline \# of static tests & 1 \\
\hline
\end{tabular}

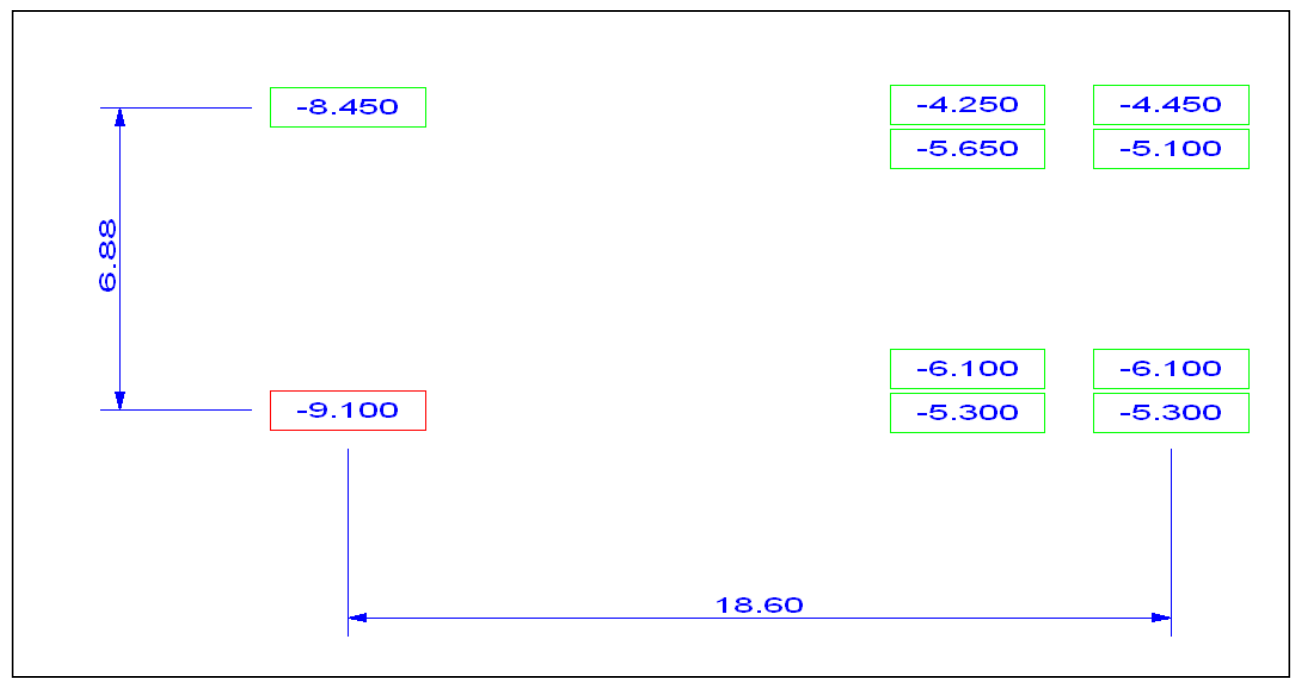

Figure 11.Tandem-axle dump truck footprint with wheel loads in kips. 


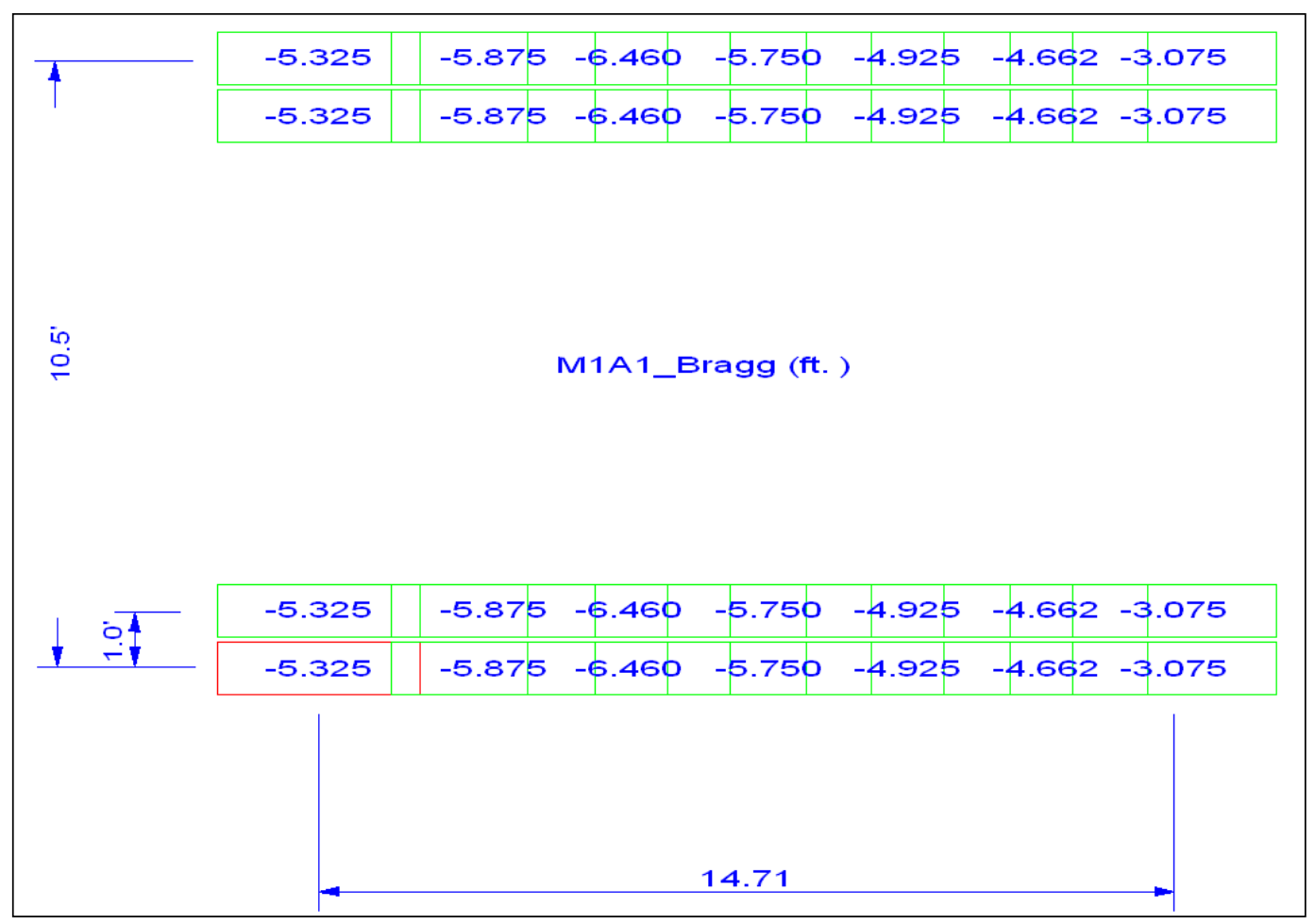

Figure 12. M1 tank footprint with weight distribution in kips.

Appendix C contains the outline for the general field-testing procedures, and Appendix D presents the specifications for the strain transducers and the wireless structural testing system (SSTII-WiFi). 


\section{Preliminary Investigation of Test Results}

All of the field data were first examined graphically to provide a qualitative assessment of the data and the structure's live-load response. Some of the indicators of data quality included reproducibility between identical truck crossings, elastic behavior (strains returning to zero after truck crossing), and any unusually shaped responses that might indicate nonlinear behavior or possible gage malfunctions.

In addition to providing a data quality check, the information obtained during the preliminary investigation was used to determine appropriate modeling procedures and help in establishing the direction that the analysis should take. Several representative response histories are provided in Appendix A. For all plots, load position on the x-axis is referencing the location of the front axle as the test vehicle travels across the bridge.

\section{Reproducibility and linearity}

Responses from duplicate truck crossings were examined for both the dump truck crossing and the M1 tank crossing to determine whether the test procedures and the load responses were reproducible and consistent. Response histories were also examined to verify that all responses returned to zero after each load cycle. Figure 13 and Figure 14 show strain and displacement histories, respectively, from the dump truck crossing. Both responses were highly reproducible, indicating that the structural responses were elastic and the load test procedures were well duplicated. It was noted, however, that the responses were very sensitive to longitudinal and lateral truck position. Strain and displacement histories from the M1 tank crossing also had a high degree of reproducibility as shown in Figure 15 and Figure 16. More variability occurred in the data for the tank crossing as compared with the data for the dump truck due to the difficulty of steering the tank and following an exact path.

\section{Variations in deck connection during dump truck tests}

During the initial load test it was noted that deck screws popped up approximately a half-inch after each truck crossing. It was also observed that the loss of deck screws was much more prevalent on Span 3 than on Span 2. Beam strain responses were compared for the two spans along the 


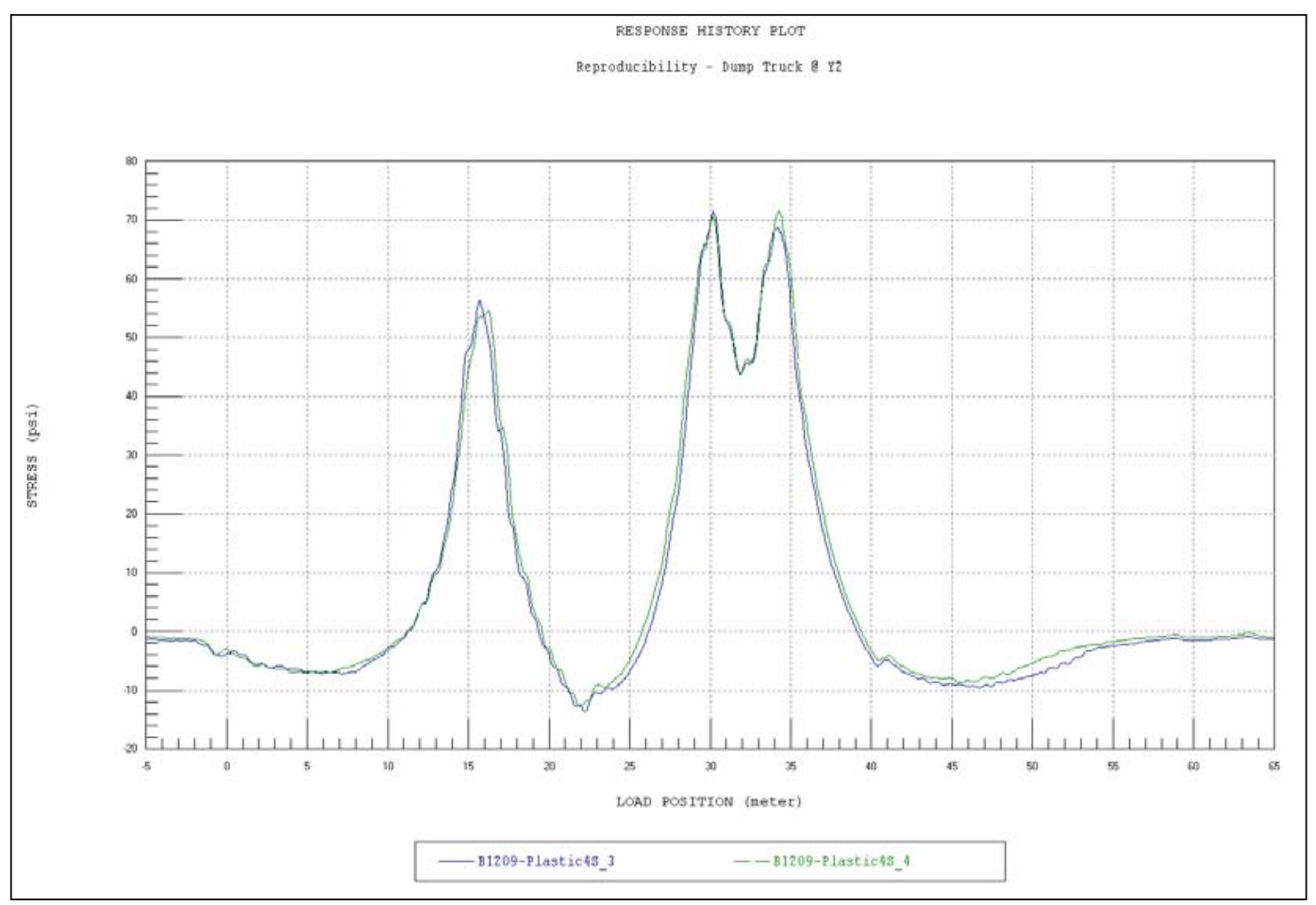

Figure 13. Reproducibility of dump truck test results - stress histories.

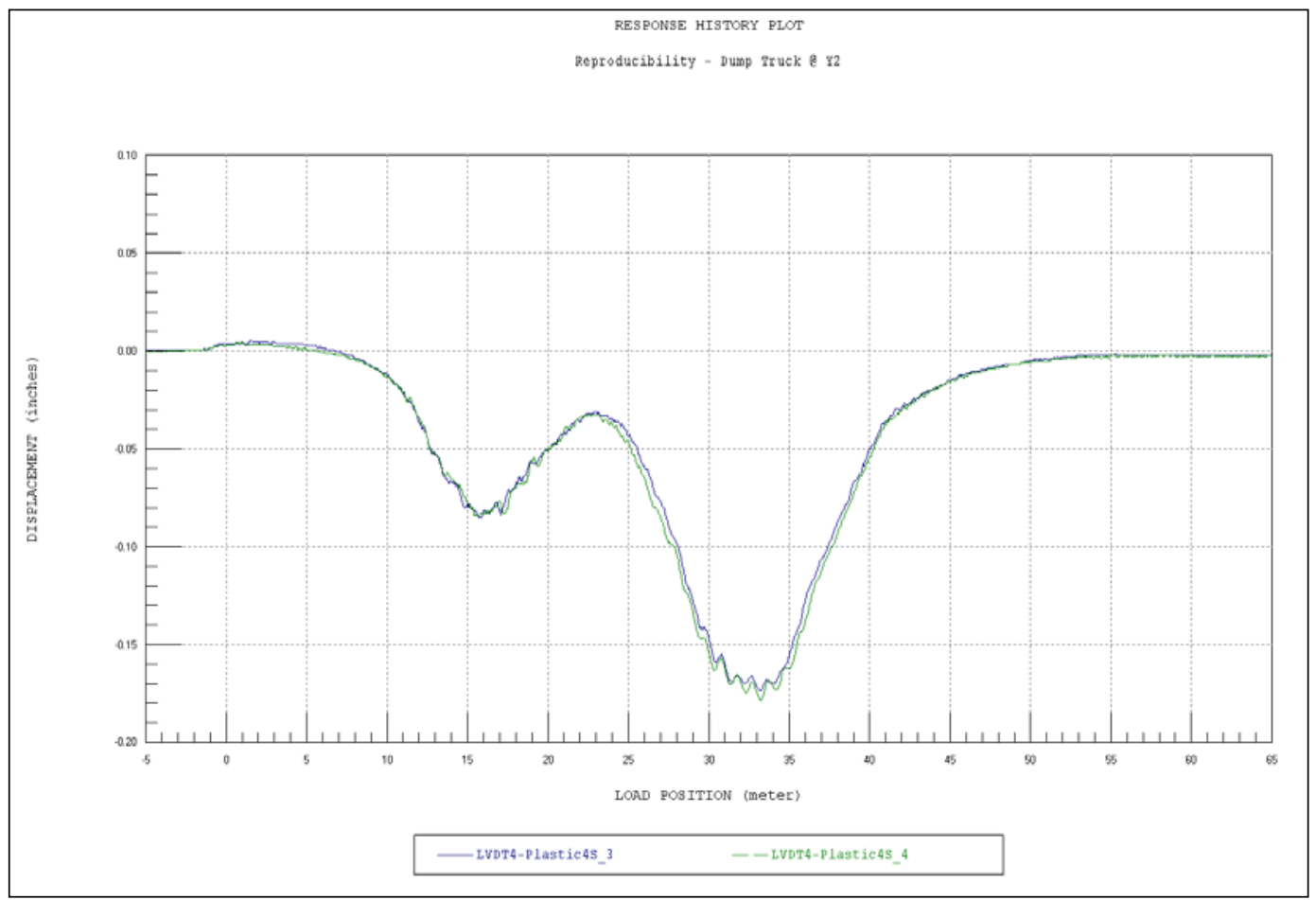

Figure 14. Reproducibility of dump truck test results - displacement histories. 


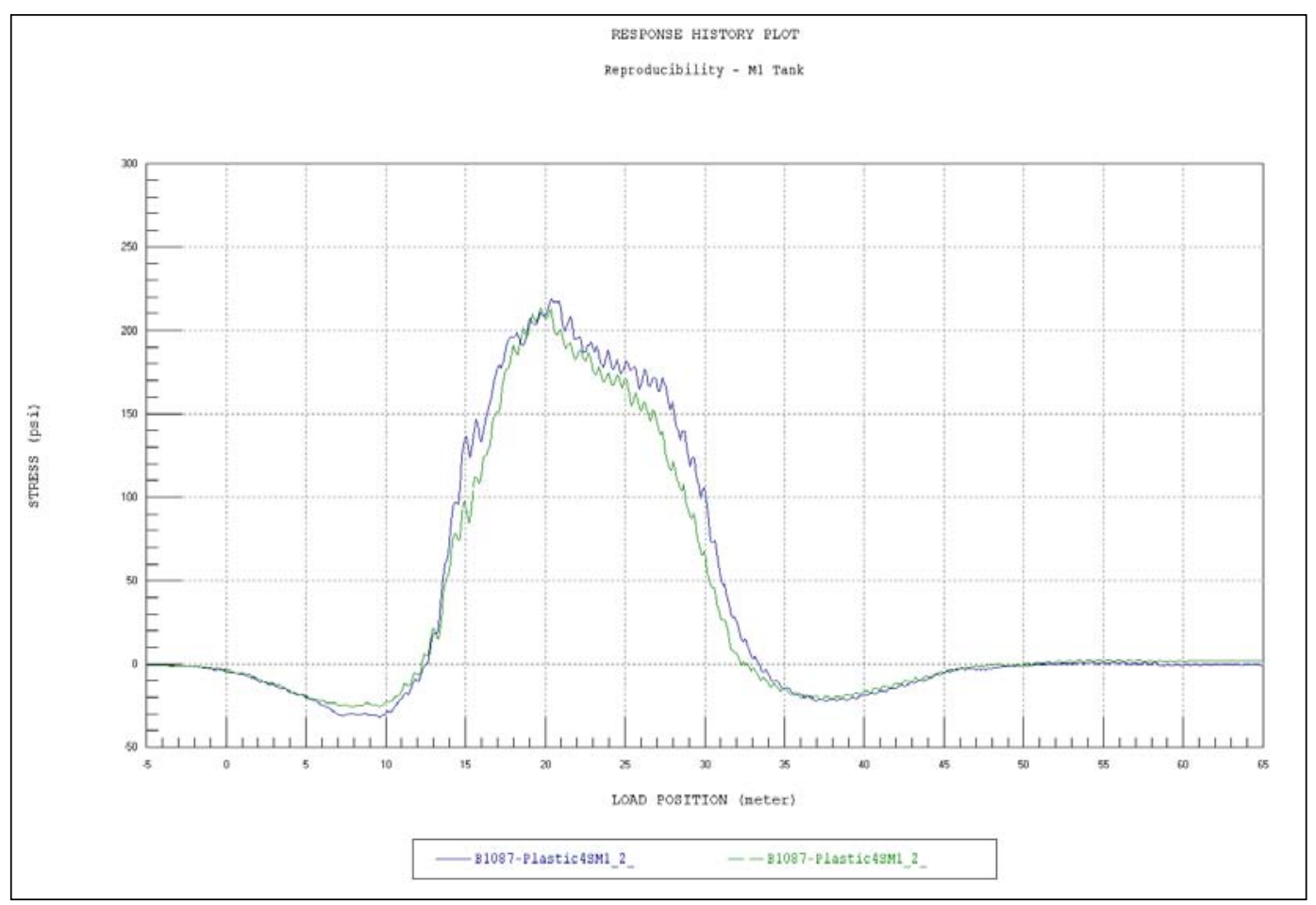

Figure 15. Reproducibility of M1 tank test results - strain histories.

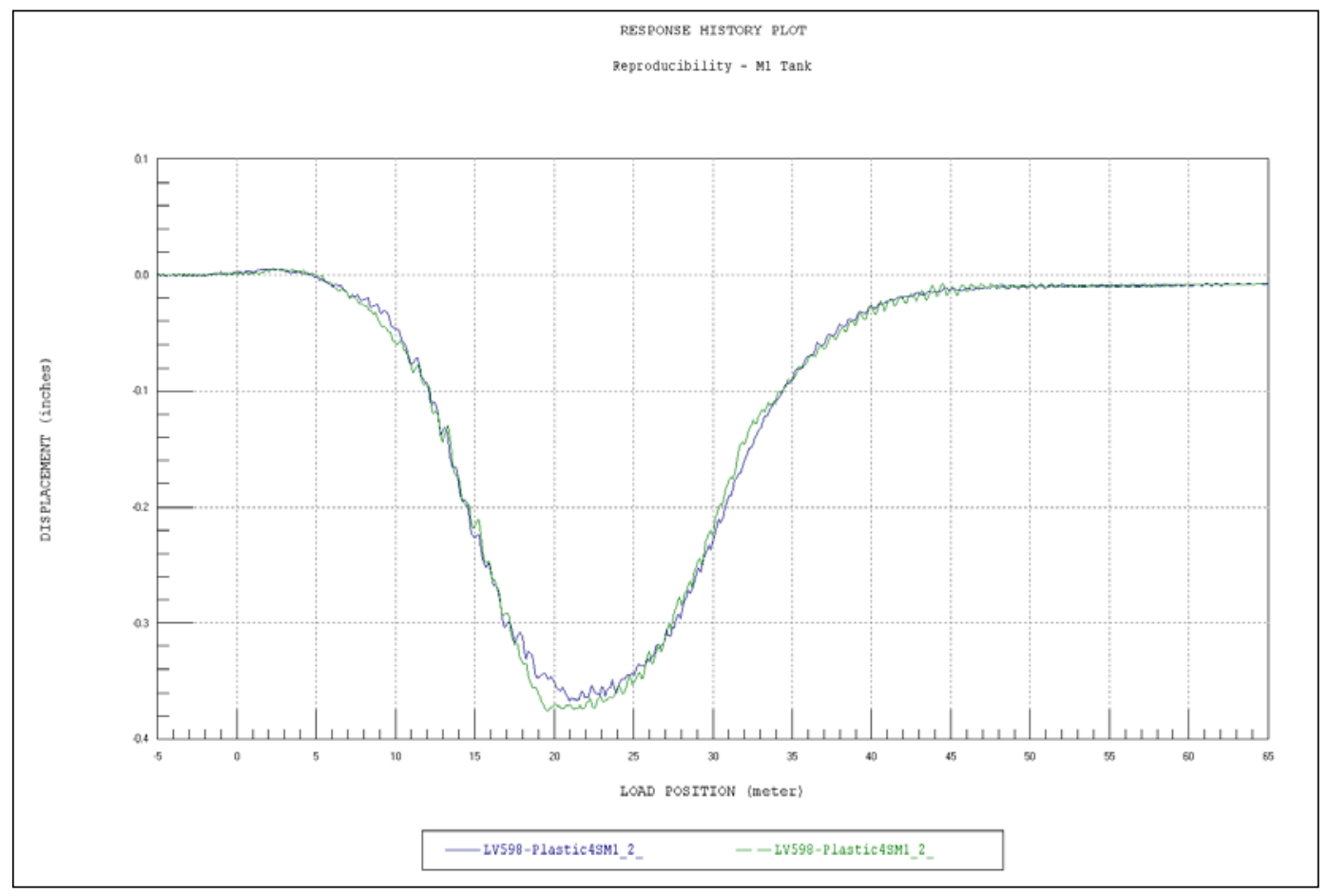

Figure 16. Reproducibility of M1 tank test results - displacement histories. 
same beam-line to determine the effects of the deck detachment. Based on the response histories shown in Figure 17, Span 3 stresses were approximately 30\% greater than at Span 2 for the beam directly under the wheel loads. However, when examining beam lines indirectly loaded via lateral load transfer, the stress magnitude of the Span 2 beams tended to be as high as, or higher than, the magnitude of the Span 3 beams as shown in Figure 18. These comparisons indicate that the loss of deck screws reduced the lateral load transfer ability of the deck, which is one of the reasons the Span 3 responses were so much higher. An additional factor was that the deck screws, when connected, provided partial composite action between the beams and the deck. Therefore, the beams were stiffer in Span 2 than they were in Span 3, which is another reason for the large variation in stress magnitude.

\section{Consistency in spans after repairs}

The M1 load tests were performed after the deck screws were replaced and the number of screws was increased to provide a more secure deck attachment. Figure 19 shows that the beam responses of Spans 2 and 3 were more consistent after the repairs were made, even though the applied load was significantly greater. There was some variation in stress magnitude between the two spans; however, this difference was likely due to the relative location of the beam splices and slight variation in the lateral position of the tank between spans.

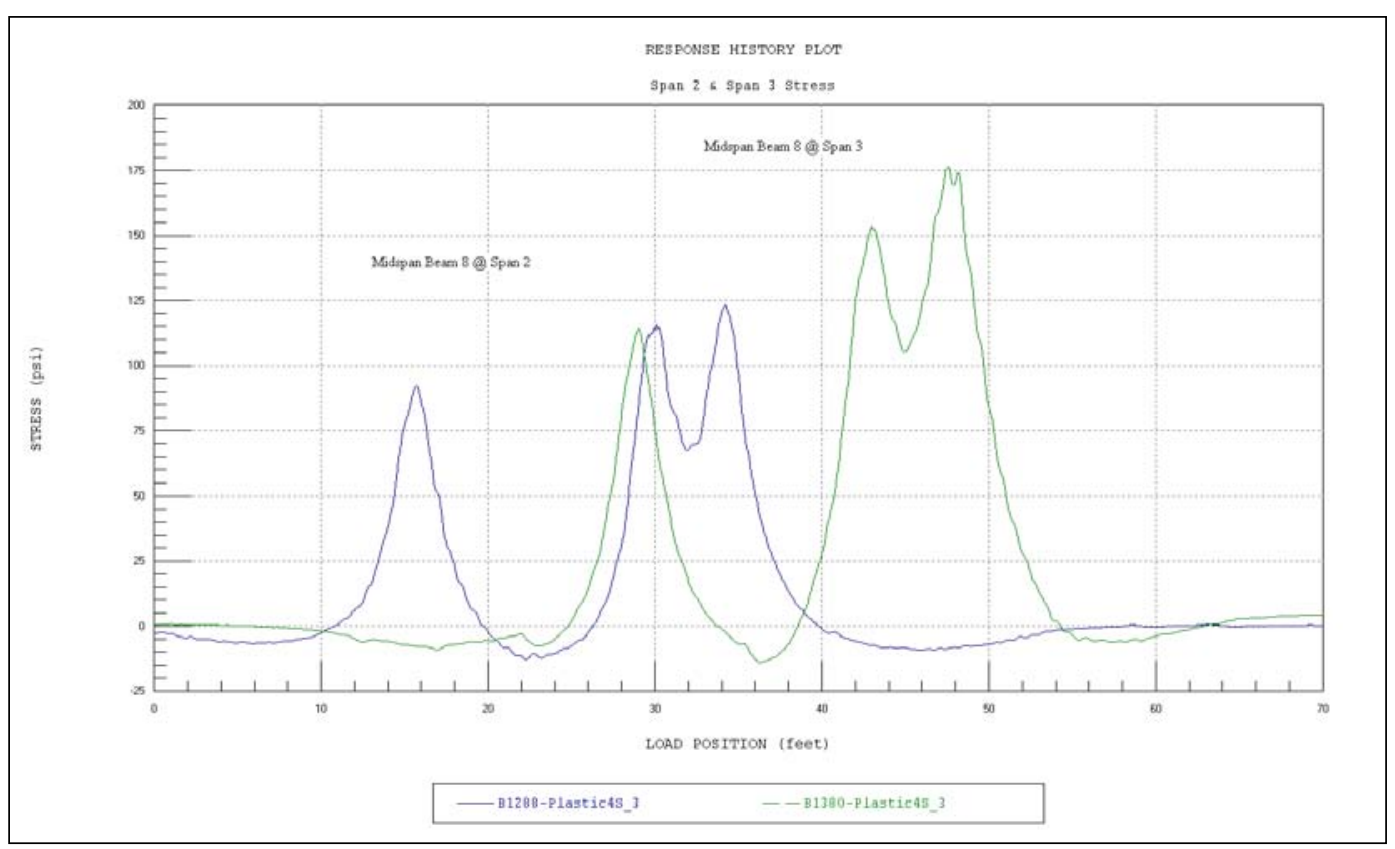

Figure 17. Comparison of Span 2 and Span 3 stress - directly loaded beam line. 


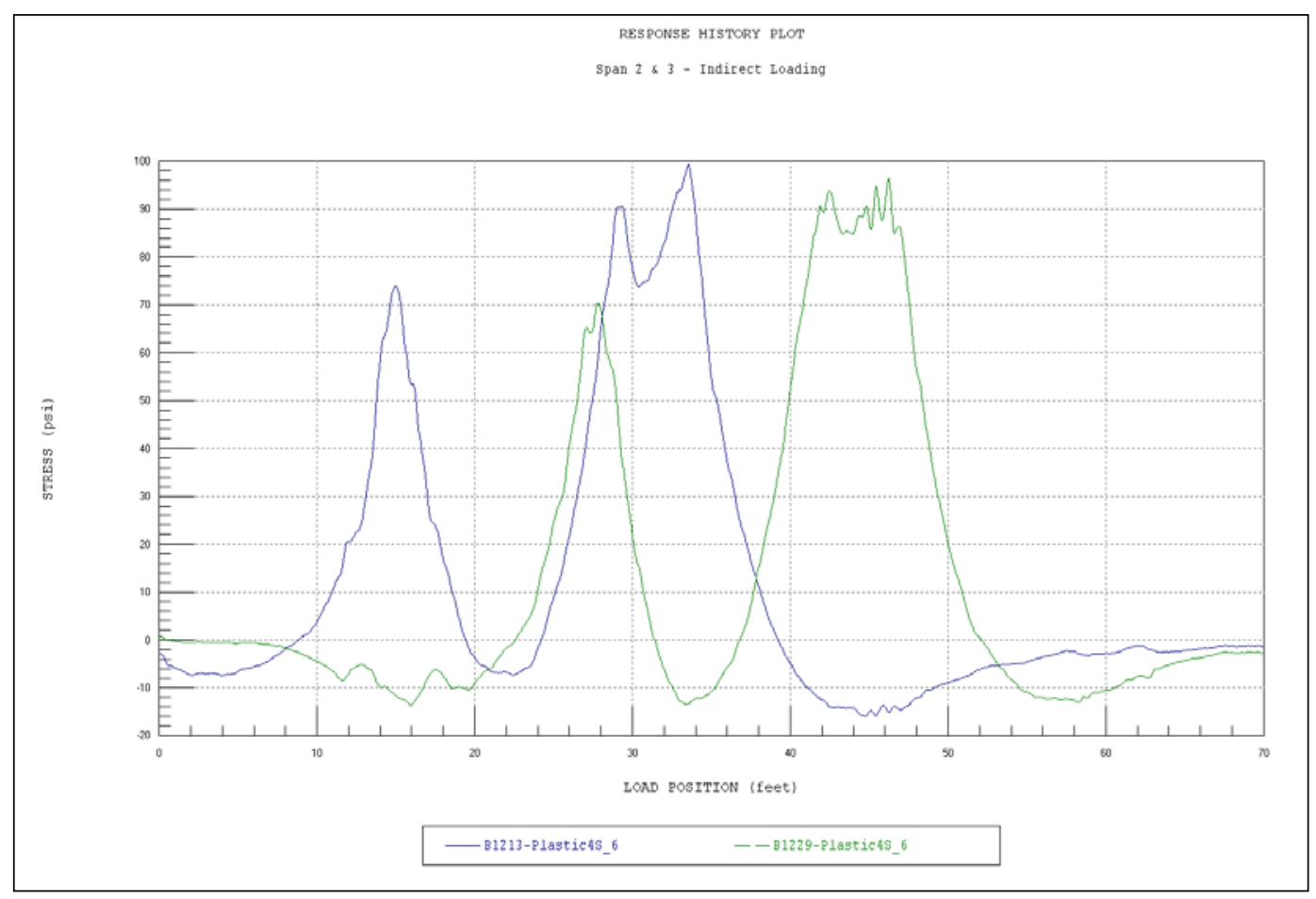

Figure 18. Comparison of Span 2 and Span 3 stress - indirect loading.

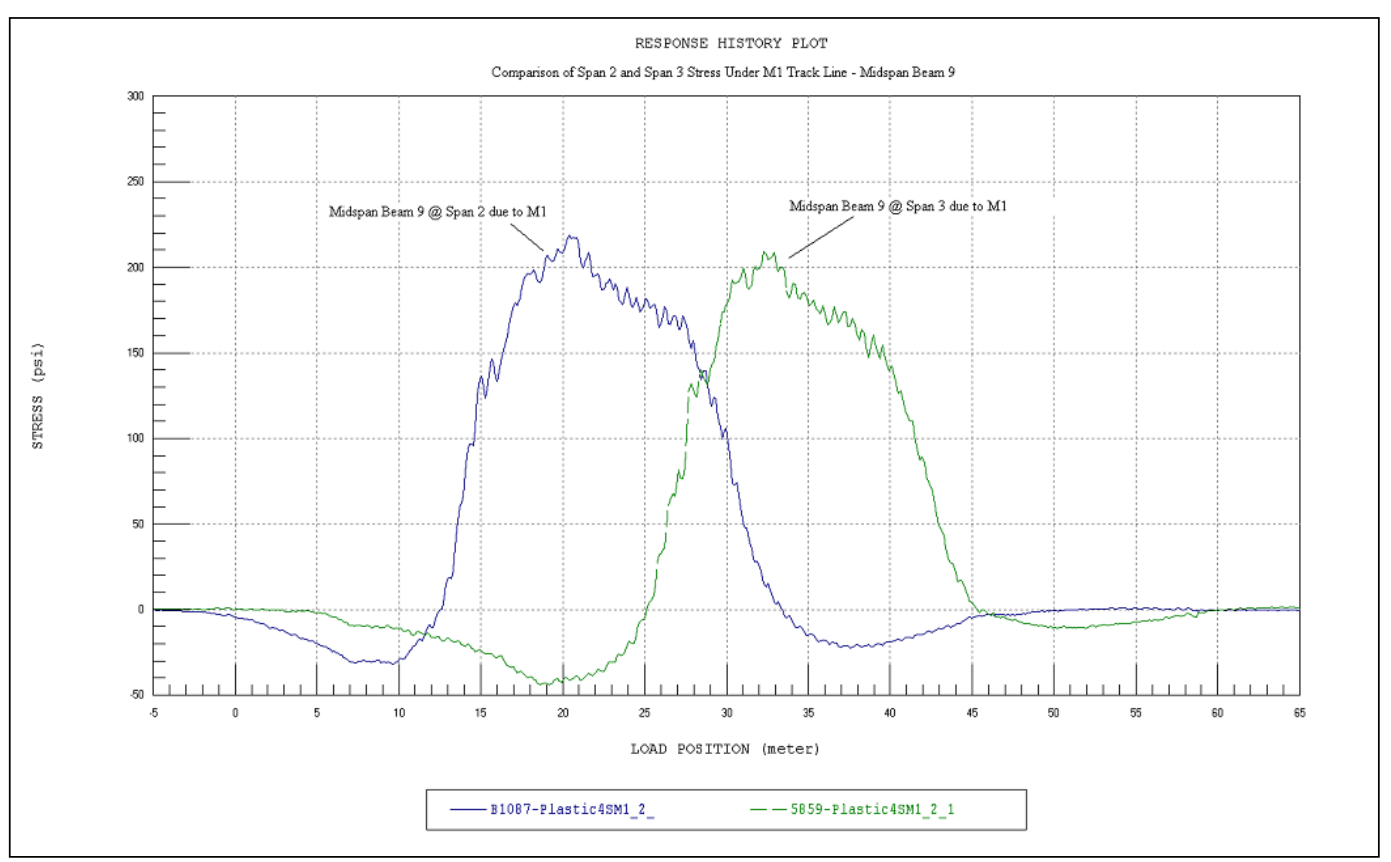

Figure 19. Consistency of beam responses between spans during M1 crossing. 


\section{Pile and beam displacement}

During the M1 load test, displacements were measured at mid-span of six beams and at an interior bent immediately adjacent to each pile. In most bridge structures, the bents and abutments are assumed to be very rigid compared to the superstructure. However, since the piles were made from the same recycled plastic material as the superstructure, the displacement in the piles was a significant portion of the overall superstructure displacement. Figure 20 shows the displacement histories at a beam mid-span location and the pile at Bent 2 due to the tank crossing, respectively. The pile displacement was approximately $45 \%$ of the beam displacement.

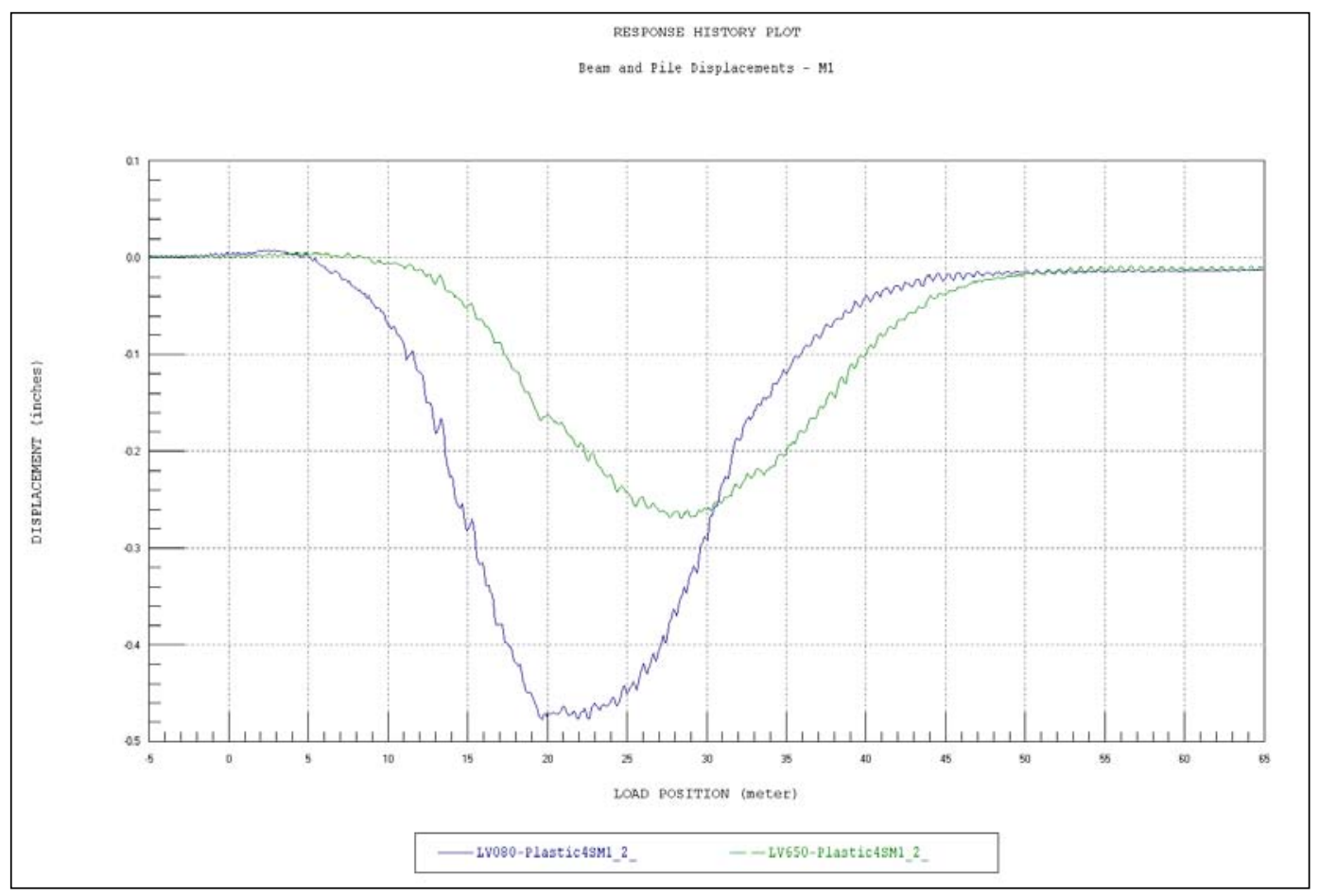

Figure 20. Beam and pile displacements due to 144-kip M1 tank.

\section{Viscoelastic response}

The responses from the tank were large enough that viscoelastic behavior was notable. Responses did return to zero, but a duration of several minutes or more was required for complete recovery. This behavior was observed from the data from the initial tests. Therefore, one of the tank tests was conducted with the tank parked on the middle of the bridge for a period of $5 \mathrm{~min}$. Data were recorded for an additional 3 or $4 \mathrm{~min}$ after the tank was removed to observe the strain and stress recovery. Figure 21 shows the strain history, and Figure 22 shows the displacement history 
during and after the static test. The viscoelastic behavior was first noted during the static loading as the responses continued to increase over a period of several minutes and then again during the recovery process after the load was removed. The observed response essentially confirmed the intended theoretical behavior, so it was not a concern.

\section{Lateral distribution}

As a means of observing lateral distribution of wheel loads, stresses in the bottom flange, associated with maximum mid-span moments, were plotted for all beams at a mid-span cross section. Figure 23 shows the stress distribution for the dump truck. Stress distribution produced by the M1 tank is shown in Figure 24. The general observation is that the deck is relatively flexible. However, due to the close spacing of the RPL beams, the lateral wheel load distribution is reasonably good. The apparent wheelload distribution factor for a single beam is approximately $40 \%$ for the dump truck and 35\% for the M1 tank. Symmetry in the lateral-load distribution is reasonably good as well.

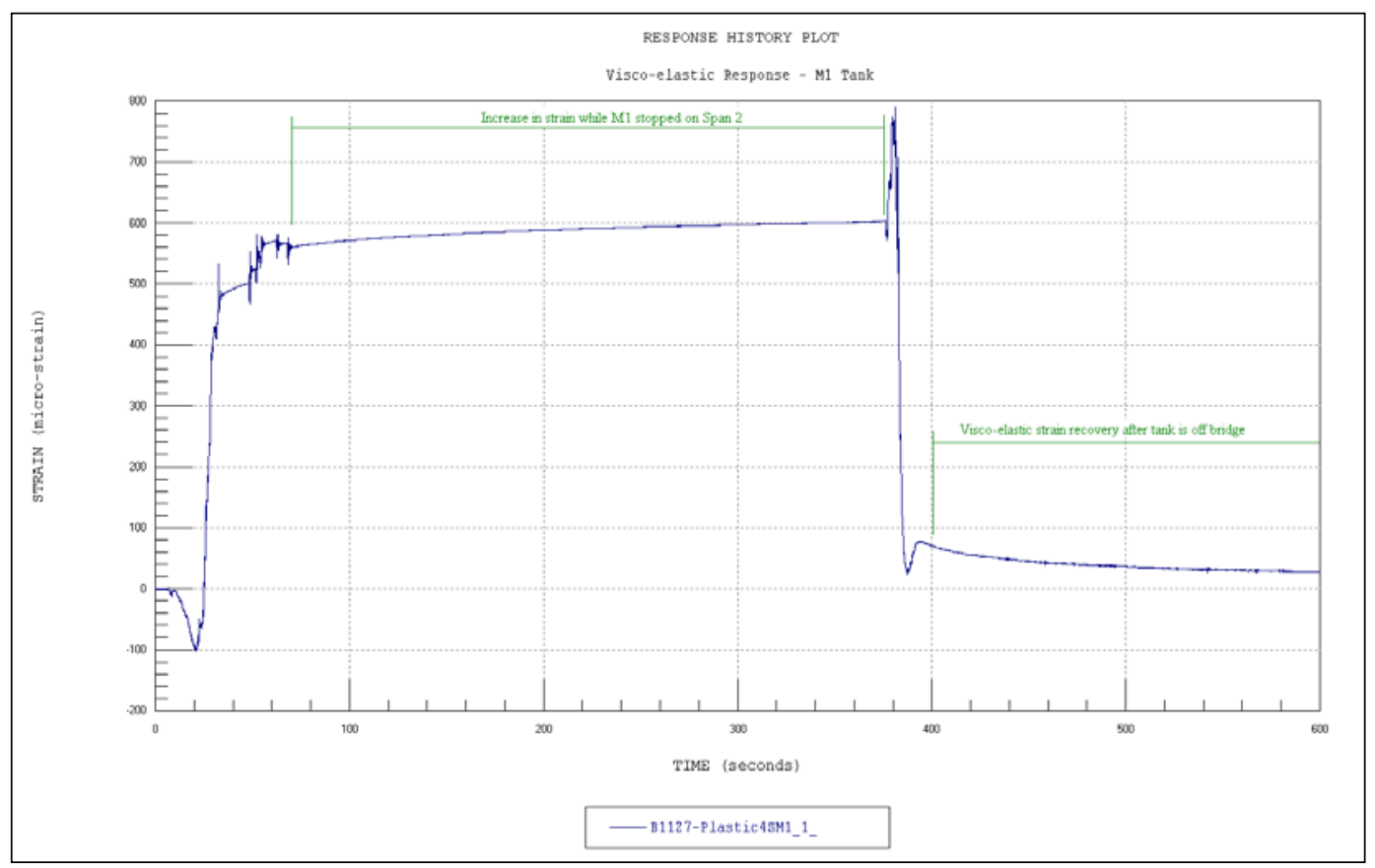

Figure 21. Viscoelastic strain observed during static test - M1 tank. 


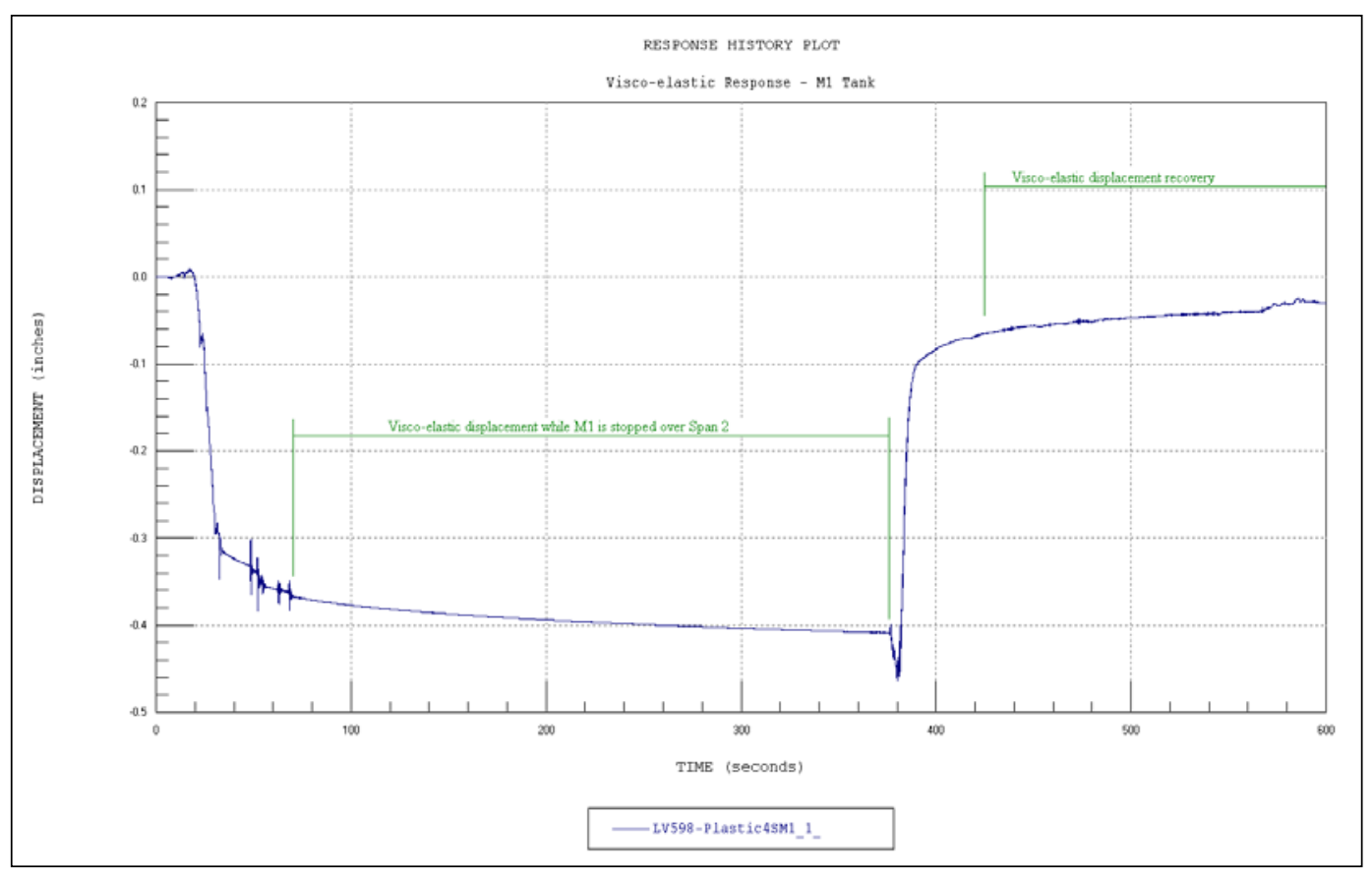

Figure 22. Viscoelastic displacement observed during static test - M1 tank.

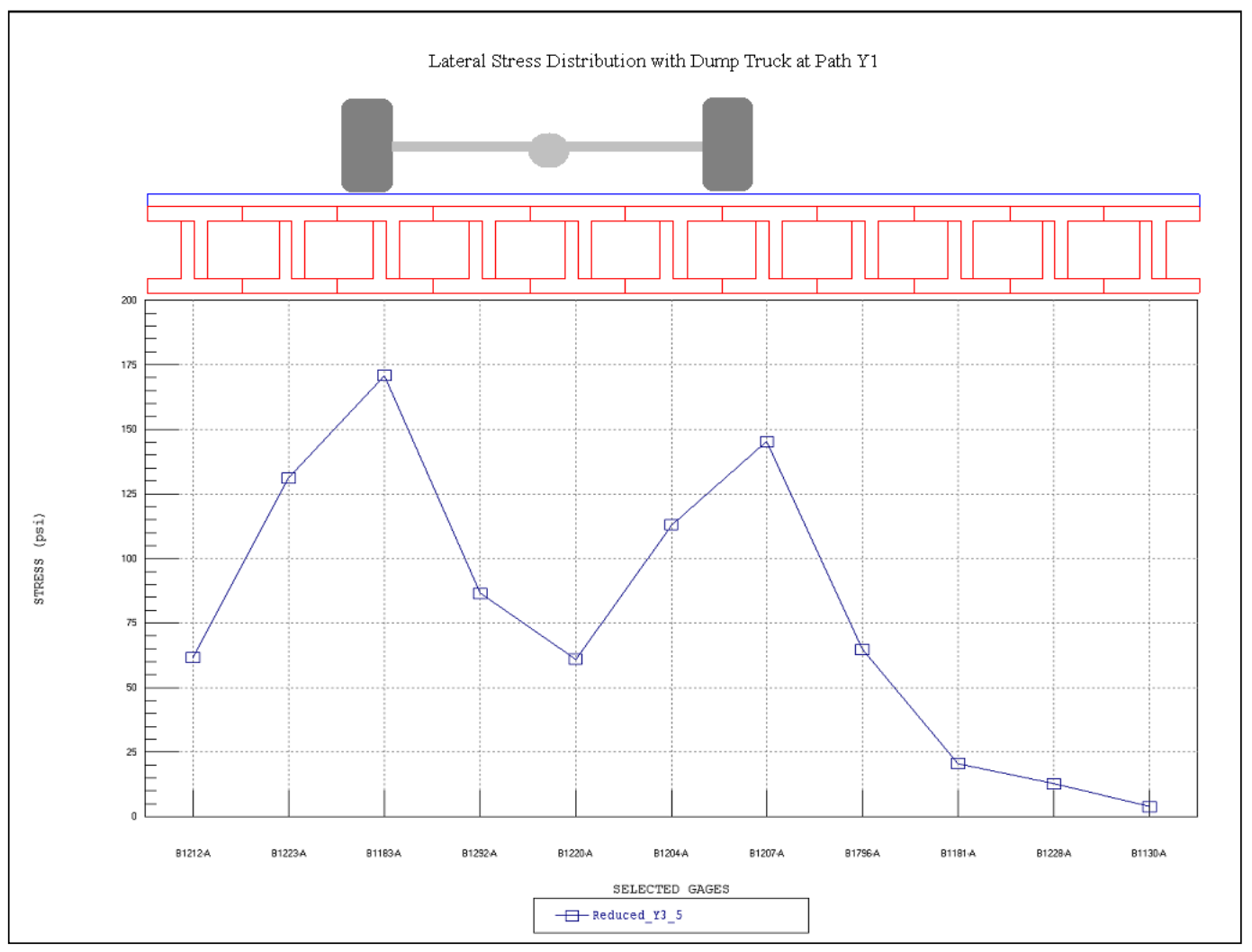

Figure 23. Lateral stress distribution at mid-span - dump truck @ Y1. 


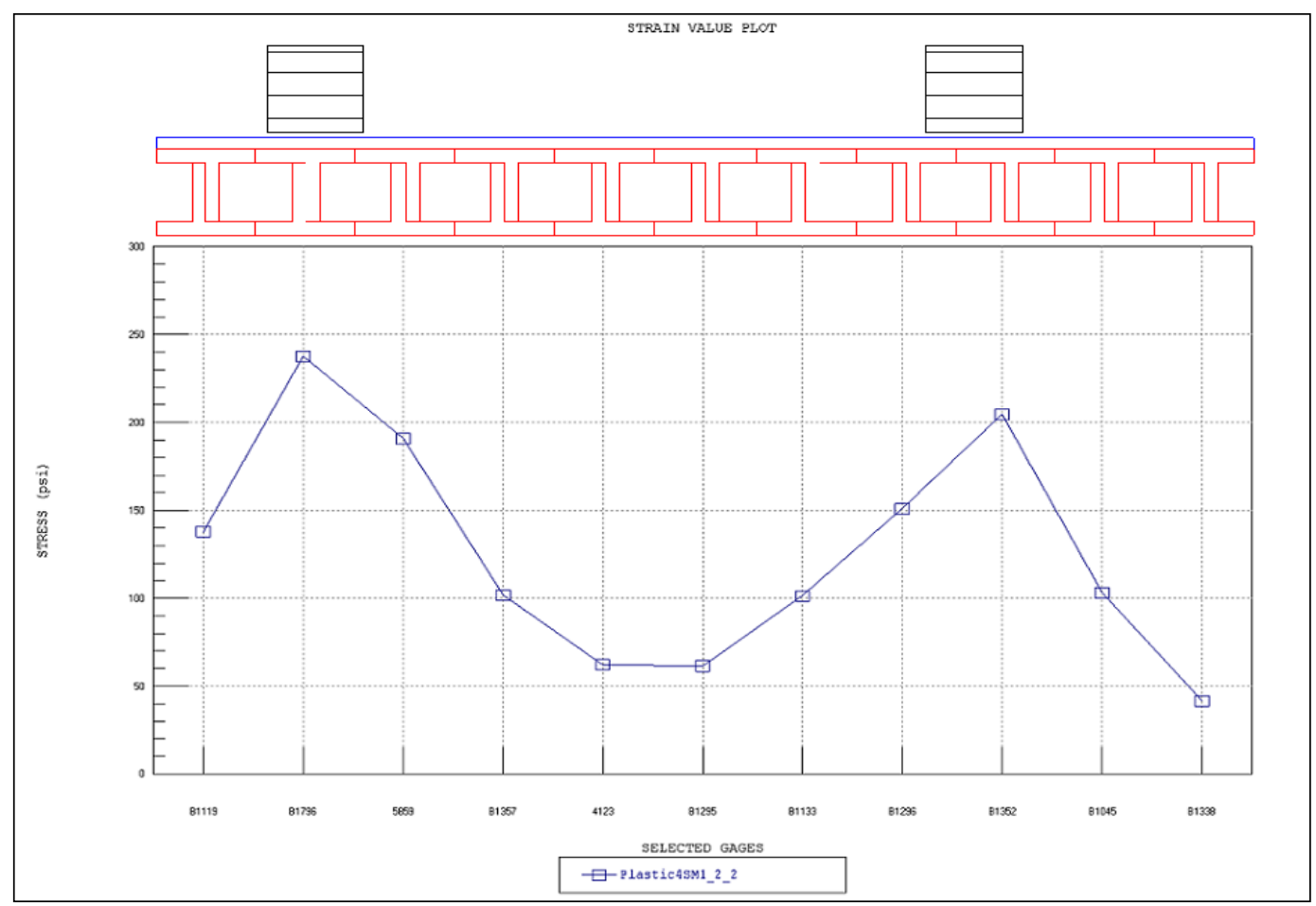

Figure 24. Lateral stress distribution at mid-span - M1 tank.

\section{Peak stress measurements}

Maximum strain and displacement measurements were extracted for both paths of the M1 tank crossing and converted to stress using an elastic modulus of $350 \mathrm{ksi}$. The M1 tank peak stress values are provided in Table 4 . The maximum measured stress and displacement for the tank were $297 \mathrm{psi}$ and 0.38 in., respectively. It is important to note that these peak responses were due to live load only, and little to no dynamic component was generated during the load test procedures. Envelope data were not provided for the dump truck tests, as the results were influenced by the detached deck and not highly relevant to the bridge in its current condition. 
Table 4. Peak stress and displacement during M1 tank crossing.

\begin{tabular}{|c|c|c|c|c|c|}
\hline \multirow[b]{3}{*}{ Location } & \multirow{3}{*}{$\begin{array}{l}\text { Transducer } \\
\text { ID }\end{array}$} & \multicolumn{4}{|c|}{ Stress (psi) } \\
\hline & & \multicolumn{2}{|c|}{ M1 - Y1 } & \multicolumn{2}{|c|}{ M1 - Y2 } \\
\hline & & Min & Max & Min & Max \\
\hline Bent - Pile 1 - East & 5565 & -297.0 & 6.6 & -223.3 & 7.8 \\
\hline Bent - Pile 1 - North & B1375 & -201.0 & 4.6 & -175.1 & 5.1 \\
\hline Bent - Pile 1 - South & B1351 & -192.0 & 4.2 & -167.2 & 7.0 \\
\hline Bent - Pile 1 - West & 7248 & -127.4 & 15.3 & -135.5 & 14.5 \\
\hline Bent-east bay-bottom & 8372 & -6.2 & 59.2 & -4.6 & 127.7 \\
\hline Bent-east bay-top & 5862 & -5.9 & 4.0 & -5.6 & 4.0 \\
\hline Bent-west bay-bottom & 4112 & -4.2 & 105.9 & -3.8 & 50.9 \\
\hline Bent-west bay-top & B1795 & -5.6 & 0.1 & -7.5 & 0.1 \\
\hline Span 1 Pier 2 Beam 8 & B1129 & -43.8 & 53.6 & -35.4 & 42.5 \\
\hline Span 1 Pier 2 Beam 9 & 8864 & -18.9 & 111.2 & -17.2 & 108.5 \\
\hline Span 1 Pier 2 Beam 10 & B1303 & -50.9 & 54.5 & -51.4 & 80.5 \\
\hline Span 1 Pier 2 Beam 11 & 8390 & -38.2 & 52.5 & -41.5 & 63.2 \\
\hline Span 2 Mid-span Beam 1 & 6617 & -39.6 & 149.1 & -33.9 & 111.7 \\
\hline Span 2 Mid-span Beam 2 & 7899 & -26.9 & 186.2 & -25.2 & 154.2 \\
\hline Span 2 Mid-span Beam 3 & B1127 & -26.9 & 233.5 & -30.6 & 250.4 \\
\hline Span 2 Mid-span Beam 3 Left & 7027 & -23.5 & 243.1 & -26.6 & 249.4 \\
\hline Span 2 Mid-span Beam 3 Right & 8368 & -30.1 & 185.8 & -33.4 & 219.1 \\
\hline Span 2 Mid-span Beam 4 & 5569 & -23.1 & 101.2 & -27.9 & 130.2 \\
\hline Span 2 Mid-span Beam 5 & 8381 & -17.4 & 64.9 & -20.1 & 76.0 \\
\hline Span 2 Mid-span Beam 6 & B1394 & -20.2 & 63.6 & -21.5 & 65.7 \\
\hline Span 2 Mid-span Beam 7 & B1315 & -21.1 & 80.0 & -22.4 & 72.5 \\
\hline Span 2 Mid-span Beam 8 & B1088 & -23.4 & 130.2 & -25.2 & 102.0 \\
\hline Span 2 Mid-span Beam 9 & B1087 & -28.0 & 225.7 & -32.1 & 218.6 \\
\hline Span 2 Mid-span Beam 10 & 5562 & -27.3 & 152.3 & -38.0 & 205.0 \\
\hline Span 2 Mid-span Beam 11 & 8861 & -32.1 & 85.5 & -36.8 & 129.7 \\
\hline Span 2 Mid-span Top Beam 1 & 4079 & -57.1 & 16.6 & -58.9 & 12.5 \\
\hline Span 2 Pier 2 Beam 1 & 8863 & -33.4 & 84.9 & -26.9 & 71.3 \\
\hline Span 2 Pier 2 Beam 2 & 5690 & -28.6 & 142.9 & -26.5 & 89.1 \\
\hline Span 2 Pier 2 Beam 3 & B1319 & -46.4 & 62.9 & -53.9 & 90.6 \\
\hline Span 2 Pier 2 Beam 4 & B1380 & -32.3 & 30.6 & -44.3 & 33.6 \\
\hline Span 2 Pier 2 Beam 5 & 5564 & -2.1 & 4.4 & -2.4 & 4.8 \\
\hline Span 2 Pier 2 Beam 6 & 4050 & -27.5 & 37.9 & -30.3 & 37.4 \\
\hline Span 2 Pier 2 Beam 7 & 5560 & -31.7 & 34.4 & -29.8 & 41.9 \\
\hline Span 2 Pier 2 Beam 8 & 8860 & -43.3 & 37.6 & -37.6 & 43.2 \\
\hline Span 2 Pier 2 Beam 9 & 8984 & -33.3 & 131.5 & -36.1 & 113.0 \\
\hline Span 2 Pier 2 Beam 10 & B1347 & -34.6 & 41.9 & -50.8 & 58.1 \\
\hline
\end{tabular}




\begin{tabular}{|c|c|c|c|c|c|}
\hline \multirow[b]{3}{*}{ Location } & \multirow{3}{*}{$\begin{array}{l}\text { Transducer } \\
\text { ID }\end{array}$} & \multicolumn{4}{|c|}{ Stress (psi) } \\
\hline & & \multicolumn{2}{|c|}{ M1 - Y1 } & \multicolumn{2}{|c|}{ M1 - Y2 } \\
\hline & & Min & Max & Min & Max \\
\hline Span 2 Pier 2 Beam 11 & 8688 & -23.0 & 37.9 & -28.9 & 42.8 \\
\hline Span 2 Pier 3 Beam 10 & 4118 & -37.3 & 90.3 & -42.9 & 116.0 \\
\hline Span 2 Pier 3 Beam 11 & 7901 & -27.7 & 61.6 & -30.4 & 87.9 \\
\hline Span 2 Pier 3 Beam 8 & B1318 & -18.3 & 97.6 & -21.6 & 81.5 \\
\hline Span 2 Pier 3 Beam 9 & B1349 & -42.2 & 151.5 & -43.5 & 145.6 \\
\hline Span 3 Mid-span Beam 1 & B1338 & -32.8 & 79.5 & -27.8 & 61.3 \\
\hline Span 3 Mid-span Beam 2 & B1045 & -38.8 & 165.8 & -35.2 & 138.2 \\
\hline Span 3 Mid-span Beam 3 & B1352 & -37.7 & 208.1 & -38.7 & 224.2 \\
\hline Span 3 Mid-span Beam 4 & B1296 & -26.3 & 105.1 & -27.8 & 127.8 \\
\hline Span 3 Mid-span Beam 5 & B1133 & -23.8 & 86.5 & -24.8 & 92.7 \\
\hline Span 3 Mid-span Beam 6 & B1295 & -21.2 & 61.7 & -22.0 & 62.0 \\
\hline Span 3 Mid-span Beam 7 & 4123 & -18.7 & 71.0 & -21.2 & 67.1 \\
\hline Span 3 Mid-span Beam 8 & B1357 & -27.6 & 136.4 & -30.8 & 120.7 \\
\hline Span 3 Mid-span Beam 9 & 5859 & -34.8 & 221.5 & -44.3 & 209.2 \\
\hline Span 3 Mid-span Beam 10 & B1796 & -31.4 & 147.5 & -40.3 & 186.0 \\
\hline Span 3 Mid-span Beam 11 & B1119 & -26.8 & 82.0 & -35.1 & 104.2 \\
\hline Span 3 Mid-span Top Beam 1 & 5696 & -38.5 & 13.3 & -30.1 & 10.0 \\
\hline Peak Stress & & -297.0 & 243.1 & -223.3 & 250.4 \\
\hline \multicolumn{6}{|c|}{ Displacements } \\
\hline Displacement Beam 6 & LV648 & -0.153 & 0.010 & -0.159 & 0.006 \\
\hline Displacement Beam 7 & LV651 & -0.178 & 0.009 & -0.176 & 0.005 \\
\hline Displacement Beam 8 & LV082 & -0.283 & 0.010 & -0.270 & 0.006 \\
\hline Displacement Beam 9 & LV598 & -0.349 & 0.007 & -0.367 & 0.005 \\
\hline Displacement Beam 10 & LV080 & -0.295 & 0.010 & -0.380 & 0.006 \\
\hline Displacement Beam 11 & LV085 & -0.227 & 0.013 & -0.322 & 0.005 \\
\hline Displacement Pile 1 & LV084 & -0.255 & 0.006 & -0.227 & 0.006 \\
\hline Displacement Pile 2 & LV076 & -0.156 & 0.018 & -0.167 & 0.017 \\
\hline Displacement Pile 3 & LV077 & -0.154 & 0.006 & -0.155 & 0.005 \\
\hline Displacement Pile 4 & LV650 & -0.197 & 0.009 & -0.228 & 0.012 \\
\hline Peak Displacements & & -0.349 & 0.018 & -0.380 & 0.017 \\
\hline
\end{tabular}




\section{Modeling, Analysis, and Data Correlation}

\section{General}

All of the information presented in the preceding chapter was determined from the field data and was used by an engineer to get a good understanding of the structural responses. This information was then used to develop a representative finite-element model, shown in Figure 25. Details regarding the structure model and analysis procedures are provided in Table 5.

Once the model was developed, the load testing procedures were essentially reproduced using the BDI WinSAC (structural analysis and correlation) software. Two-dimensional footprints of each loading vehicle were applied to the top surface of the model along the same paths that the actual test vehicles followed in crossing the bridge. A direct comparison of strain values on the structure was then made between the analytical predictions and the experimentally measured results. The initial model was then calibrated by modifying various properties and boundary conditions until the results matched those measured in the field. A complete outline of this process is provided in Appendix E.

The goal of the finite element analysis was to obtain a model that simulated the structural responses observed and recorded during the load test and to provide a basis for load-rating standard design and rating loads. An iterative process of response comparisons and model calibrations were performed until an acceptable match was obtained. The process of model calibration included identification of various aspects of the structural behavior such as the effective lateral stiffness, continuity of the beams over the piers, effective end-restraint, and general consistency of behavior at various points. The primary limitation in the analysis was that it was linear elastic. Fortunately, bridge structures generally exhibit linear-elastic response up to the operating limit, which is well beyond the design loads. An additional limitation is that the linear-elastic analysis cannot generate the time-dependent viscoelastic responses observed with loads applied for a substantial duration. Fortunately, most vehicle crossings are of short duration, and the viscous response magnitude is relatively small compared to the linear response at the allowable stress level. 


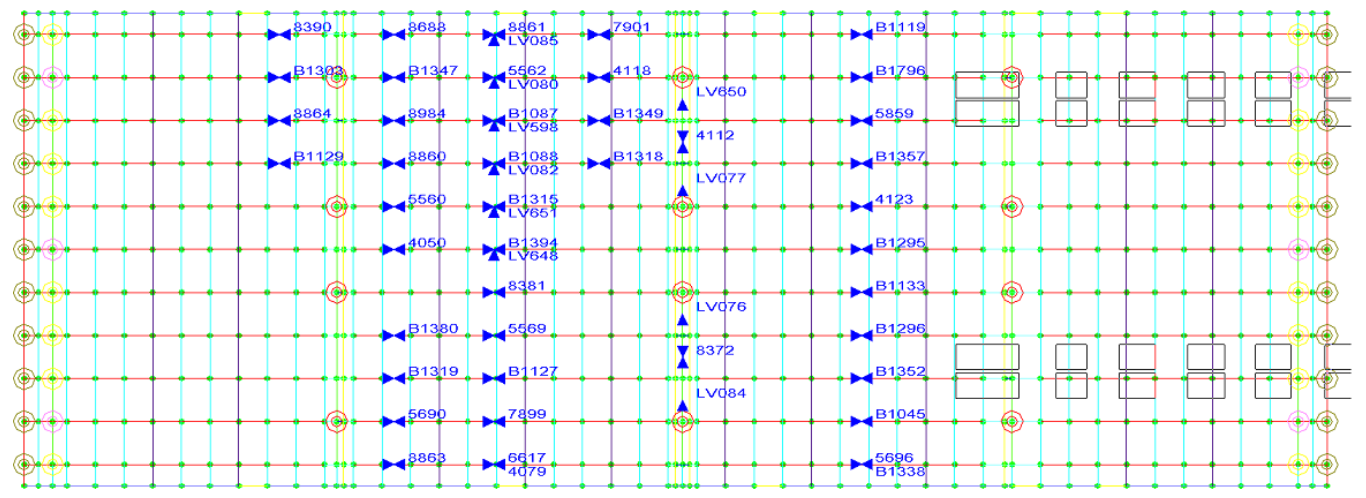

Figure 25. Finite element model of superstructure.

Table 5. Analysis and model details.

\begin{tabular}{|c|c|}
\hline Parameter & Description \\
\hline Analysis type & Linear-elastic finite element stiffness method \\
\hline Model geometry & Planar grillage composed of frame elements, nodes, and springs \\
\hline Nodal locations & $\begin{array}{l}\text { Nodes placed at all bearing locations } \\
\text { Nodes at each deck element intersection (12-in. intervals) }\end{array}$ \\
\hline Model components & $\begin{array}{l}\text { Frame elements for all beams, deck boards, and bents } \\
\text { Spring elements at each pile location }\end{array}$ \\
\hline Live load & $\begin{array}{l}\text { 2-D footprint of test dump truck consisting of } 10 \text { vertical point loads } \\
\text { 2-D footprint of test M1 tank consisting of } 28 \text { vertical point loads. The truck path } \\
\text { was simulated by a series of load cases with the truck moving at 1-ft increments. }\end{array}$ \\
\hline Dead load & Self-weight of structure \\
\hline $\begin{array}{l}\text { Total number of strain } \\
\text { comparisons }\end{array}$ & 54 measurement locations $\times 114$ load positions $=6156$ strain comparisons \\
\hline Model statistics & $\begin{array}{ll}715 & \text { Nodes } \\
2066 & \text { Elements } \\
15 & \text { Cross section/Material types } \\
114 & \text { Load Cases } \\
54 & \text { Gage locations }\end{array}$ \\
\hline $\begin{array}{l}\text { Adjustable parameters for } \\
\text { model calibration }\end{array}$ & $\begin{array}{l}\text { 1. RPL modulus for all elements } \\
\text { 2. Effective moment of inertia of beams }-+M \text { and }-M \\
\text { 3. Effective moment of inertia of bents } \\
\text { 4. Vertical stiffness of pile springs } \\
\text { 5. Horizontal resistance of pile springs }\end{array}$ \\
\hline
\end{tabular}

When load tests are performed with two different vehicles, it is generally desirable to verify that the final model can predict the responses for both vehicles with the same degree of accuracy. This step provides an additional measure and verification of how linear the actual structural behavior was. In this case, however, a significant difference in structural stiffness was present during the two separate tests due to the deck attachment. It was 
verified that the bridge responded in a much more consistent manner during the M1 tests after the deck was repaired.

The majority of the model-calibration effort was spent in simulating the flexibility of the piles, the flexibility of the deck, and the actual truck paths. Because of the close beam spacing and flexible deck, the measured responses were very sensitive to small lateral shifts in load position. Variations in the truck path, as small as 4 in. to the left or to the right, had a significant effect on each beam's stress history. Because of this effect, it was easier to match the dump truck data, as it was easier for the dump truck to maintain straight-line travel than it was for the tank. Even then, small variations occurred along each path, so less effort was put into matching each perfectly, and more effort was put into matching maximum stresses at each instrumented cross section.

\section{Model calibration results}

Various stiffness parameters were modified to obtain the best possible match between the measured and computed responses. In this case, the model was calibrated based on strain and displacement measurements. The goal of the calibration was to accurately match, as nearly as possible, the response value at every gage location for every load condition (the ability to match the minor load responses being just as important as matching the maximum values). This practice ensured that the model had the same load transfer characteristics as the real structure. Realizing that some inaccuracy would always be present due to variations in truck path, a secondary goal was to match the peak stress at each instrumented cross section. The optimization process relied on an engineer's ability to determine what stiffness values might be different from those that were initially assumed. The engineer was also required to define reasonable upper and lower limits for each variable. This process entailed visual examination of the response comparison histories and determination of which structural parameters would influence the response behavior to obtain a better correlation. An optimization algorithm built into the analysis program automated the iterations to obtain stiffness values that provided the best solution. Many manual iterations were required to determine the correct set of properties to adjust; the accuracy of these manual iterations was dependent upon the engineer's experience and the complexity of the structure. The following outline describes the stiffness parameters adjusted, along with discussions on the effect of the adjustments on the structural performance. Following the optimization procedures, the model produced a 0.9773 correlation 
coefficient, which can be considered a good match for this structure. The parameter and model accuracy values used in the initial model and obtained for the final model are provided in Table 6. Appendix E contains a description of each error value.

Table 6. Model accuracy and parameter values.

\begin{tabular}{|c|c|c|c|}
\hline \multicolumn{2}{|l|}{ Modeling Parameter } & \multirow{2}{*}{$\begin{array}{r}\text { Initial Model Value } \\
350\end{array}$} & \multirow{2}{*}{\begin{tabular}{|r|} 
Final Model Value \\
350
\end{tabular}} \\
\hline RPL modulus - E & (ksi) & & \\
\hline Beam stiffness - I & $\left(\mathrm{in}^{4}\right)$ & 6876 & 9638 \\
\hline Deck stiffness - I & $\left(\mathrm{in}^{4}\right)$ & 27 & 27 \\
\hline Deck@ diaphragm locations - I & $\left(\mathrm{in}^{4}\right)$ & 27 & 855 \\
\hline Pile bearing stiffness - Fz & $(\mathrm{k} / \mathrm{in})$ & 10000 & 113 \\
\hline Pile rotational stiffness @ pier Rx \& Ry & $(\mathrm{k}$-in/rad) & 0 & 20530 \\
\hline Pile horizontal stiffness @ abut Rx \& Ry & $(\mathrm{k}$-in/rad) & 0 & 124900 \\
\hline Vertical end-plate bearing - Fx & $(\mathrm{k} / \mathrm{in})$ & 0 & 0 \\
\hline \multicolumn{2}{|c|}{ Error Parameters - 36 ton Dump Truck ( 3 paths) } & Initial Model Value & Final Model Value \\
\hline Absolute Error & & 42096 & 24364 \\
\hline Percent Error & & 36.8 & 11.2 \\
\hline Scale Error & & 4.0 & 3.4 \\
\hline Correlation Coefficient & & 0.8115 & 0.9423 \\
\hline Error Parameters - M1 Tank (2 paths) & & & Final Model Value \\
\hline Absolute Error & & & 18890 \\
\hline Percent Error & & & 4.5 \\
\hline Scale Error & & & 3.3 \\
\hline Correlation Coefficient & & & 0.9773 \\
\hline
\end{tabular}

\section{RPL material stiffness}

The modulus of the plastic material provided by the design specifications was $350 \mathrm{ksi}$. Results from early optimization cycles ranged from 350 to $400 \mathrm{ksi}$. There appeared to be some variation in stiffness for the deck and the beams. Whether the variations were related to material properties or to construction/ geometry effects could not be conclusively determined. To simplify the problem, it was assumed that the modulus for all components was $350 \mathrm{ksi}$ and that any variation in stiffness was a geometric effect (i.e., composite action between the deck and beams). One of the challenges here was that the modulus was approximately $1 / 10$ that of concrete and 1/ 100 that of steel. 


\section{Deck stiffness}

The modulus value of $350 \mathrm{ksi}$ provided the best overall lateral distribution for the deck. In general, there was no justification for additional geometric stiffness. One exception was that the location of the internal blocking members and the transverse decking member attached to the bottom did provide additional load transfer through the deck. This transfer was generated primarily by the axial-force couple obtained from the top deck elements and the bottom transverse element. This stiffening effect is therefore dependent on the tightness of the deck screws and may not be a permanent condition.

\section{Beam stiffness}

Based on the deck properties, it was assumed that a modulus of $350 \mathrm{ksi}$ was appropriate; however, the beams tended to be stiffer than initially modeled. The additional stiffness was therefore assumed to be due to geometric properties. Slight composite behavior between the deck and the beams appeared to be present. Providing the composite behavior in the model did in fact improve its correlation with the load test data. The level of composite behavior was relatively minor since it was generated by planks and not by a continuous slab. It was also apparent the composite behavior was highly variable. While it was important to identify the effect of the deck attachment, the composite behavior should not be accounted for during load rating procedures as it is likely that the deck screws will loosen with time and normal usage of the deck.

\section{Pile stiffness}

This bridge was somewhat unusual in that the vertical stiffness of the piles had a significant effect on the live-load responses. Normally the foundation responses are negligible compared to the superstructure responses. In this case, the piles had displacements on the same order of magnitude as those obtained from the beam flexure. The piles were modeled with elastic spring elements that had stiffness terms in the vertical and horizontal directions. The resulting vertical spring stiffness was slightly greater than $\mathrm{AE} / \mathrm{L}$ of the piles, where $\mathrm{A}$ is the cross-sectional area, $\mathrm{E}$ is the modulus of elasticity, and L is the length of the pile. It would appear that the majority of the pile resistance was therefore obtained from the toe resistance with minor contribution from skin friction. The piles also provided significant 
horizontal resistance. The interior piers were simulated based on $12 \mathrm{EI} / \mathrm{L}^{3}$, with $L$ being the length of pile above grade and I being the moment of inertia. Additional horizontal resistance was present at the abutments due to the soil's pressing against vertical end plates.

\section{Tank wheel loads}

Due to the flexibility of the deck and the close beam spacing, the actual width of each wheel load had to be simulated. Normally each wheel load is applied as a single-point load. While this adjustment worked reasonably well with the dump truck, it was necessary to apply each tank wheel load as two side-by-side wheel loads, similar to dual tires. It was assumed that the tank tracks provided little load distribution longitudinally but provided a relatively wide footprint. By modeling each wheel load as two-point loads separated by 12 in., the model correlation was greatly improved.

Following the optimization procedures, the model produced acceptable accuracy. The parameter and model accuracy values used in the initial model and obtained for the final model are provided in Table 6.

A more accurate model was obtained with the M1 tank results than with the initial dump truck test, because the deck attachment condition was much more consistent during the second test after the additional deck screws were installed. Therefore, all subsequent load ratings should be based on the model calibrated to the M1 load test. 


\section{Load Rating Procedures and Results}

\section{Procedures}

The goal of producing an accurate model was to be able to predict the structure's actual live-load behavior when subjected to design or rating loads. This approach is essentially identical to standard load rating procedures, except that a field verified model was used to determine live-load responses instead of a beam-line analysis with load distribution factors. Appendix F provides a detailed outline of the load rating procedures.

Once the finite element model was calibrated to field conditions, engineeringjudgment was used to address any optimized parameters that may change over time or that may be unreliable with heavy loads or future deterioration. In the case of this bridge, the majority of the optimized parameters remained the same for rating purposes. However, a couple of changes were made to add a level of conservatism to the ratings. First, the effective beam stiffness (I) was reduced to the noncomposite value since it was conceivable that the deck screws would loosen over time and with repeated load cycles. Second, the additional lateral load transfer provided by the bottom decking member located at the rail post locations was eliminated because this condition was also dependent on the tightness of the deck screws.

Because the bridge was constructed of recycled plastic lumber (RPL components, there are no applicable American Association of State Highway and Transportation Officials (AASHTO) specifications for the material. Basic material properties were provided by the bridge designer and the RPL manufacturer. The response behavior of the material was defined as elastoplastic, meaning it had primarily elastic behavior combined with time-dependent fluid properties as well. Allowable stress and ultimate stress values were given for axial, flexure, and shear responses. The allowable stress values corresponded to stress limits that the members could withstand for a long period of time (25 years) and still return to their original state after the load was removed. The ultimate stress values were generally three to four times greater than the allowable stresses. Because of the extremely low modulus compared to most structural materials, displacements associated with ultimate stresses would be extremely large, and the responses would be well out of the linear range. Therefore, the 
most appropriate load rating method was determined to be allowable stress. The allowable stresses provided were assumed to be consistent with inventory load rating limits because the stress levels could be applied repeatedly for a long duration.

For allowable stress design (ASD), the entire factor of safety is built into the stress limit. This plan means that the dead- and live-load responses are given the same level of importance and reliability, and a load factor of 1.0 is applied to both load effects. While this situation is generally not the case, it suggests a factor of safety against collapse of at least 3. Material properties provided by the bridge designer are listed in Table 7. The shear and moment member capacities computed for the beams and bents are provided in Table 8 and Table 9, respectively.

Table 7. RPL material properties.

\begin{tabular}{|l|c|}
\hline Response Type & Value \\
\hline Elastic modulus (ksi) & 350 \\
\hline Allowable compression parallel to grain (psi) & 1000 \\
\hline Allowable flexural stress (psi) & 600 \\
\hline Allowable shear strength parallel to grain (psi) & 350 \\
\hline Unit weight (pci) & 0.032 \\
\hline
\end{tabular}

Table 8. Allowable moment capacities.

\begin{tabular}{|c|c|c|l|l|l|}
\hline Member & $\begin{array}{l}\mathrm{F}_{\mathrm{b}} \\
(\mathrm{ksi})\end{array}$ & $\begin{array}{l}\mathrm{Y}_{\mathrm{b}} \\
\text { (in) }\end{array}$ & $\begin{array}{l}\mathrm{I}_{\mathrm{x}} \\
\left(\mathrm{in}^{4}\right)\end{array}$ & $\begin{array}{l}\mathrm{S}_{\mathrm{xb}} \\
\left(\mathrm{in}^{3}\right)\end{array}$ & $\begin{array}{l}\phi \mathrm{M}_{\mathrm{n}} \\
(\mathrm{kip}-\mathrm{in})\end{array}$ \\
\hline Beam +M & 0.60 & 9 & 6876 & 764 & 458 \\
\hline Beam -M & 0.60 & 9 & 6876 & 764 & 458 \\
\hline
\end{tabular}

Table 9. Allowable shear capacities.

\begin{tabular}{|c|l|l|l|l|l|}
\hline Member & $\begin{array}{l}F_{v h} \\
(k s i)\end{array}$ & $\begin{array}{l}T \\
\text { (in) }\end{array}$ & $\begin{array}{l}\mathrm{I}_{\mathrm{x}} \\
\left(\mathrm{in}^{4}\right)\end{array}$ & $\begin{array}{l}\mathrm{Q} \\
\left(\text { (n }^{3}\right)\end{array}$ & $\begin{array}{l}\phi \mathrm{V}_{n} \\
(\mathrm{kip})\end{array}$ \\
\hline Beam & 0.35 & 5 & 6876 & 495 & 24.3 \\
\hline
\end{tabular}

Load ratings were performed on the calibrated model according to AASHTO Load and Resistance Factor Rating (LRFR) methods using the allowable stress/ serviceability limit state. An impact factor of 33\% was applied to all live-load responses. 
Due to its narrow width, loading of this bridge was limited to single-lane loading. Several different load paths were applied to obtain maximum responses for each component, but there were no combined truck paths. Furthermore, because there was no room for pedestrians or additional equipment on the bridge when a truck was crossing, the AASHTO LRFD factor for single-lane loading of 1.2 was not applicable. A condition factor of good was selected because the bridge was new. A list of the load and resistance factors is provided in Tables F2 and F3.

The configurations and layouts for frequently used AASHTO and military vehicles used for load rating are in Appendix F. The dead load of the structure was applied automatically within the program based on the material unit weight and the member cross-sectional dimensions. The applied load paths for each loading vehicle are listed in Table 10.

Table 10. Load path locations.

\begin{tabular}{|l|l|l|}
\hline Rating Vehicle & Paths & Location \\
\hline \multirow{2}{*}{$\begin{array}{l}\text { AASHTO \& Military } \\
\text { Rating Vehicles }\end{array}$} & 1 & Driver tire 2' from edge of roadway \\
\cline { 2 - 3 } & 2 & Driver tire 3' from edge of roadway \\
\cline { 2 - 3 } & 3 & Driver tire 4' from edge of roadway \\
\hline
\end{tabular}

\section{Results}

The load rating factors for the four AASHTO vehicles and the military load classification (MLC) tracked and wheeled vehicles for moment and shear are in Tables 11 and 12, respectively. The values were very similar for most load configurations. For the vehicles examined for this report, the controlling rating factor was either flexure or shear of the RPL beams. The critical load rating factors and corresponding load limits are in Table 13. Table 14 contains an example computation of an inventory load rating factor for a mid-span beam element with HS-20 loading, and Table 15 is an example computation of an inventory load rating factor for a mid-span beam element with MLC (tracked) loading.

It should be noted that the load ratings presented in Table 13 are applicable to the superstructure only. It is assumed that the pile bearing capacities are sufficient to handle the maximum superstructure loads. 
Table 11. Vehicle rating factors and responses - positive moment in RPL beams.

\begin{tabular}{|l|l|c|l|l|l|}
\hline \multirow{2}{*}{ Truck } & \multirow{2}{*}{ Location } & \multicolumn{2}{|c|}{ Maximum Response } & \multicolumn{2}{c|}{ Inventory Limits } \\
\cline { 2 - 7 } & DL (K-in) & LL (K-in) & RF & Tons \\
\hline HS-20 & Mid-span beam & 8.44 & 208.85 & 1.66 & 59.8 \\
\hline Type 3 & Mid-span beam & 9.63 & 140.22 & 2.46 & 61.5 \\
\hline Type 3S2 & Mid-span beam & 8.40 & 133.49 & 2.59 & 93.2 \\
\hline Type 3-3 & Mid-span beam & 10.76 & 121.03 & 2.85 & 114.0 \\
\hline MLC (tracked)* & Mid-span beam & 9.71 & 325.35 & 1.06 & 76.3 \\
\hline MLC (wheeled)** & Mid-span beam & 9.24 & 308.21 & 1.12 & 89.6 \\
\hline $\begin{array}{l}* \text { MLC (tracked) based on M1 tank. } \\
\text { **MLC (wheeled) based on hypothetical MLC 80 with maximum single axle. }\end{array}$ \\
\hline
\end{tabular}

Table 12. Vehicle rating factors and responses - shear in RPL beams.

\begin{tabular}{|l|l|l|l|l|l|}
\hline \multirow{2}{*}{ Truck } & \multirow{2}{*}{ Location } & \multicolumn{2}{|c|}{ Maximum Response } & \multicolumn{2}{c|}{ Inventory Limits } \\
\cline { 2 - 6 } & DL (Kips) & LL (Kips) & RF & Tons \\
\hline HS-20 & Beam @ pier & 0.68 & 9.18 & 1.98 & 71.28 \\
\hline Type 3 & Beam @ pier & 0.68 & 7.46 & 2.44 & 61.00 \\
\hline Type 3S2 & Beam @ pier & 0.68 & 6.80 & 2.67 & 96.12 \\
\hline Type 3-3 & Beam @ pier & 0.68 & 6.13 & 2.97 & 118.80 \\
\hline MLC (tracked)* & Beam @ pier & 0.55 & 17.05 & 1.07 & 77.04 \\
\hline MLC (wheeled)** & Beam @ pier & 0.55 & 13.43 & 1.36 & 108.80 \\
\hline$*$ MLC (tracked) based on M1 tank. \\
**MLC (wheeled) based on hypothetical MLC 80 with maximum single axle. \\
\hline
\end{tabular}

Table 13. Critical load rating factors and weights.

\begin{tabular}{|l|l|l|l|}
\hline \multirow{2}{*}{ Rating Vehicle } & \multirow{2}{*}{ Location } & \multicolumn{2}{|c|}{ LRFR - Inventory } \\
\cline { 3 - 4 } & RPL Beams: + Moment & 1.66 & Tons \\
\hline HS-20 & RPL Beams: Shear & 2.37 & 60 \\
\hline Type 3 & RPL Beams: Shear & 2.58 & 93 \\
\hline Type 3S2 & RPL Beams: + Moment & 2.85 & 114 \\
\hline Type 3-3 & RPL Beams: + Moment & 1.06 & 76 \\
\hline MLC (tracked)* & RPL Beams: + Moment & 1.12 & 89 \\
\hline MLC (wheeled)** & \multicolumn{3}{|l}{} \\
\hline \multirow{2}{*}{ *MLC Tracked computed from 72 ton M1 tank. } \\
**MLC Wheeled computed from hypothetical with maximum single axle.
\end{tabular}


Table 14. Rating factor calculation for HS-20.

\begin{tabular}{|l|l|l|l|}
\hline Description & Term & Value & Unit \\
\hline $\begin{array}{l}\text { Moment capacity available for dead load and live } \\
\text { load at mid-span }\end{array}$ & Mcap & 458.0 & Kip-in \\
\hline Dead-load effect due to self-weight of structure & DW & 22.02 & Kip-in \\
\hline Live-load effect (HS-20) & LL & 207.01 & Kip-in \\
\hline Resistance factor for RPL in flexure & $\Phi_{\mathrm{b}}$ & 1.0 & \\
\hline Condition factor (good) & $\varphi_{\mathrm{C}}$ & 1.0 & \\
\hline System Factor (multiple girders/slab) & $\varphi_{\mathrm{S}}$ & 1.0 & \\
\hline ASD dead-load factor & YDC & 1.0 & \\
\hline ASD live-load factor & YLL & 1.0 & Inventory \\
\hline Dynamic influence (impact) factor & IM & 1.30 & \\
\hline $\begin{array}{l}\text { Using Equation F1: } \\
\text { RF Inv }=[(1.0)(1.0)(458.0)-(1.0 * 8.44)] /(1.0 * 208.85 * 1.30)\end{array}$ & 1.66 & \\
\hline
\end{tabular}

Table 15. Rating factor calculation for M1 tank (tracked).

\begin{tabular}{|l|l|l|l|}
\hline Description & Term & Value & Unit \\
\hline $\begin{array}{l}\text { Moment capacity available for dead load and live } \\
\text { load at mid-span }\end{array}$ & Mcap & 458.0 & Kip-in \\
\hline Dead-load effect due to self-weight of structure & DW & 9.71 & Kip-in \\
\hline Live-load effect (MLC70) & LL & 325.35 & Kip-in \\
\hline Resistance factor for RPL in flexure & $\Phi_{\mathrm{b}}$ & 1.0 & \\
\hline Condition factor (good) & $\varphi_{\mathrm{C}}$ & 1.0 & \\
\hline System factor (multiple girders) & $\varphi_{\mathrm{S}}$ & 1.0 & \\
\hline $\begin{array}{l}\text { LRFR dead-load factor for structural components } \\
\text { and attachments }\end{array}$ & YDC & 1.0 & \\
\hline Live-load factor & YLL & 1.0 & Inventory \\
\hline Dynamic Influence (Impact) factor & IM & 1.30 & \\
\hline $\begin{array}{l}\text { Using Equation F1: } \\
\text { RFInv = [(1.0)(1.0)( 458.0) - (1.0*9.71)] / (1.0*325.35*1.30) }=1.06\end{array}$ \\
\hline
\end{tabular}




\section{Conclusions and Recommendations}

Load tests were performed with a 60-kip tandem-axle dump truck and a 144-kip M1 tank crossing a RPL bridge. Results from both sets of tests indicated that the structure generally performed in a normal linear-elastic manner. Relatively small viscoelastic responses were observed with the heavier M1 tank. A long-duration static test with the tank showed that it took several minutes for deflections to stop moving while the bridge was loaded and a similar amount of time for the measurements to return to zero after the load was removed. This behavior appeared to be consistent with the material properties of RPL and the intended design.

One difference between the load test results on the RPL bridge and other bridges constructed with conventional materials was that strain and displacement magnitudes were relatively high. While this difference was expected due to the low modulus of the material, the notable observation was the amount of displacement induced in the substructure. Normally, bridge foundations have negligible deformation compared to the superstructure responses. In this case, the pile deflections were approximately $50 \%$ of the beam deflections. This deformation is not seen as a problem with the bridge, particularly since it is single lane, the spans are short, and it has no pedestrian traffic. However, it will be interesting to determine whether there are any unintended long-term consequences due to the large deflections.

Load ratings for this bridge were computed using an allowable stress method. Because of the material properties, this was the only applicable method. The allowable stresses provided were within the linear response range and were associated with a stress limit where all deformations could be recovered even after 25-years of repeated load application. A load rating based on ultimate load would have been difficult because the responses would have been extremely nonlinear with large deflections. The load rating results indicated that the bridge performed as well as or even better than designed. The inventory load rating factor for the HS-20 vehicle was 1.66, indicating it can handle HS-33. The load rating factor for the 144-kip M1 tank was 1.06, which provides a military load classification of MLC76. 
It is important to note that the load test, analysis, and load rating results are primarily an evaluation of the superstructure (beams and bent). While deflections of the piles were measured and maximum reaction loads were determined for each pile, the load test does not provide any insight as to the capacity of the piles. The design notes for the piles indicated an allowable load of 40 kips and an ultimate load of at least 120 kips per pile. The specified allowable load per pile provides a lower load rating than obtained for the superstructure. The ultimate load capacity is, however, sufficient to obtain the necessary load rating using LRFD methods. Notes from the pile driving contractor indicated that the piles were driven to $75 \mathrm{kips}$. It is assumed that this load limit corresponds to an allowable load and that the ultimate load would be at least three times this value. If this assumption is the case, the pile capacities are well beyond the superstructure load limit. The allowable pile capacity necessary to be approximately equal to the allowable superstructure capacity would be 50 kips per pile.

The load rating factors and conclusions presented in this report are provided as recommendations based on the structure's response behavior and condition at the time of load testing. The structure was brand new and considered to be in good condition. Any structural degradation or damage must be considered in future load ratings. 


\section{References}

AASHTO. 2003. Manual for the condition evaluation and load and resistance factor rating (LRFR) of highway bridges. Washington, DC: American Association of State Highway and Transportation Officials.

. 2004. AASHTO LRFD bridge design specifications [with 2005 and 2006 Interims]. Washington, DC.

Commander, B. 1989. An improved method of bridge evaluation: comparison of field test results with computer analysis. MS thesis, University of Colorado- Boulder.

Gerstle, K. H., and M. H. Ackroyd. 1990. Behavior and design of flexibly-connected building frames. Engineering J ournal 27(1):22- 29.

Goble, G., J . Schulz, and B. Commander. 1992. Load prediction and structural response. Final Report FHWA DTFH61-88-C-00053. Prepared by University of Colorado.

Headquarters, Department of the Army. 2002. Military nonstandard fixed bridging. Field Manual 3-34.343. Washington, DC.

Lichtenstein, A. G. 1995. Bridge rating through nondestructive load testing. NCHRP Technical Project Report 12-28(13)A. Washington, DC: National Cooperative Highway Research Program.

Schulz, J . L. 1989. Development of a digital strain measurement system for highway bridge testing. MS thesis. University of Colorado- Boulder.

. 1993. In search of better load ratings. Civil Engineering 63(9):62- 65. 


\section{Appendix A: Measured and Computed Stress and Displacement}

While statistical terms provide a means of evaluating the relative accuracy of various modeling procedures or help determine the improvement of a model during a calibration process, the best conceptual measure of a model's accuracy is visual examination of the response histories. The following graphs contain measured and computed stress and displacement histories from each crossing of the M1 tank. In each graph of strain versus longitudinal front-axle position, the continuous lines represent the measured strain at the specified gage location as a function of truck position as it traveled across the bridge. Computed strains are shown as markers at discrete truck intervals.

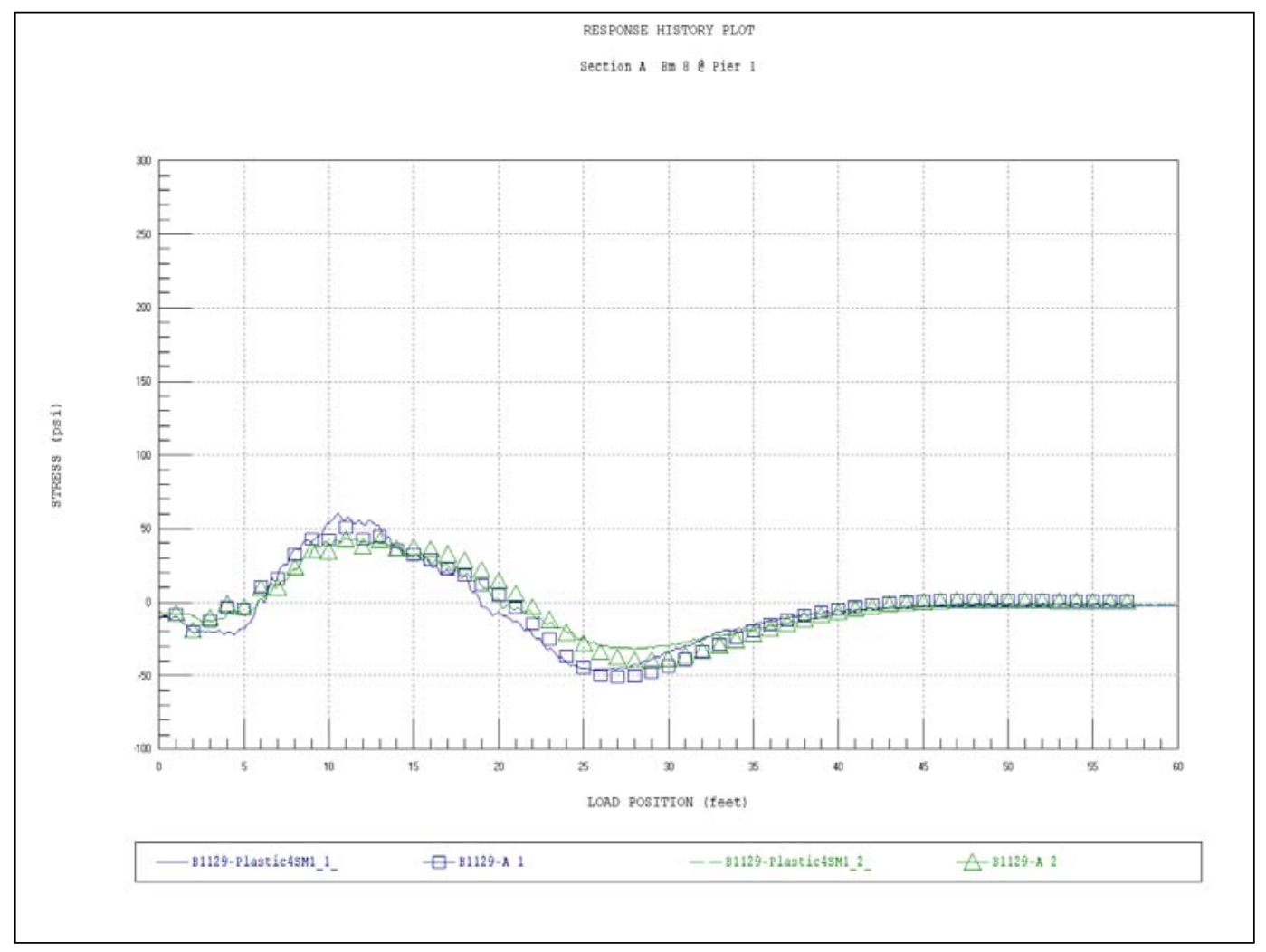

Figure A1. Strain comparison - Sec A - Beam 8. 


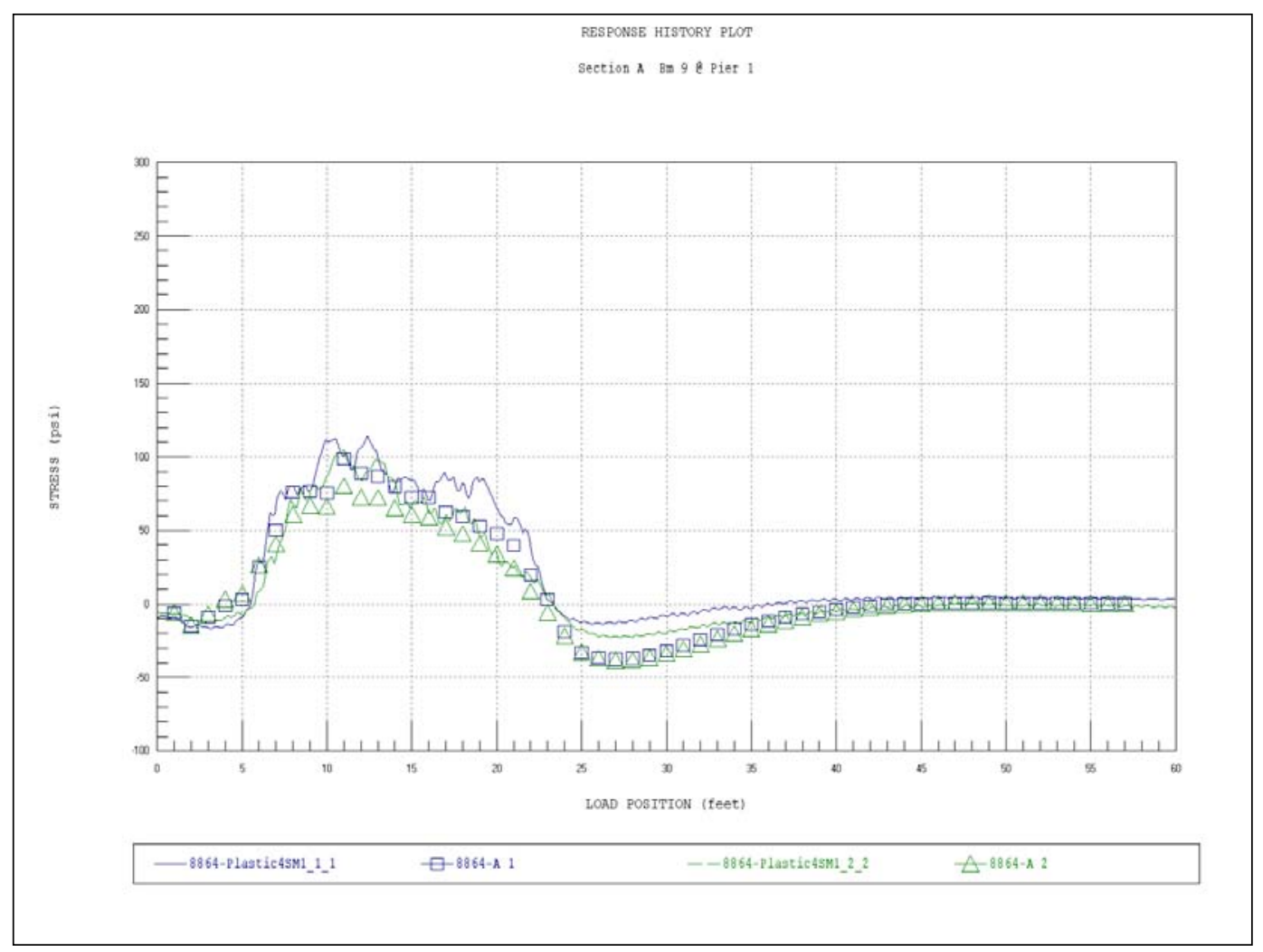

Figure A2. Strain comparison - $\operatorname{Sec} A-B e a m 9$.

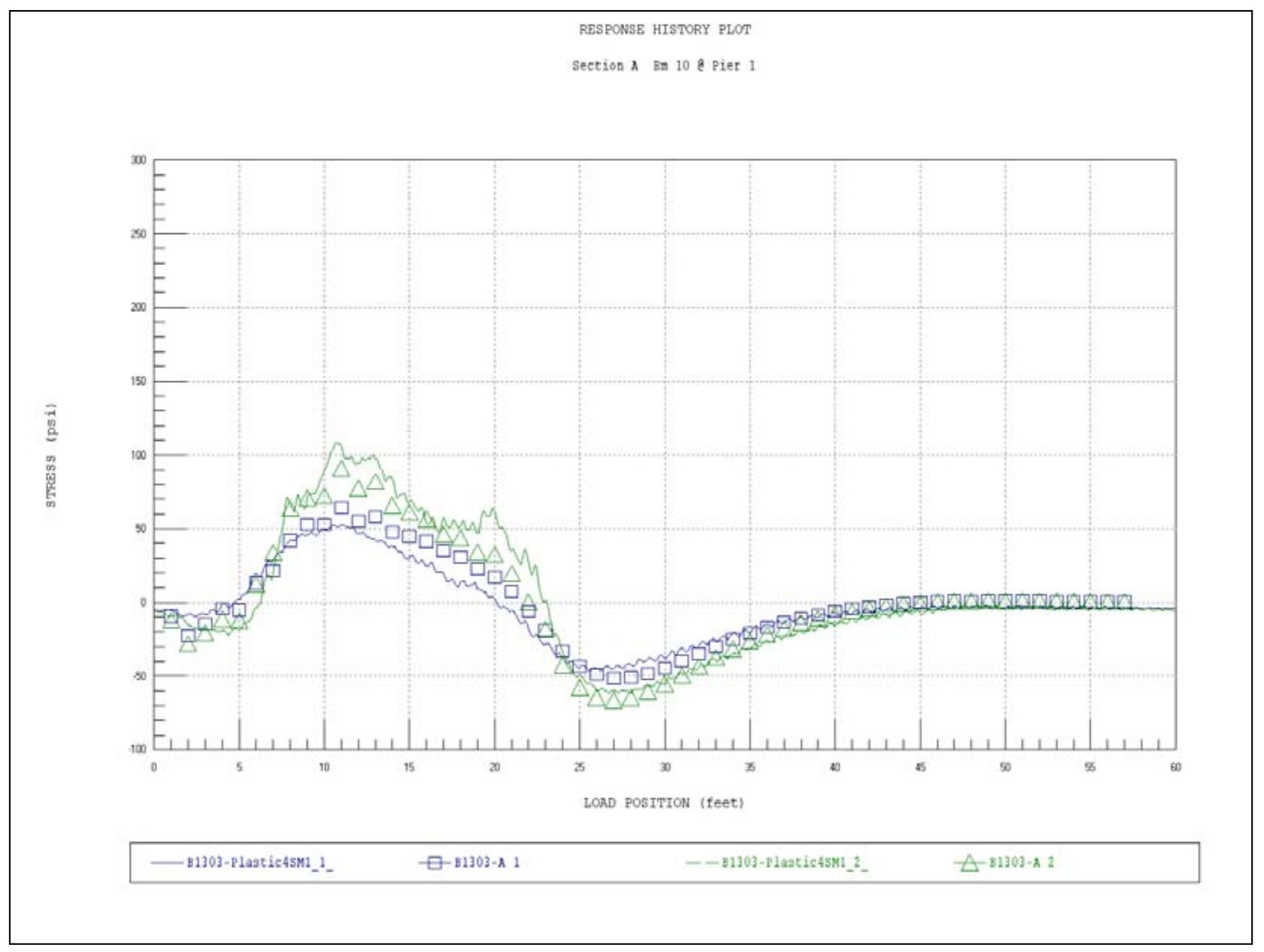

Figure A3. Strain comparison - Sec A - Beam 10. 


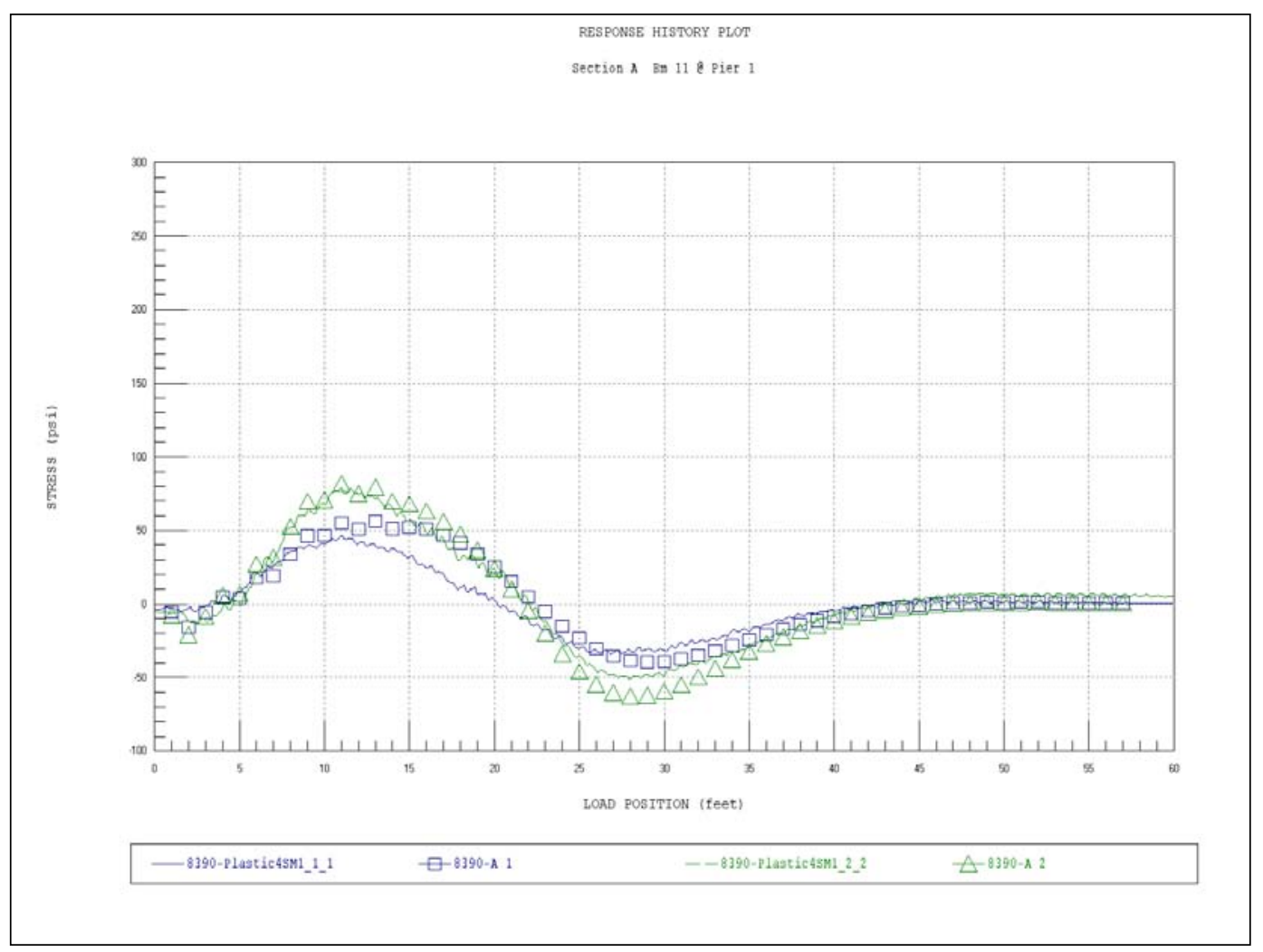

Figure A4. Strain comparison - Sec A - Beam 11.

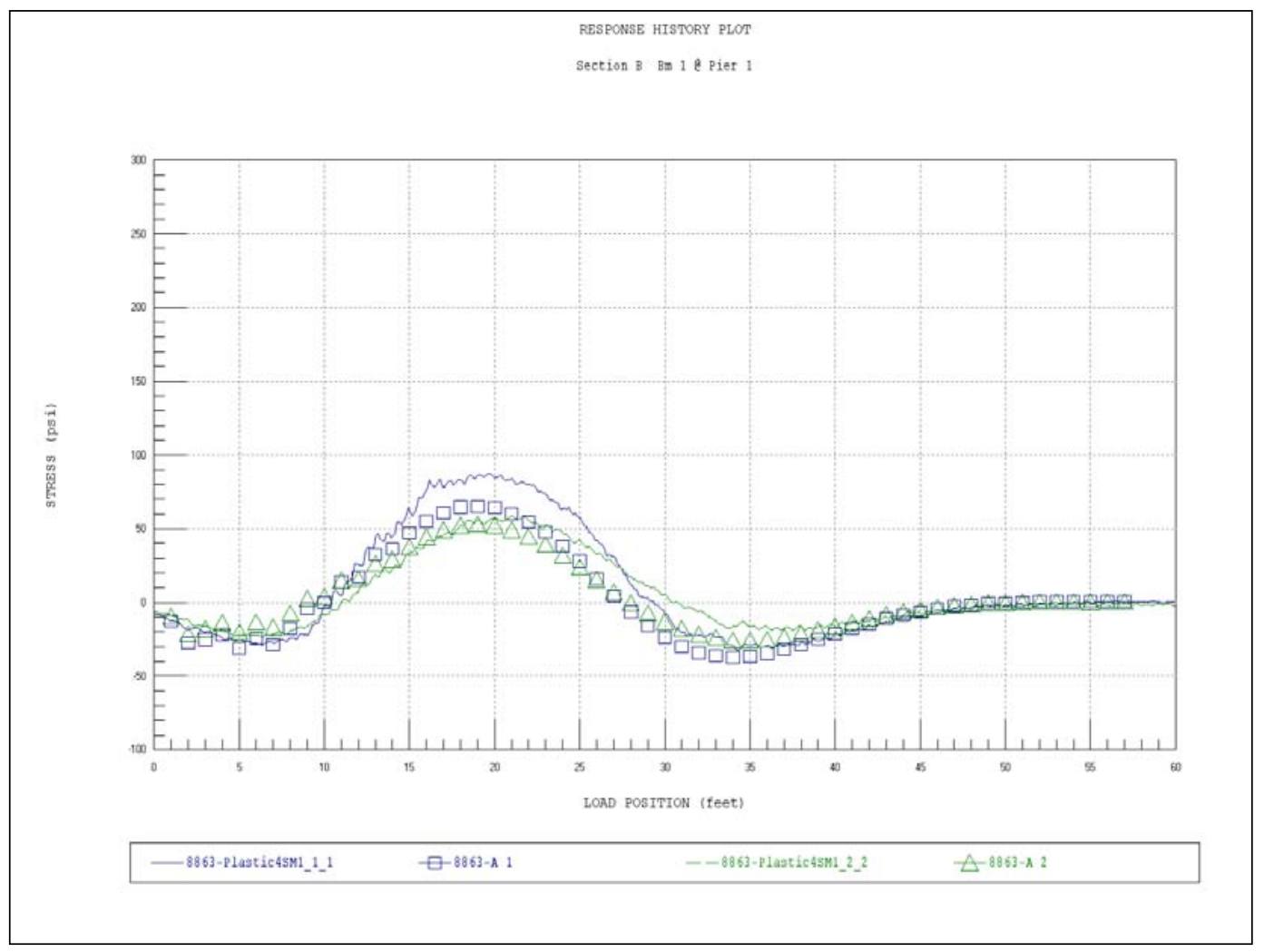

Figure A5. Strain comparison - Sec B - Beam 1. 


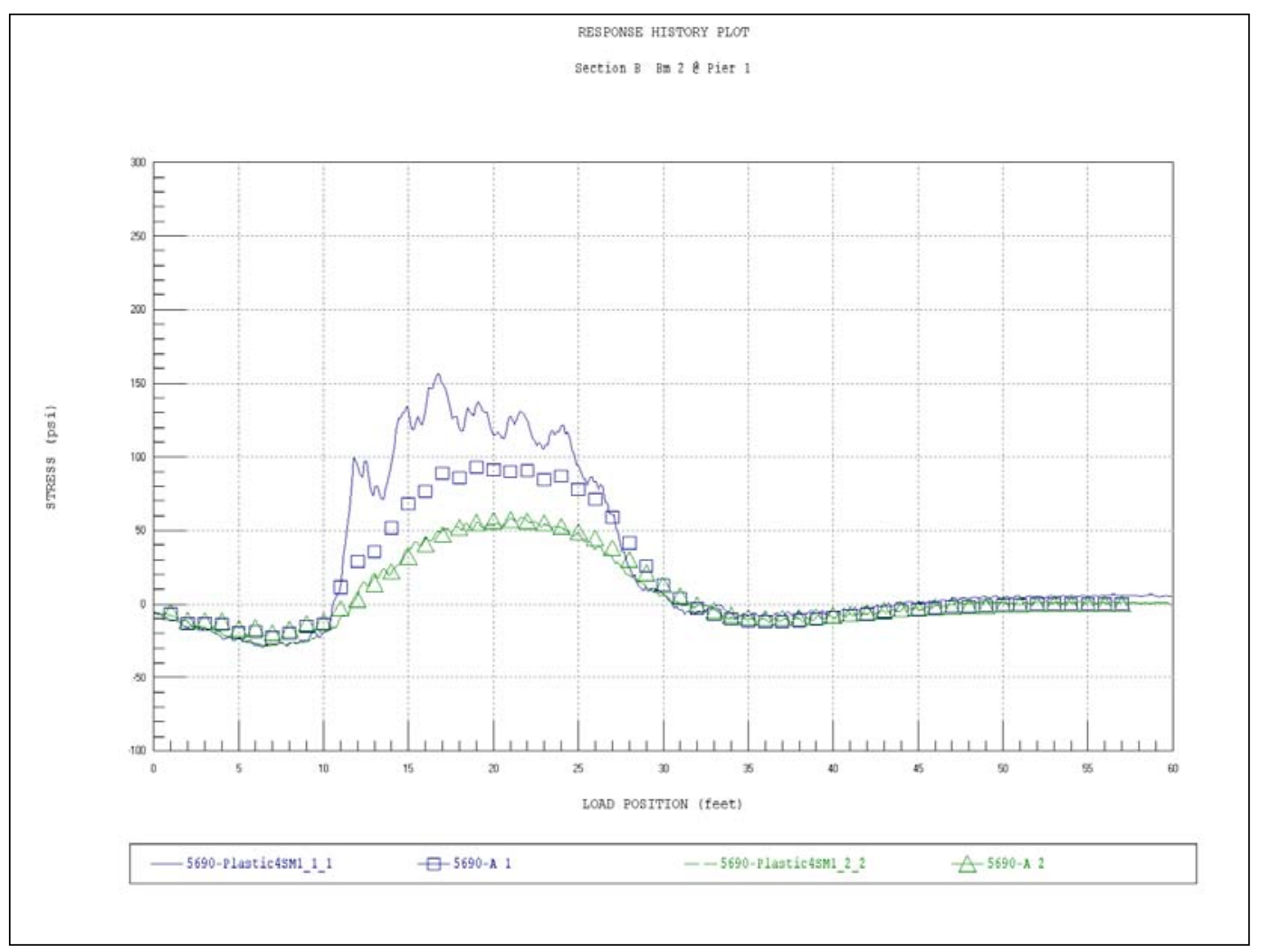

Figure A6. Strain comparison - Sec B - Beam 2.

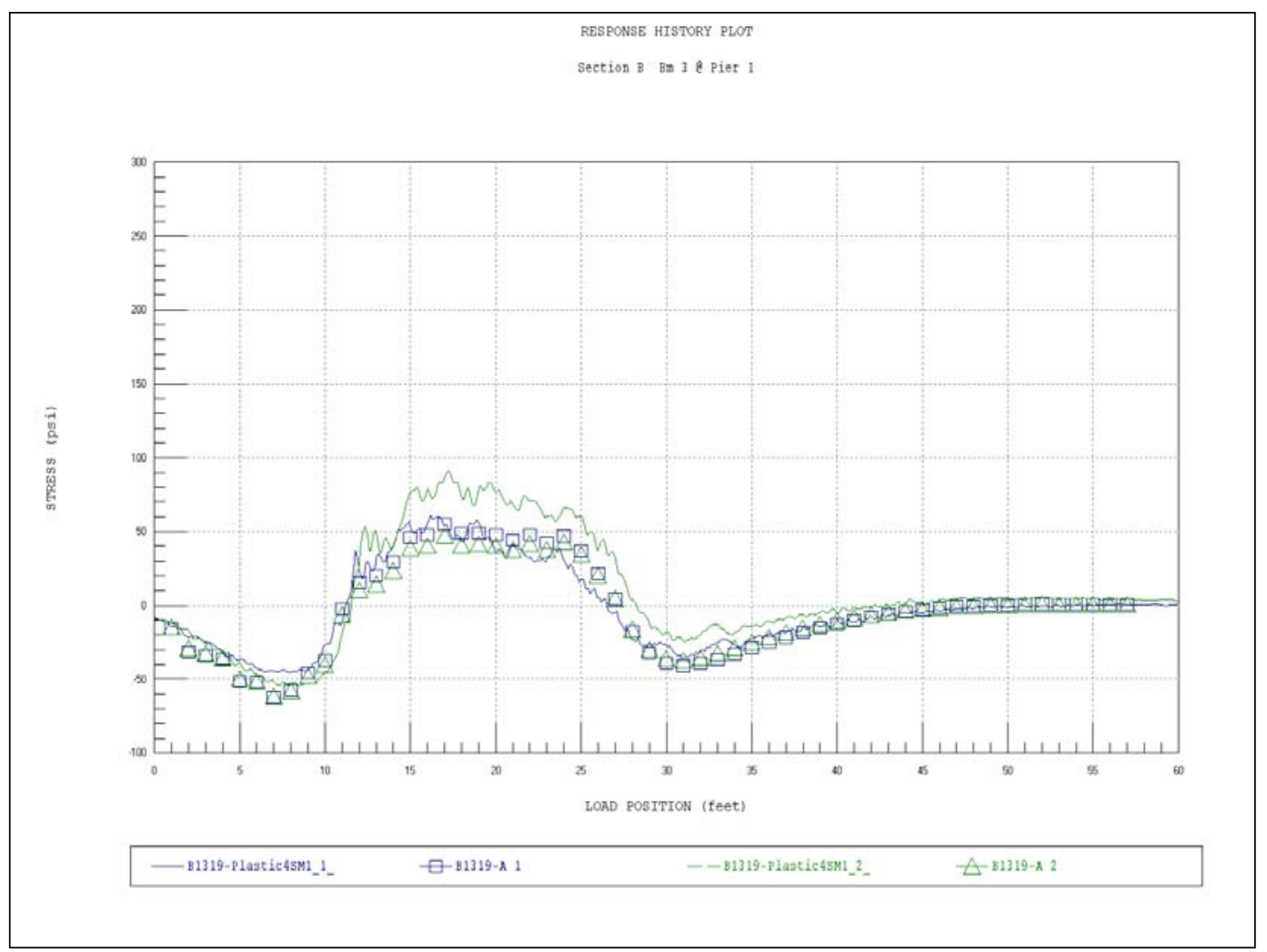

Figure A7. Strain comparison - Sec B - Beam 3. 


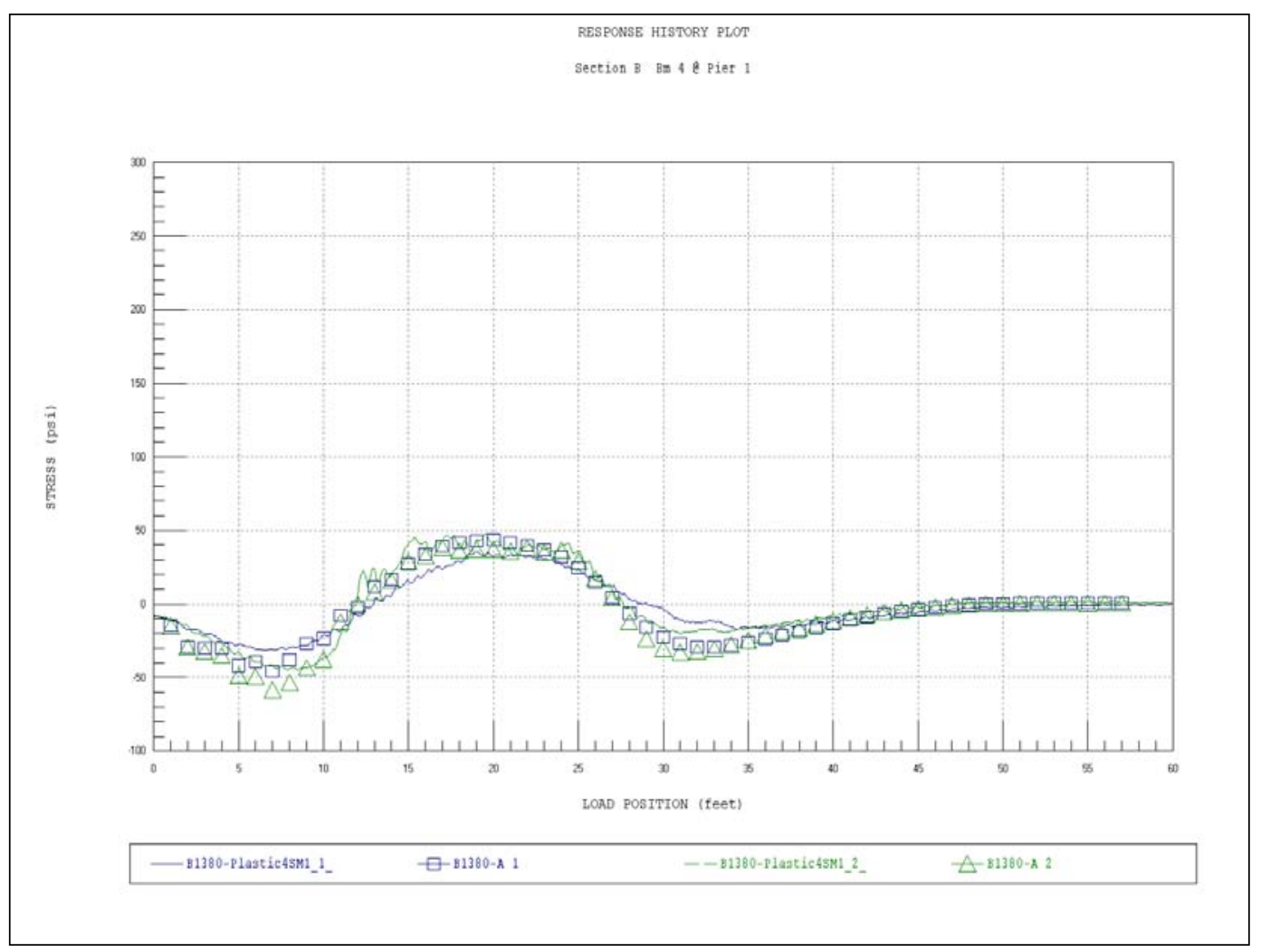

Figure A8. Strain comparison - Sec B - Beam 4.

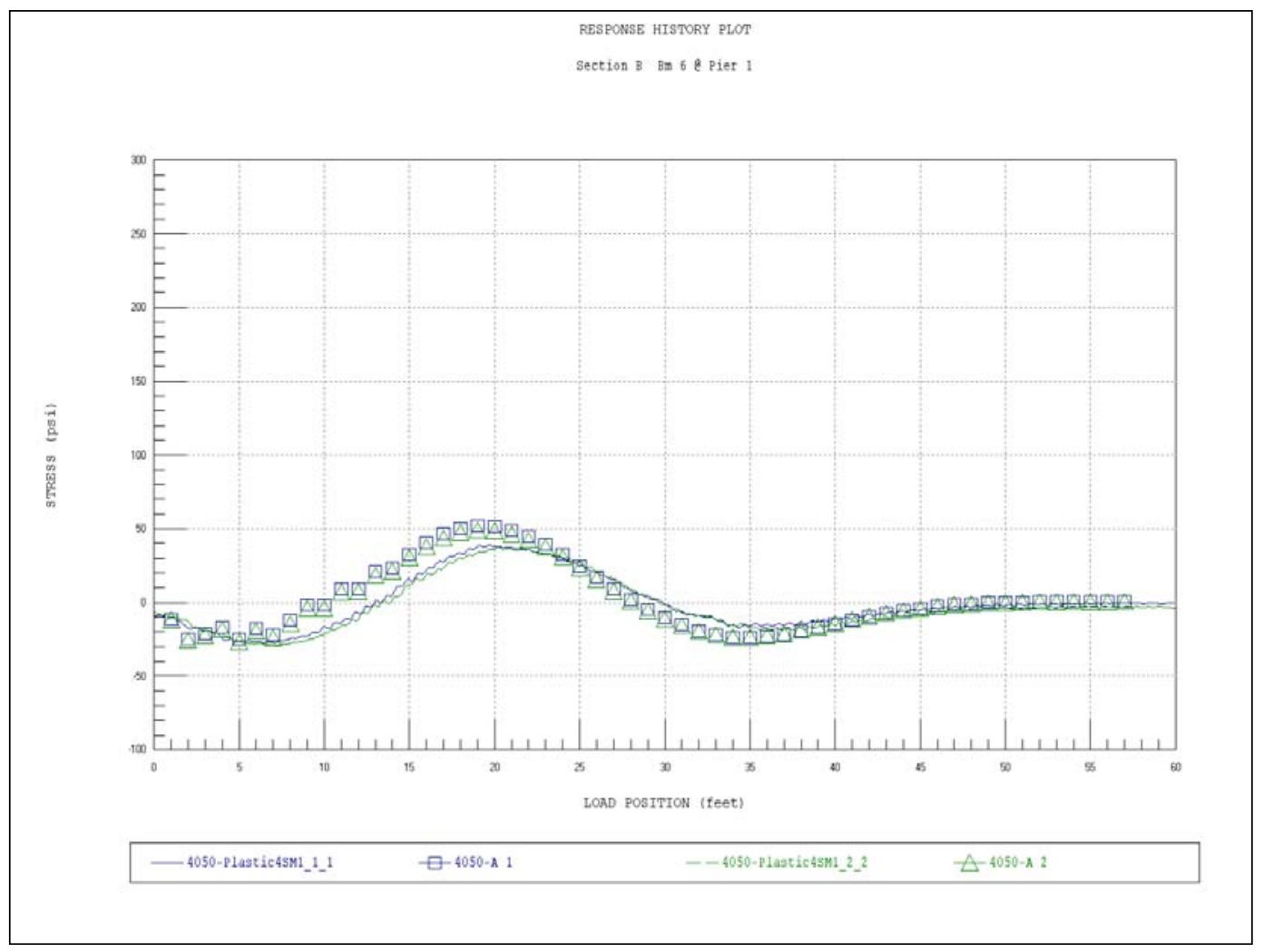

Figure A9. Strain comparison - Sec B - Beam 6. 


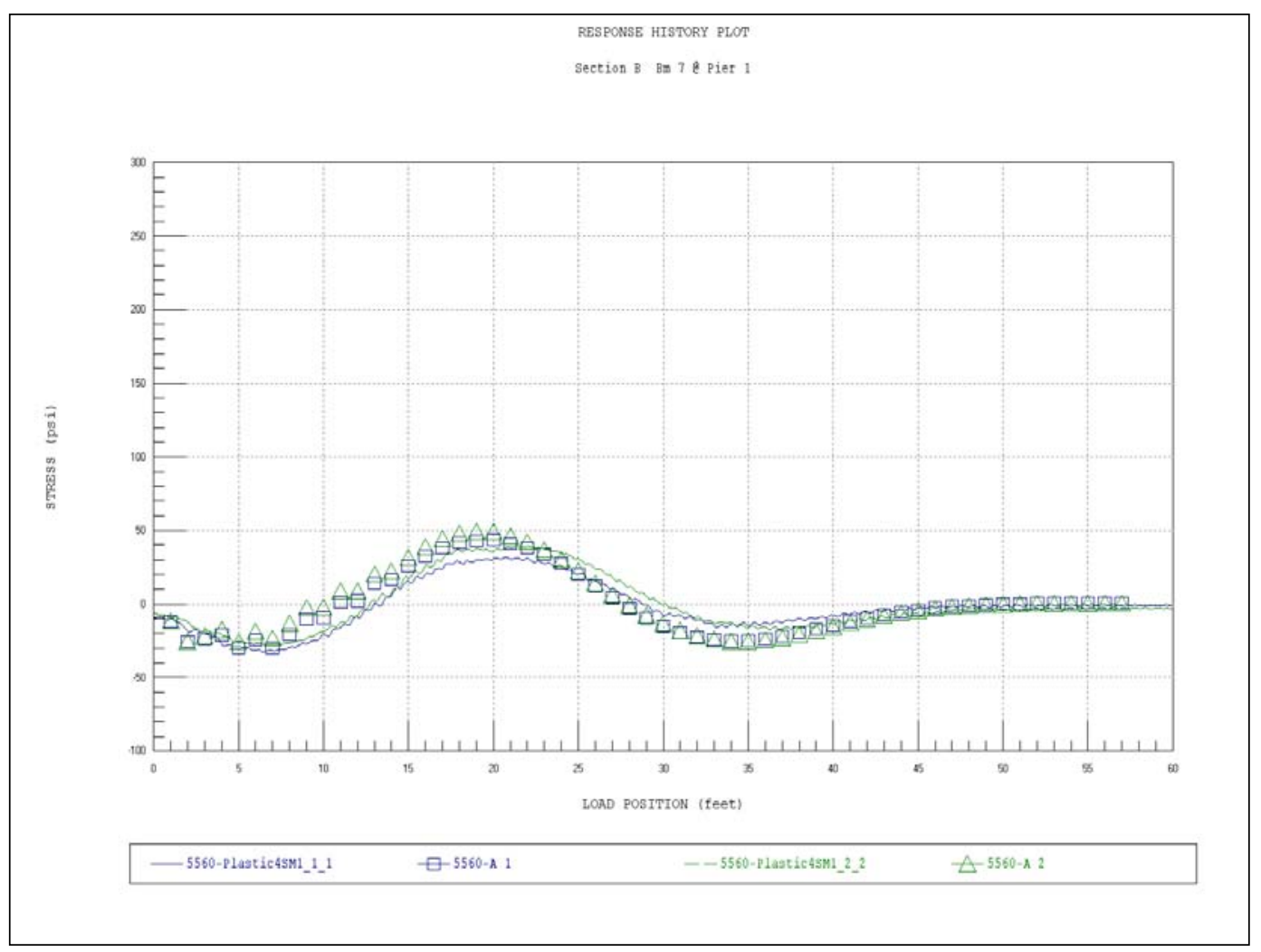

Figure A10. Strain comparison - Sec B - Beam 7.

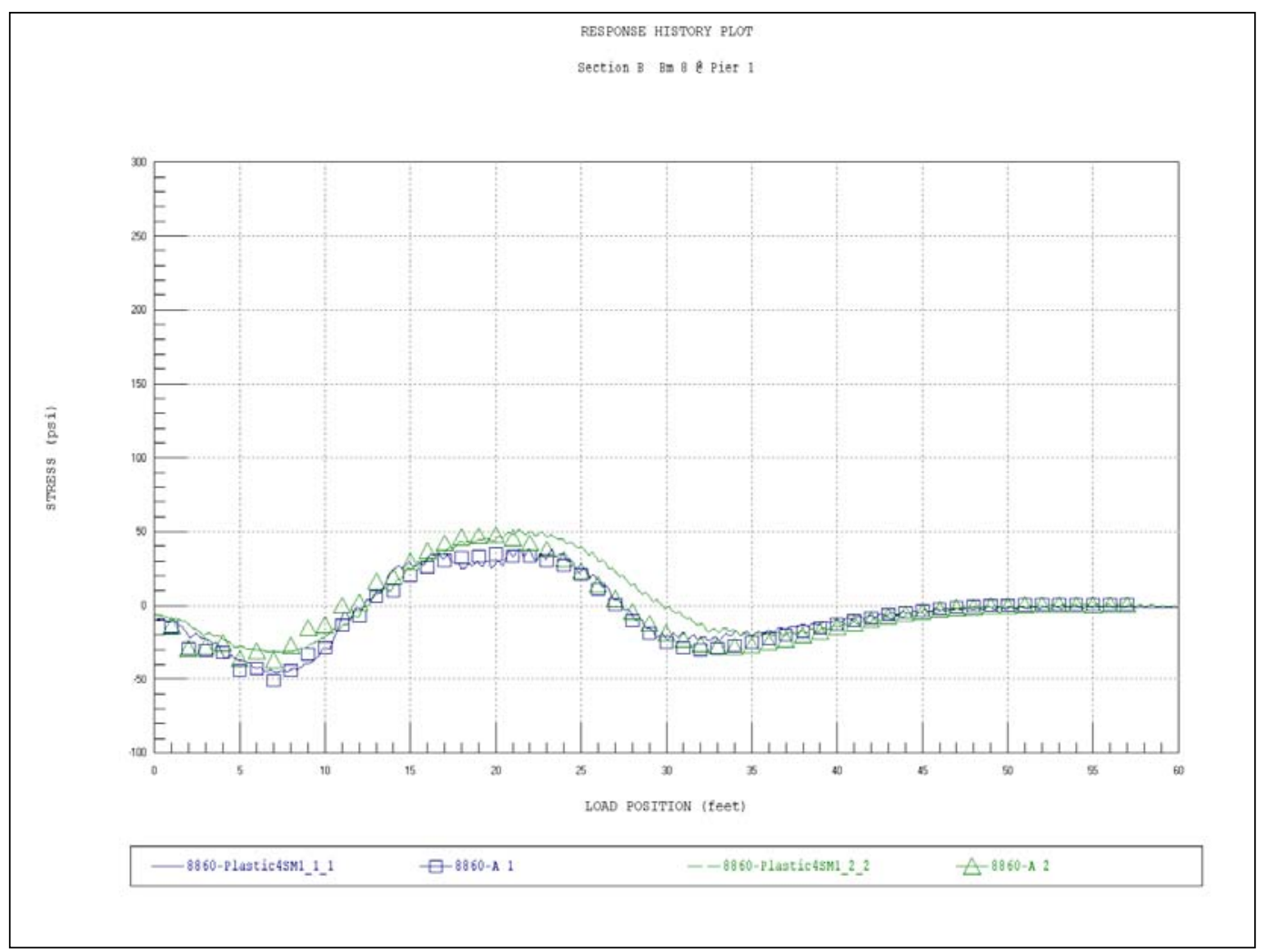

Figure A11. Strain comparison - Sec B - Beam 8. 


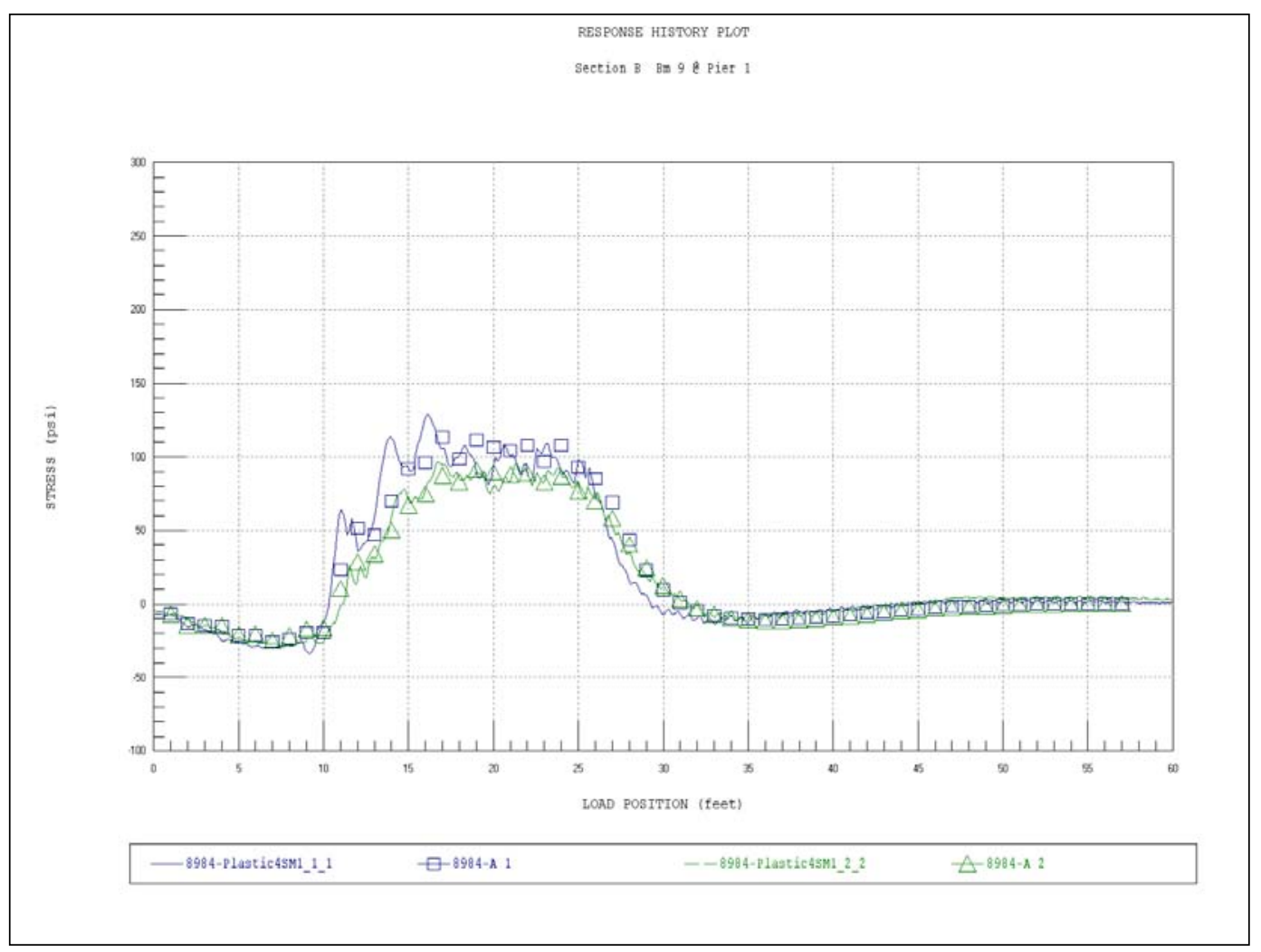

Figure A12. Strain comparison - Sec B - Beam 9.

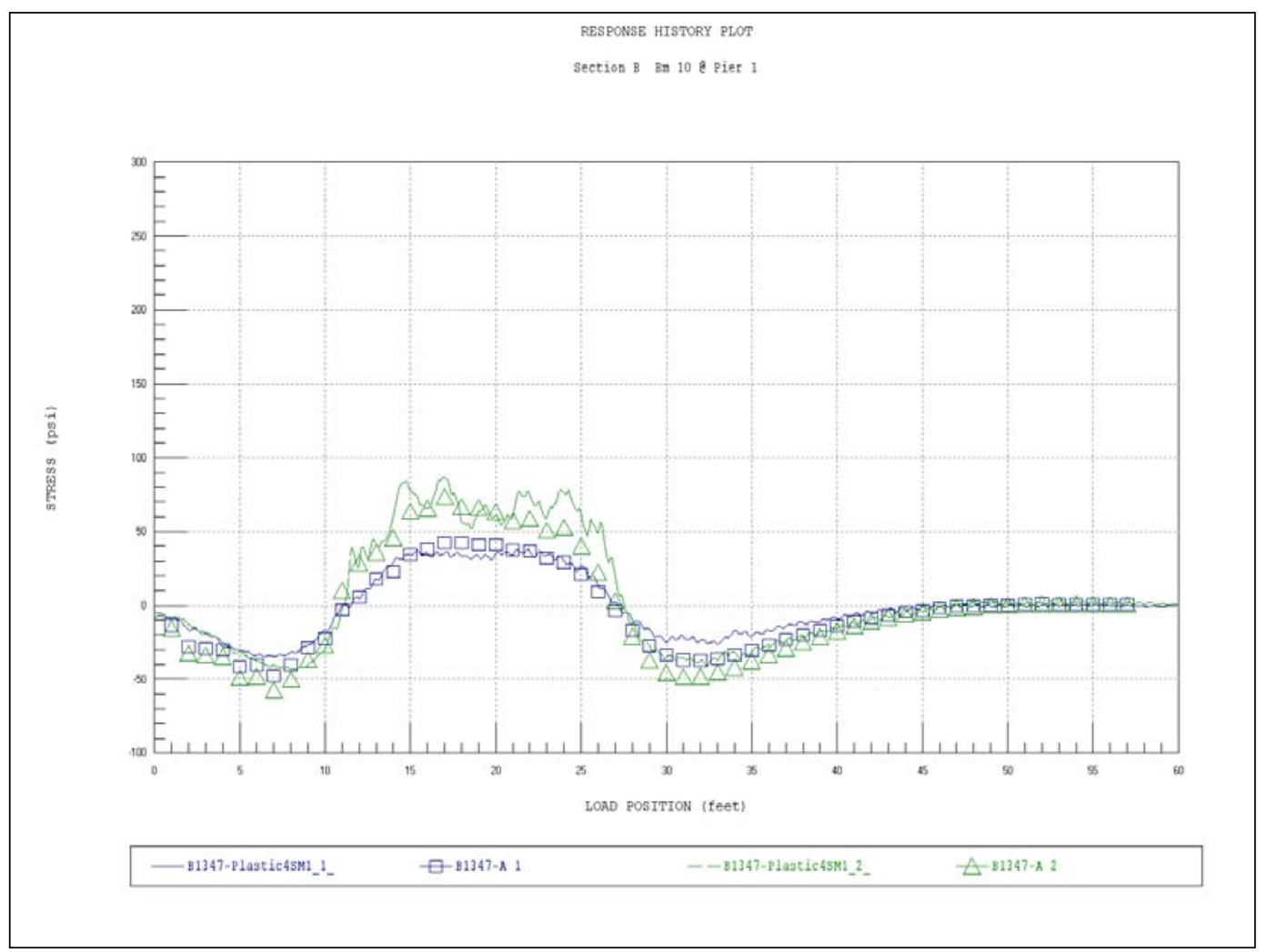

Figure A13. Strain comparison - Sec B - Beam 10. 


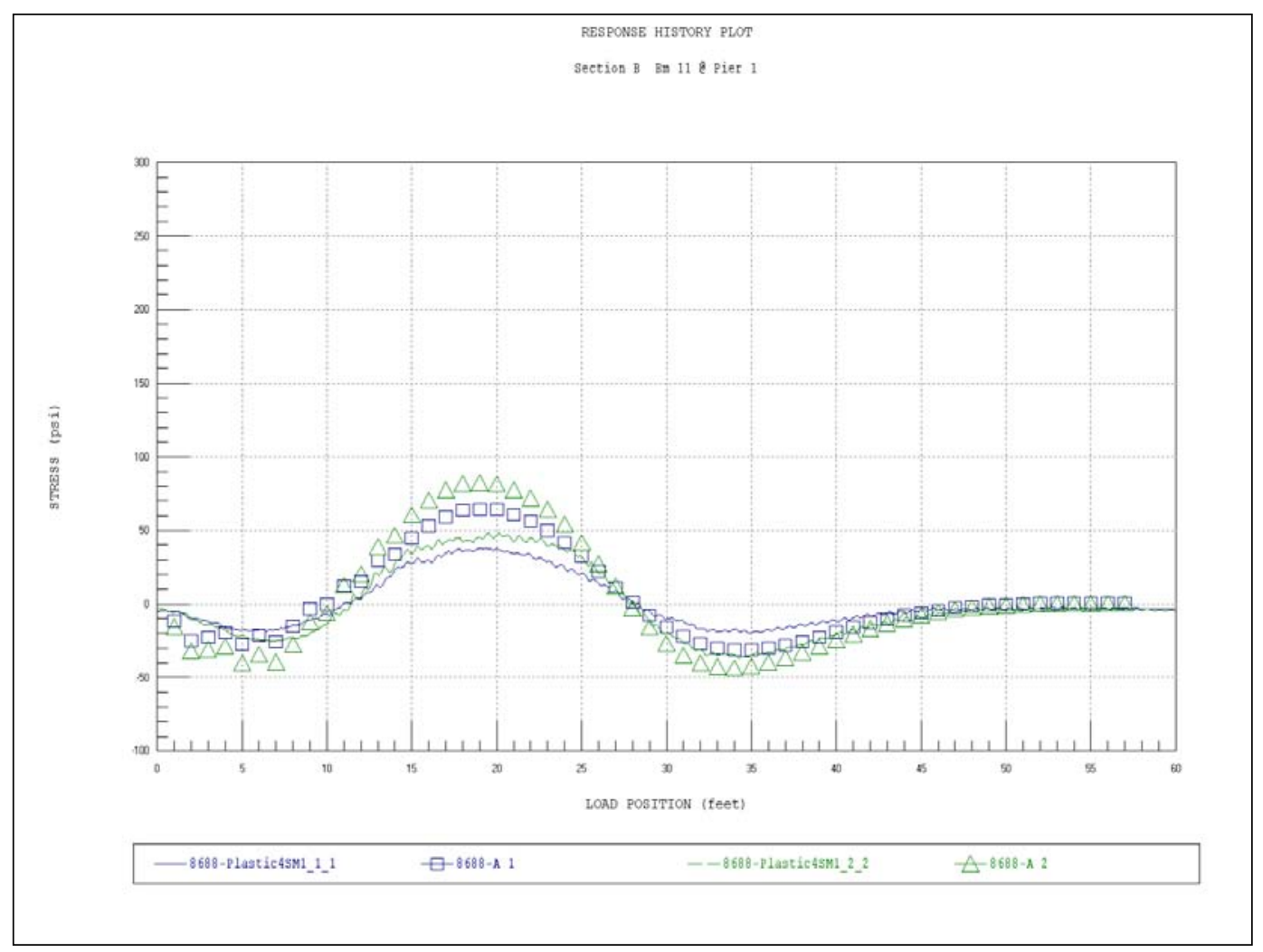

Figure A14. Strain comparison - Sec B - Beam 11.

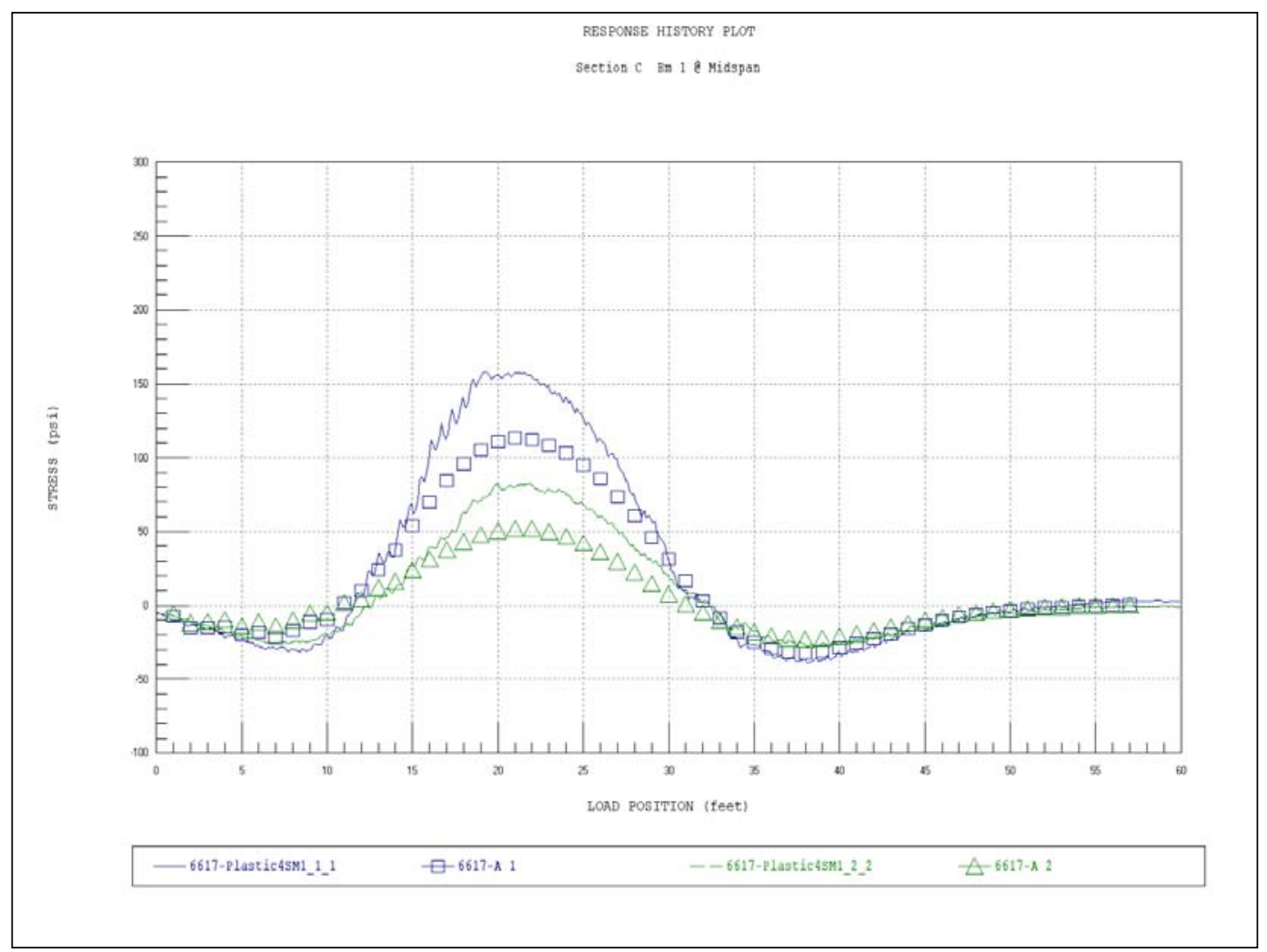

Figure A15. Strain comparison - Sec C - Beam 1. 


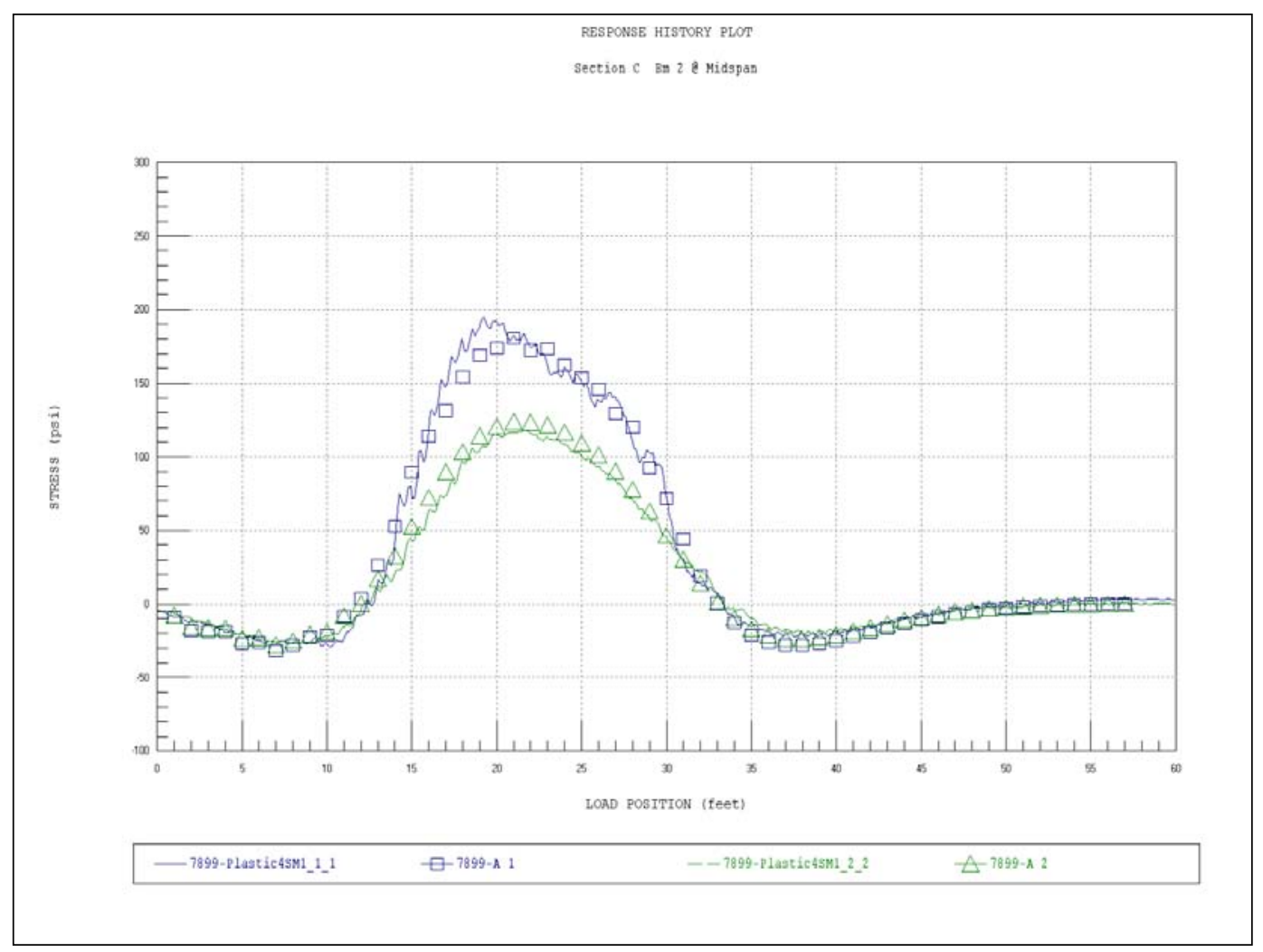

Figure A16. Strain comparison - Sec C - Beam 2.

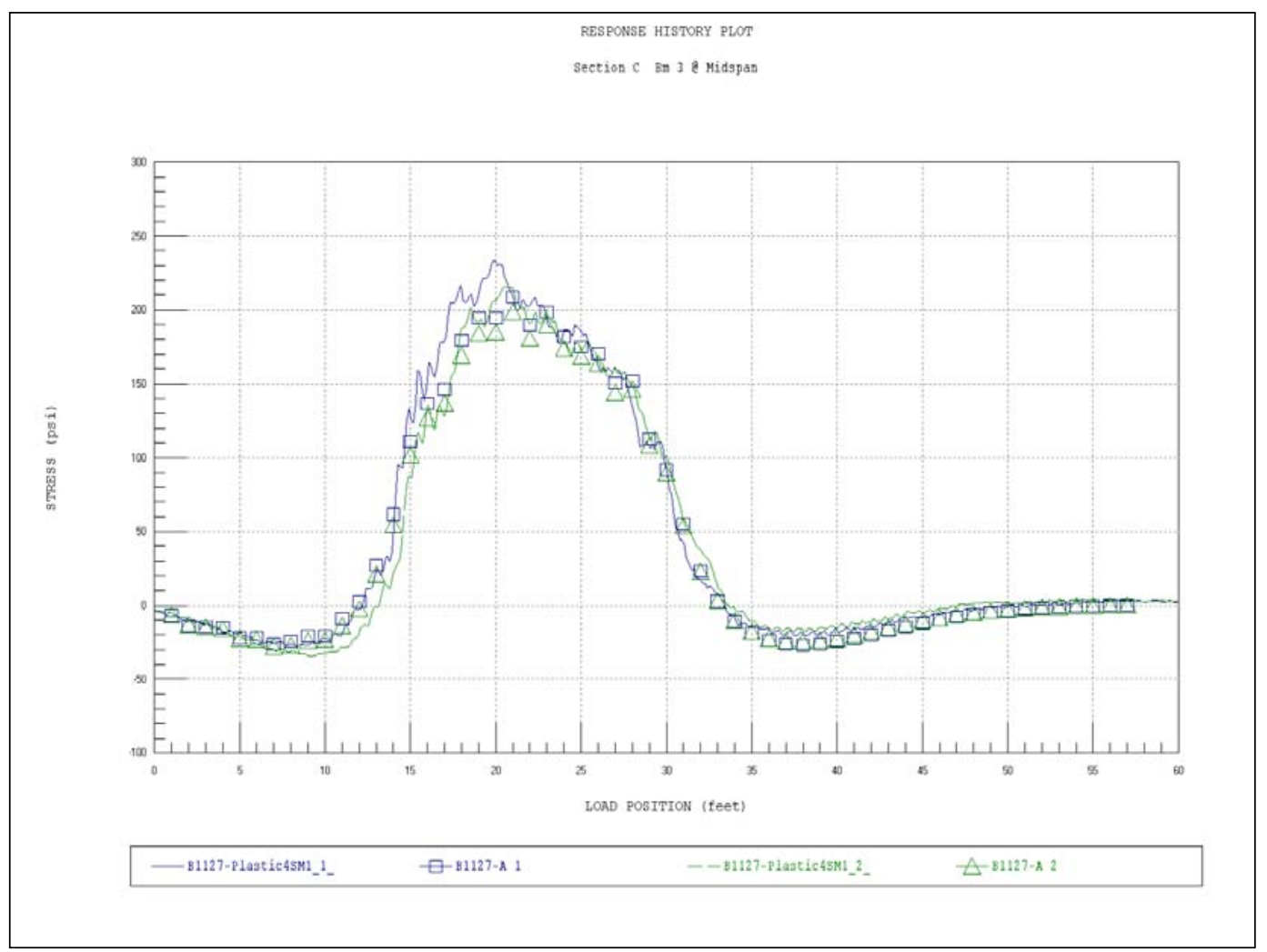

Figure A17. Strain comparison - Sec C - Beam 3. 


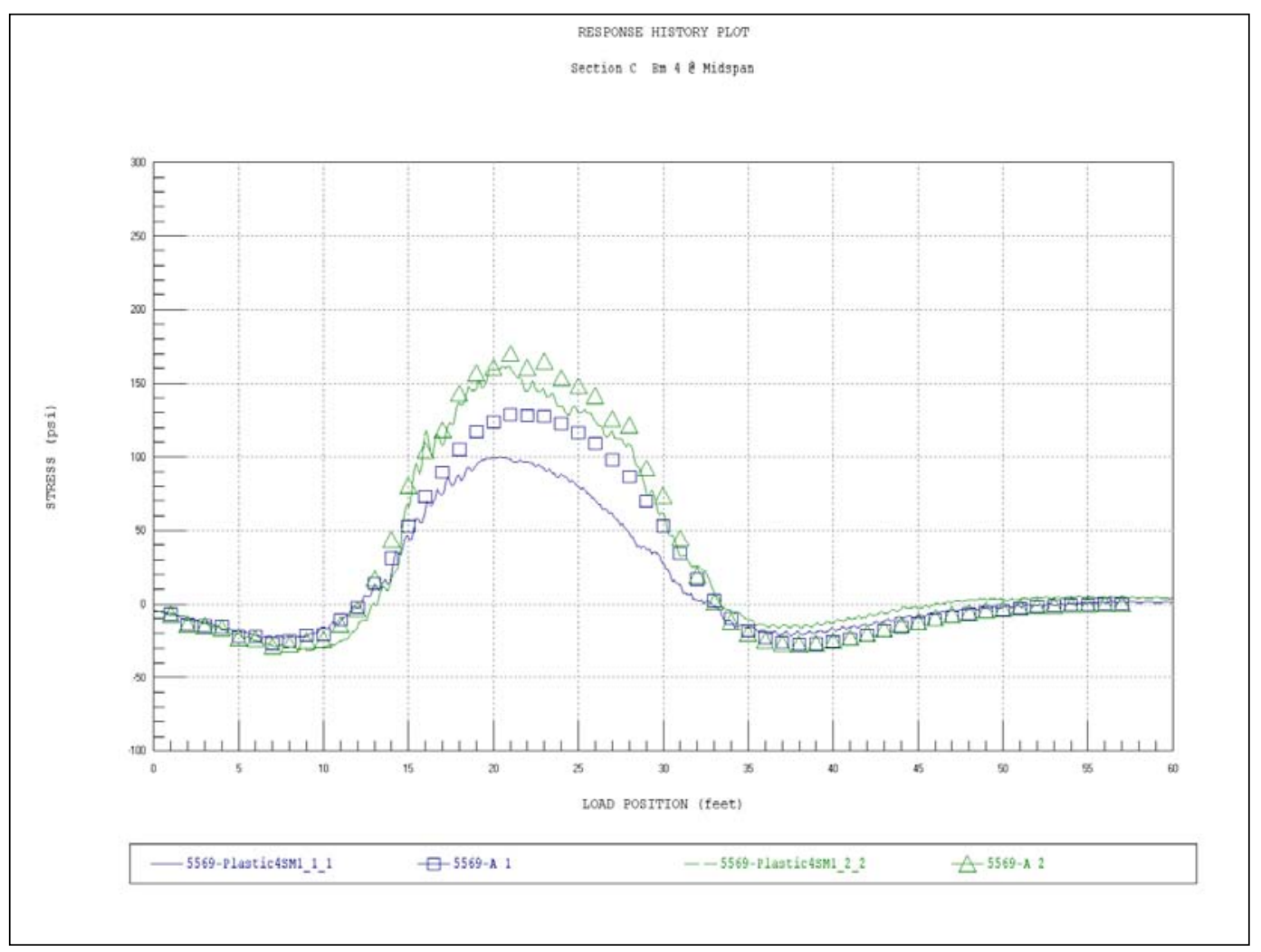

Figure A18. Strain comparison - Sec C - Beam 4.

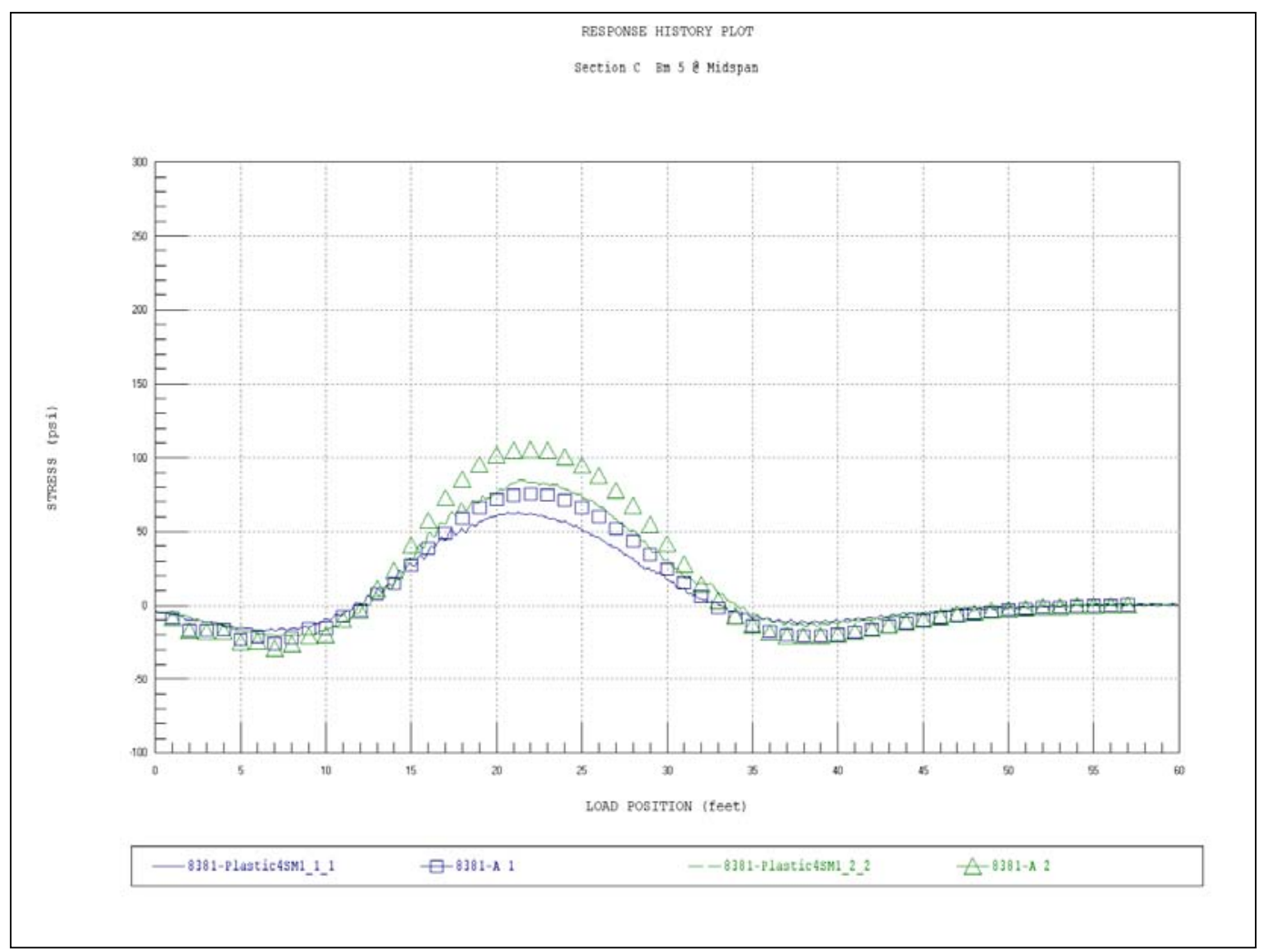

Figure A19. Strain comparison - Sec C - Beam 5. 


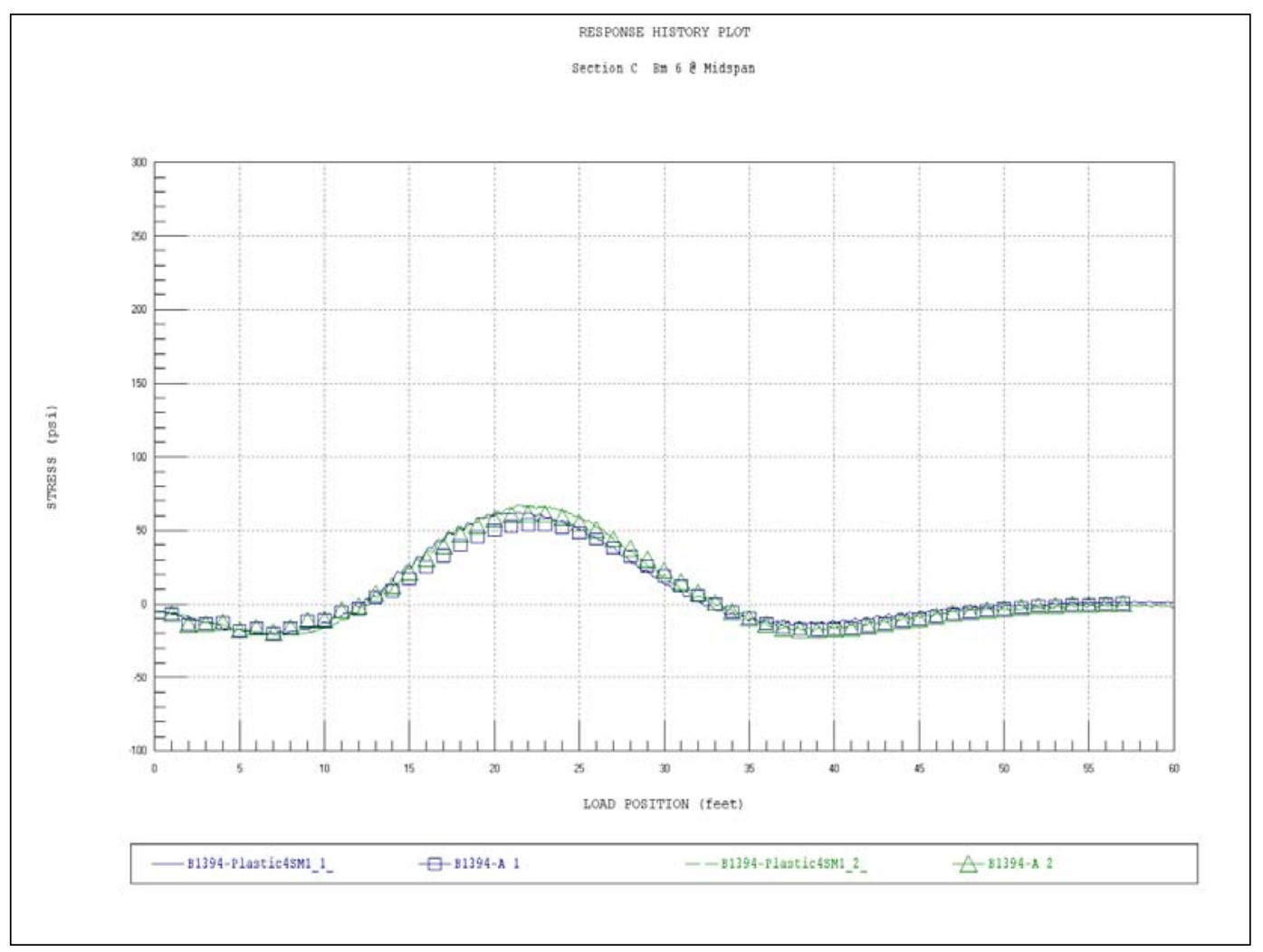

Figure A20. Strain comparison - Sec C - Beam 6.

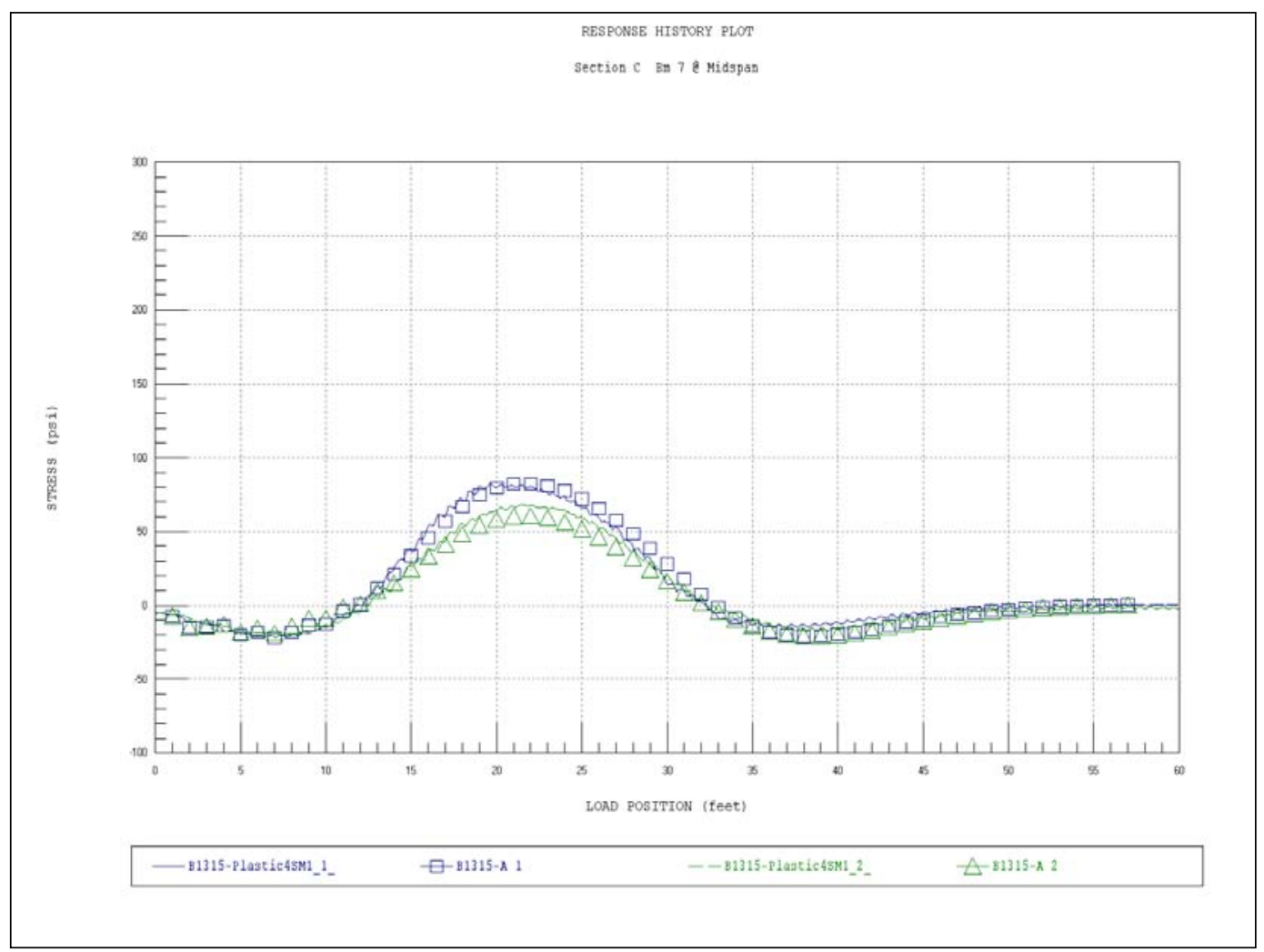

Figure A21. Strain comparison - Sec C - Beam 7. 


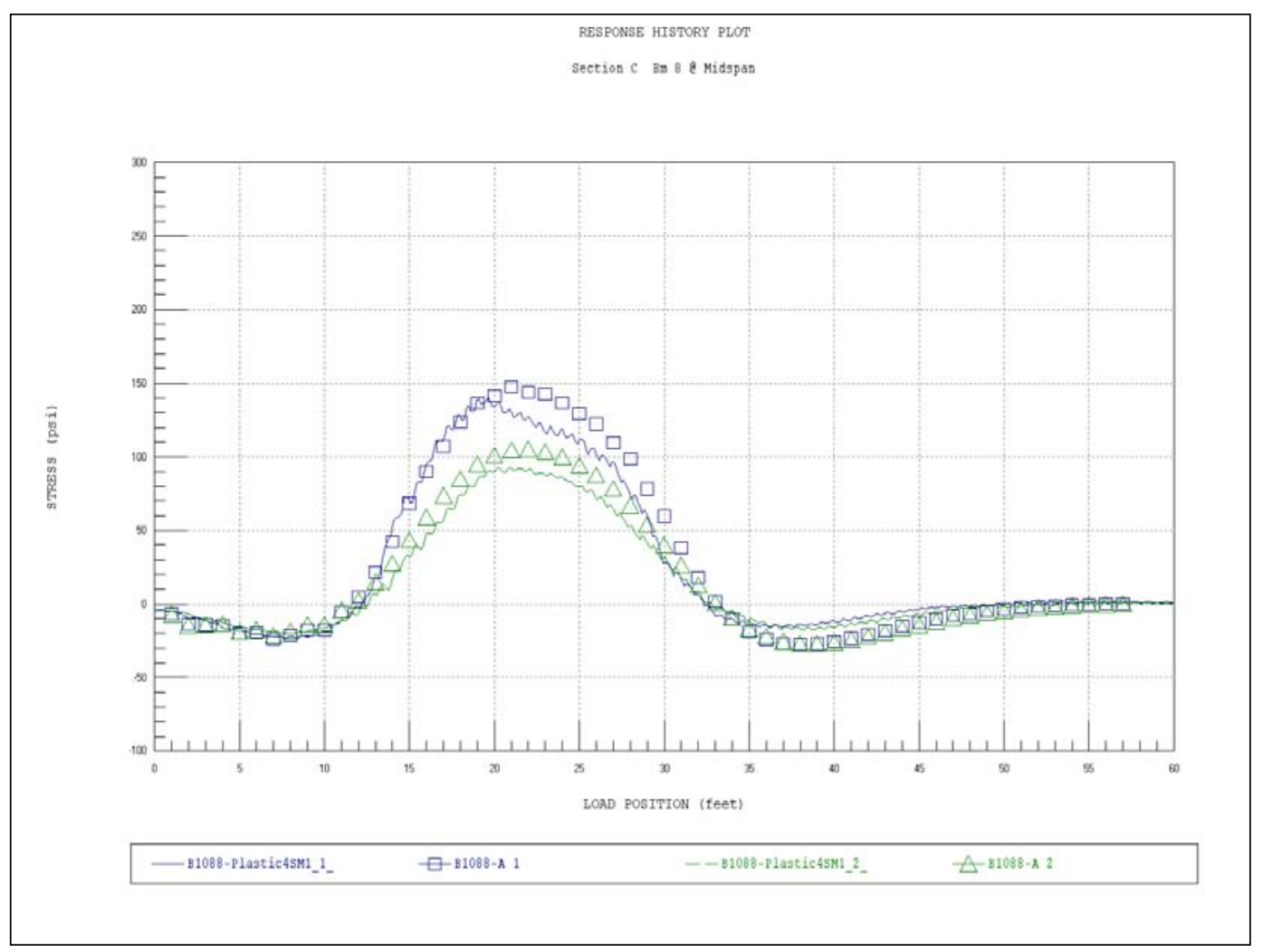

Figure A22. Strain comparison - Sec C - Beam 8.

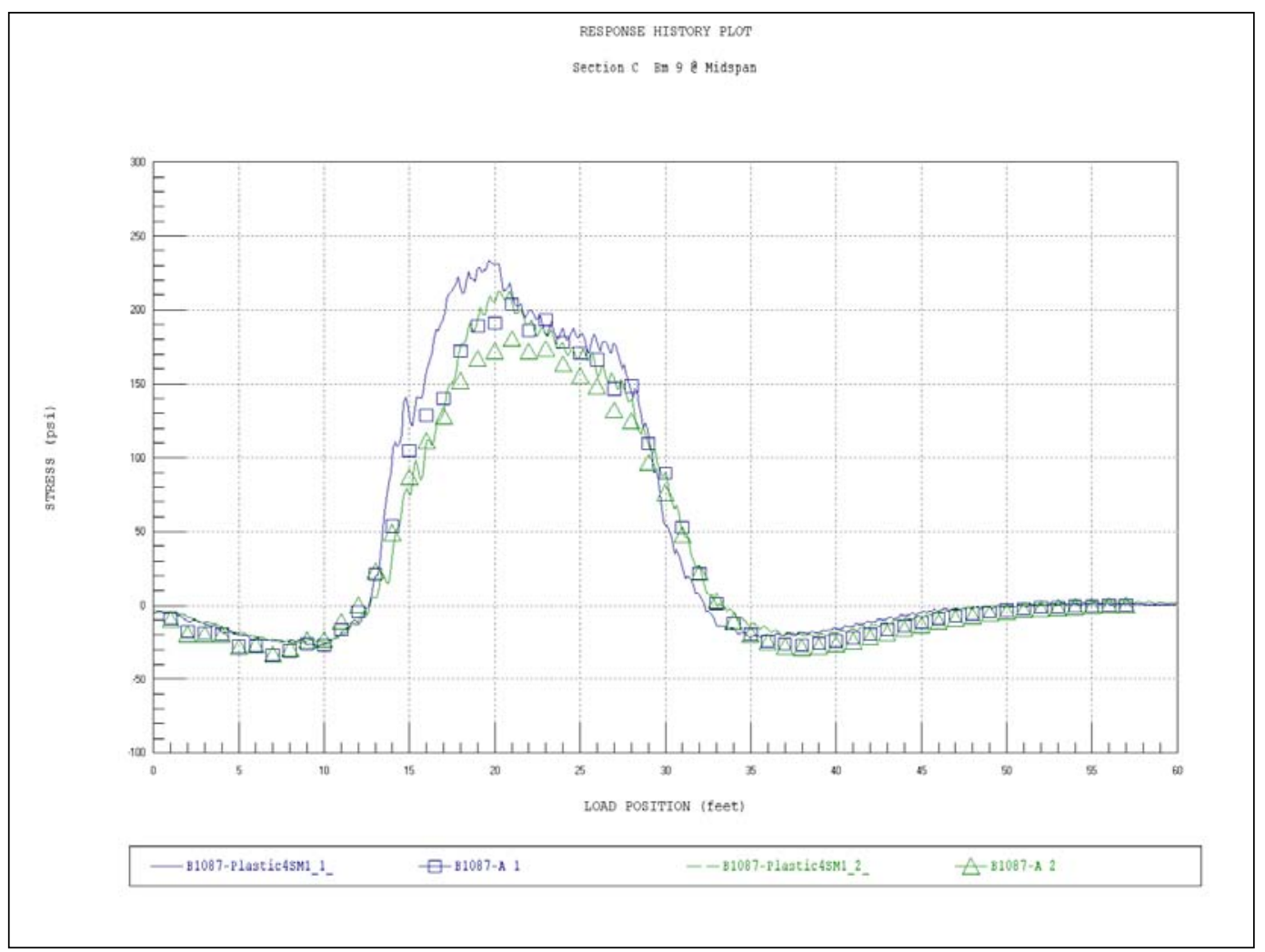

Figure A23. Strain comparison - Sec C - Beam 9. 


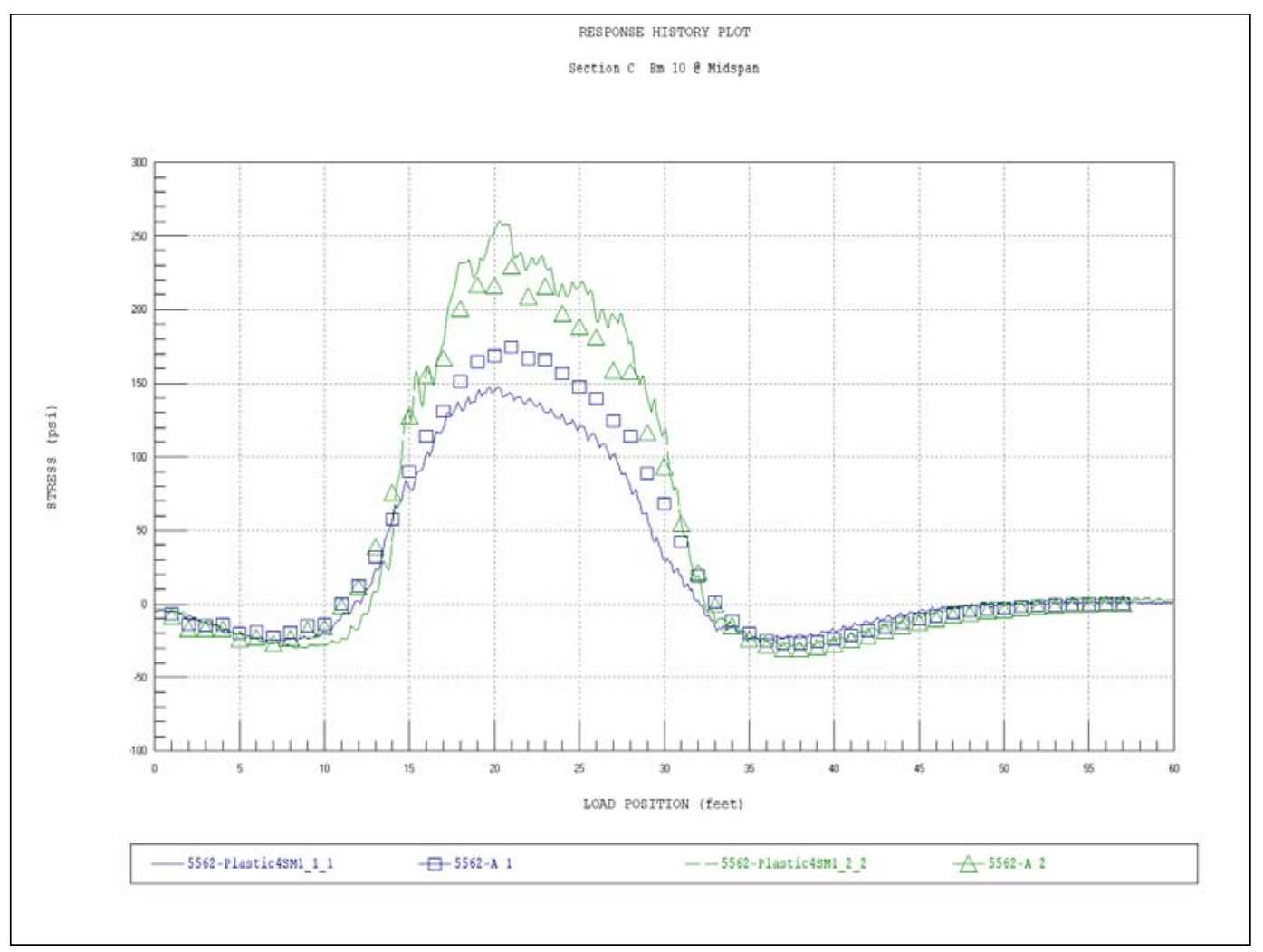

Figure A24. Strain comparison - Sec C - Beam 10.

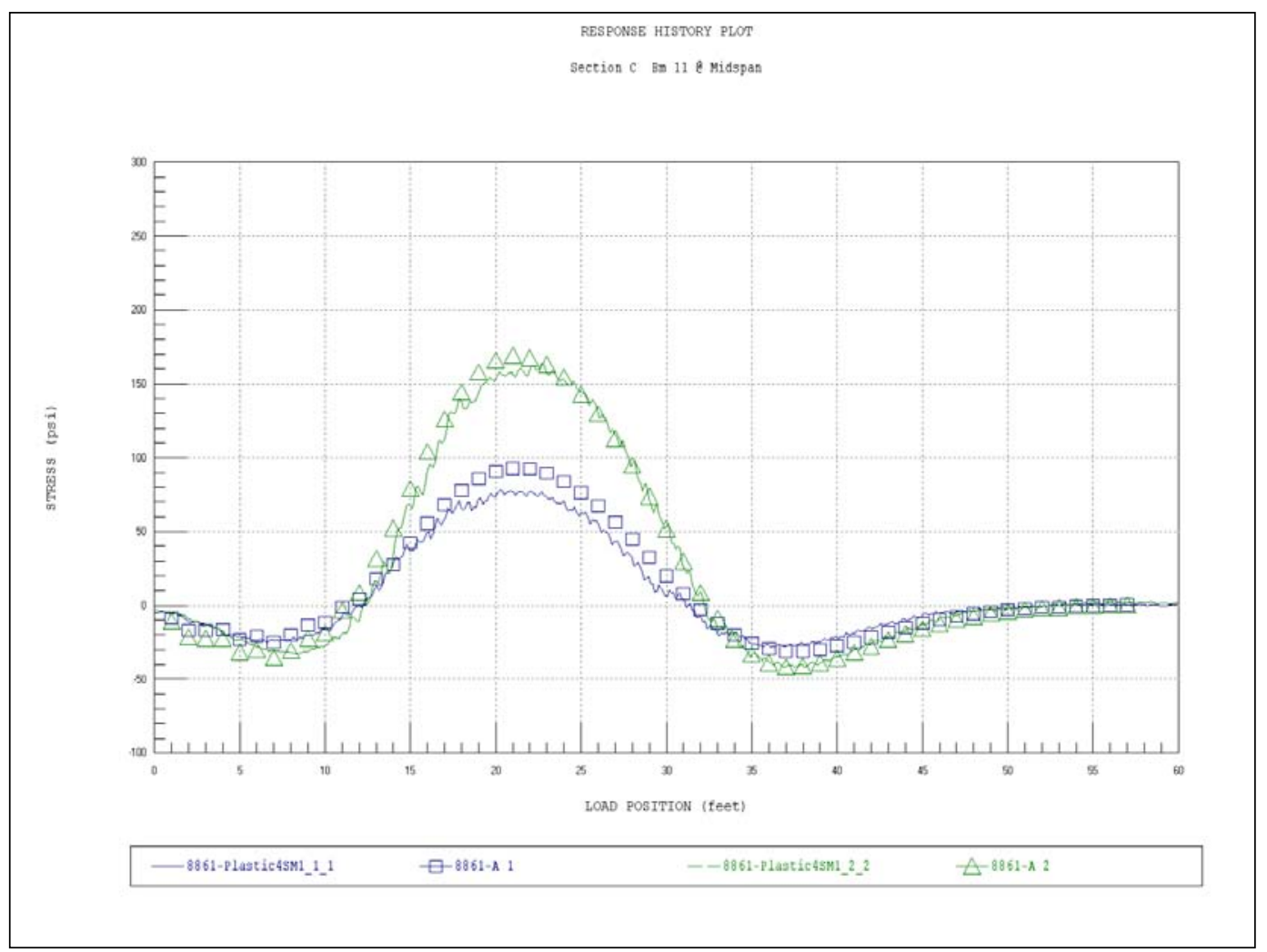

Figure A25. Strain comparison - Sec C - Beam 11. 


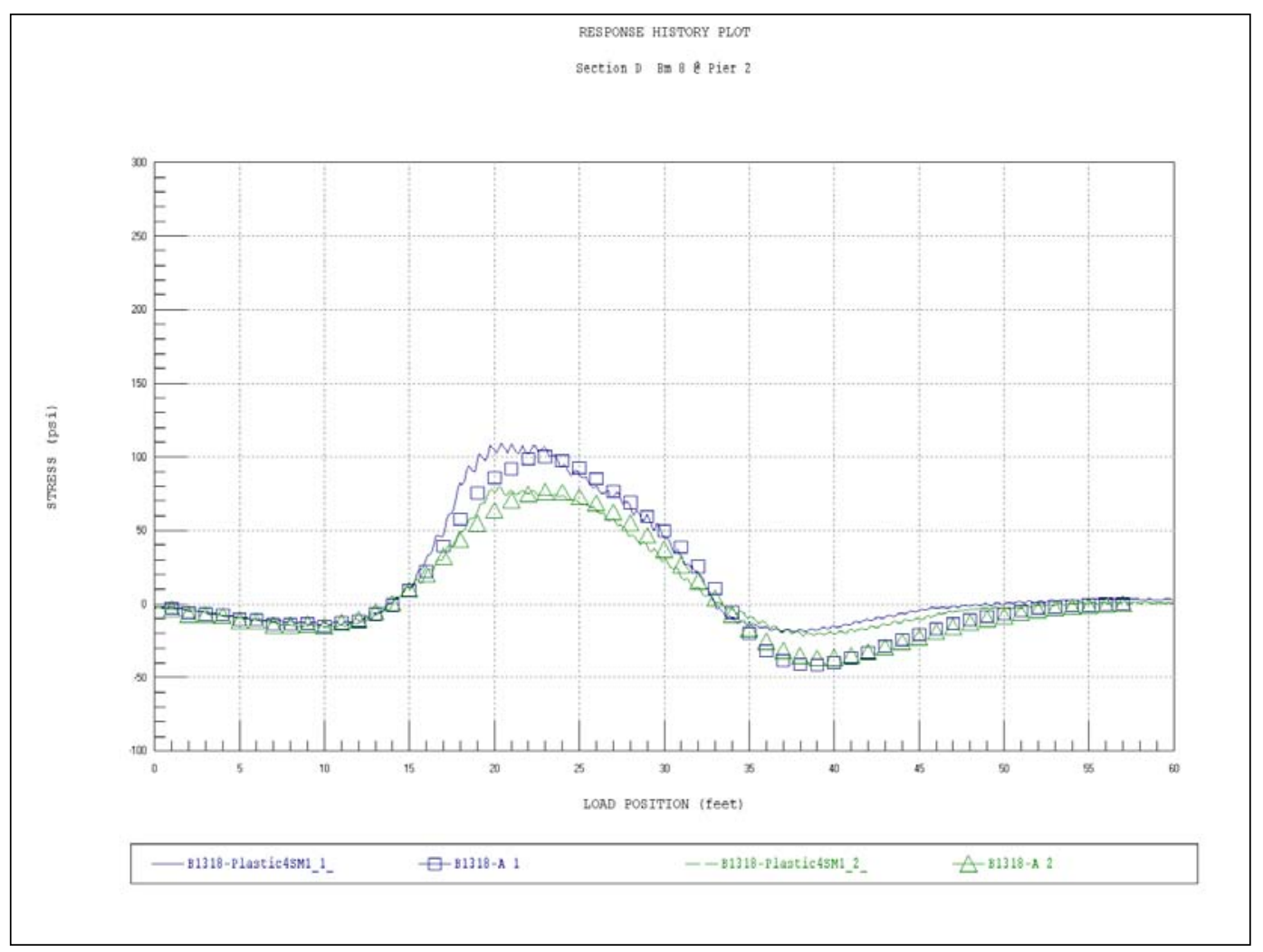

Figure A26. Strain comparison - Sec D - Beam 8.

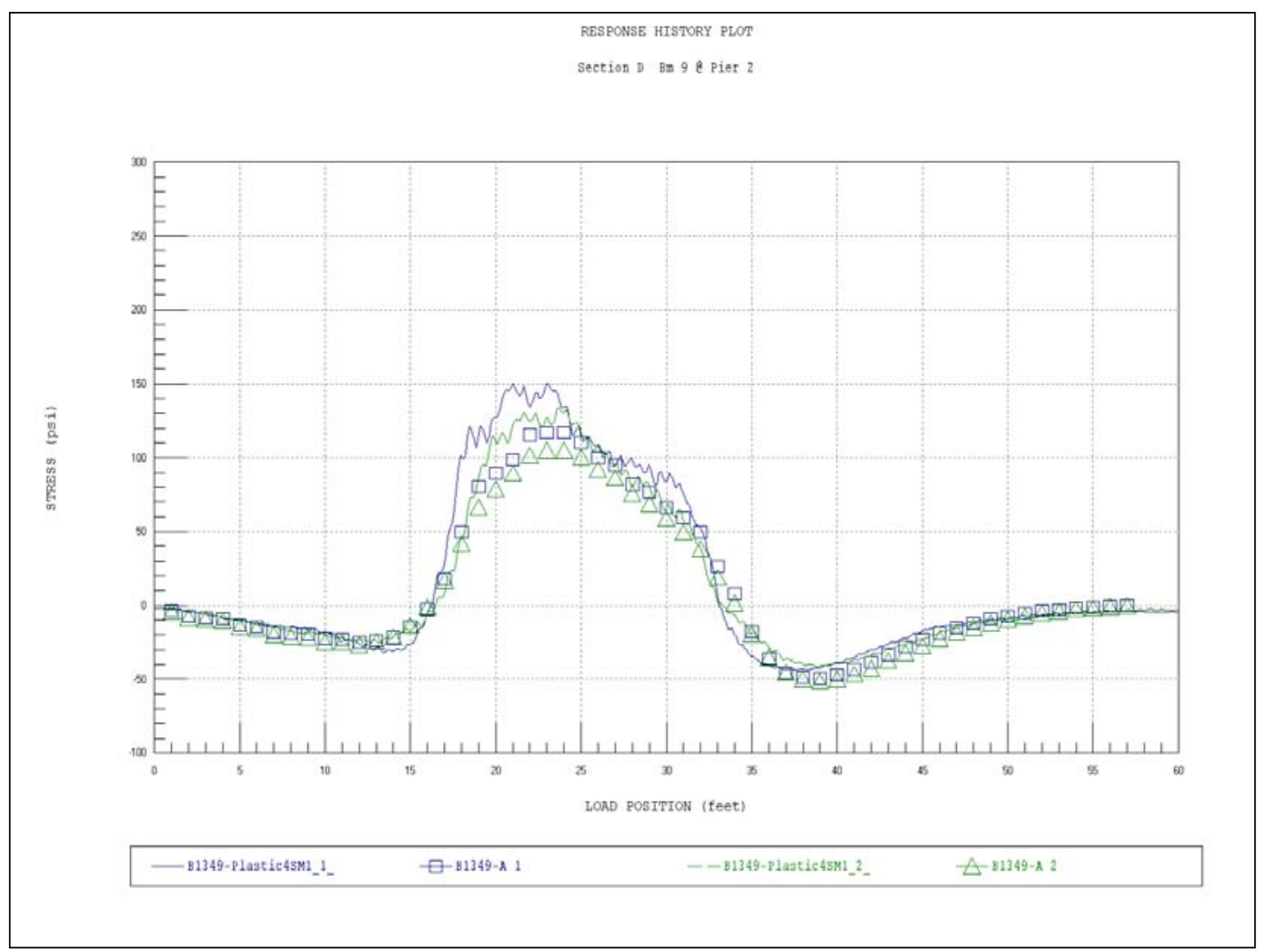

Figure A27. Strain comparison - Sec D - Beam 9. 


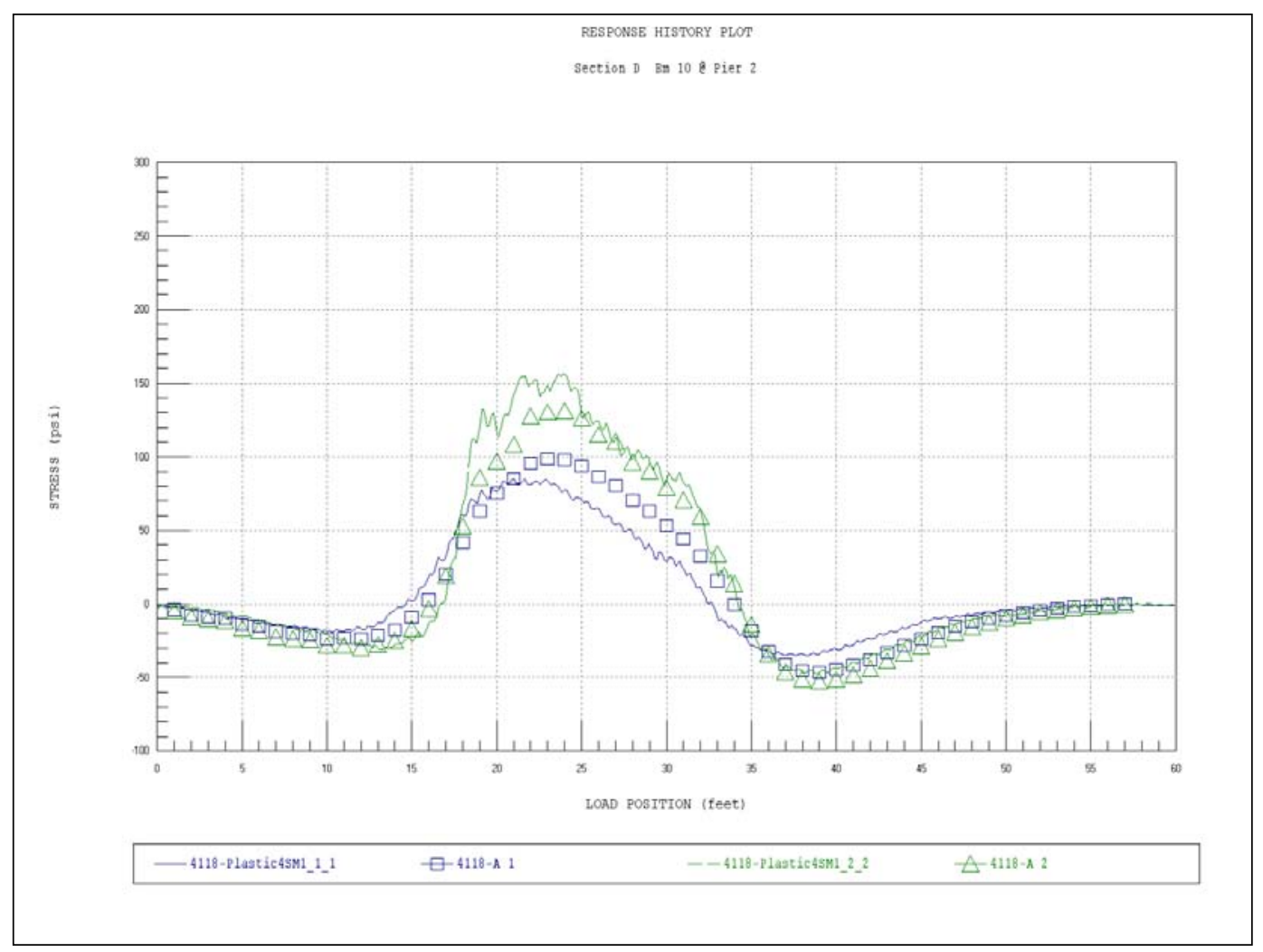

Figure A28. Strain comparison - Sec D - Beam 10.

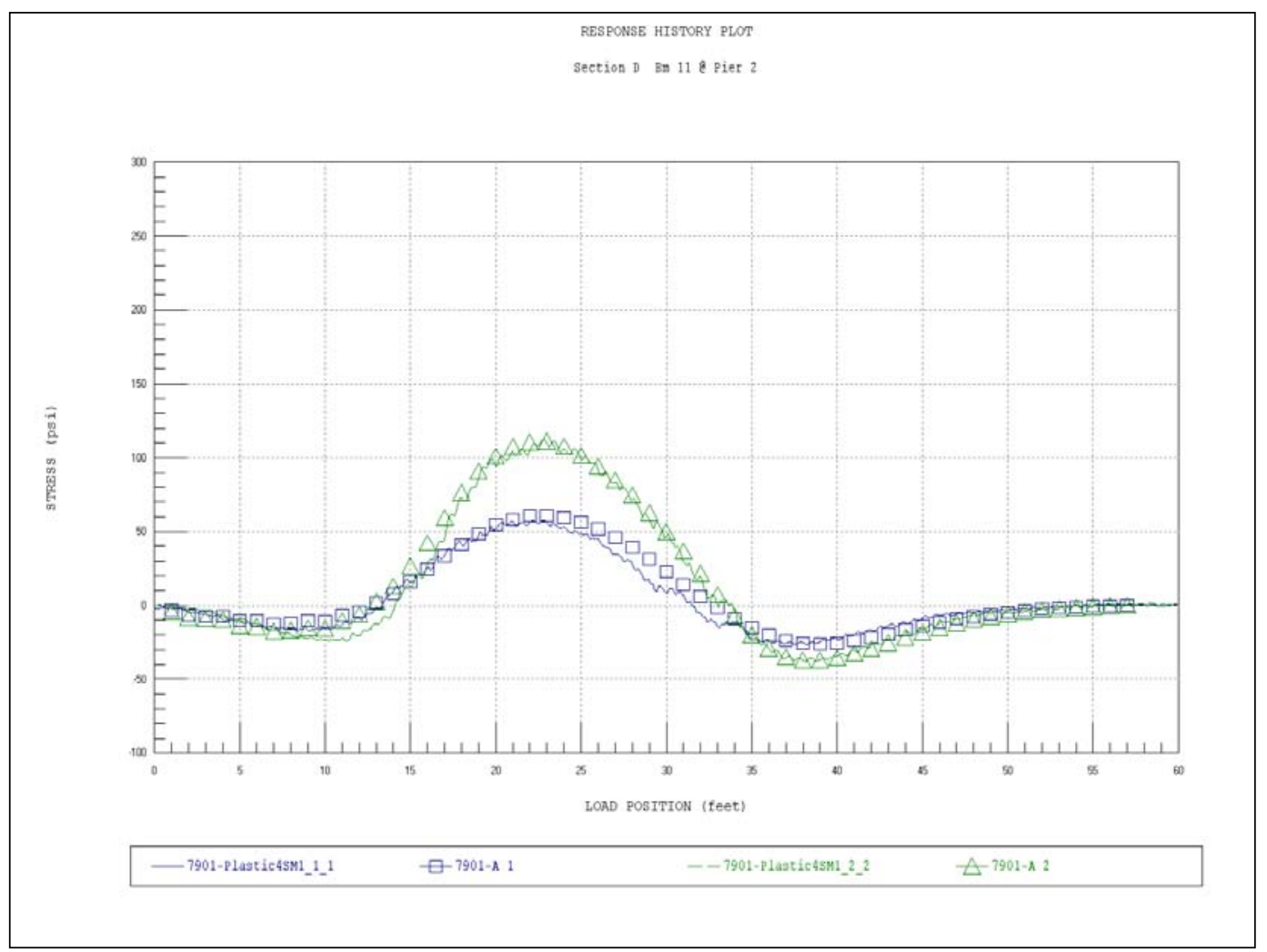

Figure A29. Strain comparison - Sec D - Beam 11. 


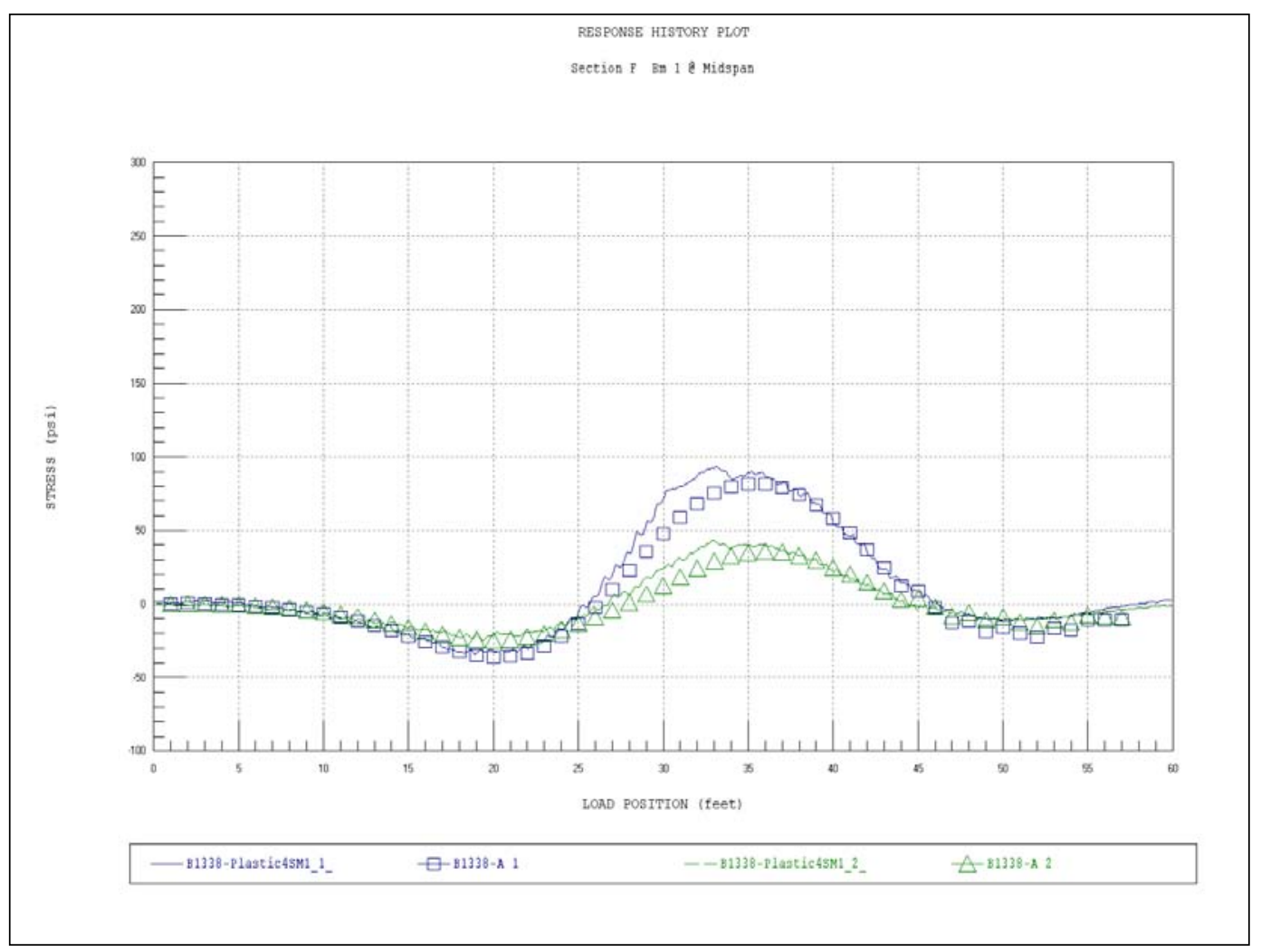

Figure A30. Strain comparison - Sec F - Beam 1.

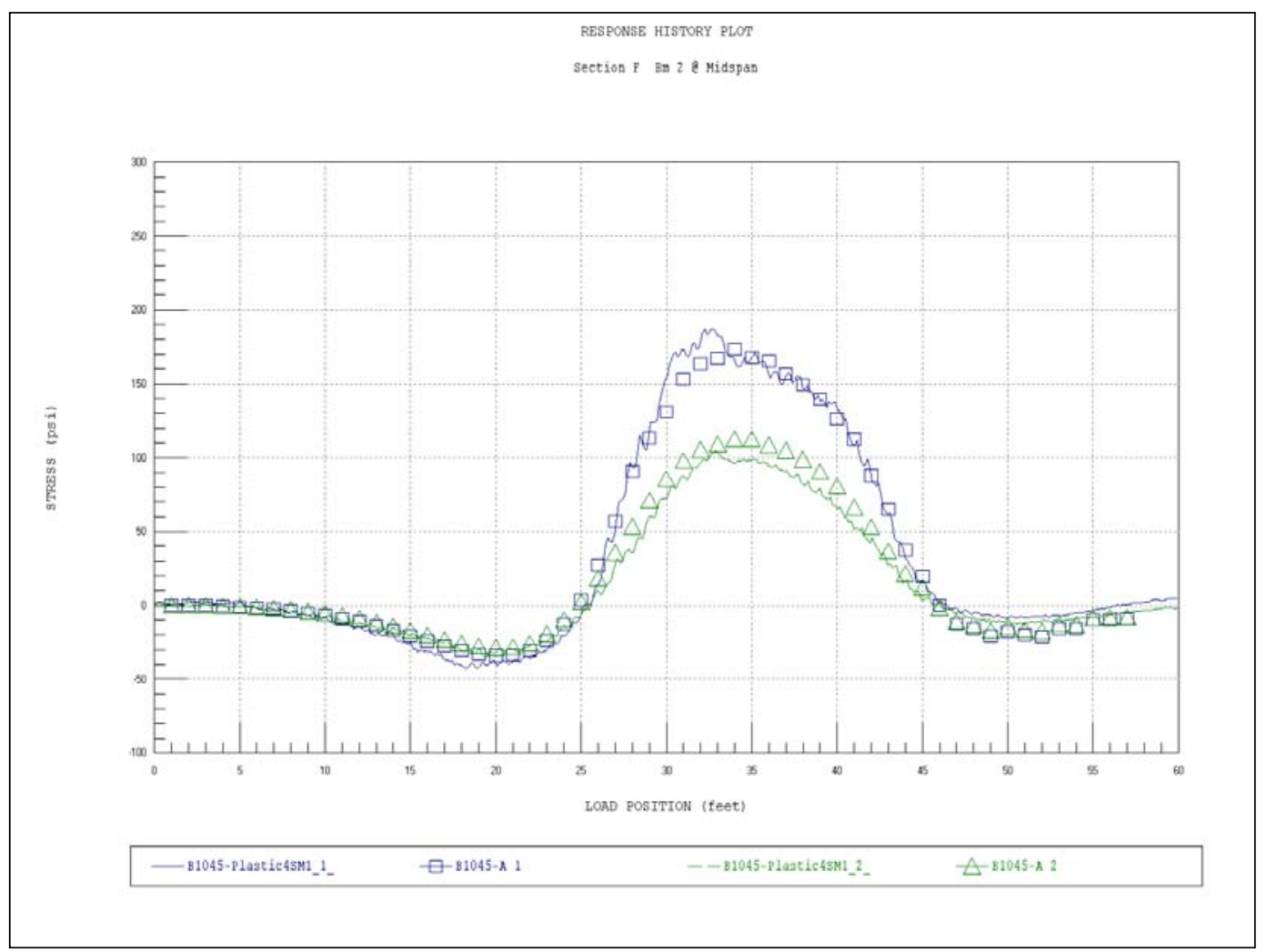

Figure A31. Strain comparison - Sec F - Beam 2. 


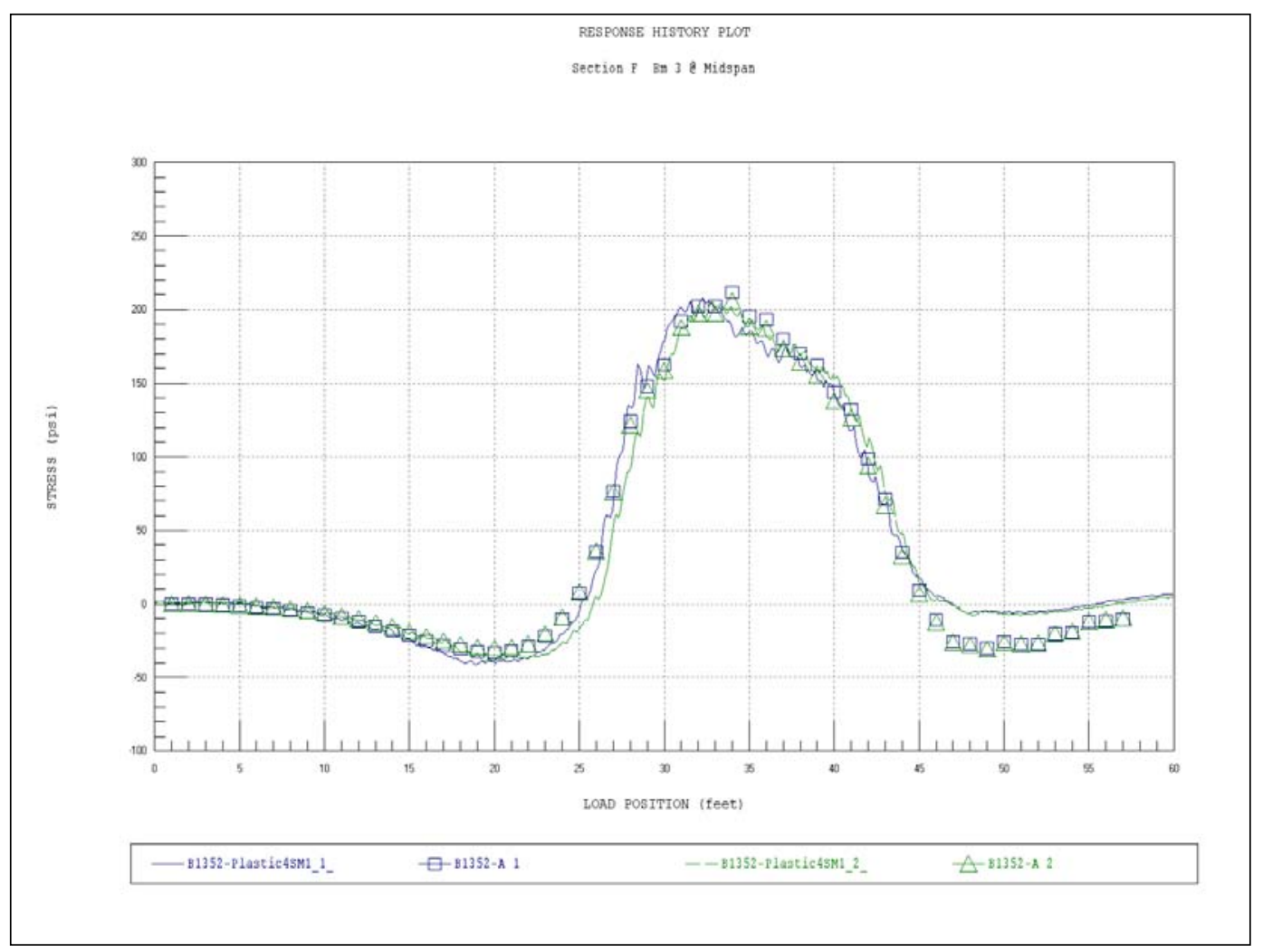

Figure A32. Strain comparison - Sec F - Beam 3.

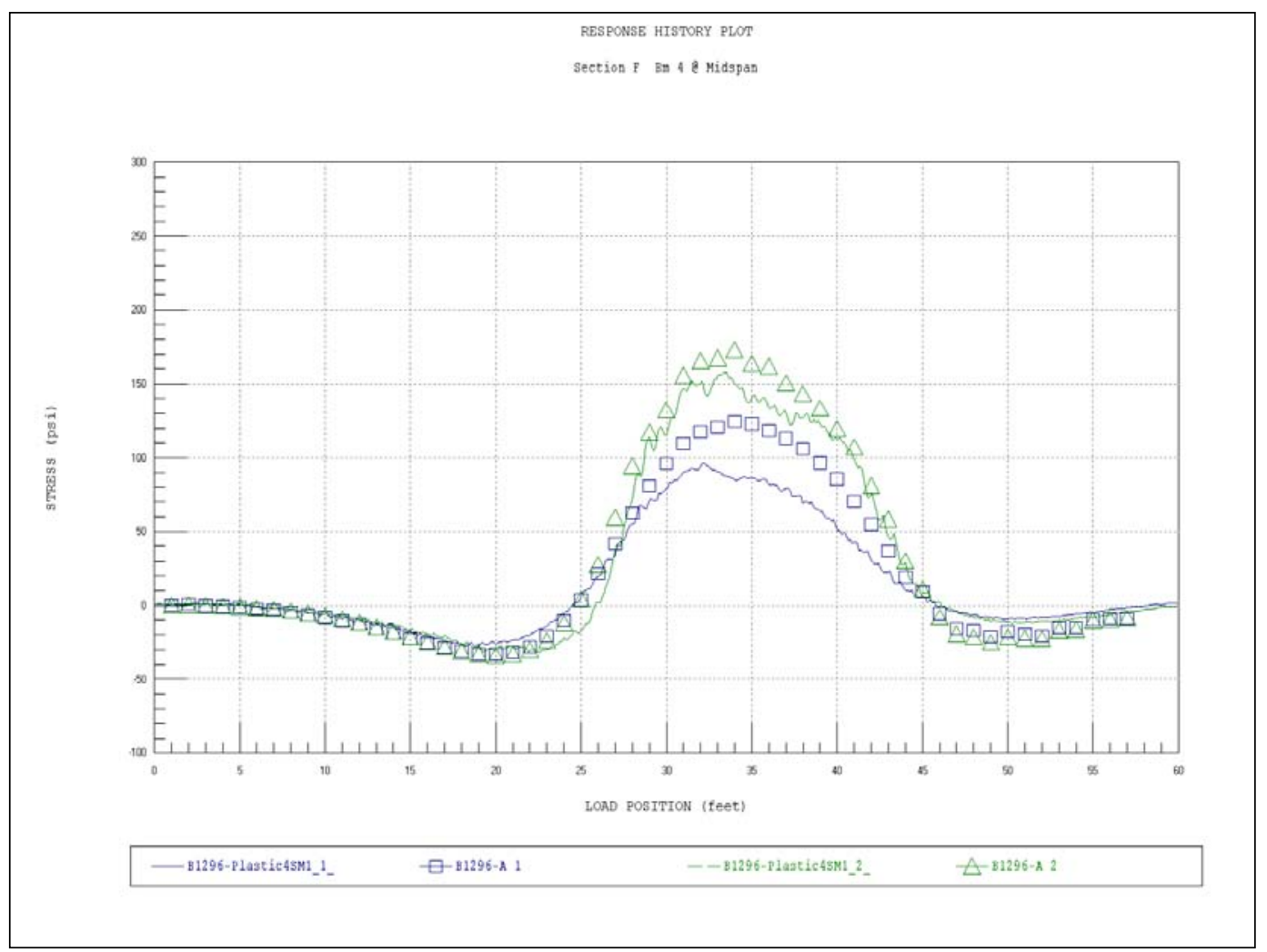

Figure A33. Strain comparison - Sec F - Beam 4. 


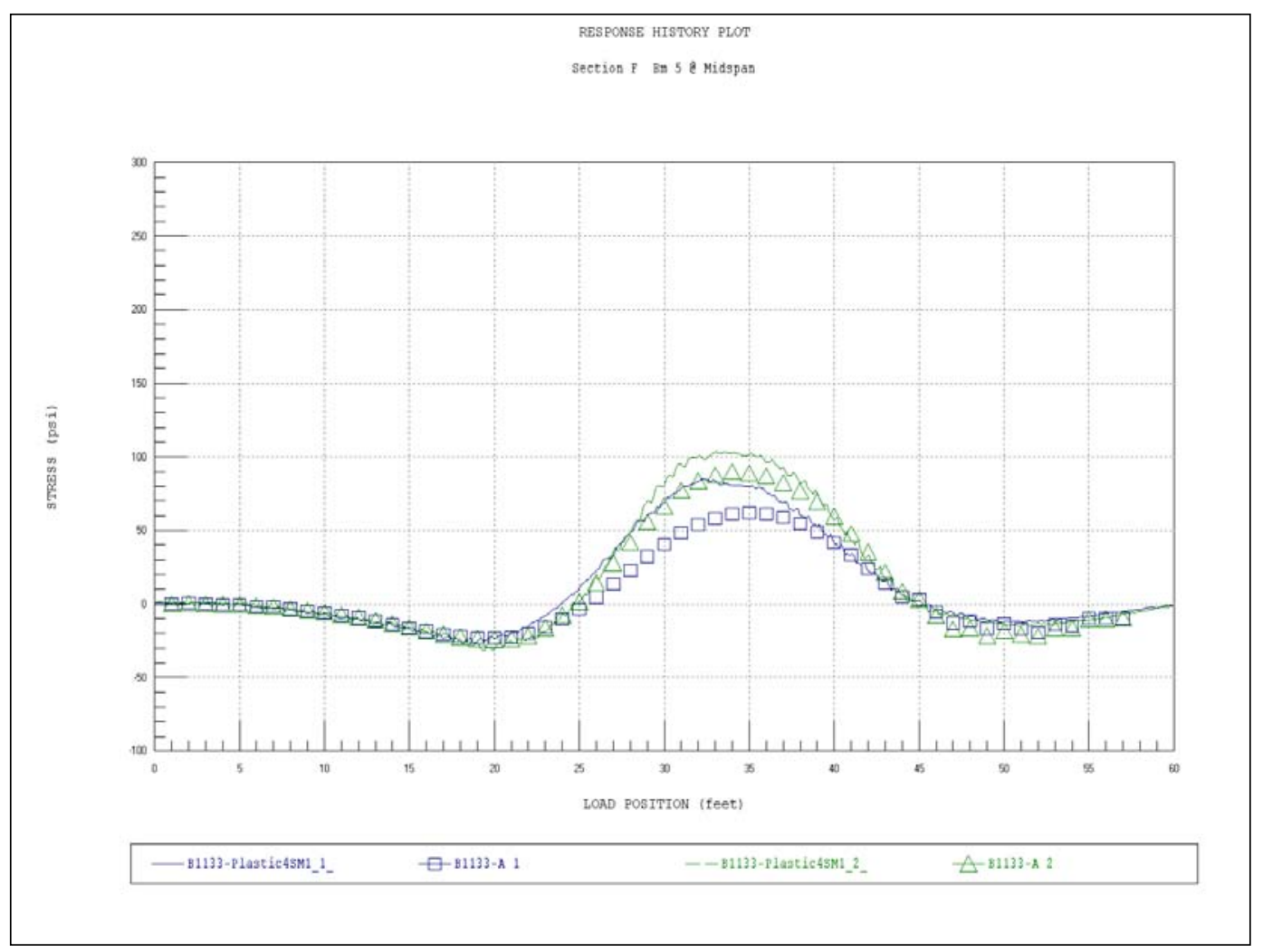

Figure A34. Strain comparison - Sec F - Beam 5.

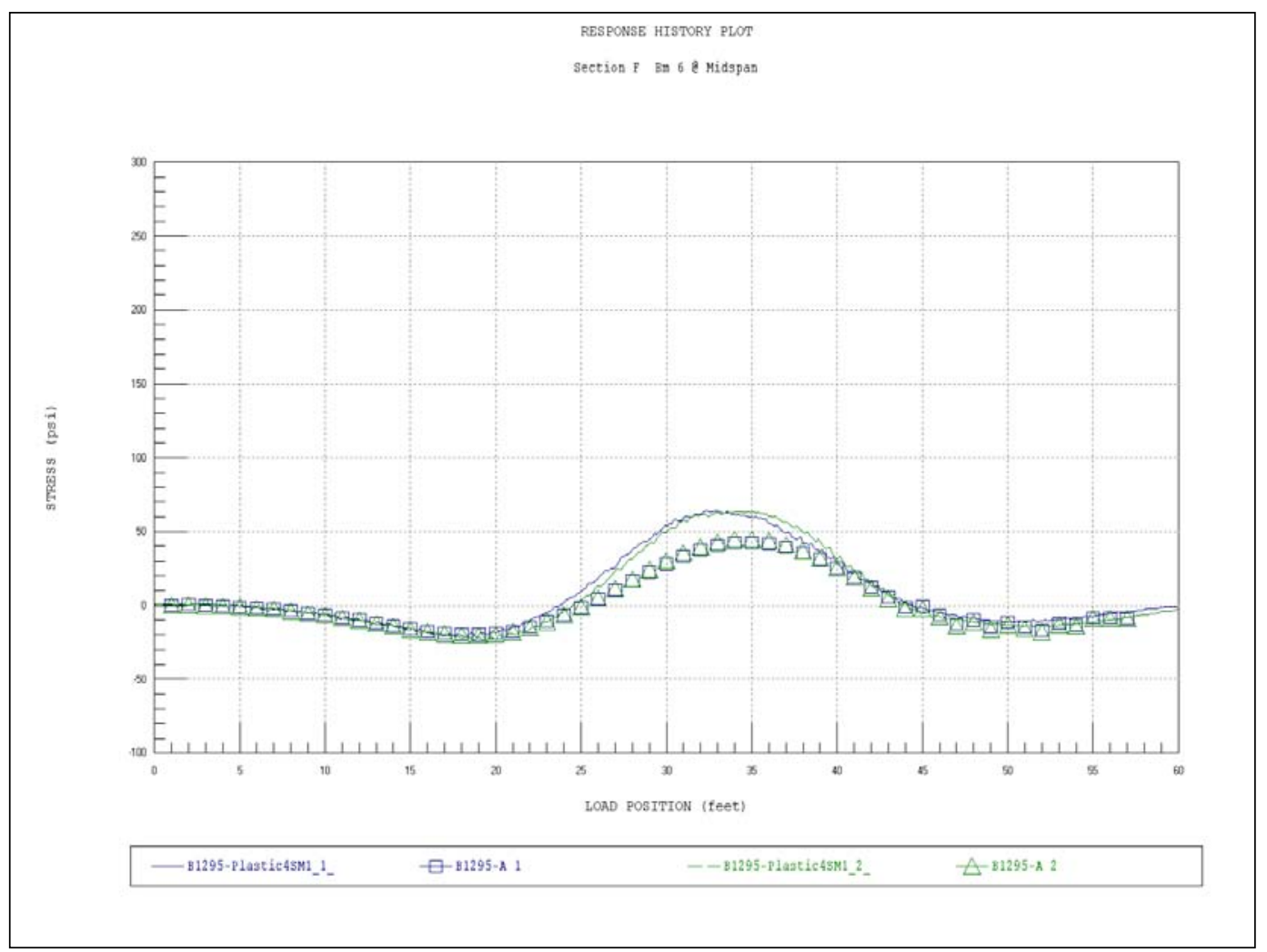

Figure A35. Strain comparison - Sec F - Beam 6. 


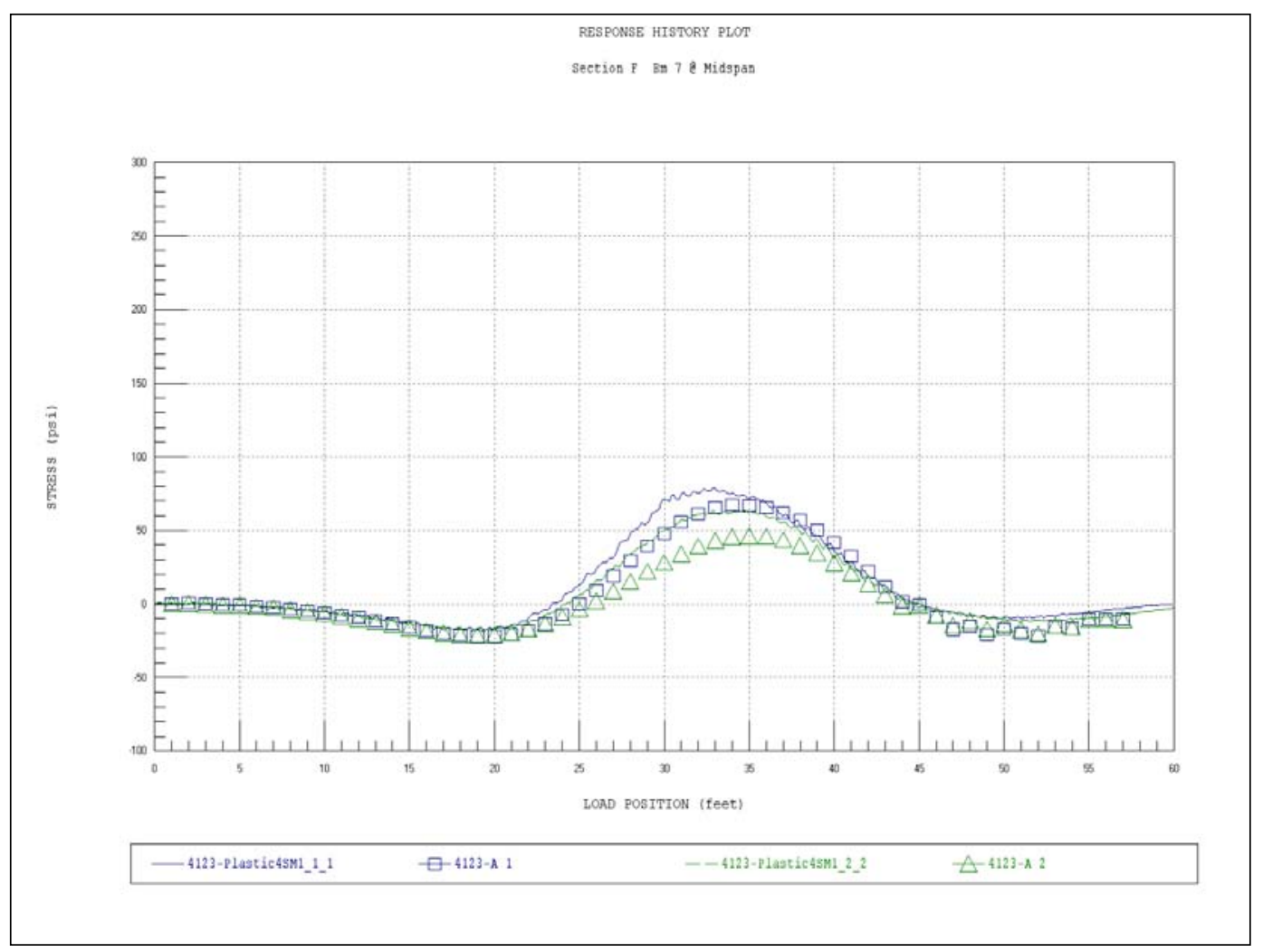

Figure A36. Strain comparison - Sec F - Beam 7.

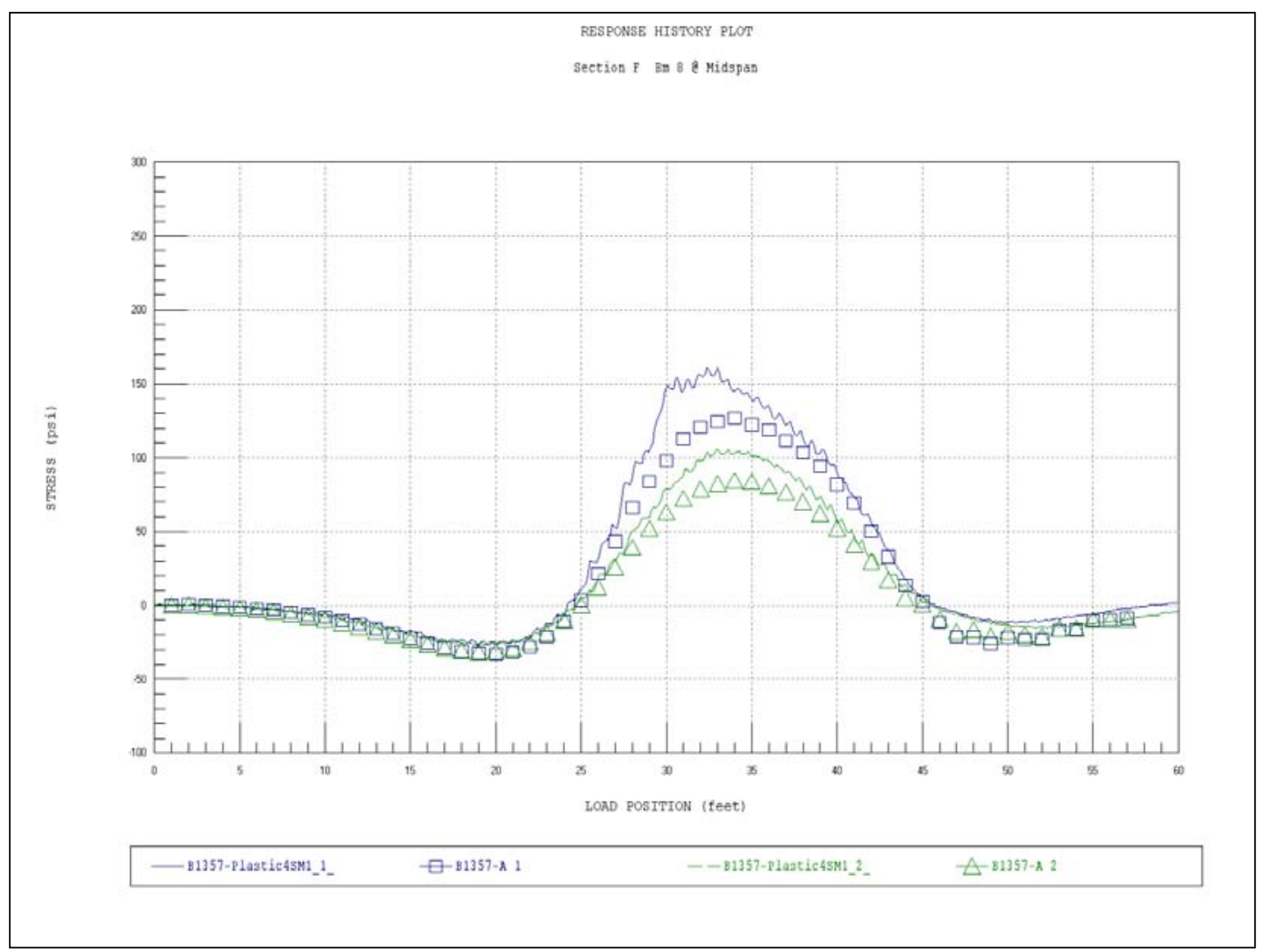

Figure A37. Strain comparison - Sec F - Beam 8. 


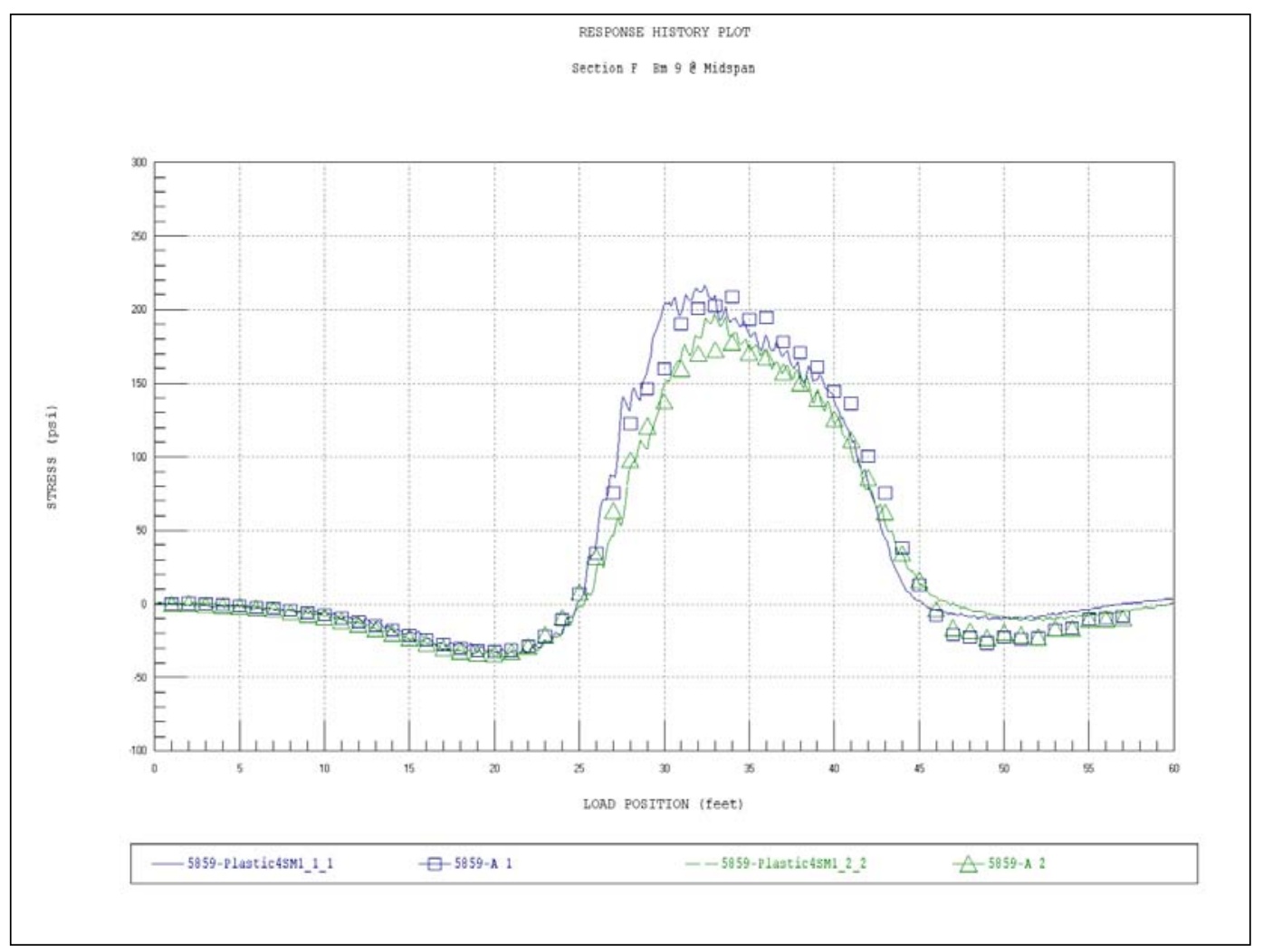

Figure A38. Strain comparison - Sec F - Beam 9.

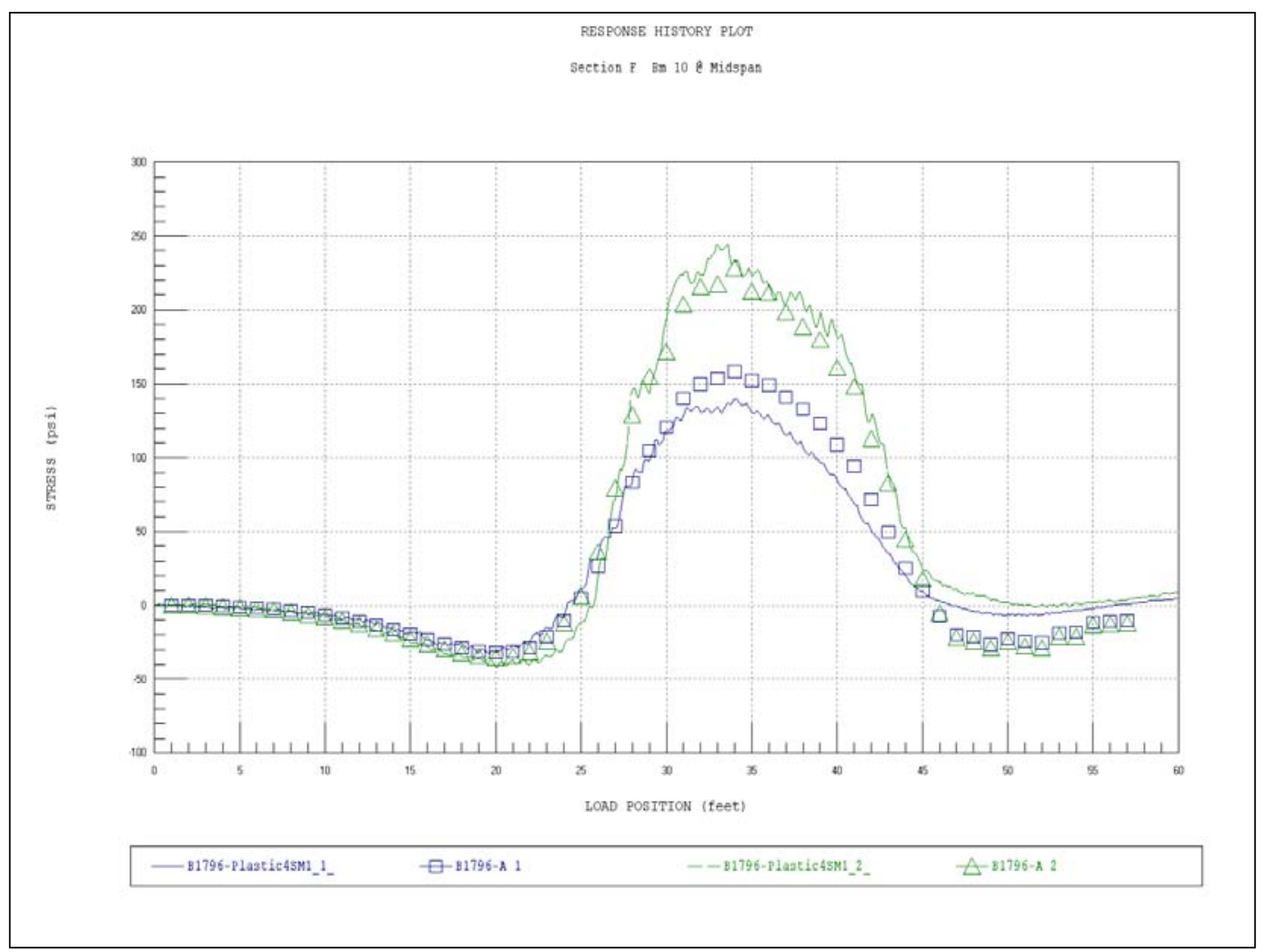

Figure A39. Strain comparison - Sec F - Beam 10. 


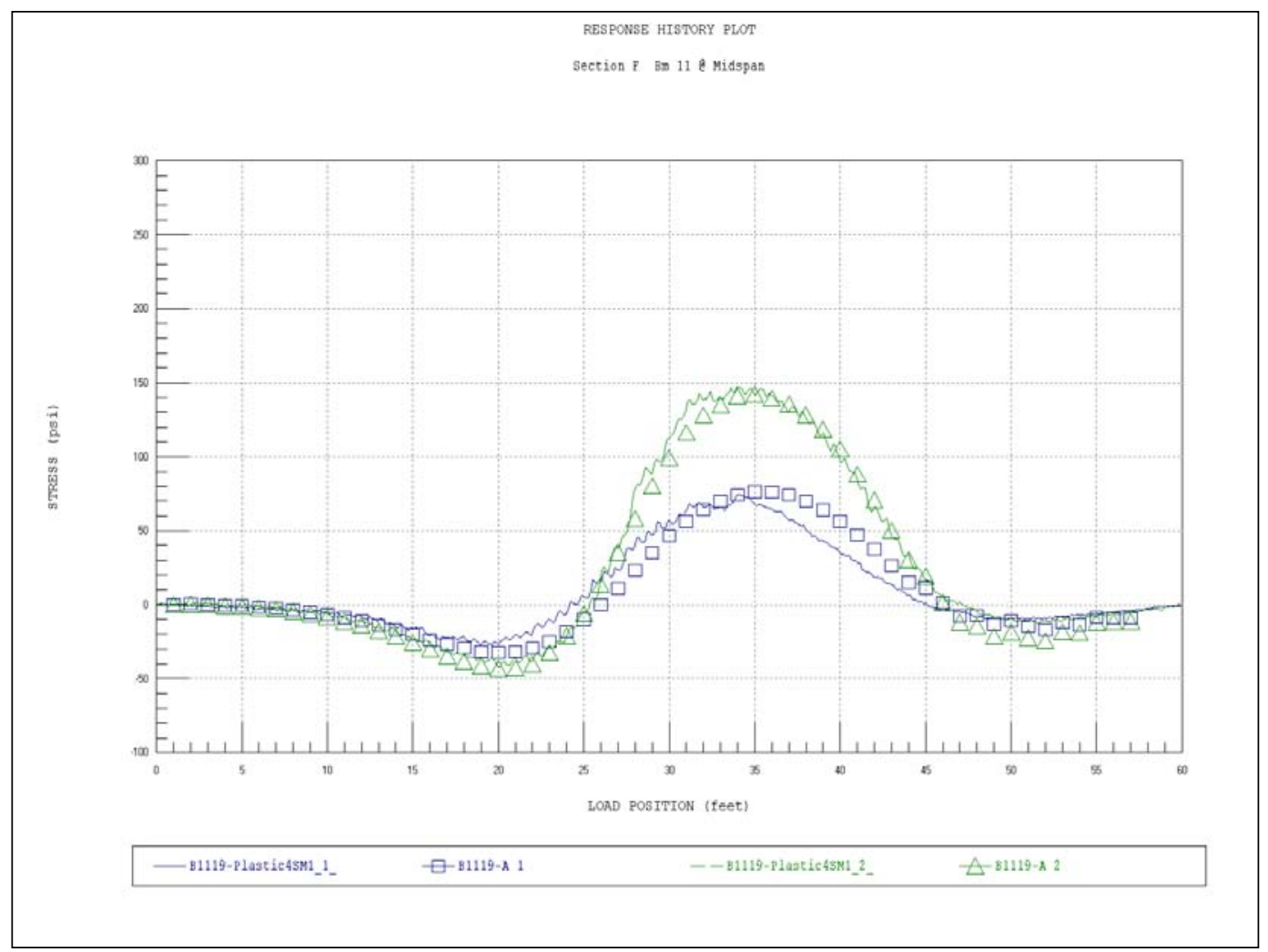

Figure A40. Strain comparison - Sec F - Beam 11.

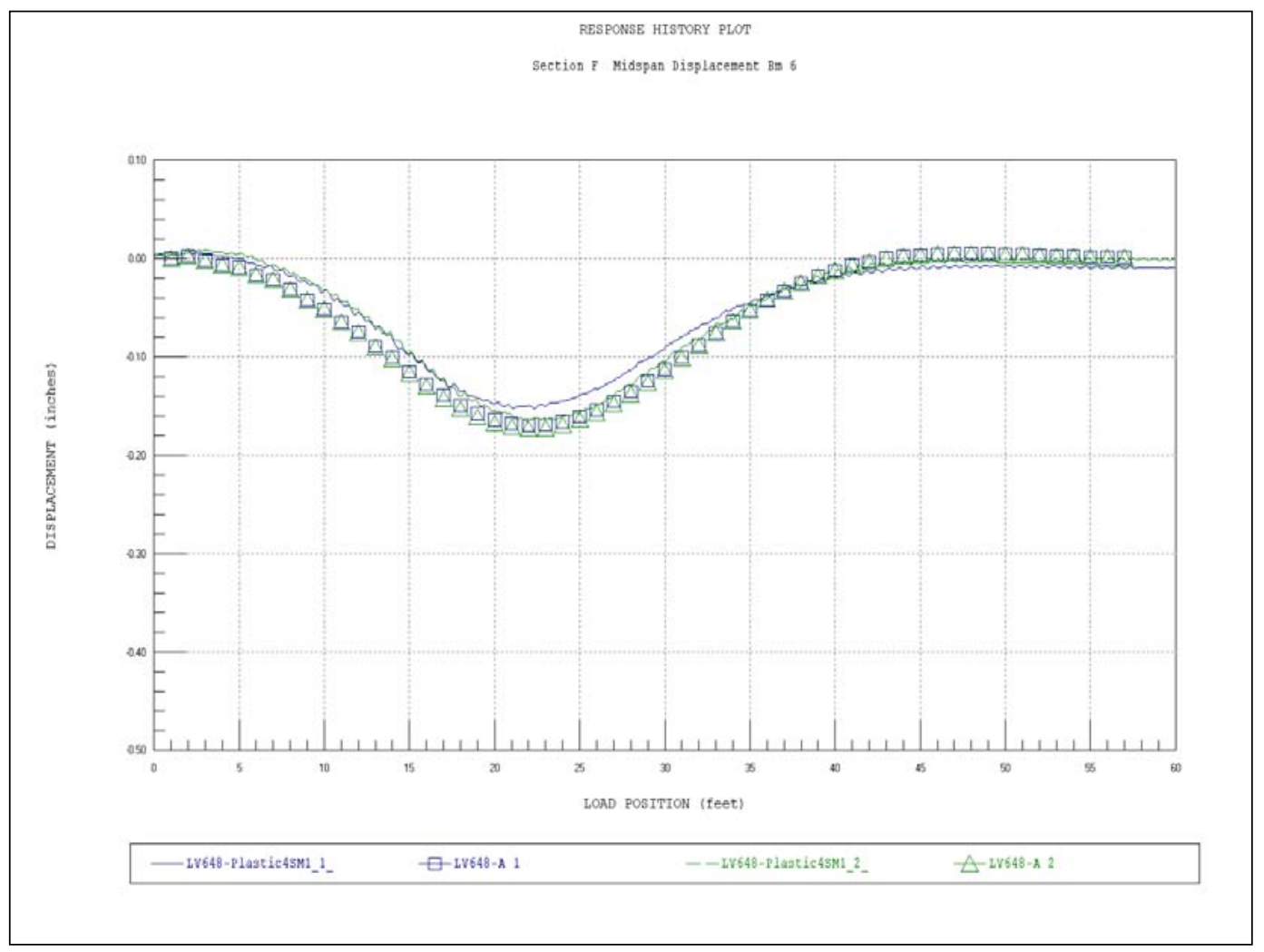

Figure A41. Displacement comparison - Mid-span - Beam 6. 


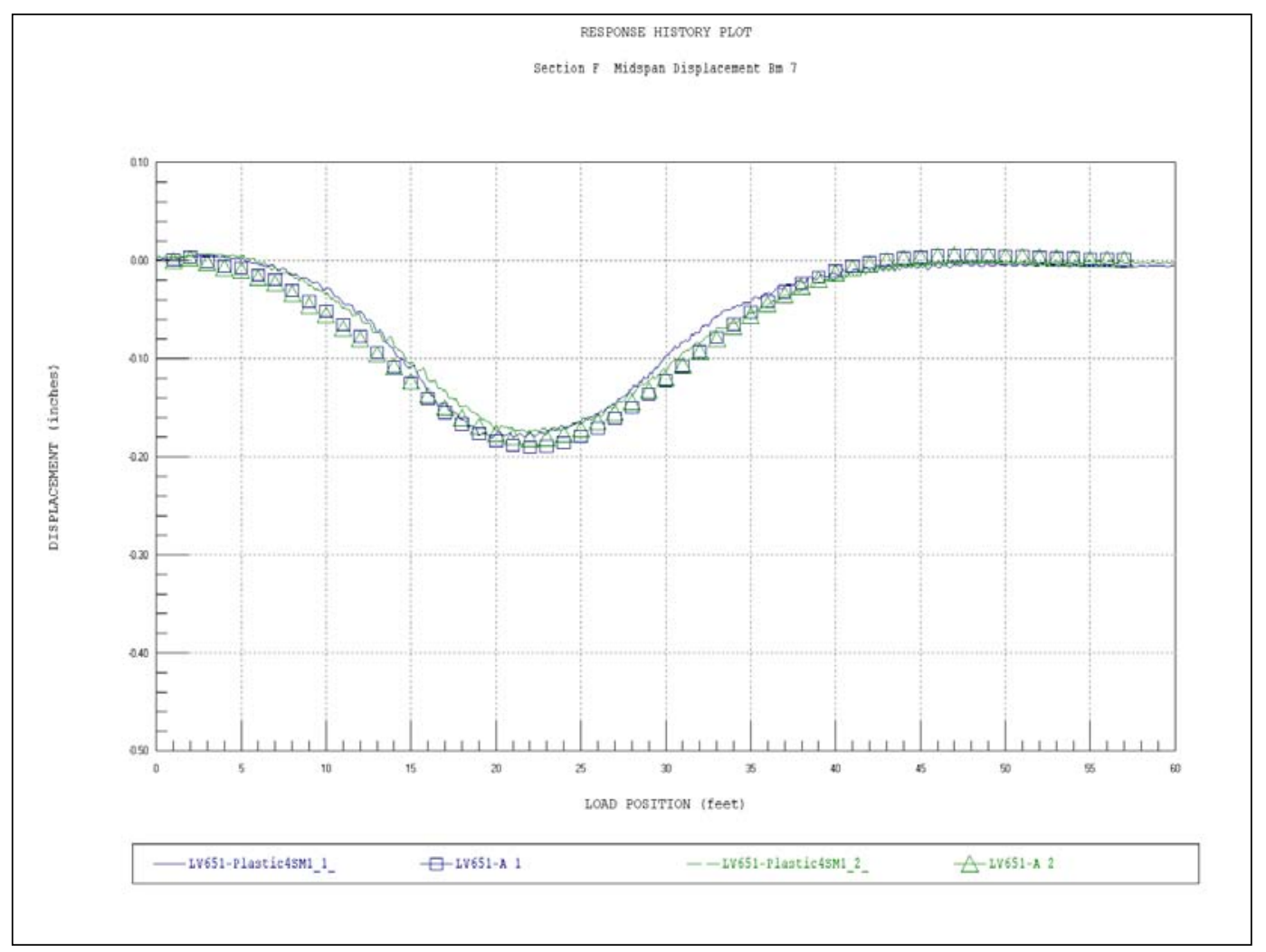

Figure A42. Displacement comparison - Mid-span - Beam 7.

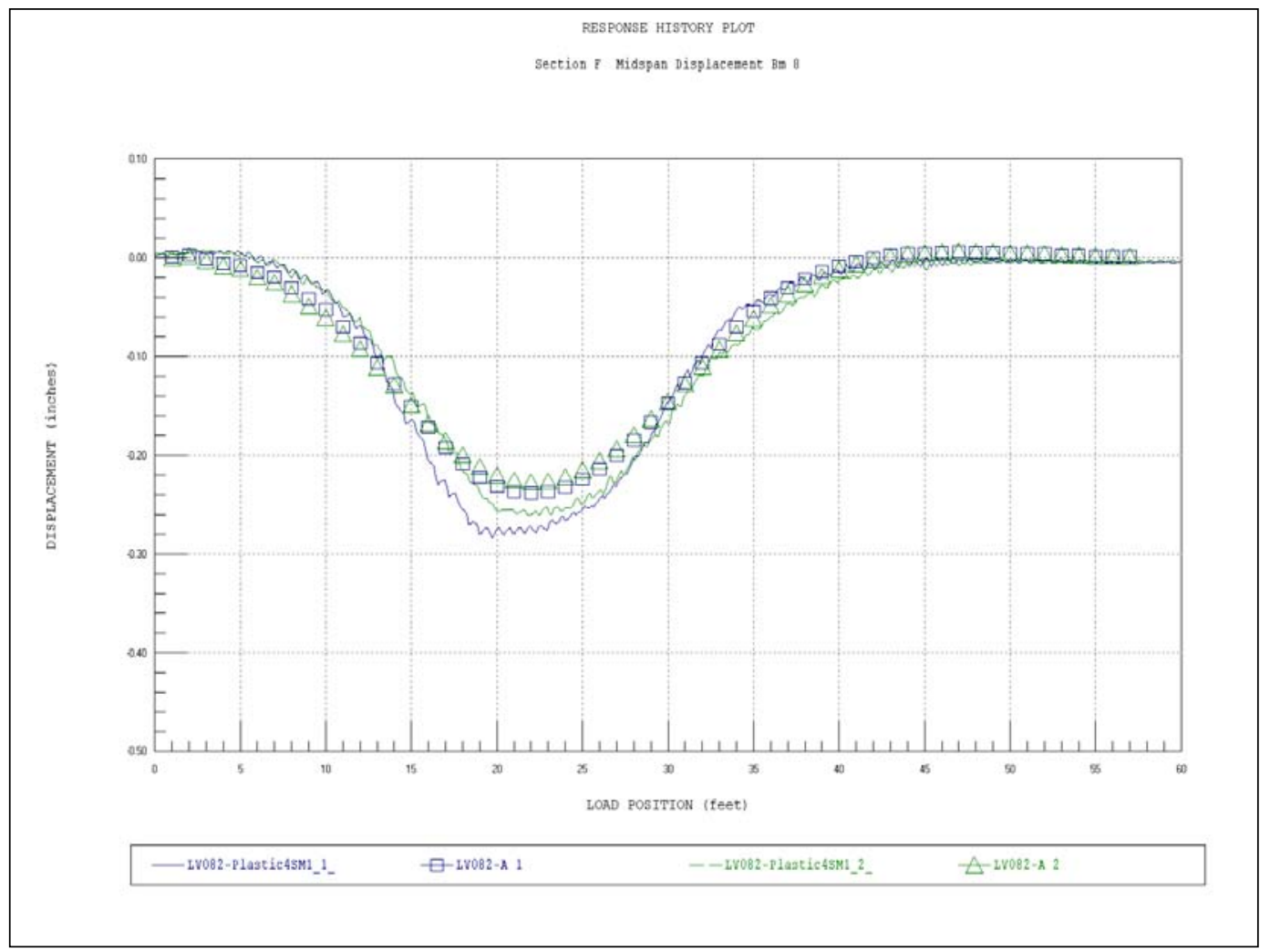

Figure A43. Displacement comparison - Mid-span - Beam 8. 


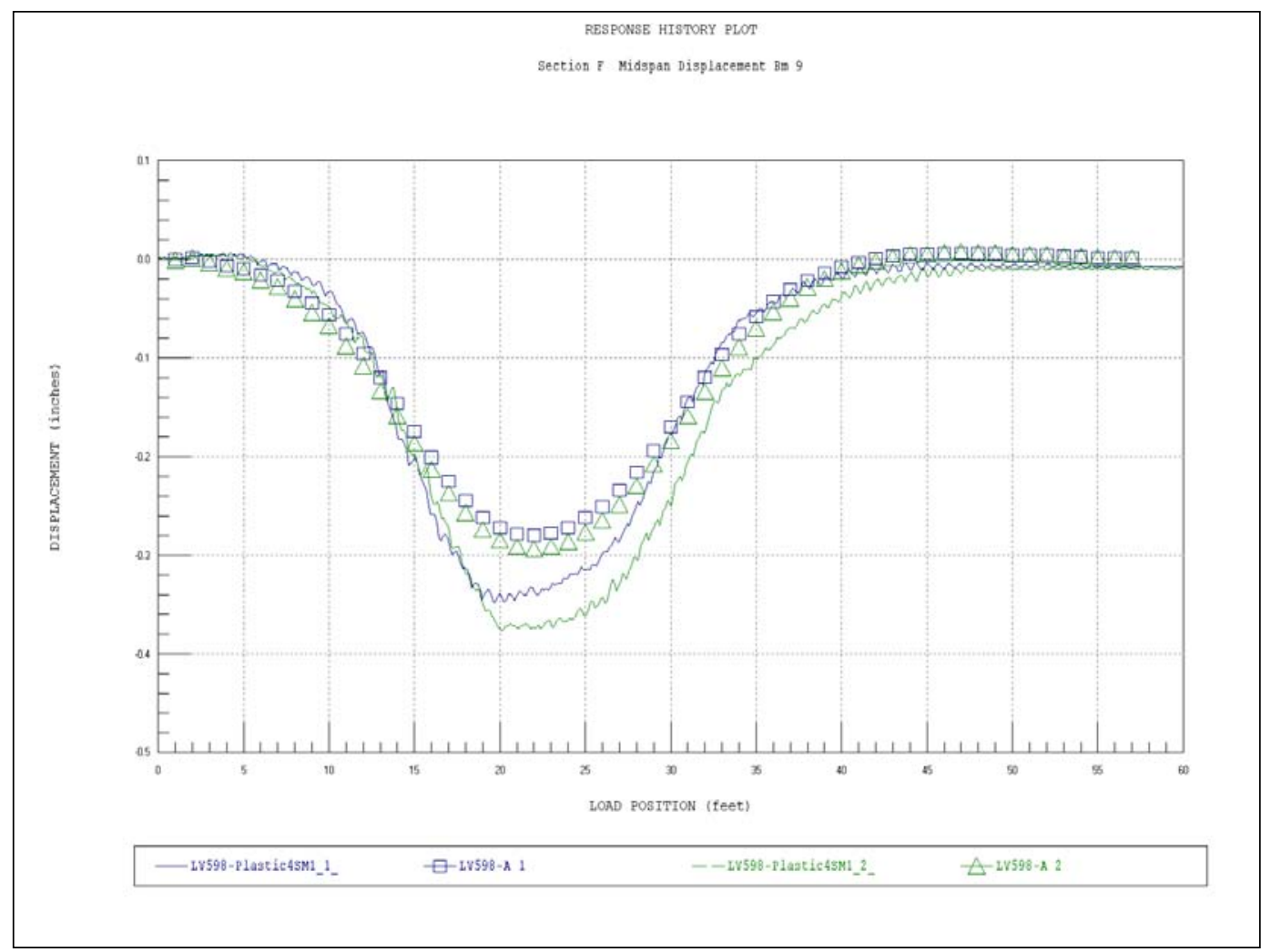

Figure A44. Displacement comparison - Mid-span - Beam 9.

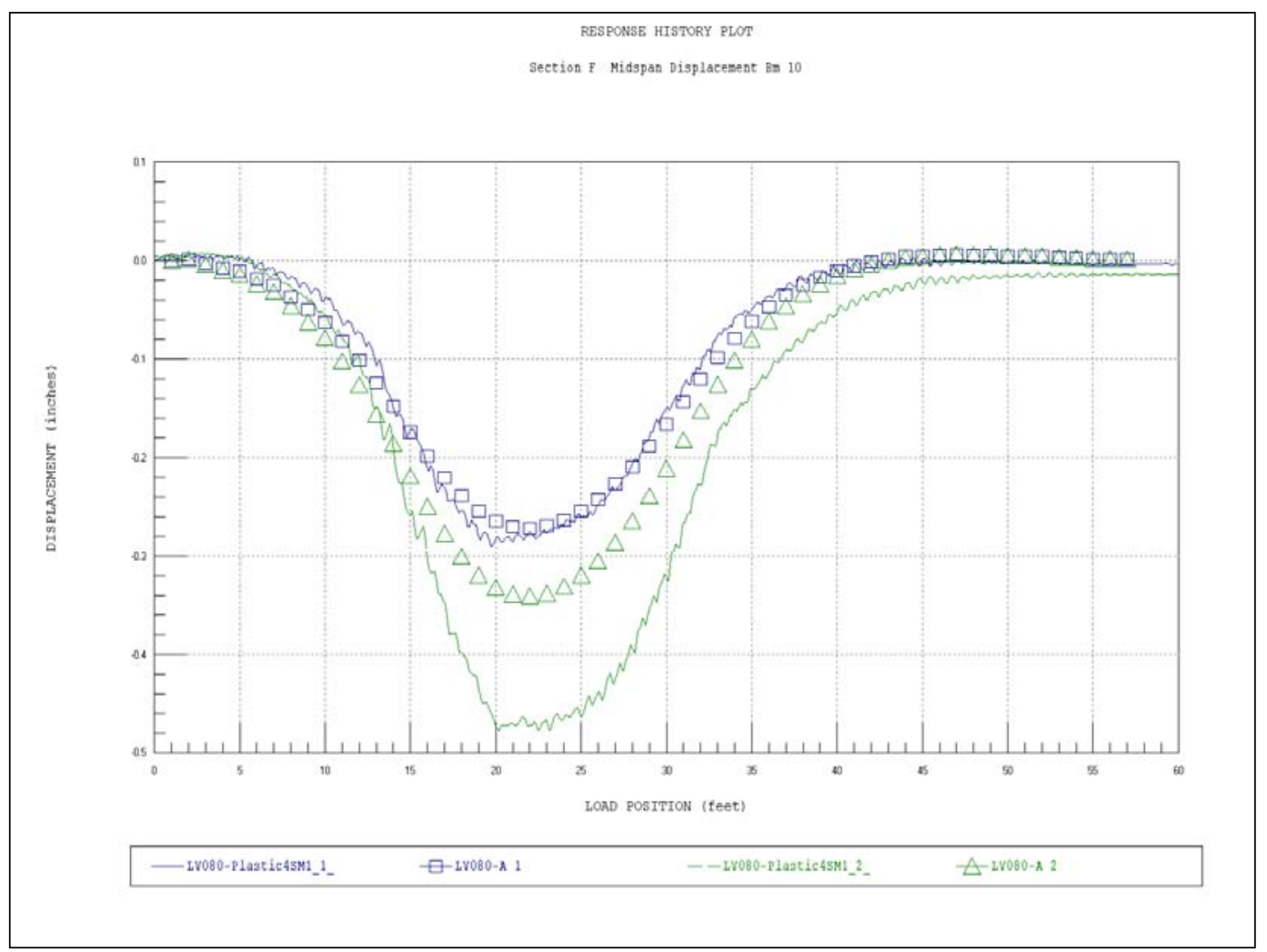

Figure A45. Displacement comparison - Mid-span - Beam 10. 


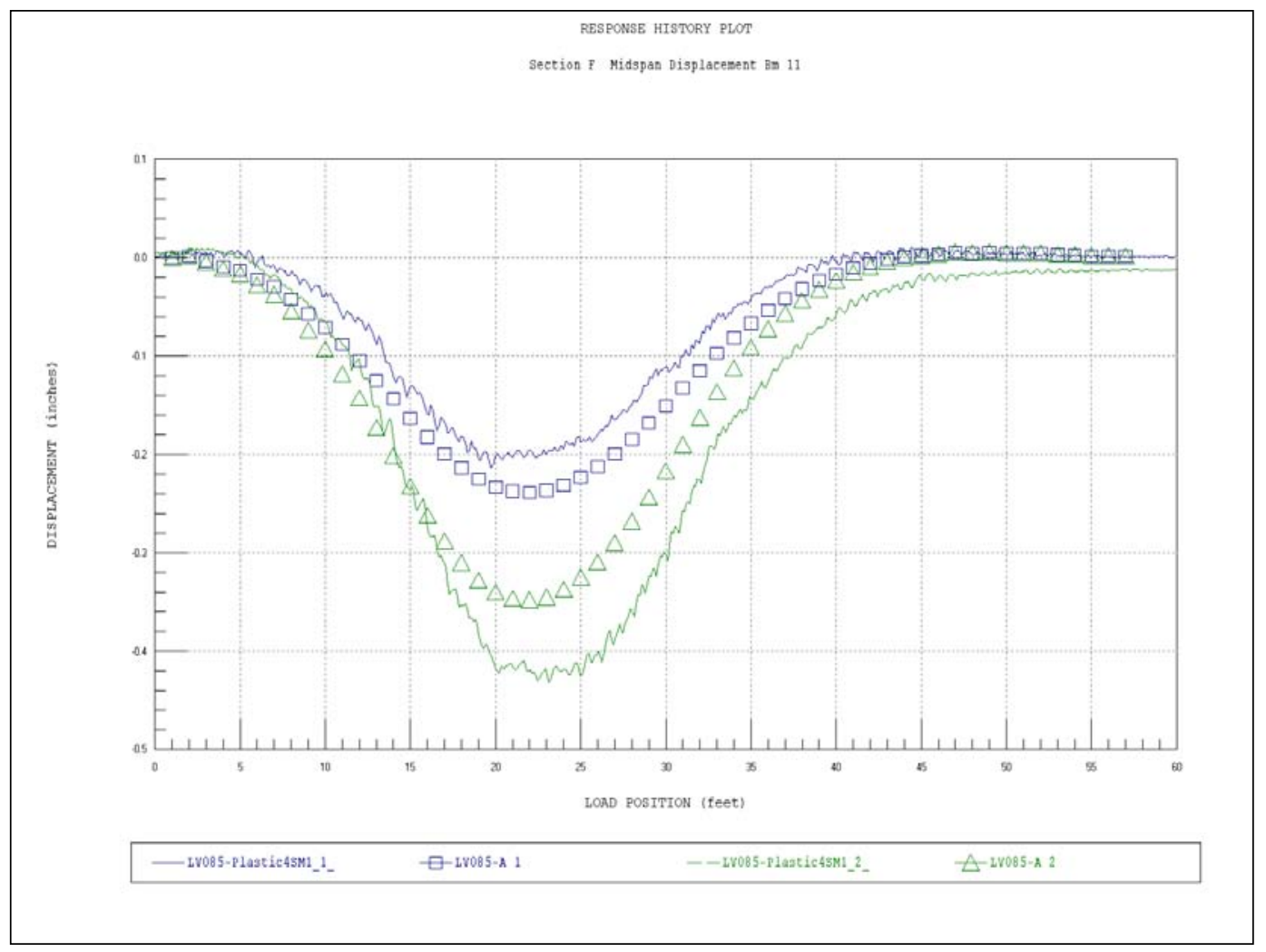

Figure A46. Displacement comparison - Mid-span - Beam 11.

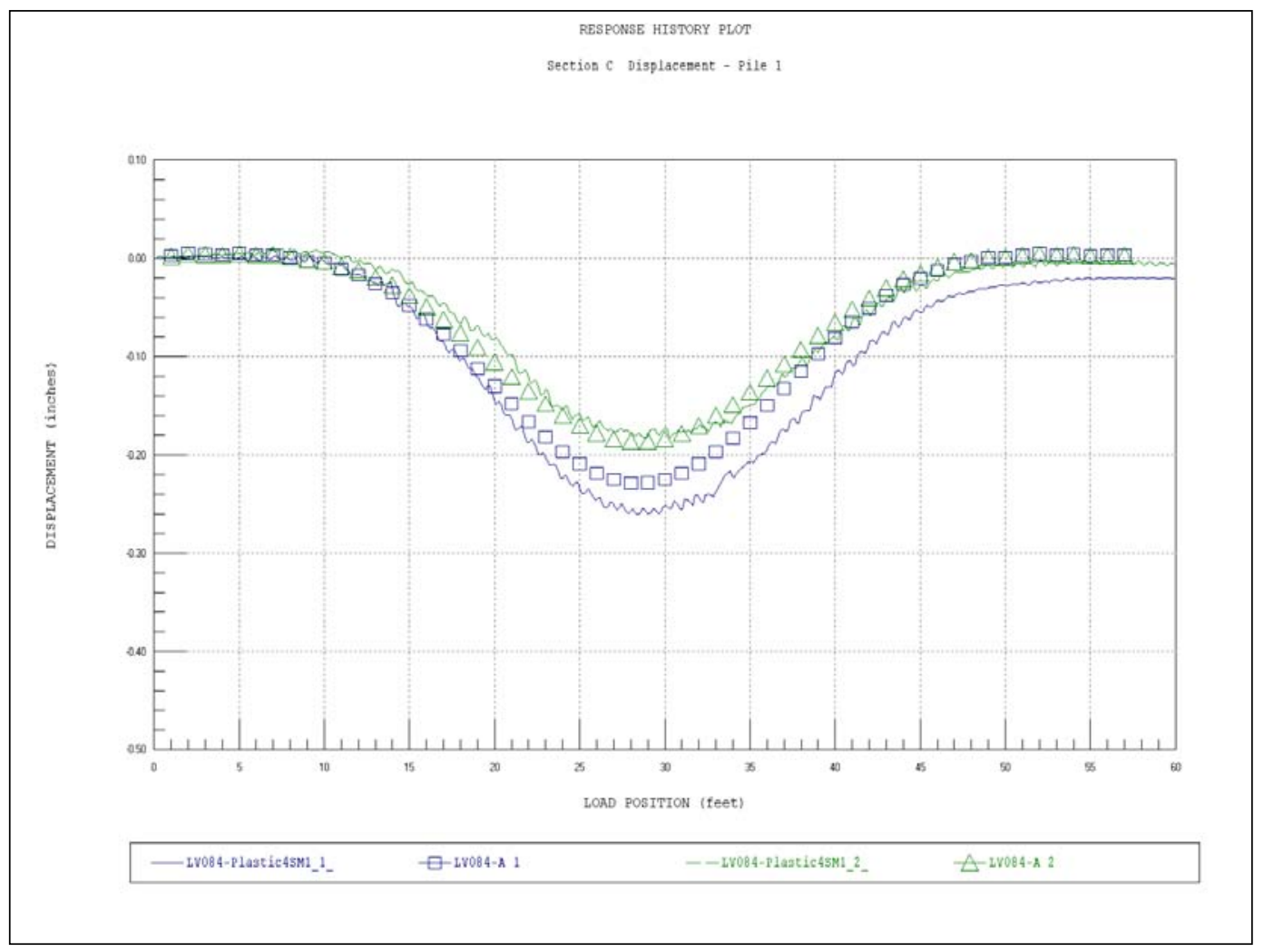

Figure A47. Displacement comparison - Pile 1. 


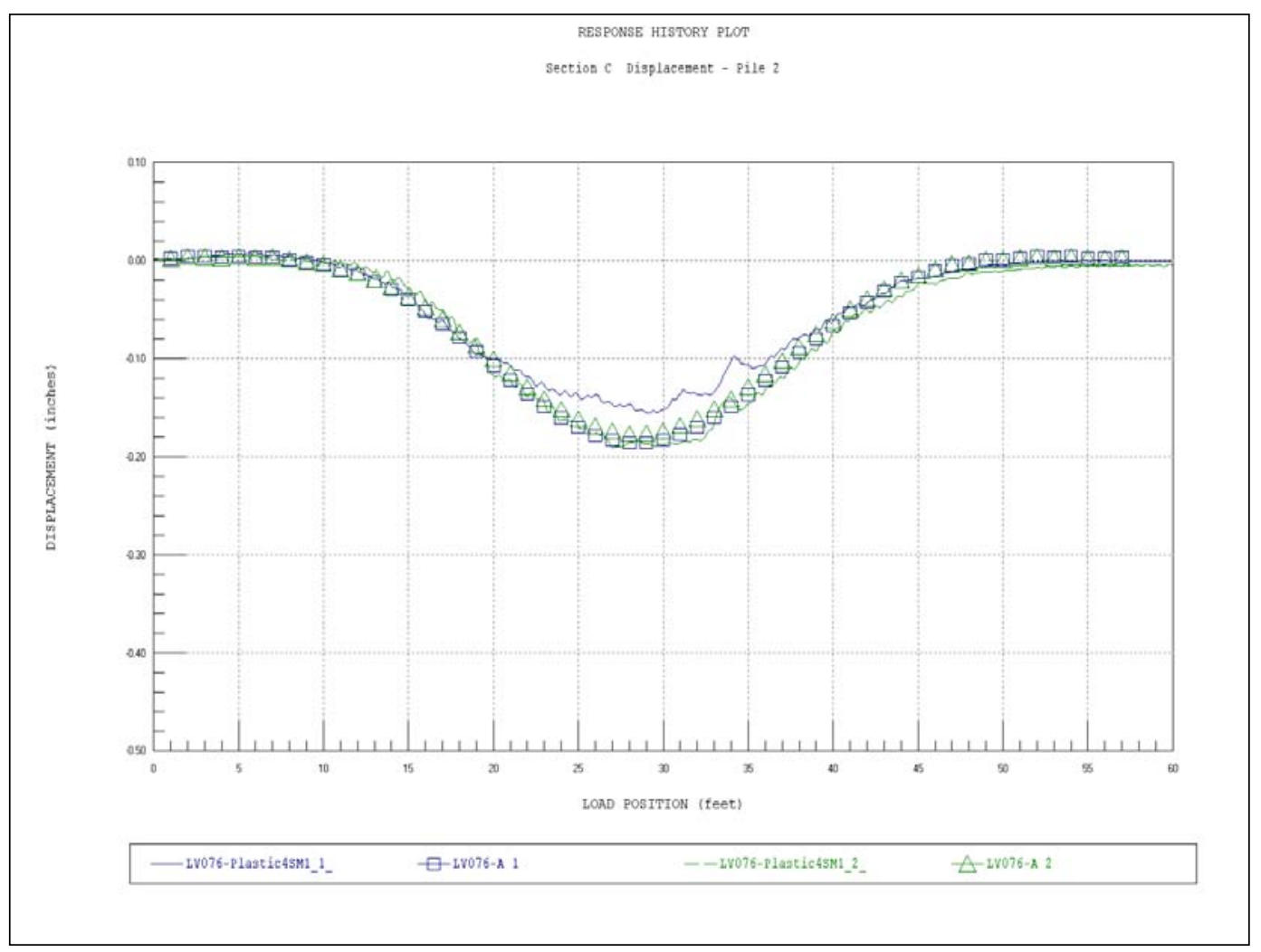

Figure A48. Displacement comparison - Pile 2.

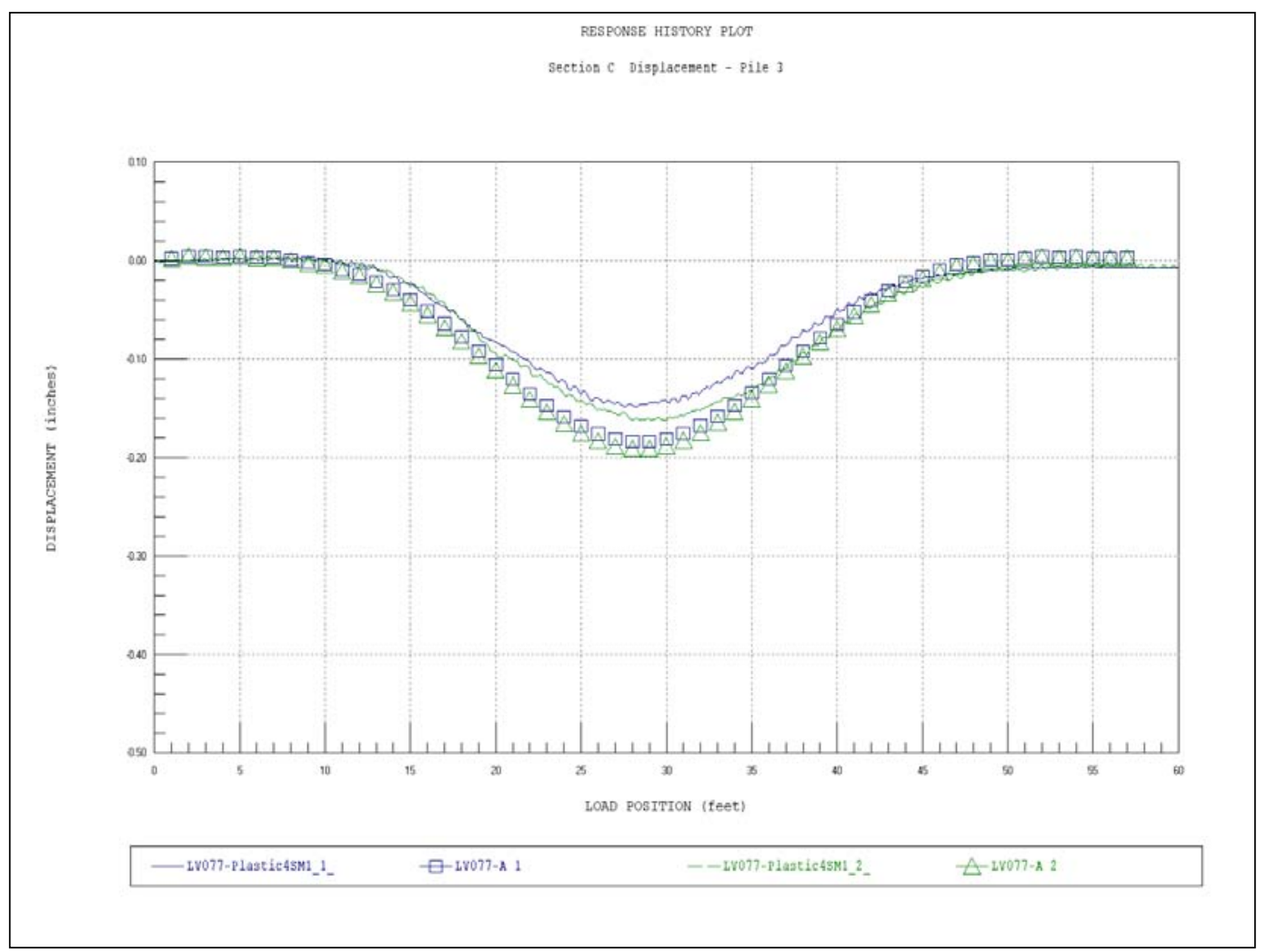

Figure A49. Displacement comparison - Pile 3. 


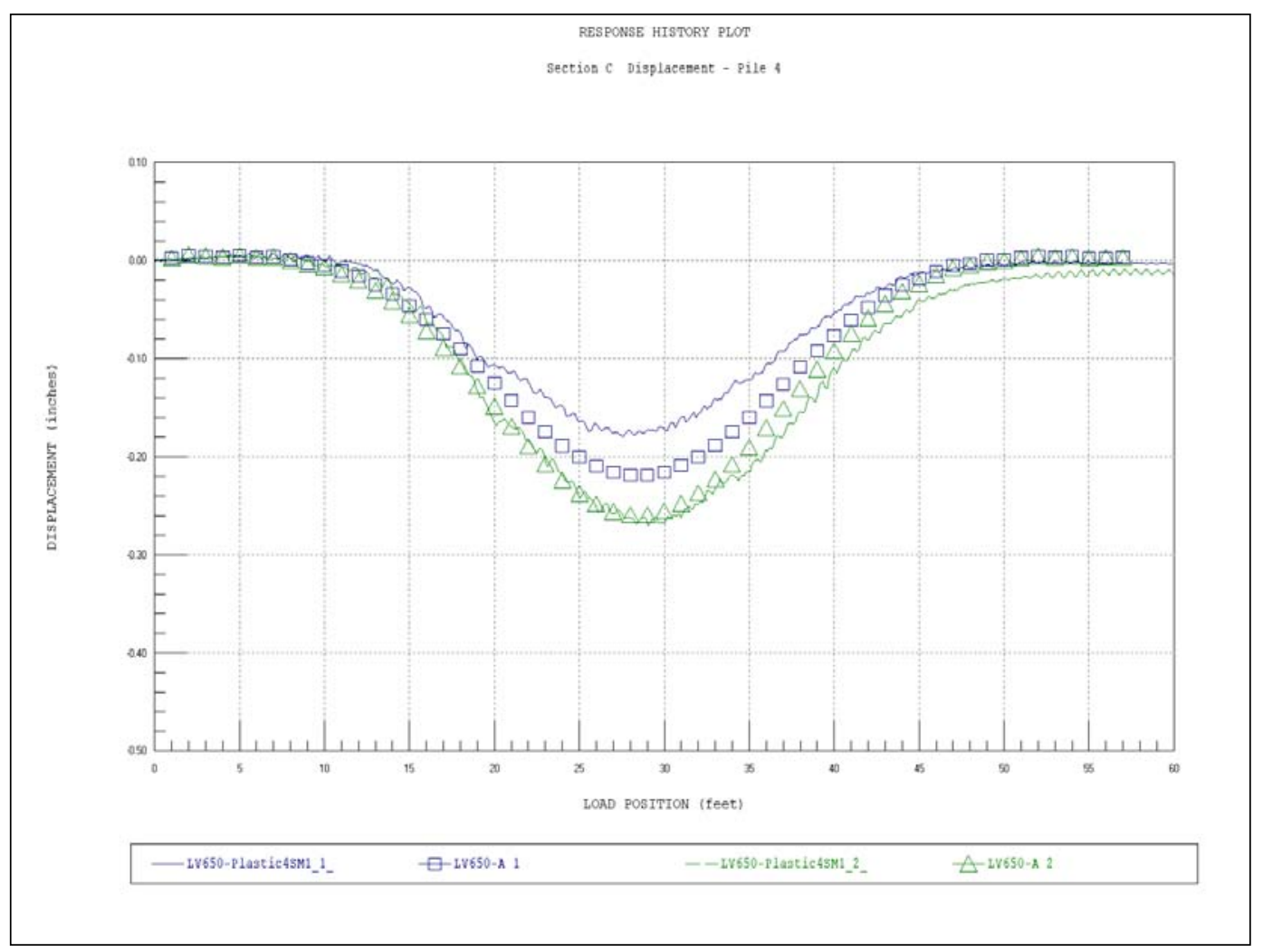

Figure A50. Displacement comparison - Pile 4. 


\section{Appendix B: Field Notes (Scanned)}

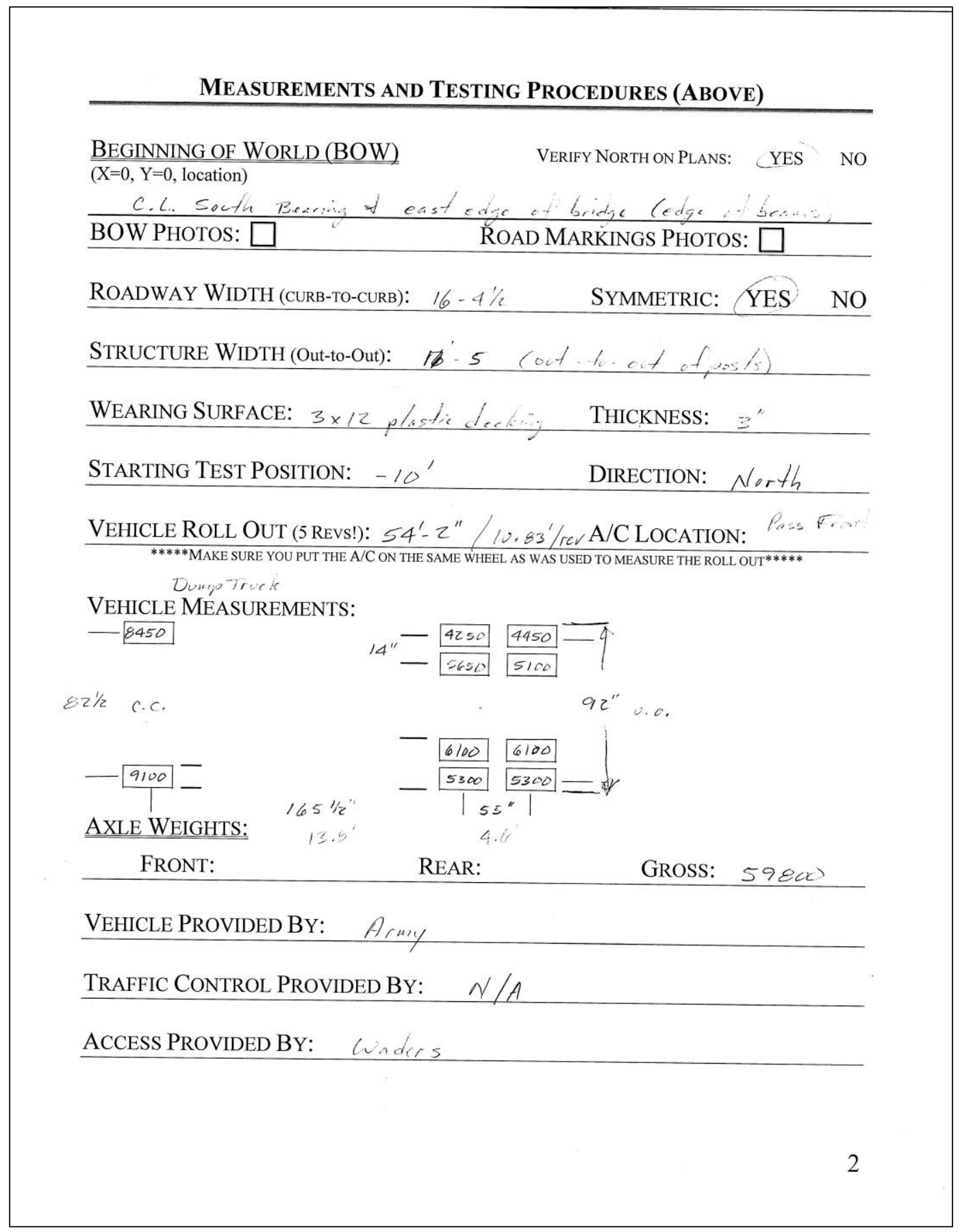

Figure B1. Field testing notes (Sheet 1 of 12). 


\begin{tabular}{c}
\hline Field Notes \& Testing CHecklist \\
(Typical Beam-Slab Bridges)
\end{tabular}

PROJECT NAME OR \#:

Ft Brs.

Iin Bune $4-5, \ldots$

FIELD NOTE TAKER: BC

DATE:

STRUCTURE NAME OR ID: Plasti: Bridge 4-spat

3 CAD DRAWINGS: 1-Gage ID, 1-Gage Dimensions, 1-General Dimensions.

MEASUREMENTS AND Gage InStallation Procedures (Below)

SPAN LENGTH(s):

SKEW: YES (NO) ANGLE:

BEAM SIZE: $16 \times 1 \varepsilon^{\prime \prime}$ I. Beres BEAM SPACING: diacet

DIAPHRAGM SPACING: $N / A) \quad$ SIZE:

BENT INFO: SIZE: pl.sti \# OF PILES: 4 PILE SPACING:

GAGE INSTALLATION: 1. Measure gage location \& write it on the beam.

2. Install gage and take picture(s) $\mathrm{w} /$ a reference point.

3. Write gage ID and dimensions on CAD notes.

4. Repeat for every gage location!!!

5. Take multiple pics from different angles.

SUPPORT CONDITIONS:

simplats on plastir beats applastie pits

ABUTMENT DETAILS - Elevation VieW $\square$ - PLAN View $\square$ REFERENCE BOW!!

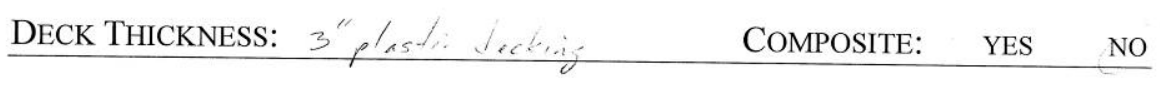

GENERAL OBSERVATIONS: thot thomid

Figure B1. (Sheet 2 of 12). 
LATERAL TESTING POSITIONS: (REFERENCED FROM BOW)

\begin{tabular}{ll} 
Y1: 3' pass side & Y2: 4'-10 pass side \\
\hline Y3: & Y4: \\
\hline Y5: & Y6:
\end{tabular}

LATERAL POSITIONS CHECKED BY:

TESTING OPERATIONS (WINSTS)

13 Eoxes 52 Claneds

VERIFY GAGE ID \& \# OF CHANNELS WITH WINSTS:

RUN WINSTS TO VERIFY RESPONSES:

WEATHER CONDITIONS \&

AMBIENT TEMPERATURE:

RUNNING THE FIELD TESTS

STS OPERATOR: BCC TRUCK OPERATOR: I G

CONTROLLED SEMI-STATIC TESTS

SAMPLE RATE: $\quad 40 \mathrm{~Hz}$

GAIN: 1000 acetcols

\begin{tabular}{|c|c|c|}
\hline FILE NAME & \begin{tabular}{|l|} 
LATERAL \\
POSITION \\
\end{tabular} & COMMENTS \\
\hline Plastic $45-1$ & y/ & 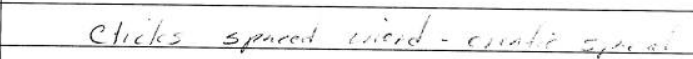 \\
\hline$-z$ & Y/ & Erod \\
\hline-3 & $y z$ & Good atite Jeow o..., ter crum \\
\hline-4 & $y z$ & Good \\
\hline-5 & $y_{3}$ & Good Verk $\operatorname{sen}^{4} \quad \ldots \quad t$ \\
\hline$-\sigma$ & $y 3$ & C... \\
\hline-1 & $1 / 3$ & 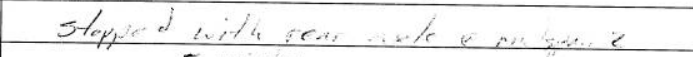 \\
\hline-2 & $-x-2$ & 5. maxtos \\
\hline & & \\
\hline & & \\
\hline & & \\
\hline & & \\
\hline
\end{tabular}

Figure B1. (Sheet 3 of 12). 


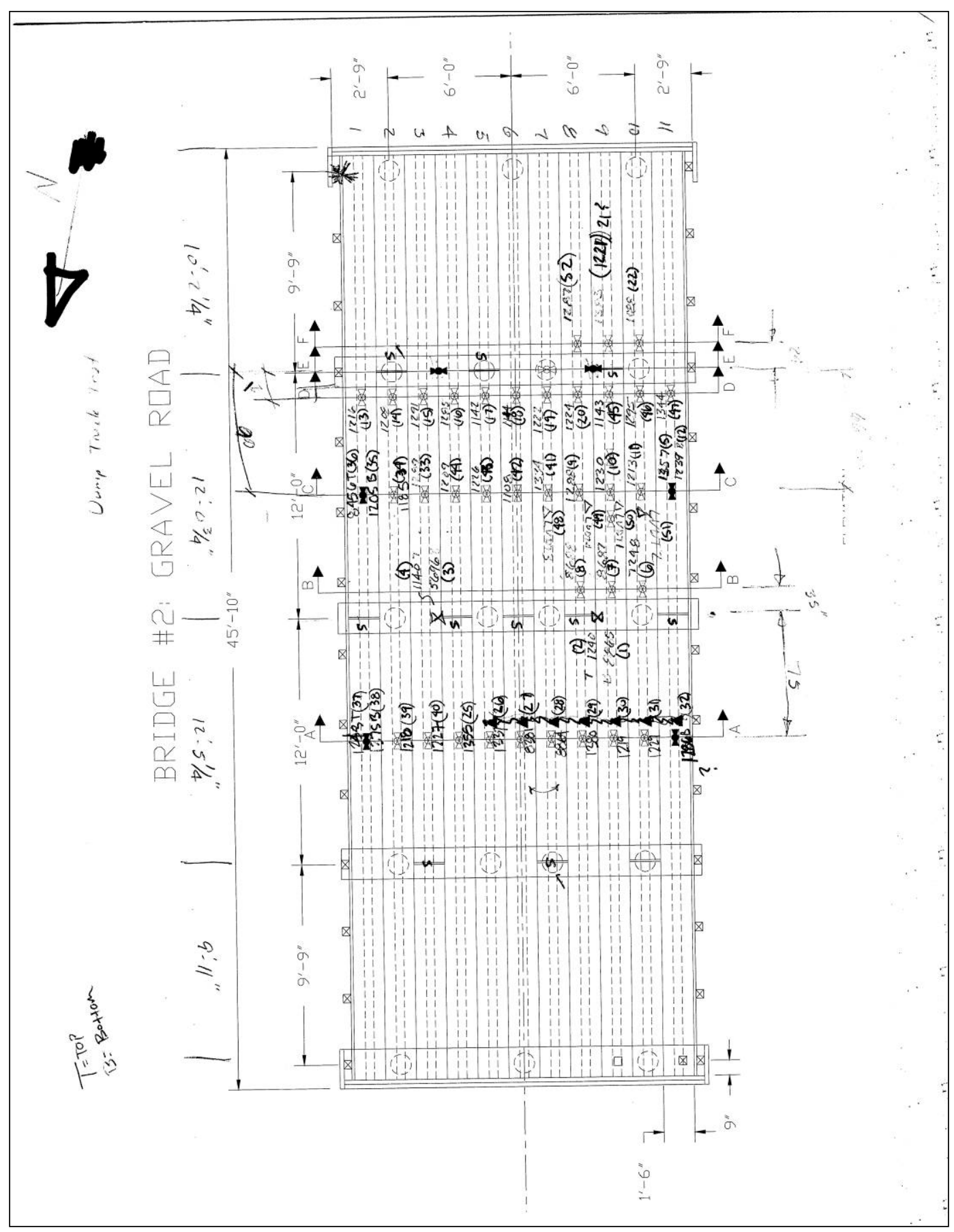

Figure B1. (Sheet 4 of 12). 


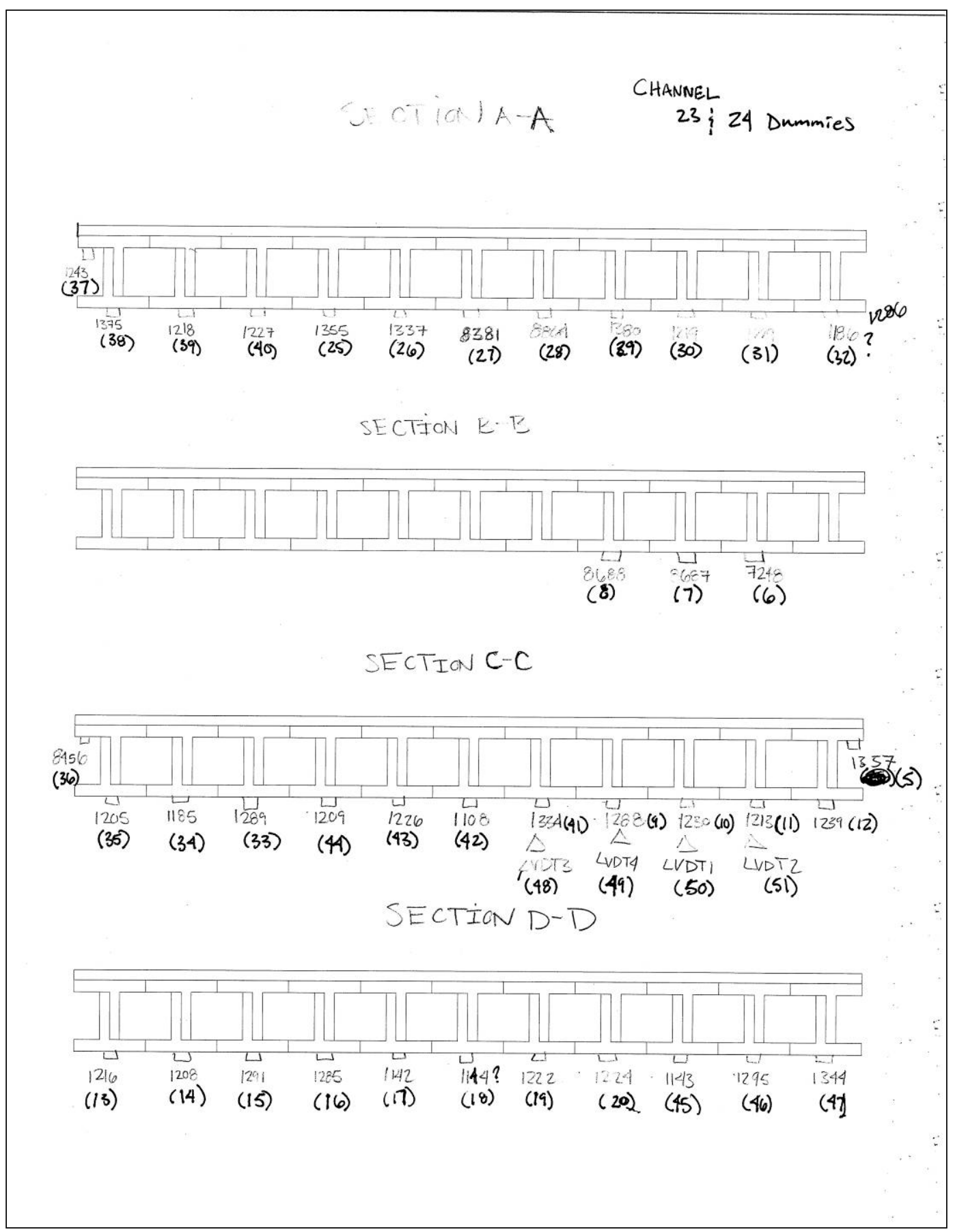

Figure B1. (Sheet 5 of 12). 


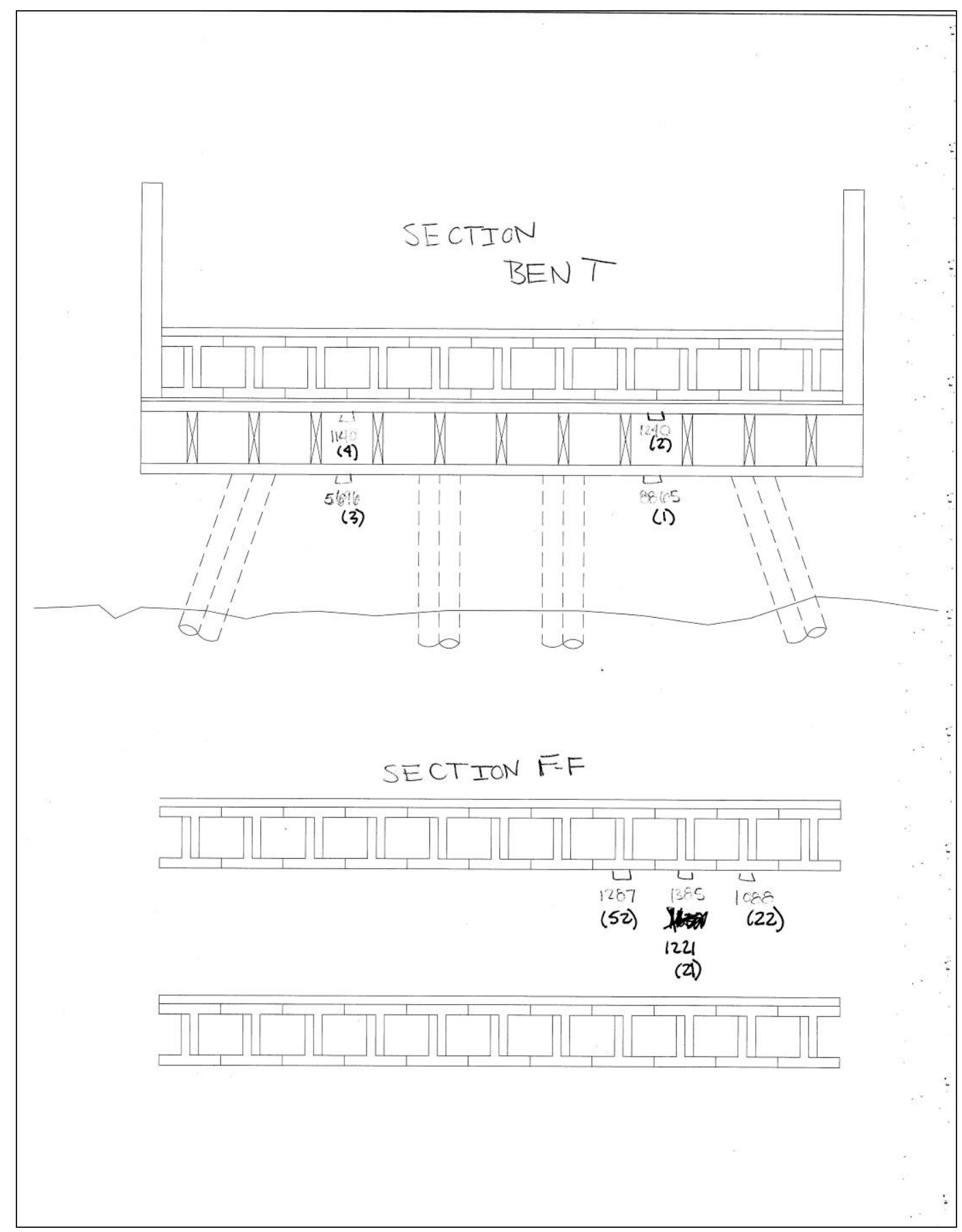

Figure B1. (Sheet 6 of 12). 


\section{FIELD NOTES \& TESTING CHECKLIST}

(TYPICAL BEAM-SLAB BRIDGES)

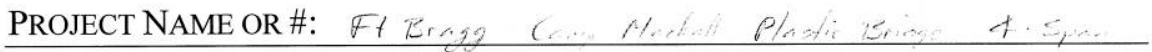

FIELD NOTE TAKER: $\angle B A C$

DATE:

STRUCTURE NAME OR ID:

3 CAD DRAWINGS: 1-Gage ID, 1-Gage Dimensions, 1-General Dimensions.

MEASUREMENTS AND Gage InStallation PROCEDURES (BELOW)

SPAN LENGTH(S):

$9 \cdot 16$

SKEW: YES NO ANGLE:

BEAM SIZE: $1 \delta^{\prime \prime} \times 1 \varepsilon^{\prime \prime R P L}$ T. REA BEAM SPANG:

DIAPHRAGM SPACING:

SIZE:

BENT INFO: SIZE: \# OF PILES: $\quad+$ PILE SPACING:

GAGE INSTALLATION: 1. Measure gage location \& write it on the beam.

2. Install gage and take picture(s) w/ a reference point.

3. Write gage ID and dimensions on CAD notes.

4. Repeat for every gage location!!!

5. Take multiple pics from different angles.

SUPPORT CONDITIONS: plastic I beaws on fur at pilos

ABUTMENT DETAILS - ElEVATION VIEW $\square$ - PLAN View $\square$ REFERENCE BOW!!

DECK THICKNESS: $<x / 2 \times$, dholi, ded, COMPOSITE: YES CN

GENERAL OBSERVATIONS:

?:

Figure B1. (Sheet 7 of 12). 


\section{Measurements and Testing Procedures (ABove)}

BEGINNING OF WORLD (BOW) VERIFY NORTH ON PLANS: YES NO $(\mathrm{X}=0, \mathrm{Y}=0$, location)

BOW PHOTOS: $\square$

ROADWAY WIDTH (CURB-TO-CURB): $15 \cdot 6 \quad$ SYMMETRIC: YES NO

STRUCTURE WIDTH (Out-to-Out):

WEARING SURFACE:

THICKNESS:

STARTING TEST Position: -15 DIRECTION: Nothe

VeHICLE Roll OUT 19 Revs!): $69-11$ A/C LOCATION:

A/C LOCATION: " *****MAKE SURE YOU PUT THE A/C ON THE SAME WHEEL AS WAS USED TO MEASURE THE ROLL OUT ${ }^{* * * * *}$

VEHICLE MEASUREMENTS:
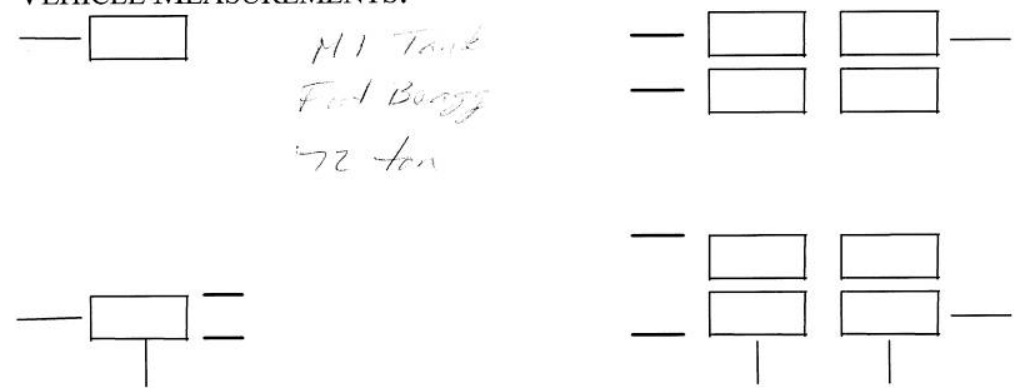

AXLE WEIGHTS:

FRONT:

REAR:

GROSS:

VEHICLE PROVIDED BY:

TRAFFiC CONTROL PROVIDED BY:

ACCESS PROVIDED BY:

Figure B1. (Sheet 8 of 12). 
LATERAL TESTING POSITIONS: (REFERENCED FROM BOW)

\begin{tabular}{ll} 
Y1: $3^{\prime}$ & Y2: 13: \\
\hline Y3: & Y4: \\
\hline Y5: & Y6: \\
\hline
\end{tabular}

LATERAL POSITIONS CHECKED BY:

\section{TESTING OPERATIONS (WINSTS)}

VERIFY GAGE ID \& \# OF CHANNELS WITH WINSTS:

RUN WINSTS TO VERIFY RESPONSES:

WEATHER CONDITIONS \& AMBIENT TEMPERATURE:

+ disnd tig 140

RUNNING THE FIELD TESTS

STS OPERATOR:

TRUCK OPERATOR:

\section{CONTROLLED SEMI-STATIC TESTS}

SAMPLE RATE: 40

GAIN: $\quad 32$

\begin{tabular}{|c|c|c|}
\hline FILE NAME & $\begin{array}{l}\text { LATERAL } \\
\text { POSITION }\end{array}$ & / Didu't ha opsen \\
\hline$T+11=-1$ & $\mathrm{YH}$ & Ist crosstad opet \\
\hline Plasic $4541-1-1$ & Y1 & Good \\
\hline Plactic $45 \pi:-1-2$ & Y1 & Reverse, Good \\
\hline Plastec $45: 1-1,3$ & $y$ & Good. \\
\hline Pl..., $45 N-1-4$ & Y1 & Reverse. Stoped for Stalic test \\
\hline & & 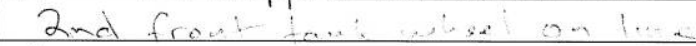 \\
\hline & & $\tan k$ ou bridae for $\sim 5 \mathrm{~m}: \mathrm{A}$ \\
\hline Plastic $49 M 1-2-1$ & 42 & Good. \\
\hline Tastic-15M-2-2 & 12 & Good. \\
\hline & & \\
\hline & & \\
\hline
\end{tabular}

Figure B1. (Sheet 9 of 12). 
HIGH-SPEED TEST(S) OR ADDITIONAL TESTS

SAMPLE RATE:

\begin{tabular}{|l|c|l|l|}
\hline FILE NAME & $\begin{array}{l}\text { LATERAL } \\
\text { POSITION }\end{array}$ & SPEED & COMMENTS \\
\hline & y/ & & \\
\hline & & & \\
\hline & & & \\
\hline & & & \\
\hline & & & \\
\hline & & & \\
\hline & & & \\
\hline & & & \\
\hline & & & \\
\hline
\end{tabular}

BACKUP DATA FIlEs: $\quad 2$ Flash: $\square \quad$ 2 PC's: $\square \quad$ EMAIL: $\square$

TAKE PICTURES OF NOTES: $\square \quad$ BACKUP PICS: $\square$

ALl NoTES CHECKED BY:

ANY ADDITIONAL TESTING COMMENTS:

\begin{tabular}{l}
\hline Lotr af ratiof \\
\hline \\
\hline \\
\hline \\
\hline
\end{tabular}

Figure B1. (Sheet 10 of 12). 


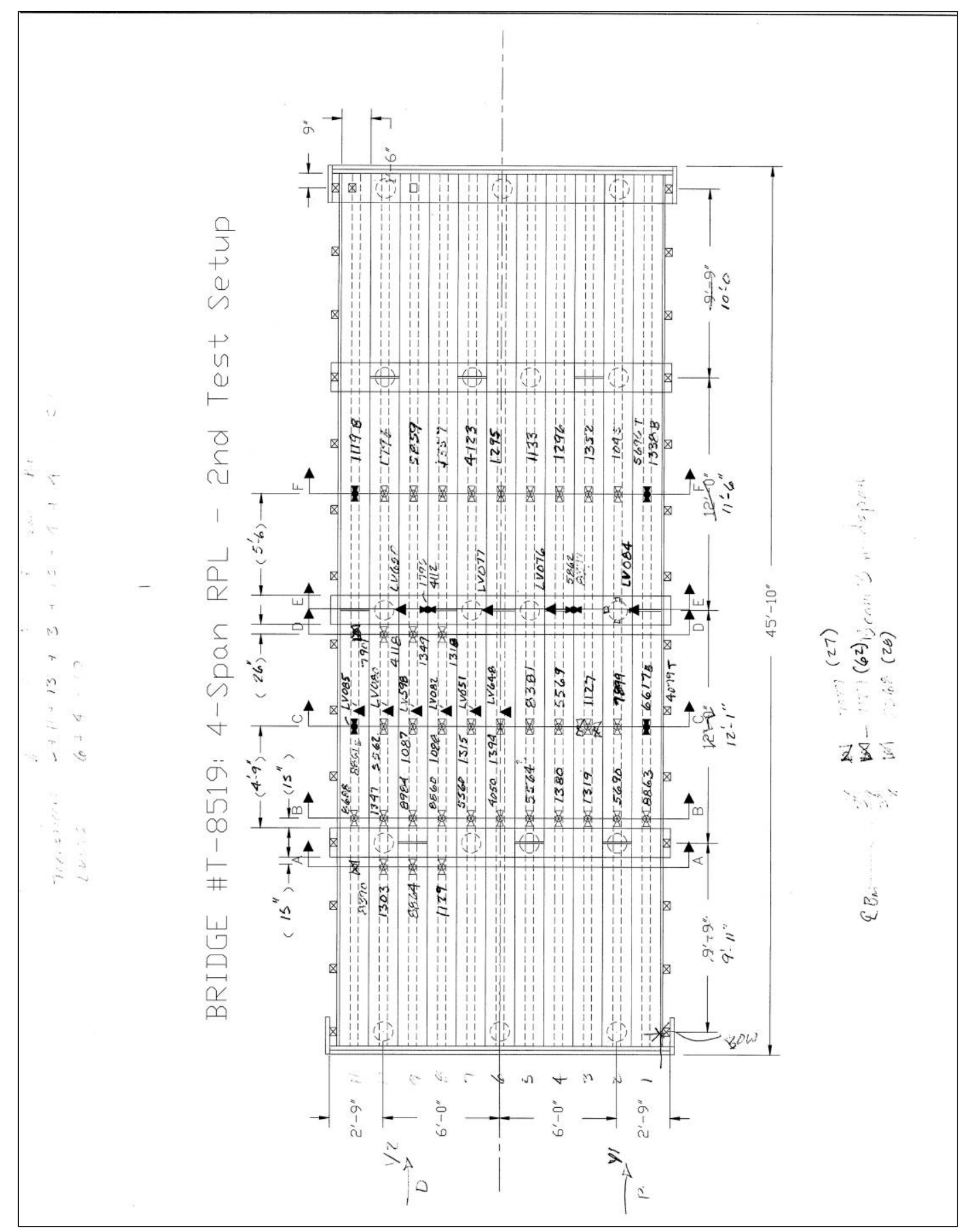

Figure B1. (Sheet 11 of 12). 


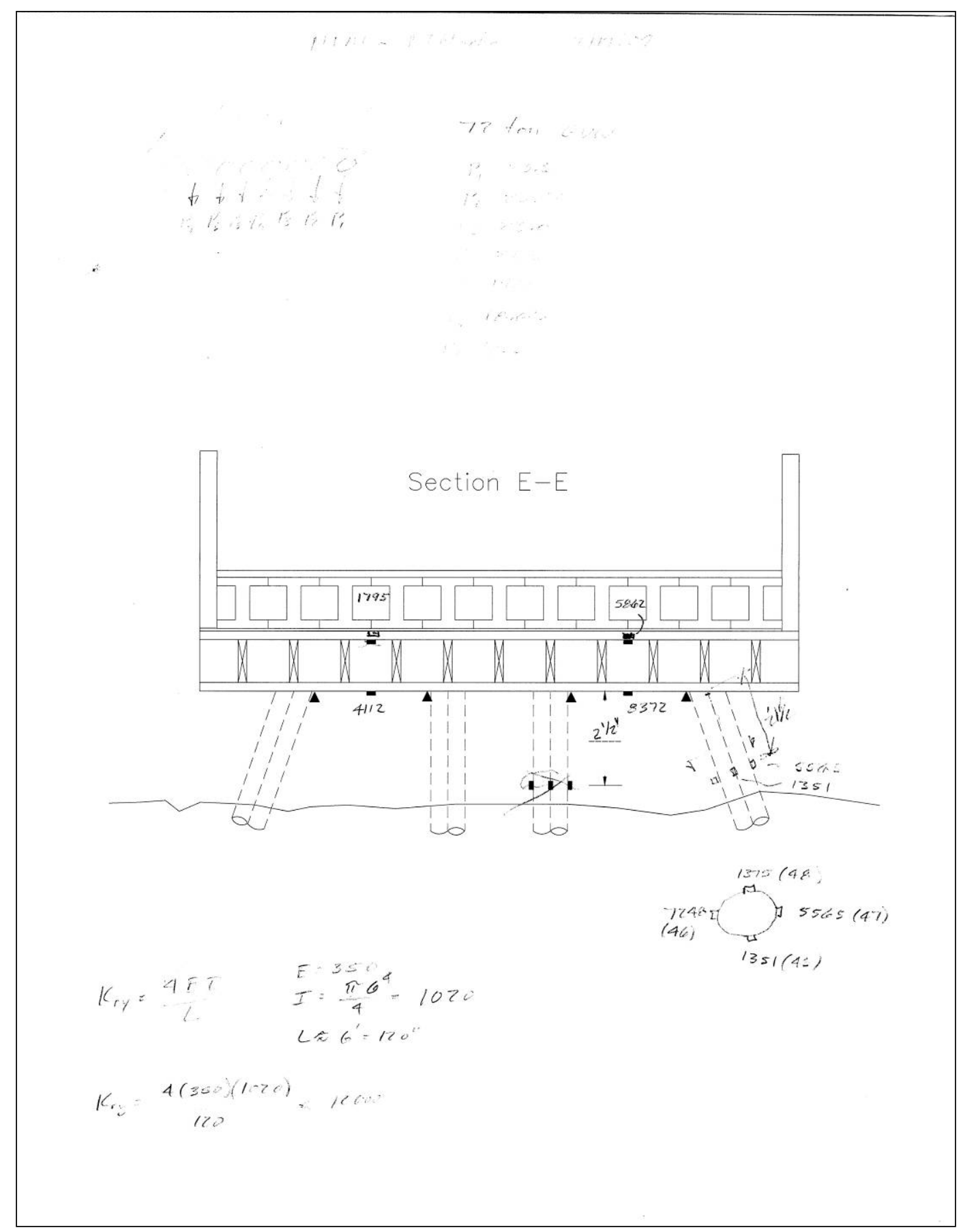

Figure B1. (Sheet 12 of 12). 


\section{Appendix C: BDI Field Testing Procedures}

\section{Background}

The motivation for developing a relatively easy-to-implement field-testing system was to allow short- and medium-span bridges to be tested on a routine basis. Original development of the hardware was started in 1988 at the University of Colorado under a contract with the Pennsylvania Department of Transportation (PennDOT). Subsequent to that project, the integrated technique was refined on another study funded by the Federal Highway Administration (FHWA) in which 35 bridges located on the Interstate system throughout the country were tested and evaluated. Further refinement has been implemented over the years through testing and evaluating hundreds of bridges, lock gates, and other structures.

\section{Structural testing hardware}

The real key to being able to complete the field-testing quickly is the use of strain transducers (rather than standard foil strain gages) that can be attached to the structural members in just a few minutes. These sensors were originally developed for monitoring dynamic strains on foundation piles during the driving process. They have been adapted for use in structural testing through special modifications, have very high accuracy, and are periodically recalibrated to National Institute of Standards and Technology (NIST) standards. Please refer to Appendix D for specifications on the Bridge Diagnostics, Inc. (BDI), strain transducers.

In addition to the strain sensors, the data acquisition hardware has been designed specifically for structural live-load testing, which means it is extremely easy to use in the field. Please see Appendix D for specifications on the BDI Structural Testing System. Briefly, some of the features include military-style connections for quick assembly and self-identifying sensors that dramatically reduce bookkeeping efforts. The structural testing system (WinSTS) software has been written to allow easy hardware configuration and data recording operation. Other enhancements include the BDI AutoClicker, which is an automatic load position indicator that is mounted directly on the vehicle. As the test truck crosses the structure along the preset path, a communication radio sends a signal to the STS that receives it and puts a mark in the data. This mark allows the field 
strains to be compared to analytical strains as a function of vehicle position, not only as a function of time. Refer to Appendix D for the AutoClicker specifications. The end result of using all of the abovedescribed components is a system that can be used by people other than computer experts or electrical engineers. Typical testing times with the STS are usually anywhere from 20 to 60 channel tests being completed in one day, depending on access and other field conditions.

The following general directions outline how to run a typical diagnostic load test on a short- to medium-span highway bridge up to about $200 \mathrm{ft}$ $(60 \mathrm{~m})$ in length. With only minor modifications, these directions can be applied to railroad bridges (a locomotive rather than a truck is used for the load vehicle), lock gates (the water level is monitored in the lock chamber), amusement park rides (the position of the ride vehicle is tracked) and other structures in which the live load can be applied easily. The basic scenario is to first instrument the structure with the required number of sensors, run a series of tests, and then remove all the sensors. These procedures can often be completed within one working day, depending on field conditions such as access and traffic.

\section{Instrumentation of structure}

This outline is intended to describe the general procedures used for completing a successful field test on a highway bridge using the BDI-STS. For a detailed explanation of the instrumentation and testing procedures, please contact BDI and request a copy of the Structural Testing System (STS) Operation Manual.

\section{Attaching strain transducers}

Once a tentative instrumentation plan has been developed for the structure in question, the strain transducers must be attached and the STS prepared for running the test. There are several methods for attaching the strain transducers to the structural members, depending on whether they are steel, concrete, timber, fiberglass reinforced plastic (FRP), or other. For steel structures, quite often the transducers can be clamped directly to the steel flanges of rolled sections or plate girders. If significant lateral bending is assumed to be present, then one transducer may be clamped to each edge of the flange. In general, the transducers can be clamped directly to painted surfaces. The alternative to clamping is the tabattachment method that involves cleaning the mounting area and then 
using a fast-setting cyanoacrylate adhesive to temporarily install the transducers. The small steel tabs are removed when testing has been completed, and touch-up paint can be applied to the exposed steel surfaces.

Installation of transducers on prestressed concrete (PS/ C) and FRP members is usually accomplished with the tab technique outlined above, while readily available wood screws and a battery-operated hand drill are used for timber members. Installing transducers on reinforced concrete $(\mathrm{R} / \mathrm{C})$ is more complex in that gage extensions are used and must be mounted with concrete studs.

If the above steps are followed, it should be possible to mount each transducer in approximately 5 to $10 \mathrm{~min}$. Figures $\mathrm{C} 1$ and C2 illustrate transducers mounted on both steel and reinforced-concrete members.

\section{Assembly of system}

Once the transducers have been mounted, they are connected to the fourchannel STS units which are also located on the bridge. The STS units can be easily clamped to the bridge girders, or if the structure is concrete and no flanges are available to set the STS units on, transducer tabs glued to

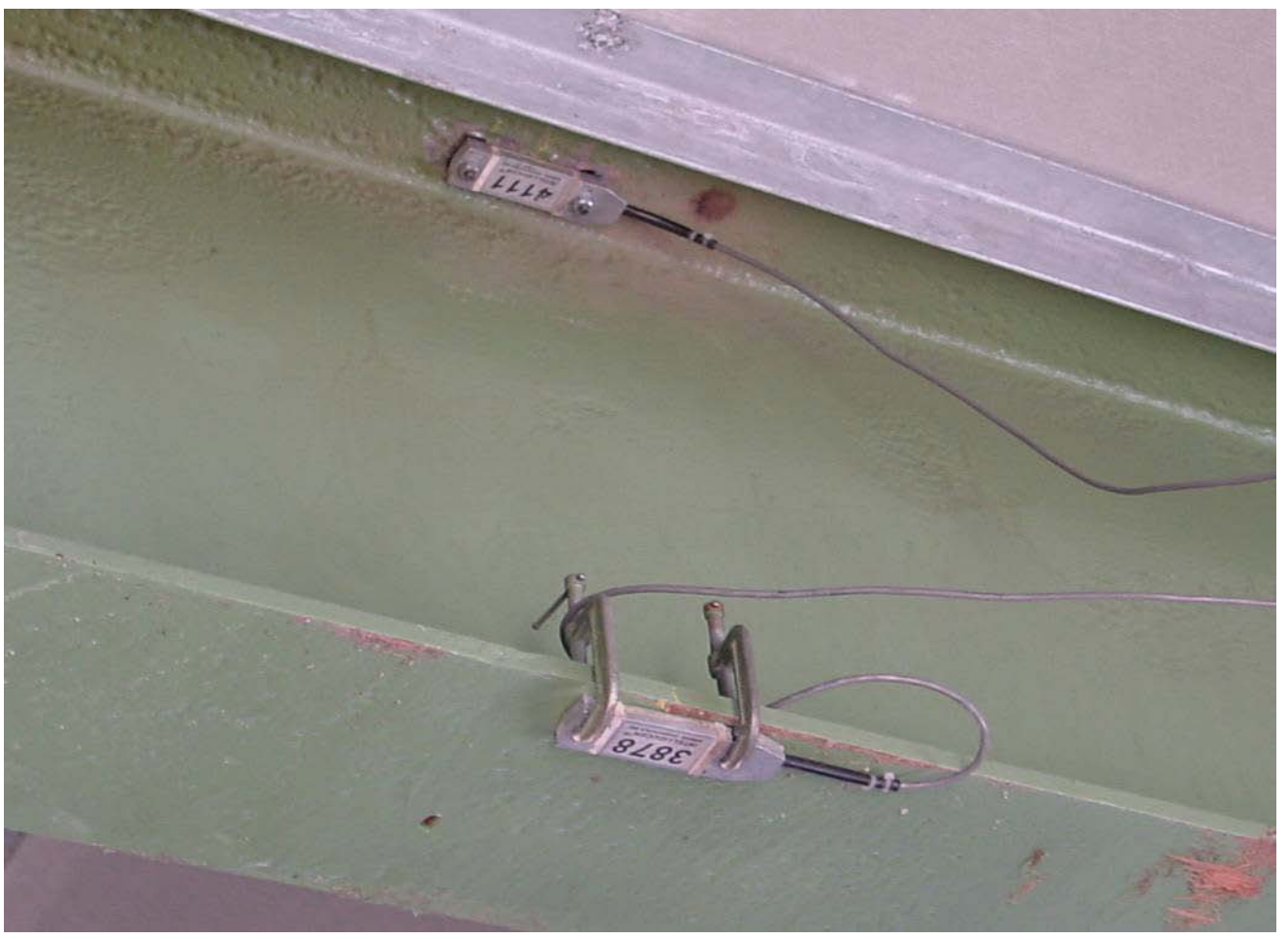

Figure C1. Strain transducers mounted on a steel girder. 


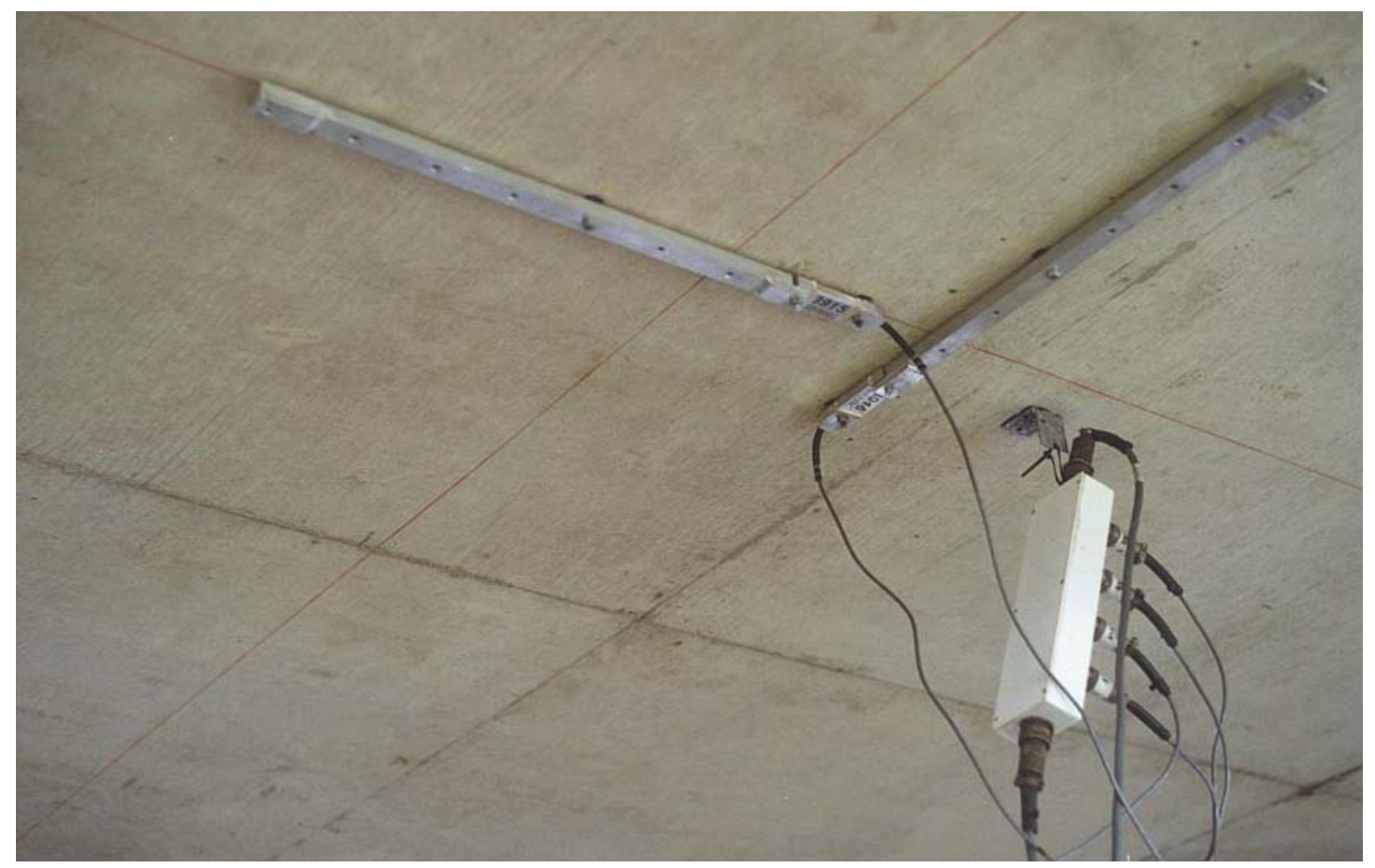

Figure C2. Transducer with gage extensions mounted on R/C slab.

the structure and plastic zip-ties or small wire can be used to mount them. Since the transducers will identify themselves to the system, there is no special order in which they must be plugged into the system. The only information that must be recorded is the transducer serial number and its location on the structure. Signal cables are then used to connect STS units together either in a series or in a tree-like structure through the use of cable splitters. If several gages are in close proximity to each other, then the STS units can be plugged directly to each other without the use of a cable.

Once all of the STS units have been connected together, only one cable must be run and connected to the STS power supply located near the PC. Once power and communication cables are connected, the system is ready to acquire data. One last step entails installing the AutoClicker on the test vehicle as seen in Figure C3.

\section{Establishing load vehicle positions}

Once the structure is instrumented and the loading vehicle prepared, some reference points must be established on the deck in order to determine where the vehicle will cross. This process is important so that future analyses/ comparisons can be made with the loading vehicle in the same 


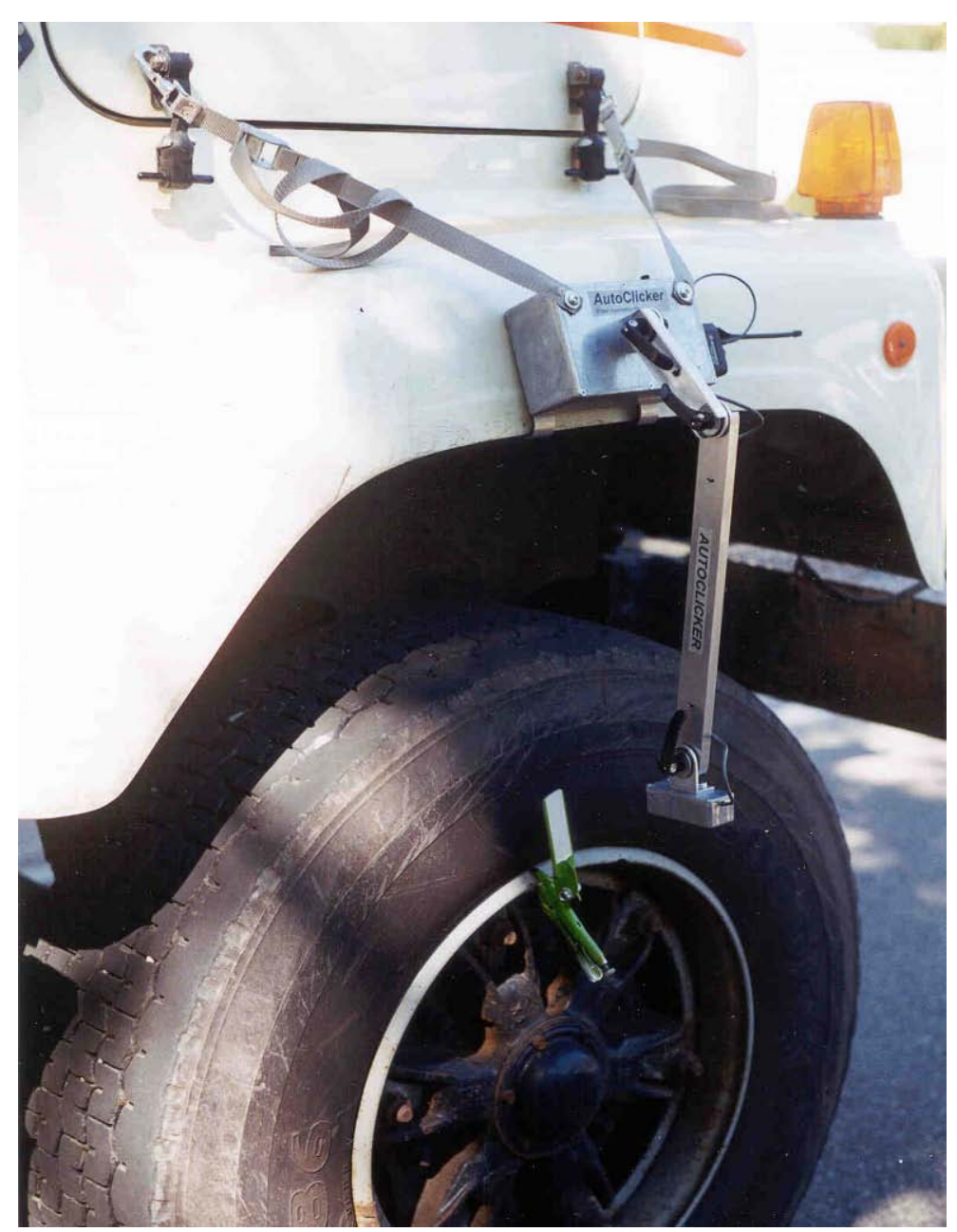

Figure C3. AutoClicker mounted on test vehicle.

locations as in the field. Therefore, a zero (or initial) reference point is selected that usually corresponds to the point on the deck directly above the abutment bearing and the centerline of one of the fascia beams. All other measurements on the deck will then be related to this zero reference point. For concrete T-beams, box beams, and slabs, this reference point can correspond to the location at which the edge of the slab or the beam web meets the face of the abutment. If the bridge is skewed, the first point encountered from the direction of travel is used. In any case, it should be a point that is easily located on the drawings for the structure.

Once the zero reference location is known, the lateral-load paths for the vehicle are determined. Often, the painted roadway lines are used for the driver to follow if they are in convenient locations. For example, for a twolane bridge, a northbound shoulder line will correspond to Y1 (passengerside wheel), the center dashed line to Y2 (center of truck), and the 
southbound shoulder line to Y3 (driver's side wheel). Often, the structure will be symmetrical with respect to its longitudinal center line. If so, it is good practice is to take advantage of this symmetry by selecting three $Y$ locations that are also symmetric. This practice will allow for a data quality check since the response should be very similar, say, on the middle beam if the truck is on the left side of the bridge or the right side of the bridge. In general, it is best to have the truck travel in each lane (at least on the lane line) and also as close to each shoulder or sidewalk as possible. When the deck layout is completed, the loading vehicle's axle weights and dimensions are recorded.

\section{Running the load tests}

After the structure has been instrumented and the reference system has been marked on the bridge deck, the actual test preparation procedures are completed. The WinSTS software is initialized and configured. When all personnel are ready to commence the test, traffic control is initiated and the Run Test option is selected, which places the system in an activated state. When the truck passes over the first deck mark, the AutoClicker is tripped and data are being collected at the specified sample rate. An effort is made to get the truck across with no other traffic on the bridge. When the rear axle of the vehicle completely crosses over the structure, the data collection is stopped, and several strain histories are evaluated for data quality. Usually, at least two passes are made at each Y position to ensure data reproducibility, and then if conditions permit, high speed or dynamic tests are completed.

The use of a moving load as opposed to placing the truck at discrete locations has two major benefits. First, the testing can be completed more quickly, meaning there is less impact on traffic. Second, and more importantly, much more information can be obtained, both quantitative and qualitative. Discontinuities or unusual responses in the strain histories, which are often signs of distress, can be easily detected. Since the load position is monitored as well, it is easy to determine what loading conditions cause the observed effects. If readings are recorded only at discreet truck locations, the risk of losing information between the points is great. The advantages of continuous readings have been proven over and over again.

When the testing procedures are complete, the instrumentation is removed and any touch-up paint work completed. 


\section{Appendix D: BDI Equipment Specifications}

\section{Specifications: BDI Strain Transducers}

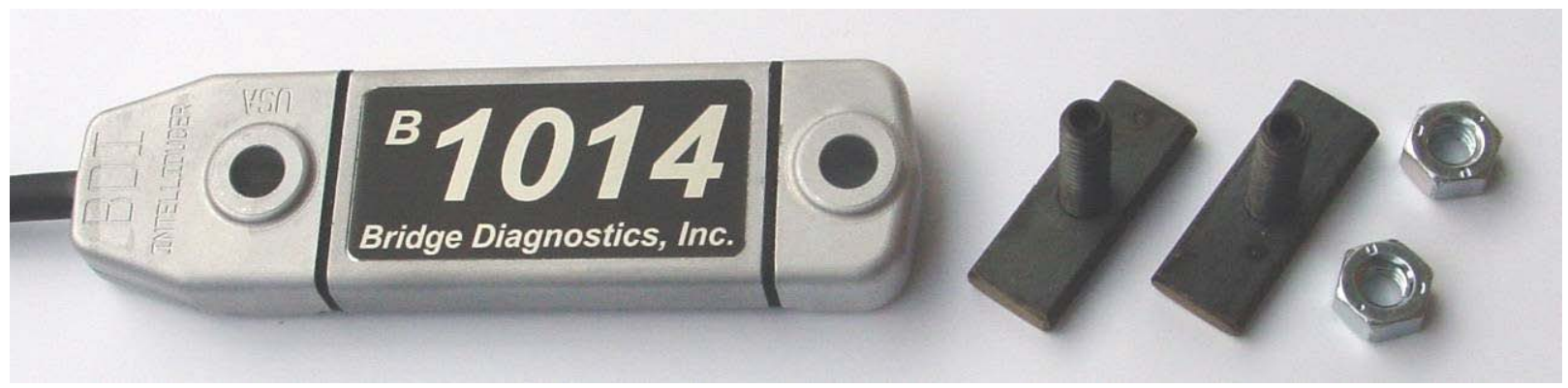

Figure D1. BDI strain transducer.

Table D1. Strain transducer specifications.

Effective Gage Length:

Overall Size:

Cable Length:

Material:

Circuit:

Accuracy:

Strain Range:

Force req'd for $1000 \mu \varepsilon$ :

Sensitivity:

Weight:

Environmental:

Temperature Range:

Cable:

Options:

Attachment Methods:
3.0 in $(76.2 \mathrm{~mm})$. Extensions available for use on $\mathrm{R} / \mathrm{C}$ structures.

4.4 in x 1.2 in x 0.5 in (110 mm x $33 \mathrm{~mm} \times 12 \mathrm{~mm}$ ).

$10 \mathrm{ft}(3 \mathrm{~m})$ standard, any length available.

Aluminum

Full Wheatstone bridge with four active $350 \Omega$ foil gages, 4-wire hookup.

$\pm 2 \%$, individually calibrated to NIST standards.

Approximately $\pm 4000 \mu \varepsilon$.

Approximately $9 \mathrm{lb}(40 \mathrm{~N})$.

Approximately $500 \mu \varepsilon / \mathrm{mV} / \mathrm{V}$,

Approximately $3 \mathrm{oz}(88 \mathrm{~g})$,

Built-in protective cover, also water resistant.

$-60^{\circ} \mathrm{F}$ to $250^{\circ} \mathrm{F}\left(-50^{\circ} \mathrm{C}\right.$ to $\left.120^{\circ} \mathrm{C}\right)$ operation range.

BDI RC-187: 22 gage, two individually-shielded pairs w/drain.

Fully waterproofed, Heavy-duty cable, Special quick-lock connector.

C-clamps or threaded mounting tabs \& quick-setting adhesive. 


\section{Specifications: BDI Wireless Structural Testing System}

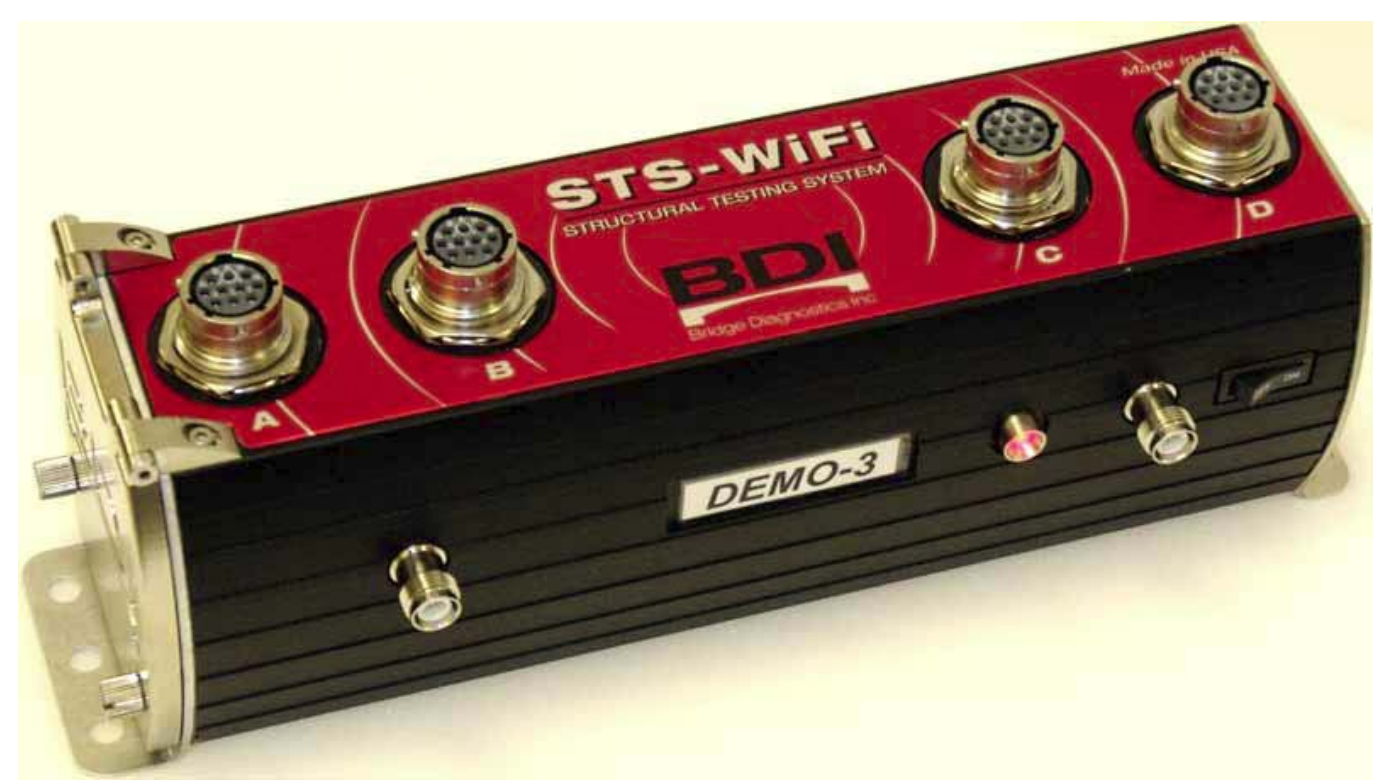

Figure D2. BDI structural testing system.

Table D2. Structural testing system specifications.

\begin{tabular}{|c|c|}
\hline Channels & 4 to 128 ; expandable in multiples of four \\
\hline Hardware Accuracy & $\pm 0.2 \%$ ( $2 \%$ for strain transducers) \\
\hline Sample Rates & $\begin{array}{l}0.1-500 \mathrm{~Hz} \\
\text { (Internal oversampling rate is } 19.5-312 \mathrm{kHz} \text { ) }\end{array}$ \\
\hline Max Test Lengths & $\begin{array}{l}21 \mathrm{~min} \text { at } 100 \mathrm{~Hz} \\
128 \mathrm{~K} \text { samples per channel maximum test lengths }\end{array}$ \\
\hline Gain Levels & $1,2,4,6,16,32,64,128$ \\
\hline Digital Filter & Fixed by selected sample rate \\
\hline Analog Filter & $200 \mathrm{~Hz},-3 \mathrm{db}, 3 r d-o r d e r$ Bessel \\
\hline Max. Input Voltage & 10.5 Volts DC \\
\hline Battery Power & $\begin{array}{l}\text { 9.6 NiMH rechargeable battery } \\
\text { (Programmable low-power sleep mode) }\end{array}$ \\
\hline Alternative Power & 9-48 Volts DC input \\
\hline $\begin{array}{l}\text { Excitation Voltages: } \\
\text { Standard: } \\
\text { LVDT/Other: }\end{array}$ & $\begin{array}{l}5 \text { Volts DC } \\
5.5 \text { Volts DC }\end{array}$ \\
\hline A/D Resolution & 0.3 uV/bit (24-Bit ADC) \\
\hline
\end{tabular}




\begin{tabular}{|c|c|}
\hline PC Requirements & Windows XP or higher \\
\hline PC Interface & Wi-Fi ethernet 802.11b: 10/100 Mbps \\
\hline Auto Zeroing & Sensors automatically zero before each test \\
\hline Enclosures & Aluminum splash resistant \\
\hline Sensor Connections & All aluminum military grade, circular bayonet "snap" lock \\
\hline Vehicle Tracking: & BDI AutoClicker, switch closure detection \\
\hline Sensors & $\begin{array}{l}\text { BDI Intelliducer Strain Transducer } \\
\text { Also supports LVDT's, foil strain gages, accelerometers, Load Cells, and other } \\
\text { various DC output sensors } \\
\text { Single RS232 serially-interfaced sensor }\end{array}$ \\
\hline $\begin{array}{l}\text { On-Board PC } \\
\text { Processor: } \\
\text { RAM: }\end{array}$ & $\begin{array}{l}520 \mathrm{MHz} \text { Intel XScale PXA270 } \\
64 \mathrm{MB}\end{array}$ \\
\hline $\begin{array}{l}\text { Dimensions } \\
\text { Base Station: } \\
\text { STS 4-Channel Node: }\end{array}$ & $\begin{array}{l}10 " \text { x 6" x 4" } \\
11^{\prime \prime} \text { x } 3.5 " \text { x } 3.23 "\end{array}$ \\
\hline
\end{tabular}




\section{Specifications: BDI AutoClicker}

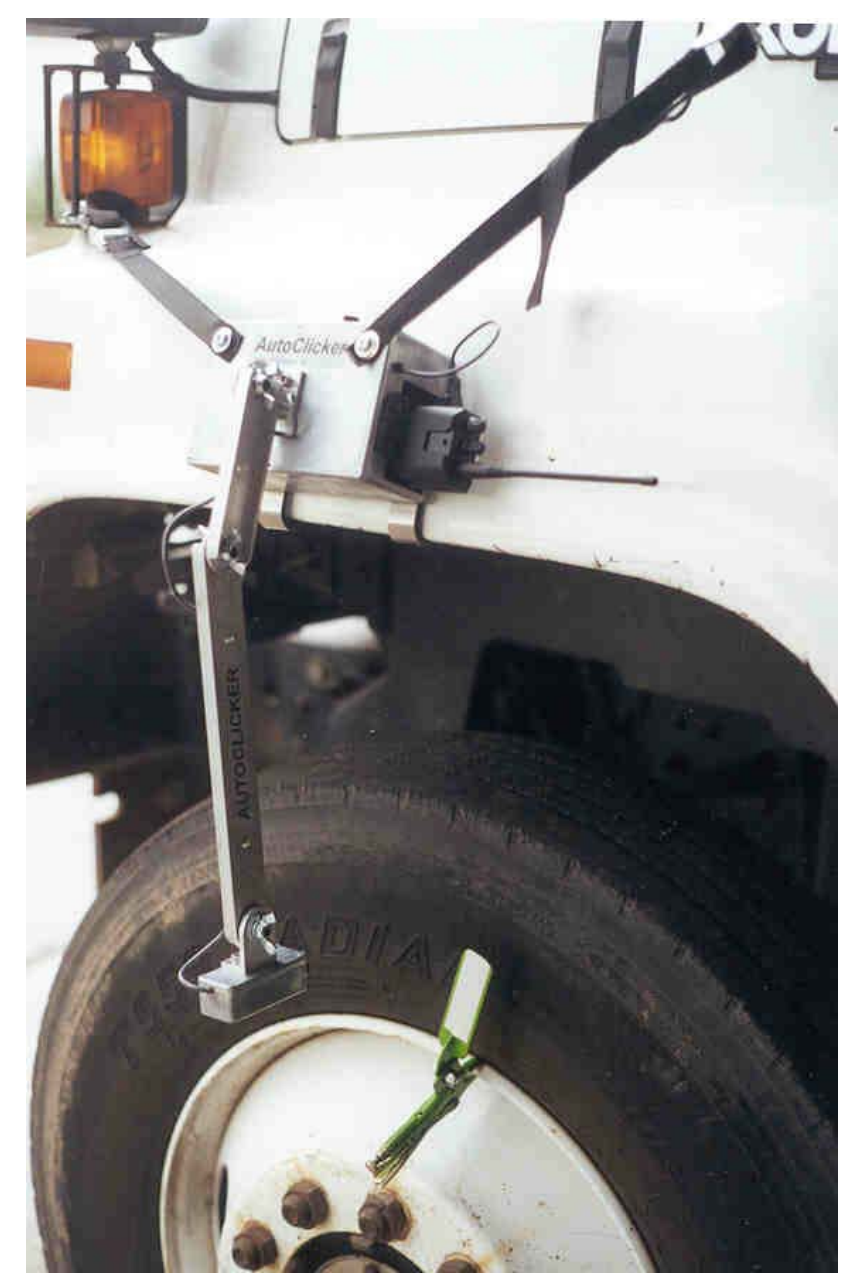

Figure D3. AutoClicker mounted on test truck.

Table D3. AutoClicker specifications.

\begin{tabular}{|l|l|}
\hline 3 Handheld Radios & Motorola P1225 2-Channel (or equal) modified for both “Rx" and “Tx" \\
\hline Power & 9 V battery \\
\hline Mounting & Universal front fender mounting system \\
\hline Target & Retroreflective tape mounted on universal wheel clamp \\
\hline Bands/Power & VHF/1 Watt or UHF/2 Watt \\
\hline Frequencies & User-specified \\
\hline $\begin{array}{l}\text { Data Acquisition System } \\
\text { Requirements }\end{array}$ & TTL/CMOS input (pull-up resistor to 5V) \\
\hline Output & Isolated contact closure (200V 0.5A max switch current) \\
\hline
\end{tabular}




\section{Appendix E: Modeling and Analysis- The Integrated Approach}

\section{Introduction}

For load testing to be a practical means of evaluating short- to mediumspan bridges, it is apparent that testing procedures must be economical to implement in the field and the test results translatable into a load rating. A well-defined set of procedures must exist for the field applications as well as for the interpretation of results. An evaluation approach based on these requirements was first developed at the University of Colorado during a research project sponsored by the Pennsylvania Department of Transportation (PennDOT). Over several years, the techniques originating from this project have been refined and expanded into a complete bridge rating system.

The ultimate goal of the Bridge Diagnostics, Inc., integrated approach is to obtain realistic rating values for highway bridges in a cost effective manner. This goal is accomplished by measuring the response behavior of the bridge due to a known load and determining the structural parameters that produce the measured responses. With the availability of field measurements, many structural parameters in the analytical model can be evaluated that are otherwise conservatively estimated or ignored entirely. Items that can be quantified through this procedure include the effects of structural geometry, effective beam stiffness, realistic support conditions, effects of parapets and other nonstructural components, lateral load transfer capabilities of the deck and transverse members, and the effects of damage or deterioration. Often, bridges are rated poorly because of inaccurate representations of the structural geometry or because the material and/ or cross-sectional properties of main structural elements are not well defined. A realistic rating can be obtained, however, when all of the relevant structural parameters are defined and implemented in the analysis process.

One of the most important phases of this approach is a qualitative evaluation of the raw field data. Much is learned during this step to aid in the rapid development of a representative model. 


\section{Initial data evaluation}

The first step in structural evaluation consists of a visual inspection of the data in the form of graphic response histories. Graphic software was developed to display the raw strain data in various forms. Strain histories can be viewed in terms of time or truck position. Since strain transducers are typically placed in pairs, neutral axis measurements, curvature responses, and strain averages can also be viewed. Linearity between the responses and load magnitude can be observed by the continuity in the strain histories. Consistency in the neutral axis measurements from beam to beam and as a function of load position provides great insight into the nature of the bridge condition. The direction and relative magnitudes of flexural responses along a beam line are useful in determining whether end restraints play a significant role in the response behavior. In general, the initial data inspection provides the engineer with information concerning modeling requirements and can help locate damaged areas.

Having strain measurements at two depths on each beam cross section, flexural curvature and the location of the neutral axis can be computed directly from the field data. Figure E1 illustrates how curvature and neutral axis values are computed from the strain measurements.

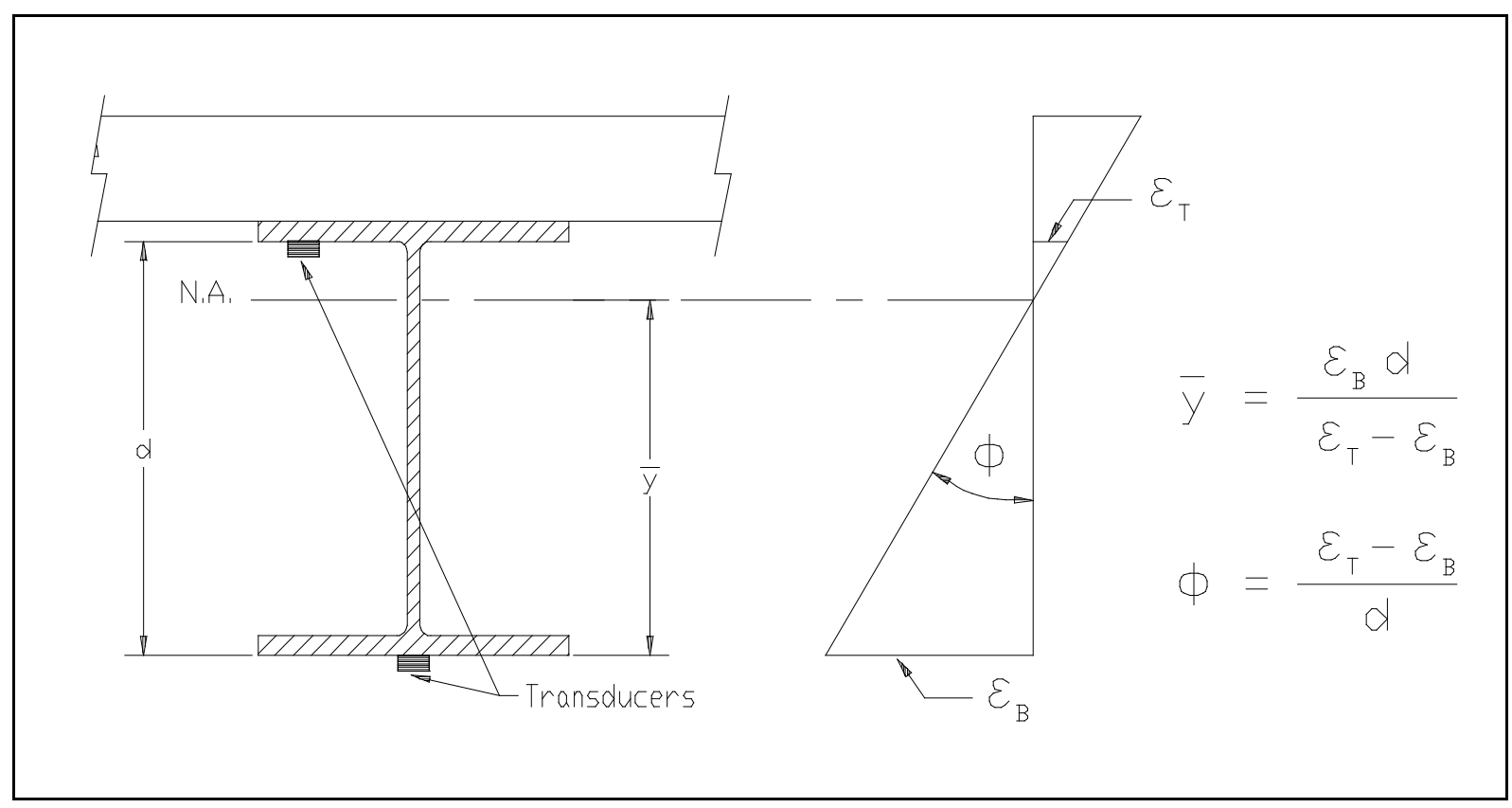

Figure E1. Illustration of neutral axis and curvature calculations. 
The consistency in the neutral axis (NA) values between beams indicates the degree of consistency in beam stiffness. Also, the consistency of the NA measurement on a single beam as a function of truck position provides a good quality check for that beam. If for some reason a beam's stiffness changes with respect to the applied moment (i.e., loss of composite action or loss of effective flange width due to a deteriorated deck), it will be observed by a shift in the NA history.

Since strain values are translated from a function of time into a function of vehicle position on the structure and the data acquisition channel and the truck position tracked, a considerable amount of book keeping is required to perform the strain comparisons. In the past, this information gathering required manipulation of result files and spreadsheets, all of which was tedious and a major source of error. This process in now performed automatically by the software, and all of the information can be verified visually.

\section{Finite element modeling and analysis}

The primary function of the load test data is to aid in the development of an accurate finite element model of the bridge. Finite element analysis is used because it provides the most general tool for evaluating various types of structures. Since a comparison of measured and computed responses is performed, it is necessary that the analysis be able to represent the actual response behavior. This task requires that actual geometry and boundary conditions be realistically represented. In maintaining reasonable modeling efforts and computer run times, a certain amount of simplicity is also required. Hence, a planar grid model is generated for most structures, and linear-elastic responses are assumed. A grid of frame elements is assembled in the same geometry as the actual structure. Frame elements represent the longitudinal and transverse members of the bridge. The load transfer characteristics of the deck are provided by attaching plate elements to the grid. When end restraints are determined to be present, elastic spring elements having both translational and rotational stiffness terms are inserted at the support locations.

Loads are applied in a manner similar to the actual load test. A model of the test truck, defined by a two-dimensional group of point loads, is placed on the structure model at discrete locations along the same path that the test truck followed during the load test. Gage locations identical to those in 
the field are also defined on the structure model so that strains can be computed at the same locations under the same loading conditions.

\section{Evaluation of rotational end restraint}

A common requirement in structural identification is the need to determine effective spring stiffnesses that best represent in situ support conditions. While it is generally simple to evaluate a spring constant in terms of moment per rotation, the value generally has little meaning to the engineer. A more conceptual approach is to evaluate the spring stiffness as a percentage of a fully restrained condition, e.g., $0 \%$ being a pinned condition and $100 \%$ being fixed. This is best accomplished by examining the ratio of the beam or slab stiffness to the rotational stiffness of the support.

As an illustration, a point load is applied to a simple beam with elastic supports (Figure E2). By examining the moment diagram, it is apparent that the ratio of the end moment to the mid-span moment $\left(\mathrm{M}_{\mathrm{e}} / \mathrm{M}_{\mathrm{m}}\right)$ equals 0.0 if the rotational stiffness $\left(\mathrm{K}_{\mathrm{r}}\right)$ of the springs is equal to 0.0. Conversely, if the value of $K_{r}$ is set to infinity (rigid) the moment ratio will equal 1.0. If a fixity term is defined as the ratio $\left(\mathrm{M}_{\mathrm{e}} / \mathrm{M}_{\mathrm{m}}\right)$, which ranges from 0 to 100 percent, a more conceptual measure of end restraint can be obtained.

The next step is to relate the fixity term to the actual spring stiffness $\left(\mathrm{K}_{\mathrm{r}}\right)$. The degree to which the $\mathrm{K}_{\mathrm{r}}$ affects the fixity term depends on the beam or slab stiffness to which the spring is attached. Therefore the fixity term must be related to the ratio of the beam stiffness to the spring stiffness. Figure E3 contains a graphical representation of the end restraint effect on a simple beam. Using the graph, one can define a conceptual measure of end-restraint after the beam and spring constants are evaluated through structural identification techniques.

\section{Model correlation and parameter modification}

The accuracy of the model is determined numerically by an analysis that uses several statistical relationships and visual comparison of the strain histories. The numeric accuracy values are useful in evaluating the effect of any changes to the model, while the graphical representations provide the engineer with the best perception for why the model is responding differently from the way the measurements indicate. Member properties that cannot be accurately defined by conventional methods or directly 


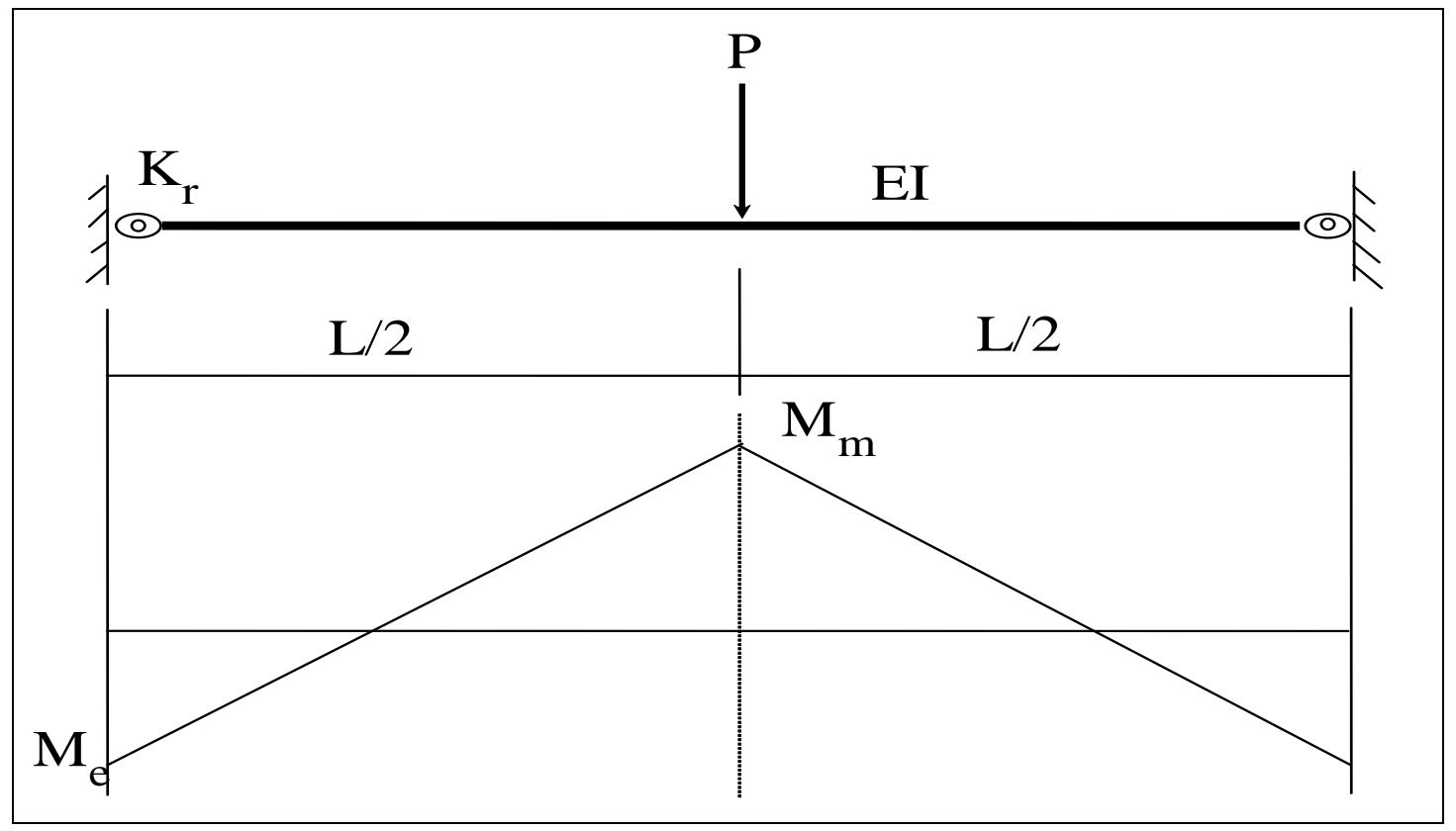

Figure E2. Moment diagram of beam with rotational end restraint.

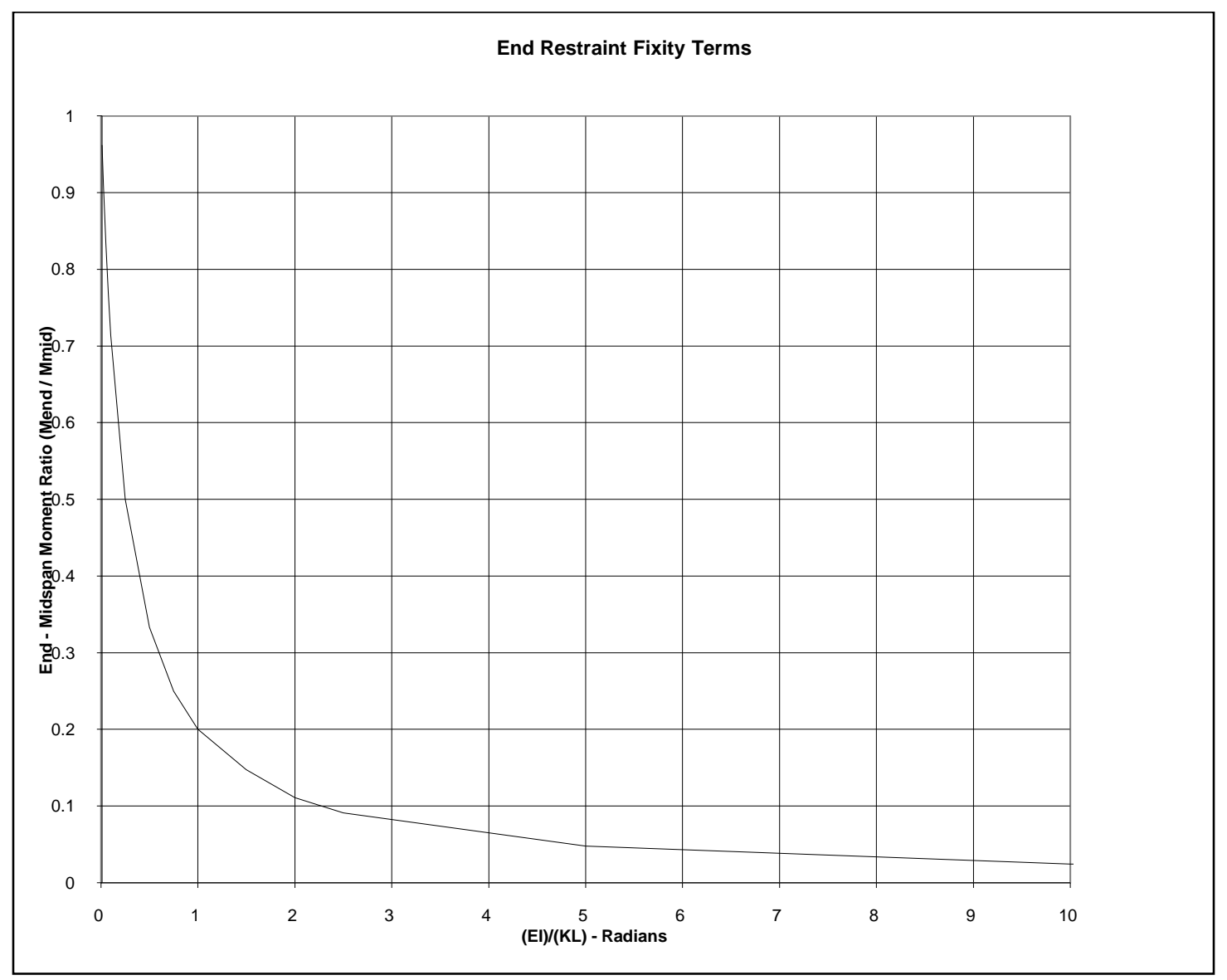

Figure E3. Relationship between spring stiffness and fixity ratio. 
from the field data are evaluated by comparing the computed strains with the measured strains. These properties are defined as variable and are evaluated such that the best correlation between the two sets of data is obtained. It is the engineer's responsibility to determine which parameters need to be refined and to assign realistic upper and lower limits to each parameter. The evaluation of the member property is accomplished with the aid of a parameter identification process (optimizer) built into the analysis. In short, the process consists of an iterative procedure of analysis, data comparison, and parameter modification. It is important to note that the optimization process is merely a tool to help evaluate various modeling parameters. The process works best when the number of parameters is minimized, and reasonable initial values are used.

During the optimization process, various error values which provide a quantitative measure of model accuracy and improvement are computed by the analysis program. The error is quantified in four different ways, each providing a different perspective of the model's ability to represent the actual structure, i.e., an absolute error, a percent error, a scale error, and a correlation coefficient.

The absolute error is computed from the absolute sum of the strain differences. Algebraic differences between the measured and theoretical strains are computed at each gage location for each truck position used in the analysis; therefore, several hundred strain comparisons are generally used in this calculation. This quantity is typically used to determine the relative accuracy from one model to the next and to evaluate the effect of various structural parameters. It is used by the optimization algorithm as the objective function to minimize. Because the absolute error is in terms of microstrain $(\mathrm{m} \varepsilon)$, the value can vary significantly depending on the magnitude of the strains, the number of gages, and the number of different loading scenarios. For this reason, it has little conceptual value except for determining the relative improvement of a particular model.

A percent error is calculated to provide a better qualitative measure of accuracy. It is computed as the sum of the strain differences squared divided by the sum of the measured strains squared. The terms are squared so that error values of different sign will not cancel each other and to put more emphasis on the areas with higher strain magnitudes. A model with acceptable accuracy will usually have a percent error less than 10 . 
The scale error is similar to the percent error except that it is based on the maximum error from each gage divided by the maximum strain value from each gage. This number is useful because it is based only on strain measurements recorded when the loading vehicle is in the vicinity of each gage. Depending on the geometry of the structure, the number of truck positions and various other factors, many of the strain readings are essentially negligible. This error function uses only the most relevant measurement from each gage.

Another useful quantity is the correlation coefficient, which is a measure of the linearity between the measured and computed data. This value determines how well the shapes of the computed response histories match the measured responses. The correlation coefficient can have a value between 1.0 (indicating a perfect linear relationship) and -1.0 (exact opposite linear relationship). A good model will generally have a correlation coefficient greater than 0.90 . A poor correlation coefficient is usually an indication that a major error in the modeling process has occurred. This is generally caused either by poor representations of the boundary conditions or incorrect application of the loads, e.g., truck traveling in wrong direction.

Table E1 contains the equations used to compute each of the statistical error values.

In addition to the numerical comparisons made by the program, periodic visual comparisons of the response histories are made to obtain a conceptual measure of accuracy. Again, engineering judgment is essential in determining which parameters should be adjusted so as to obtain the most accurate model. The selection of adjustable parameters is performed by a determination of which properties have a significant effect on the strain comparison and which values cannot be accurately estimated through conventional engineering procedures. Experience in examining the data comparisons is helpful; however, two general rules apply concerning model refinement. First, when the shapes of the computed response histories are similar to the measured strain records but the magnitudes are incorrect, member stiffness probably should be adjusted. Second, when the shapes of the computed and measured response histories are not very similar, the boundary conditions or the structural geometry are not well represented and must be refined. 
Table E1. Error functions.

\begin{tabular}{|l|l|}
\hline ERROR FUNCTION & EQUATION \\
\hline Absolute Error & $\sum\left|\varepsilon_{m}-\varepsilon_{C}\right|$ \\
\hline Percent Error & $\sum\left(\varepsilon_{m}-\varepsilon_{C}\right)^{2} / \Sigma\left(\varepsilon_{m}\right)^{2}$ \\
\hline Scale Error & $\frac{\sum \max \left|\varepsilon_{m}-\varepsilon_{C}\right|_{\text {gage }}}{\sum \max \left|\varepsilon_{m}\right| \text { gage }}$ \\
\hline Correlation Coefficient & $\frac{\sum\left(\varepsilon_{m}-\overline{\varepsilon_{m}}\right)\left(\varepsilon_{C}-\overline{\varepsilon_{C}}\right)}{\left.\sum \sqrt{\left(\varepsilon_{m}-\overline{\varepsilon_{m}}\right.}\right)^{2}\left(\varepsilon_{C}-\overline{\varepsilon_{C}}\right)^{2}}$ \\
\hline
\end{tabular}

In some cases, an accurate model cannot be obtained, particularly when the responses are observed to be nonlinear with load position. Even then, a great deal can be learned about the structure, and intelligent evaluation decisions can be made. 


\section{Appendix F: Load Rating Procedures}

A load-rating factor is a numeric value indicating a structure's ability to carry a specific load. Load rating factors were computed by applying standard design loads along with the structure's self-weight. Rating factors are computed for various structural components and are equal to the ratio of the component's live-load capacity and the live load applied to that component, including all appropriate load factors. A load-rating factor greater than 1.0 indicates that a member's capacity exceeds the applied loads with the desired factors of safety. A rating factor less than 1.0 indicates a member is deficient to the point that a specific vehicle cannot cross the bridge with the desired factor of safety. A number near 0.0 indicates the structure cannot carry its own dead weight and maintain the desired safety factor. The lowest component rating-factor generally controls the load rating of the entire structure. Additional factors are applied to account for variability in material, load application, and dynamic effects. Two levels of load rating are performed for the bridge. An inventory level rating corresponds to the design stress levels and/ or factors of safety and represents the loads that can be applied on a daily basis. The operating rating levels correspond to the maximum load limits above which the structure may experience damage or failure.

For borderline bridges (those for which calculations indicate a posting is required), the primary drawback to conventional bridge rating is an oversimplified procedure for estimating the load applied to a given beam; i.e., the loading is based on generic wheel-load distribution factors and a poor representation of the beam itself. Due to lack of information and the need for conservatism, material and cross-section properties are generally overestimated and beam end-supports are assumed to be simple - when, in fact, even relatively simple beam bearings have a substantial effect on the mid-span moments. Inaccuracies associated with conservative assumptions are compounded with complex framing geometries. From an analysis standpoint, the goal here is to generate a model of the structure that is capable of reproducing the measured strains. Decisions concerning load rating are then based on the performance of the model once it is proven to be accurate. 
The main purpose for obtaining an accurate model is to evaluate how the bridge will respond when standard design loads, rating vehicles, or permit loads are applied to the structure. Since load testing is generally not performed with all of the vehicles of interest, an analysis must be performed to determine load-rating factors for each truck type. Load rating is accomplished by applying the desired rating loads to the model and computing the stresses on the primary members. Rating factors are computed using the equation specified in the AASHTO Manual for Condition Evaluation of Bridges.

It is important to understand that diagnostic load testing and the integrated approach are most applicable to obtaining Inventory (service load) rating values, because it is assumed that all of the measured and computed responses are linear with respect to load. The integrated approach is an excellent method for estimating service-load stress values, but it generally provides little additional information regarding the ultimate strength of specific structural members. Therefore, operating rating values must be computed using conventional assumptions regarding member capacity. This limitation of the integrated approach is not viewed as a serious concern because load responses should never be permitted to reach the inelastic range.

Operating and/ or load factor rating values must also be computed to ensure a factor of safety between the ultimate strength and the maximum allowed service loads. The safety to the public is of vital importance, but as long as load limits are imposed such that the structure is not damaged, then safety is no longer an issue.

The following is an outline describing how field data are used to help in developing a load rating for the superstructure. These procedures will only complement the rating process and must be used with due consideration to the substructure and inspection reports.

1. Preliminary investigation: Verify linear and elastic behavior through continuity of strain histories, locate neutral axis of flexural members, detect moment resistance at beam supports, and qualitatively evaluate behavior.

2. Develop representative model: Use graphic preprocessors to represent the actual geometry of the structure, including span lengths, 
girder spacing, skew, transverse members, and deck. Identify gage locations and model them identically to those applied in the field.

3. Simulate load test on computer model: Generate a twodimensional model of the test vehicle and apply it to the structure model at discrete positions along same paths defined during field tests. Perform analyses and compute strains at each gage location for each truck position.

\section{Compare measured and initial computed strain values:} Compute various global and local error values at each gage location, and make visual comparisons with postprocessor.

5. Evaluate modeling parameters: Improve the model based on data comparisons. Engineering judgment and experience are required to determine which variables are to be modified. Use a combination of direct evaluation techniques and parameter optimization to obtain a realistic model. General rules have been defined to simplify this operation.

6. Model evaluation: Quantify secondary stiffening effects on the structural response so that a representative computer model can be obtained. However, in some cases, it is not desirable to rely on secondary stiffening effects if it is likely they will not be effective at higher load levels. The stiffening effects that are deemed unreliable can be eliminated from the model prior to the computation of rating factors. For instance, if a noncomposite bridge is exhibiting composite behavior, then it can conservatively be ignored for rating purposes. However, if it has been in service for 50 years and it is still behaving compositely, chances are that very heavy loads have crossed over it, and any bond-breaking would have already occurred. Therefore, probably some level of composite behavior can be relied upon. When unintended composite action is allowed in the rating, compute additional load limits based on an allowable shear stress between the steel and concrete and an ultimate load of the noncomposite structure.

7. Perform load rating: Apply HS-20 and/ or other standard design, rating and permit loads to the calibrated model. Rating and posting load configurations recommended by AASHTO are illustrated in Figures F1- F2 and summarized in Tables F1- F3. 
8. The same rating equation specified by the AASHTO Manual for the Condition Evaluation of Bridges is applied:

$$
R F=\frac{C-\gamma_{D C}(D C)-\gamma_{D W}(D W) \pm \gamma_{P}(P)}{\gamma_{L}(L L+I M)}
$$

where:

$$
\begin{aligned}
\mathrm{RF}= & \text { rating factor for individual member } \\
\mathrm{C}= & \text { member capacity } \\
\gamma_{\mathrm{DC}}= & \mathrm{LRFD} \text { load factor for structural components and attachments } \\
\mathrm{DC}= & \text { dead-load effect due to structural components } \\
\gamma_{\mathrm{DW}}= & \mathrm{LRFD} \text { load factor for wearing surfaces and utilities } \\
\mathrm{DW}= & \text { dead-load effect due to wearing surface and utilities } \\
\gamma_{\mathrm{P}}= & \mathrm{LRFD} \text { load factor for permanent loads other than dead } \\
& \text { loads }=1.0 \\
\mathrm{P}= & \text { permanent loads other than dead loads } \\
\mathrm{LL}= & \text { live-load effect } \\
\mathrm{IM}= & \text { impact effect, either AASHTO or measured. }
\end{aligned}
$$

The only difference between this rating technique and standard beam rating programs is that a more realistic model is used to determine the dead-load and live-load effects. Two-dimensional loading techniques are applied because wheel load distribution factors are not applicable to a planar model. Stress envelopes are generated for several truck paths and envelopes for paths separated by normal lane widths are combined to determine multiple lane loading effects.

9. Consider other factors: Take into consideration other factors, such as the condition of the deck and/ or substructure, traffic volume, and other information in the inspection report, and adjust the rating factors accordingly. 


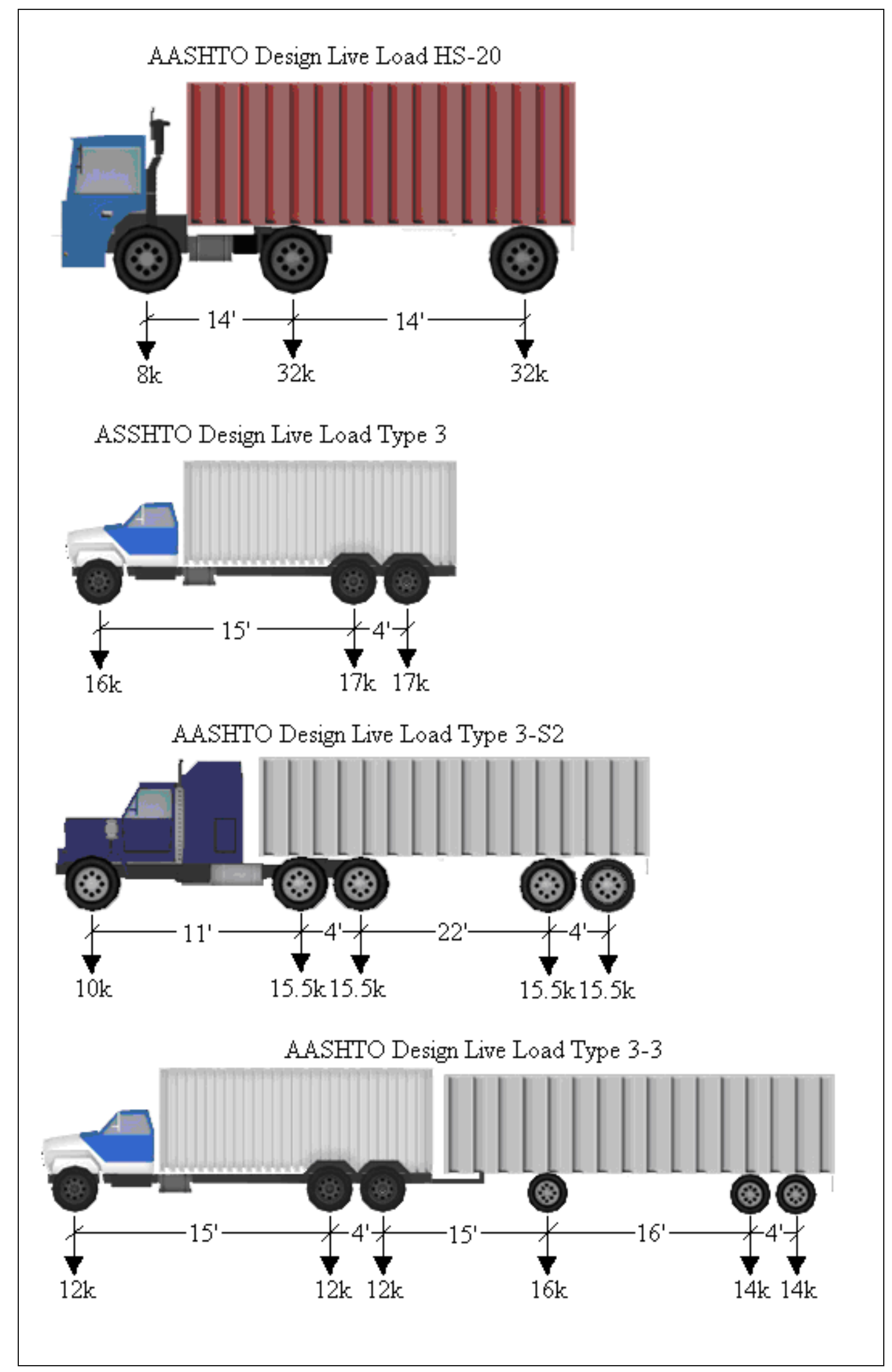

Figure F1. AASHTO rating and posting load configurations. 


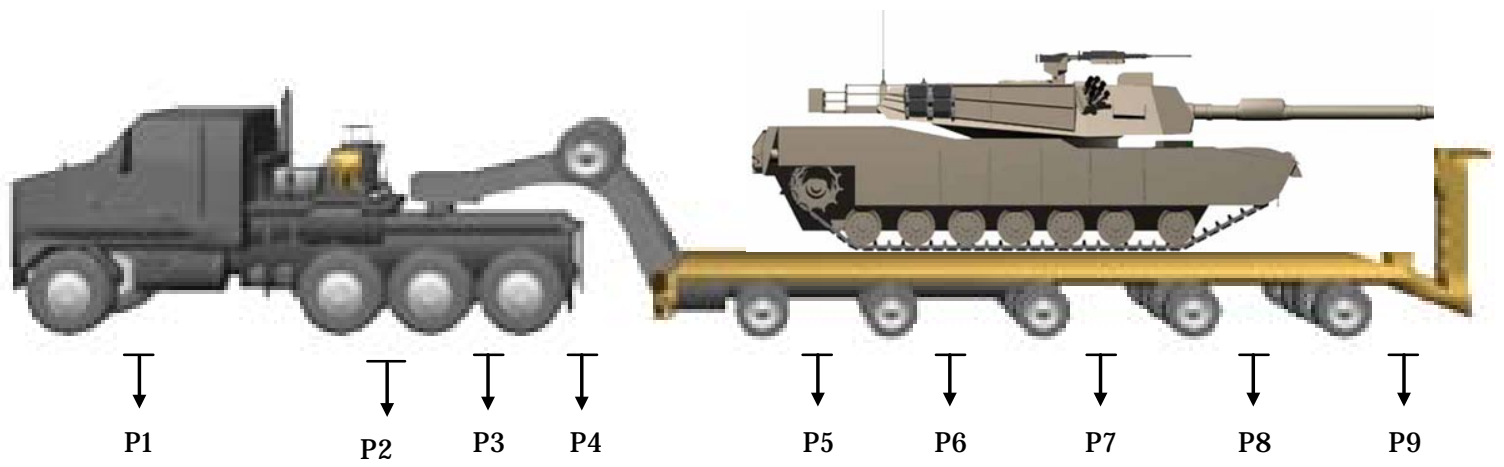

a) Side View

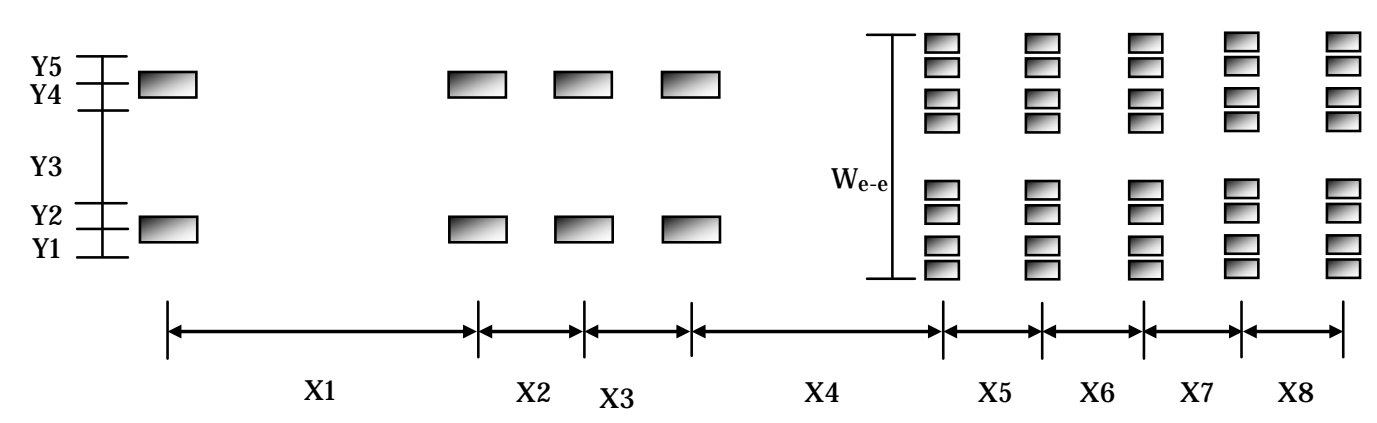

b) Top View

Figure F2. Configuration of HETS vehicle load distribution (FM 3-34.343).

Table F1. Loading data and dimensions of HETS.

\begin{tabular}{|l|l|l|l|l|l|l|l|l|l|}
\hline \multicolumn{2}{|l|}{ Loading Data } \\
\hline \multirow{2}{*}{ Axle Loads (k) } & P1 & P2 & P3 & P4 & P5 & P6 & P7 & P8 & P9 \\
\cline { 2 - 10 } & 21.7 & 22.3 & 21.7 & 19.9 & 27.0 & 29.7 & 28.0 & 28.0 & 31.4 \\
\hline Dimensions & We-e & Y1 & Y2 & Y3 & Y4 & Y5 & & & \\
\hline \multirow{2}{*}{$\begin{array}{l}\text { Transverse } \\
\text { Spacing (ft) }\end{array}$} & 12.0 & 1.67 & 1.12 & 4.85 & 1.12 & 1.67 & & & \\
\cline { 2 - 12 } & X1 & X2 & X3 & X4 & X5 & X6 & X7 & X8 & \\
\cline { 2 - 11 } & 12.92 & 5.0 & 5.0 & 15.94 & 5.94 & 5.94 & 5.94 & 5.94 & \\
\hline $\begin{array}{l}\text { Longitudinal } \\
\text { Spacing (ft) }\end{array}$ & & & & & & & & & \\
\hline
\end{tabular}


Table F2. LRFR load and resistance factors.

\begin{tabular}{|l|l|l|}
\hline \multirow{4}{*}{ Dead Load } & Allowable stress (serviceability limit state) & 1.00 \\
\cline { 2 - 3 } & $\begin{array}{l}\text { DC (Dead-load effects due to structural components and } \\
\text { attachments) }\end{array}$ & 1.25 \\
\cline { 2 - 3 } & DW (Dead-load effect due to wearing surface and utilities) & 1.50 \\
\hline \multirow{4}{*}{ Live Load } & Allowable stress (serviceability limit state) & 1.00 \\
\cline { 2 - 3 } & Inventory & 1.75 \\
\cline { 2 - 3 } & Operating & 1.35 \\
\hline \multirow{5}{*}{ System Factor, $\varphi_{S}$} & Good or Satisfactory & 1.00 \\
\cline { 2 - 3 } & Fair & 0.95 \\
\cline { 2 - 3 } & Poor & 0.85 \\
\cline { 2 - 3 } & Welded members in two-girder/truss/arch bridges & 0.85 \\
\cline { 2 - 3 } & Riveted members in two-girder/truss/arch bridges & 0.90 \\
\cline { 2 - 3 } & Multiple I-bar members in truss bridges & 0.90 \\
\cline { 2 - 3 } & Four-girder bridges with girder spacing $\leq 4 \mathrm{ft}$ & 0.85 \\
\cline { 2 - 3 } & All other girder bridges and slab bridges & 0.95 \\
\cline { 2 - 3 } & Floor beams with spacing >12 ft and noncontinuous stringers & 0.85 \\
\cline { 2 - 3 } & Redundant stringers subsystems between floor beams & 1.00 \\
\hline
\end{tabular}

Table F3. LRFD resistance factors.

\begin{tabular}{|l|l|l|l|}
\hline Capacity & $\begin{array}{l}\text { Steel } \\
\text { Resistance } \\
\text { Factor }\end{array}$ & $\begin{array}{l}\text { R/C } \\
\text { Resistance Factor }\end{array}$ & $\begin{array}{l}\text { PS/C } \\
\text { Resistance } \\
\text { Factor }\end{array}$ \\
\hline Flexure, $\Phi_{\mathrm{b}}$ & 1.00 & 0.90 & 1.00 \\
\hline Shear, $\Phi_{\mathrm{v}}$ & 1.00 & 0.90 & 0.90 \\
\hline
\end{tabular}




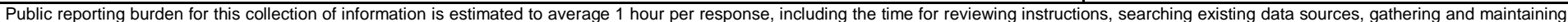

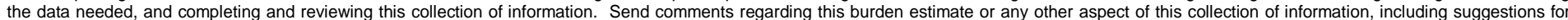

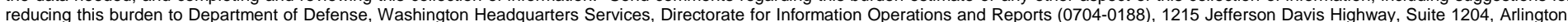

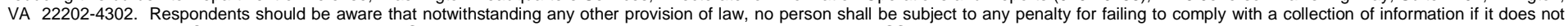
display a currently valid OMB control number. PLEASE DO NOT RETURN YOUR FORM TO THE ABOVE ADDRESS.
1. REPORT DATE (DD-MM-YYYY) 2. REPORT TYPE
November 2010 Final report

\section{TITLE AND SUBTITLE}

Field Testing and Load Rating of a Short-Span Thermoplastic Bridge System, Bridge T-8519

\section{DATES COVERED (From - To)}

5a. CONTRACT NUMBER

5b. GRANT NUMBER

5c. PROGRAM ELEMENT NUMBER

\section{AUTHOR(S)}

\section{5d. PROJECT NUMBER}

Brett Commander and Henry Diaz-Alvarez

5e. TASK NUMBER

\section{5f. WORK UNIT NUMBER}

\section{PERFORMING ORGANIZATION NAME(S) AND ADDRESS(ES)}

8. PERFORMING ORGANIZATION REPORT

U.S. Army Engineer Research and Development Center

Geotechnical and Structures Laboratory NUMBER

3909 Halls Ferry Road

ERDC/GSL TR-10-48

Vicksburg, MS 39180-6199

\section{SPONSORING I MONITORING AGENCY NAME(S) AND ADDRESS(ES)}

10. SPONSOR/MONITOR'S ACRONYM(S)

U.S. Army Installation Management Command

Arlington, VA 22202

11. SPONSOR/MONITOR'S REPORT NUMBER(S)

\section{DISTRIBUTION / AVAILABILITY STATEMENT}

Approved for public release; distribution is unlimited.

\section{SUPPLEMENTARY NOTES}

\section{ABSTRACT}

Live-load tests were conducted on Bridge T-8519, located on Tuckers Road in Camp Mackall near Fort Bragg, North Carolina. This bridge was tested in conjunction with a similar nearby bridge (T-8518). Both bridges were constructed of a new structural material consisting primarily of recycled plastic lumber (RPL). The primary goal of the live-load testing was to determine load capacity ratings for civilian and military vehicles and, specifically, to determine whether the RPL structures could safely carry an M1 tank.

A finite element model of the entire superstructure was developed and used to simulate the responses of the RPL bridge. The resulting model was very accurate; however, responses were very sensitive to small variations in load position due to the flexibility of the plank deck and the spacing of the support beams. Following the addition of deck fasteners, the bridge performance was much more consistent for the M1 tank responses, and more accurate modeling was obtained. Therefore, all ratings were based on the model developed from the second set of load test results.

(Continued)

\section{SUBJECT TERMS}

BDI

Corrosion prevention

16. SECURITY CLASSIFICATION OF:

a. REPORT

UNCLASSIFIED
Load test

Recycled plastic lumber

17. LIMITATION
OF ABSTRACT

RPL

Thermoplastic bridge

18. NUMBER 1 19a. NAME OF RESPONSIBLE OF PAGES

111
PERSON

19b. TELEPHONE NUMBER (include area code) 


\section{ABSTRACT (Concluded)}

Once a realistic yet conservative model of the structure was obtained, load ratings were computed based on an allowable stress approach. Allowable stress limits that were provided by the manufacturer corresponded to stresses that could be applied to the RPL material for a long period of time with deformations being $100 \%$ recoverable once the load was removed. These allowable stress limits were a small fraction of the ultimate stress limits for RPL. However, an ultimate stress approach would be difficult to calculate because it would result in highly nonlinear and time-dependent responses with extremely large deformations.

The load rating results apply only to the bridge superstructure. Pile deformations were measured during the load test, but no assessment could be made concerning the pile capacity. The pile capacity should be verified through the design engineer and the piling contractor to ensure the piles have sufficient bearing capacity to support the load limits of the superstructure. 